
ช 



AND

\section{OUTLINES}

OF

\section{ANATOMY AND PHYSIOLOGY $0 \mathrm{~F}$ THE HORSE; \\ ALso,}

A GENERAL HISTORY OF THE RISE AND PROGRESS OF THE VETERINARY SCIENCE IN ENGLAND, WITH PRACTICAL OBSERVATIONS ON FEEDING, TWATERING, GROOMING, SHOEING, \&c., \&c.: TWRITTEN WITH A viEW OF REFORMING THE VETERINARY SCIENCE, AND TEACHING EVERY MAN HOW TO PREVENT DISEASE IN ANIMALS. $\perp$ CONTAINING, ALSO,

\section{A VETERINARY DICTIONARY,}

SELECTED FROM THE WORKS OF

R. WHITE, V.S.,

OF LONDON, AND ADAPTED TO THE PRESENT STATE OF THE REFORMED PRACTICE IN THE UNITED STATEs,

AS PRACTISED BY THE AUTHOR;

WITH SELECTIONS FROM THE WORKS OF YOUATT, PERCIVAL, AND CURTIS, TOGETHER WITH REMARKS AND OBSERVATIONS ON

BLOODLETTING, AND THE USE OF POISONS;

SHOWING THEIR DEstructive TENDENCY, ETC.

The fundamental principles taught in this work are, that all medicine should be given with a view of aiding the vital power, iustead of depressing, as heretofore.

\section{BY}

GEORGE H. DADD, M. D.,

FRACTITIONER OF THE PHYSIOLOGICAL PRACTICE OF VETERINARY MEDICINE AND SURGER, AUTHOR OF "DADD'S CHART OF REFORMED PRACTICE."

\section{BOS TON:}

PUBLISHED BY THE AUTHOR.

1850 . 
Entered according to Act of Congress, in the year 1850, By G. H. DADD, M. D.

in the Clerk's Office of the District Court of the District of Massachusetts.

STEREOTYPED AT THE

BOBTON STEREOTYPE FOUNDRY. 


\section{CONTENTS.}

Introduction, $\ldots \ldots \ldots \ldots \ldots \ldots \ldots \ldots \ldots \ldots \ldots \ldots \ldots \ldots \ldots \ldots \ldots \ldots \ldots, 7$

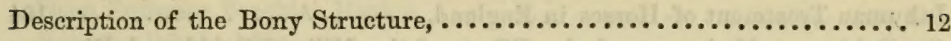

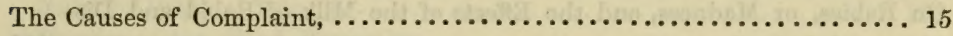

General History of the Horse,............................ 22

External Conformation of the Horse, . . . . . . . . . . . . . . . . 23

Progress of the Veterinary Art in Fingland,.................... 25

Outlines of Anatomy in the Horse, $\ldots \ldots \ldots \ldots \ldots \ldots \ldots \ldots \ldots \ldots . . \ldots \ldots$

Description of the Structure of the Different Organs,............. 29

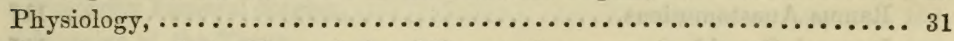

Description of the Uses of the different Organs and Functions of the

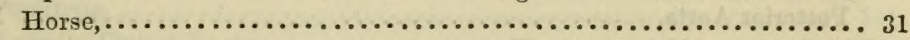

Nutrition, .......................................... 31

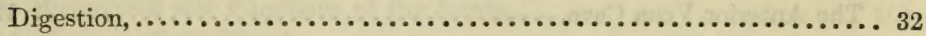

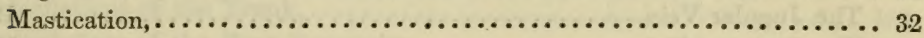

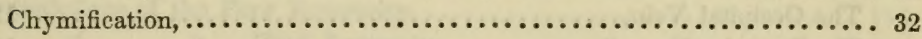

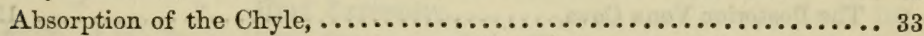

Circulation of the Blood, . . . . . . . . . . . . . . . . . . . . . . 34

Respiration and Structure of the Lungs, ........................ 38

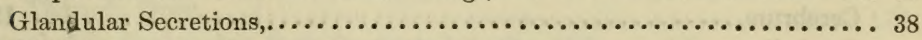

Anatomy and Physiology of the Eye, ...................... 39

Remarks on the Causes of Disease in the Eye,............... 42

Anatomy of the Female Organs of Generation, ................. 43

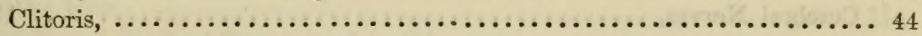

Membrane of the Vagina, ............................. 45

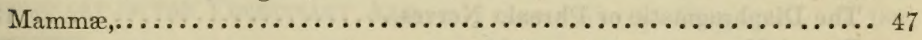

Physiology of the Organs of Generation, Male and Female,.......... 48

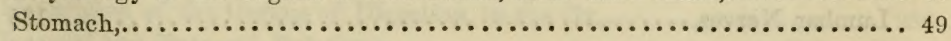

Anatomy of the Foot, and its Diseases,.................... 52

Foot Lameness,...................................... 56

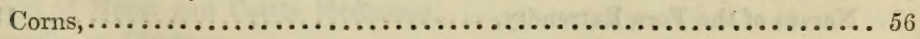

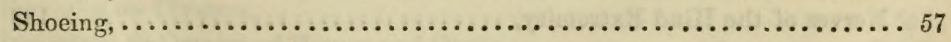

Contraction of the Hoof,.................................... 61

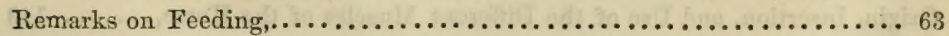

Steaming and Preparing Food for Animals, ................. 66 
Watering,......................................... 69

Exercise,.......................................... 70

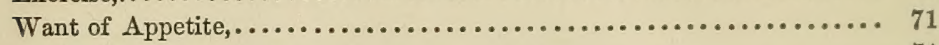

On Stable Management,.............................. 74

Ventilation and Admission of Light into the Stable,........... 75

Admission of Light,................................ 76

On the Ill Effects of Manures of large Cities on the Qualities of Plants,.. 77

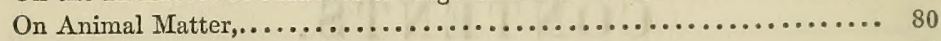

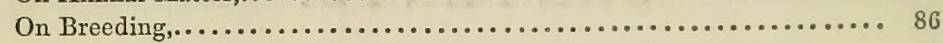

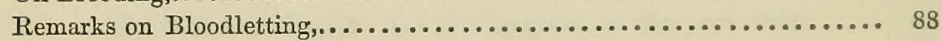

On the Theory of Health, Disease, Fever, and Inflammation,......... 95

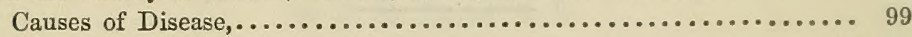

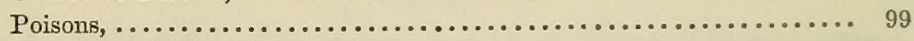

Congestion of the Brain, \&c., .............................. 100

How to avoid Congestion, Staggers, and Apoplexy,............. 104

Inhuman Treatment of Horses in England,................... 104

On Rabies, or Madness, and the Effects of the Milk of Rabid and Dis-

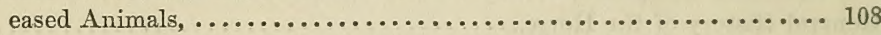

Preliminary Remarks on the Distribution of the Arteries, Veins, \&c., ... 110

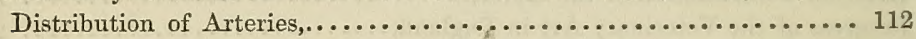

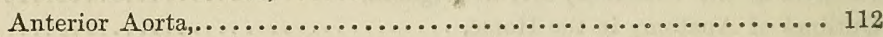

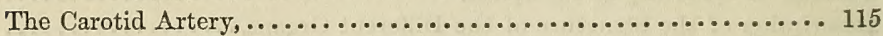

Ramus Anastomoticus,............................. 117

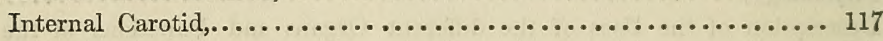

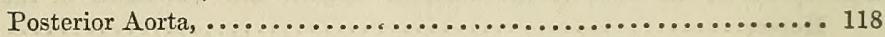

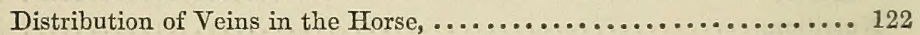

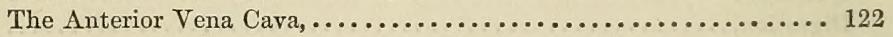

The Jugular Vein,............................. 122

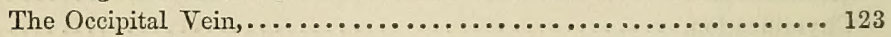

The Posterior Vena Cava,............................ 125

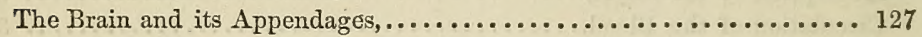

The Sinuses,....................................... 128

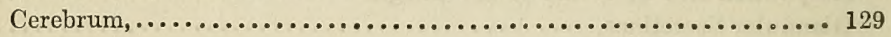

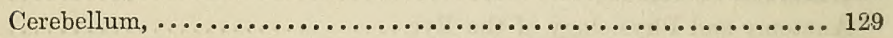

Medulla Spinalis, ............................... 129

Origin and Distribution of the Nerves, ................... 130

Cerebral Nerves, . . . . . . . . . . . . . . . . . . . . . . 130

Cervical Nerves, .............................. 134

The Diaphragmatic or Phrenic Nerves,.................. 135

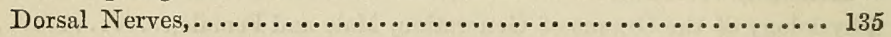

Lumbar Nerves, .............................. 135

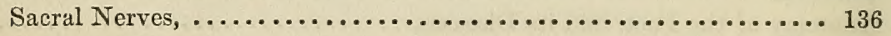

Coccygeal Nerves, ............................ 136

Nerves of the Fore Extremity, ....................... 137

Nerves of the Hind Extremity, . . . . . . . . . . . . . . . . 138

Sympathetic Nerve,................................ 139

Origin, Insertion, and Use of the Different Muscles of the Horse,...... 140

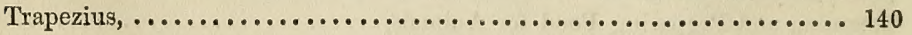


Latismus Dorsi,..................................... 140

Rhomboideus Brcvis,................................... 140

Rhomboideus Longus,.............................. 141

Levator Humeri,.................................... 141

Muscles of the Neck,................................ 141

Anterior Cervical Region, ............................... 143

Muscles of the Head,................................. 144

Muscles of the Trunk. - Pectoral Region, .................. 146

Lumbar Region, ..................................... 148

Internal Costal Region, ............................... 150

Museles of the Trunk. - Abdominal Region,................. 151

Muscles of the Fore Extremity. - External Scapular Region,........ 152

Posterior Humeral Region,................................ 153

Anterior Humeral Region, ............................. 153

Muscles of the Arm, ................................. 154

Deep Posterior Brachial Region, ........................ 155

Anterior Brachial Region, ............................. 155

Muscles of the Hind Extremity,........................ 156

" " Haunch, ............................. 156

Internal Femoral Region, .......................... 157

Gluteal Region,................................... 158

Pelvic Region,...................................... 159

Posterior Femoral Region, .............................. 159

Muscles of the Thigh,.............................. 160

Popliteus, ......................................... 161

Anterior Crural Region, .............................. 162

The Mechanism and Functions of the Joints,.................. 163

Articulations of the Trunk, .............................. 163

Articulations of the Fore Extremity, ........................ 165

" " Hind Extremity,..................... 167

A Table of the Bones in the Structure of the Horse,.............. 169

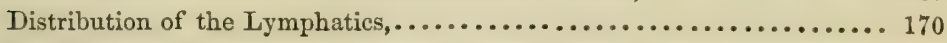

The Thoracic Duct, ................................. 170

Lymphaties discharging their Contents into the Abdominal Portion of the

Thoracic Duct, ................................. 171

Ramifications terminating in the Thoracic Portion of the Common Duet, 174

On the Hair,........................................ 176

Glossary of Medical Terms used in this work, ................ 181

Dictionary of the Vetertinary Art, $\ldots \ldots \ldots \ldots \ldots \ldots \ldots \ldots \ldots \ldots \ldots \ldots \ldots \ldots . \ldots \ldots$

Appendix, .......................................... 286

Description of the Organs of Digestion in the Ox,............... 286

Internal and External Relations,............................ 290

Horn-Ail in Cattle,.................................... 291

A List of Horse and Cattle Medicincs,....................... 297

Remarks on Clysters,................................. 305

Important to Owners of Horses and Cattle, .................... 307 


\section{PLATES。}

Plate No. 1. Showing the External Parts of the Horse; also, a View of the Muscular Structure, ................... 12

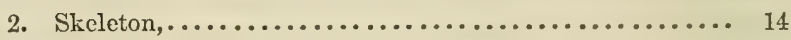

3. The Heart viewed externally, ................... 35

4. The Stomach of the Horse,.................. 50

5. The Leg from the Shank Bone, $\ldots \ldots \ldots \ldots \ldots \ldots \ldots$. 53 


\section{INTRODUCTION.}

The author is in hopes that the principles here set forth may enable those for whom the work is mainly written (viz., our farming interest, and those who have the care of and own horses) to perceive the folly of violating nature's laws, in attempting to cure disease; also, that they may be led to see the wisdom and necessity of aiding nature in her intentions for the removal of the causes of disease.

It is a subject of great importance, and should be the pride and duty of every man to sympathize with those who, though our slaves, have common feeling with us. Yes, brutes, as we call them, have, like us, memory, ideas of reflection, reason, and feelings of gratitude and duty; in fact, all those moral powers differing from ours, not in kind, but merely in degree.

There is no period, in the history of the United States, when our domestic animals have ranked so high, or have been held in such general estimation, as at the present time; yet there is no subject on which there is such a lamentable want of knowledge, as the proper treatment of the diseases of our domestic animals.

How long our citizens will suffer this important branch of study to be neglected, remains to be seen. The sons of America are ever foremost in the field of improvement. America numbers among her farming interest men of giant minds, whose cry is, Reform; they demand, and will have, 
sooner or later, a more effectual system of medication - a system that will remove the diseases of their animals, without submitting them to the excruciating torment of the firing iron, lancet, and the destructive agents that have heretofore been used for the cure of disease.

What man of common sense can for a moment suppose, that powerful destructive agents can restore a weak, sinking animal to a healthy state? Many of the means recnmmended by some works on horse-doctoring, would make a well animal sick, whatever they might do to the one already diseased. We are told that the agents they recommend provoke the system to rally her powers, and resist disease; and, at the same time, these agents, being destructive in their nature, produce another, or a secondary disease, and that the primary disease is cured by exciting a secondary one! This is just as absurd as knocking a horse down to make him stand up. But truth and experience are abroad, exerting their influence on the minds of reflecting, honest, and independent men, and the day is not far distant when the lancet and poison will be rejected in the treatment of disease in animals.

As the advocate of veterinary reform, the author has endeavored to present the subject to the reader in a brief manner, without writing all round, and failing to hit the mark. The object aimed at is the prevention of disease. It is an old but true saying, that "an ounce of prevention is worth a pound of cure;" and it is more convenient and less expensive.

Every farmer throughout the land is furnished by the Creator with ample means for preventing the introduction of disease into the animal organization, and to remove it, in some cases, when it has made its appearance; thus the man who confines his prescriptions to a few good remedies, the action of which he is well acquainted with, is far more successful than he who is constantly changing his medicines for the popular compounds of the day.

A knowledge of anatomy, physiology, and pathology is important, yet not absolutely necessary, in the cure of disease. The two former are, of course, more important that the latter. 
All the pathology on earth does not enable us to cure disease; many of our farmers, who have rejected the lancet and poisons, and use only those articles which are favorable to the whole animal functions, are in the daily habit of curing disease, of whose pathology they know nothing. The pathologist may discover alterations in tissues, the blood, and the lungs, and tell us that herein lie the cause and seat of disease; yet these changes themselves are but results, and preceding these were other manifestations of disorder; therefore pathology must always be imperfect, because it is a science of consequences.

The most powerful microscopes have been used to discover the seat of disease; yet it has not taught us to cure one single disease hitherto incurable. Experience is the only true guide of every successful practitioner.

The principles of our physiological practice may be summed up as follows :-

We contemplate the animal system as a perfect piece of mechanism, subject to life and death; that, while the vital power is free and unobstructed, the animal is in a physiological or healthy state; but when, by any means, the vital power is obstructed, it is in a diseased or pathological state.

All our intentions of cure being in accordance with nature's laws, (viz., promoting the integrity of the living powers,) we have termed our system a physiological one, though it is sometimes denominated botanic, in allusion to the fact that all our remedial agents are derived from the vegetable kingdom.

We recognize a conservative or healing power in the animal economy, whose unerring indications we endeavor to follow.

Our systen proposes, under all circumstances, to restore the diseased organs to a healthy state, by coöperating with the vitality remaining in those organs, by the exhibition of sanative means, and, under all circumstances, to assist, and not oppose, nature in her curative processes.

Poisonous substances, blood-letting, or processes of cure that contemplate destruction of parts, or, in other words, act 
pathologically, cannot be used by us. The laws of animal being are physiological. They never were, and never will be, pathological; hence we coöperate with nature, and with nature's laws, by using agents that act physiologically.

We believe that the best system of veterinary science is that which prevents disease by proper attention to breeding, rearing, and stable management. It will be perceived that our aim is to depart from the debilitating and life-destroying practice, and approach, as near as possible, to the sanative.

The greatest obstacle to veterinary knowledge is the belief, that in the science of medicine there are pathological laws; and it has led men to believe that fever and inflammation are disease. Now, there never was, and never will be, a pathological law. The divine Creator implanted in the animal organization laws to maintain it in its normal state, and those laws are physiological, and not pathological. Now, to believe that the all-wise God implanted in the constitution both normal and abnormal laws, would be but to destroy his own intention. The only laws in domestic animals, in any state, are physiological. Overfeeding and imperfect ventilation may prevent the full and free play of these laws, thereby curtailing health; but still, all the vital action that exists is physiological.

In justice to J. S. Skinner, the talented editor of the Farmer's Library, we would observe, that our notes and strictures on Youatt apply to the original work, as published in London. The work has since been republished in this country, with valuable additions by J. S. S., and is better adapted to the wants of the American people. If the latter gentleman would only employ his talents in advocating and sustaining the non-poison principle, our cause (the cause of humanity) would receive a valuable auxiliary.

To Dr. C. M. Wood we are indebted for valuable suggestions, gleaned from an extensive practice of sixteen or seventeen years in this city. He has experienced the imperfect theoretical teachings of the schools, and assures us, that he has established facts, deduced from observation and experi- 
ence, which has led to a more successful treatment of the diseases of domestic animals.

The author acknowledges his obligations to various sources for this work. The authors named in the title page have been consulted and freely employed; the most valuable assistance has been derived from the teachings and works of the professors of the P. M. College of Ohio.

G. H. D. 


\section{DESCRIPTION OF THE BONY STRUCTURE.}

The Head is composed of the following bones, which a reference to the plate will exemplify: $a$, the os frontis, or forehead; $b$, the nasal bones; $c$, the os lachrymalis ; $d$, the jugal, or cheek bone; $e$, the superior maxillary, or upper jaw ; $f$, that portion which unites with the palatine and jugal bones; $g$, the inferior maxillary bone, which contains the upper incisor teeth; $h$, the maxilla posterior, or lower jaw; the dark shade between $a, c, d$, is the orbit of the eye ; $i$, the parietal, or vertical bone; $m$, $n$, the temporal bone, consisting of the squamous and petrous portions; $n$, the petrous division, being a part of the internal ear; $l, o, p$, the occipital or knoll bone; $o$ marks the occipital elevation; $p$, the cuneiform process; $l$, the condyloid process, marking its junction with the atlas.

The Neck. $-B, B$, the seven cervical vertebræ, or bones of the neck; $a$, the first of these, is denominated the atlas.

The Spine is composed of the eighteen dorsal vertebræ, 1-18; the lumbar vertebræ, which form the loins, six in number, $1-6$; the sacrum, five in number, $a, b, c, d, e$, the coccygis, or bones of the tail, 1-15.

The Thorax, Ribs, Shoulder, and Sternum. - The true ribs are nine in number, 1-9; and are so denominated from their cartilages being united to the sternum; 10-18 mark the false ribs, their cartilages being inserted into each other; $a$, the head, which articulates with the transverse process of the first dorsal vertebræ; $b$, the end uniting the sternum; $C$, the sternum; $D$, the scapula, or shoulder-blade; $c$, the neck; $d$, coracoid process, or apophysis ; $g$, the anterior spinatus fossa; $h$, the spine; between $e$ and $f$ lies the base, which is the extent of the cartilage of the scapula; between $c$ and $e$ is the posterior costa; and between $d$ and $f$ lies the anterior costa. 
The Fore Legs. $-E$, the humerus; $k$, cervix and head, uniting the shoulder-blade; $F$, the ulna; the upper extremity, $m$, forms the olecranon, or elbow ; $n, n$, the radius; $G, G$, the carpus, or knees, consisting of seven bones; $H, H$, the metacarpal or shank bones; $o, o$, the cannons; $p, p$, the small metacarpal ; $q, q$, the pastern; $r, r$, the sessamoids; $s, s$, the coronets, or small pastern bones; $t, t$, the coffin bones, or os pedis.

The Pelvis and Hind Legs. $-I$, the pelvis, made up of three bones; $a, b, c$, the illium; $d$, the ischium, and $e$, the pubis; that part of the illium $a$ forms the hip, or haunch; $g$, the foramen thyroideum; $k$, the femur, or thigh bone; $h$, the cervix and head, articulating with the lower extremity of the pelvis; $i$, the great trochanter; $k, k$, the anterior condyles ; $l, l$, the posterior condyles; $m, m$, the patella, or stifle joint ; $n, n$, the tibia ; $o$, o, fibula; $L$, tarsus, or hock, consists of six bones; $p, p$, forms the points of the hocks; $M$, the metatarsi; $q$, the cannon, or shank; below are the seramoids, large and small pasterns, navicular and coffin bone. 



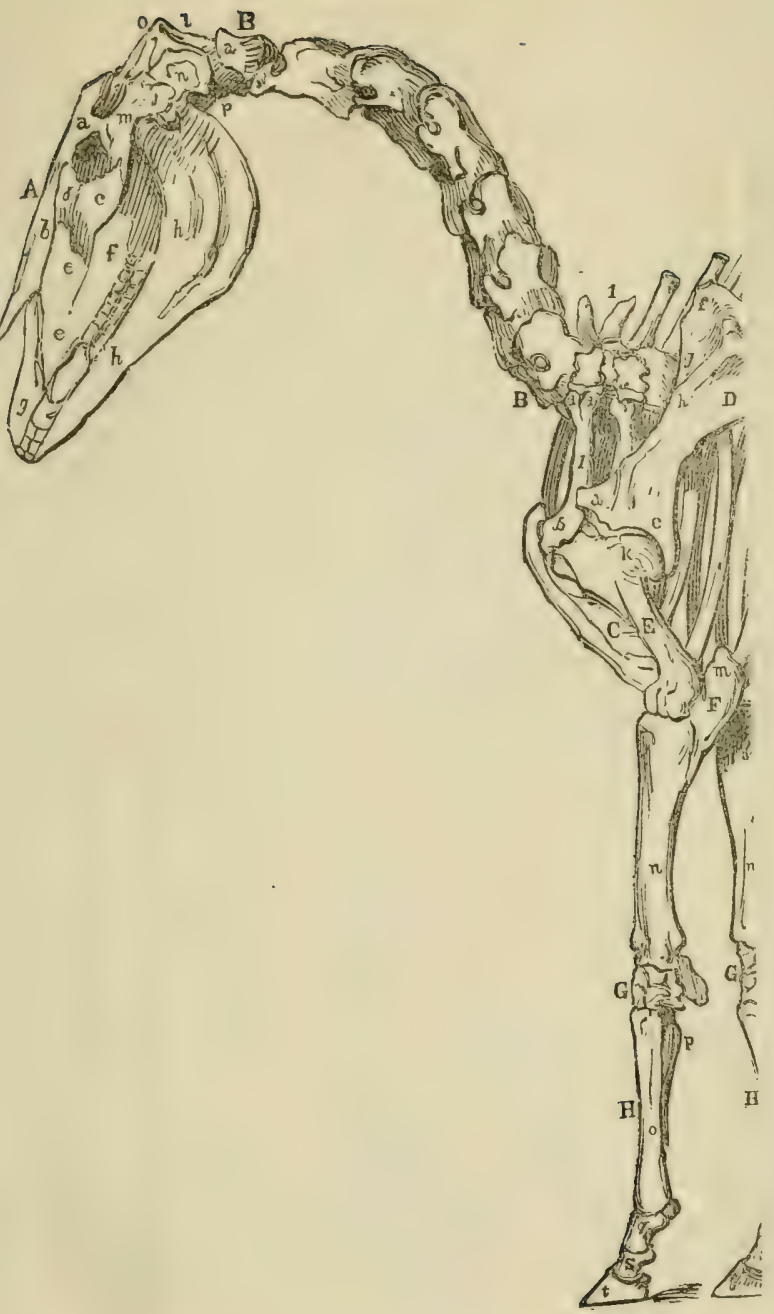

N. B. The navicular bone, which articulates between the small pasi The Skeleton, or Bony Structure of the Horse, consists of three sectic veral parts or portions. 




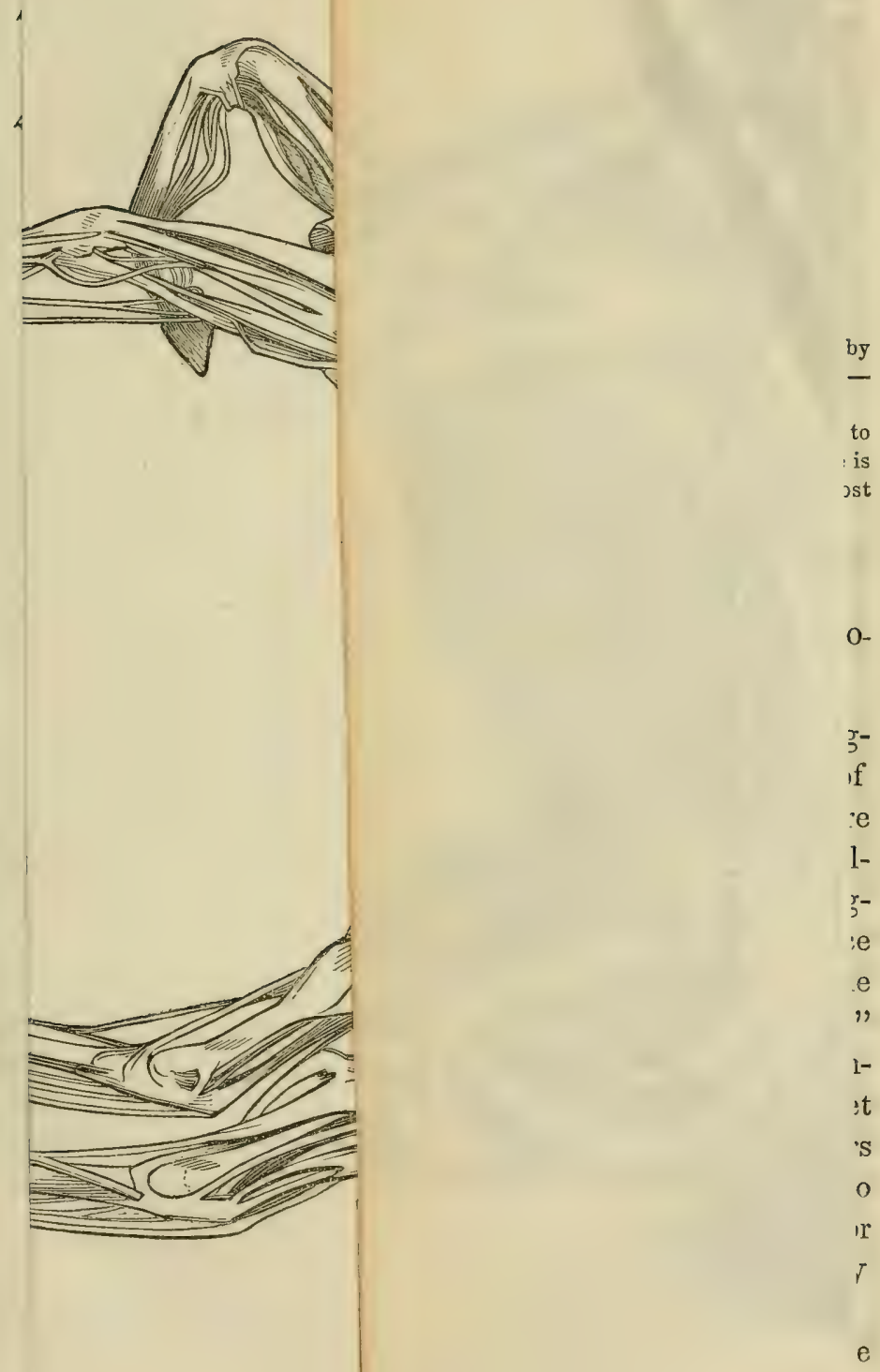






\title{
ANATOMY AND PHYSIOLOGY
}

\author{
OF
}

\section{THE HOR S}

"In horses or cattle, it is probable that almost all diseases may be prevented by judicious management with regard to feeding, breeding, rearing, and exercise." DR. WHITE, V.S.

"Nature is ever busy, by the silent operation of her own forces, endeavoring to cure disease. Her medicines are air, warmtl, food, water, and sleep. Their use is directed by instinct; and that man is most worthy the name of physician, who most reveres its unerring laws." - Dr. DrxoN.

THE CAUSES OF COMPLAINT, AND THE REASON WHY TVE ADVOCATE A REFORM IN VETERINARY PRACTICE.

Mr. Youatr writes, that the annual loss of cattle in England, by disease, amounts to $\$ 50,000,000$ ! and the loss of sheep at one tenth of the whole number; and, though there the veterinary art is taught as a science in the endowed colleges, and regular professors practise it throughout the kingdom, he says it is difficult to say which is the greatest source of this immense loss, "the ignorance and obstinacy of the cow leach, or the ignorance and supineness of the owner." 'To make this declaration clear and conclusive, we will consider the principal reasons why the healing art has never yet derived much, if any, improvement from all the various labors that the faculty have bestowed on it. We wish the reader to understand, that the same reasoning applies to animals; for they require the same general treatment as mankind, viz., by aiding the vital powers.

If the remedies are ever adapted to destroy life or injure the 
system of man, they are also adapted to injure that of the horse, and all domestic animals. If they ever recover from the effects of the lancet and poison, we must attribute it to the power of the system to defend itself against all encroachments upon its sanative operations. If good medicine, such as experience teaches us, always operates in favor of health, and has a tendency to remove disease, it always has that tendency, both on man and domestic animals, and is proper to be administered whenever the state of the system demands it. The great fault of physicians, in estimating the labors of their predecessors, has ever been, that they either received or condemned by wholesale every previous system, abandoning the truth with the errors, and subjecting themselves to the necessity of travelling over the whole ground again. By this means their confidence is impaired in their ability ever to arrive at the simple truth.

Hippocrates, the earliest systematic writer on medicine, discovered by careful observation the existence of a principle which he styled Nature. To this principle he attributes a species of intelligence, and conceived that one of its most important offices is to attract to the body what is beneficial, and to reject from it what would prove injurious. This is a truth which no argument can disprove.

Sydenham says our misfortunes proceed from our having long since forsaken our skilful guide, Hippocrates, and the ancient method of cure founded upon the knowledge of conjunct cases that plainly appear, insomuch that the art which is this day practised, being invented by superficial reasoning, is rather the art of talking than of healing.

D'Alembert represents the state of the science: "Nature is fighting with disease. A blind man armed with a club, that is, a physician, comes to settle the difference. He first tries to make peace. When he cannot accomplish this, he lifts his club and strikes at random. If he strikes the disease, he kills the disease ; if he strikes nature, he kills nature."

The very principles upon which medical theories are based were never established. They are, and always were, false. 
Dr. Rush says, "Dissections daily convince us of our ignorance of the seats of disease, and cause us to blush at our prescriptions." He also adds, "We have assisted in multiplying disease: we have done more, - we have increased their mortality." If it be true what Dr. Rush and hundreds of others assert, that the science of medicine, as practised at the present day, is no science at all, - and who doubts it? then we can easily account for the sad havoc, that, according to Youatt, has taken place in the animal kingdom. Well may we exclaim, They have heen swept away as by the blast of a dire tornado. The lancet, antimony, and corrosive sublimate have been more destructive than the pestilential sword. They are the Samsons of a barbarous practice, and have slain their thousands and tens of thousands.

The great bone of contention among men has been, "What are nature's intentions? and with what means, and in what manner, shall we second them ?"

To this Professor Curtis replies, "While Hippocrates adhered in practice to his correct principles, that nature should be aided by means and processes that act in harmony with her intentions, his practice was universally successful ; but when he departed from established principles, in the use of unknown agents, which proved useless and injurious, he often failed of curing disease.

"It must never be forgotten that, while the learned were verging to something like a correct theory of vital action in a healthy body, they were departing farther and farther from the truth in two other points of importance.

"1st. They were settling their minds in the belief that, in every case of the encroachment of offending causes, this very vital power, so essential to health, in rising to expel them, becomes at once the very sum and essence of disease, ('vital action cannot be a diseased action,') and must be checked, subdued, and destroyed at all hazards. But, finding none of the innocent and life-supporting remedies calculated to do this work in a direct manner, as the effect of their administration, - 
" 2 d. They gradually departed from the use of nature's remedies, and introduced into their therapeutics the processes of bleeding, blistering, the knife, and caustic ; and into their Materia Medica the most deadly poisons contained in the threefold kingdom of nature, whether derived at once from her laboratory, or detached from her compounds by the use of her powers, under the guidance of chemical science.

"In the beginning of the sixteenth century, the famous chemist Paracelsus introduced a new system into medicine, founded on the principles of his art. Hitherto the physicians rejected the use of opium, calomel, and other efficacious remedies. Efficacious they have been, as the ghosts of murdered millions could declare! Here, it seems, that for the art of aiding nature in her efforts to remove disease, which had been practised with a tolerable degree of consistency, and with astonishing success, by Hippocrates and Galen, was substituted the general use of poisons, which, however, in other respects agree in 'suddenly and rapidly extinguishing a great portion of the vitality of the system!' $O$, what a falling off was there!

"Permutations in the extent of depletion, or the quantity of poison to be given, the particular articles containing it, the locality or the manner of the applications, the stage of the disease, or the hour of the day to be chosen for operation, have indeed been studied, and tried, and guessed at; but still the chief practice consists in bleeding, blistering, cutting, burning, physicking, poisoning in some shape or other; insomuch that old Time long ago hung up his scythe as useless."

The veterinary science was ushered into existence by men who practised according to the doctrines of the theoretical schools. We may trace it in its infancy when, in England, in the year 1788, it was rocked in the cradle of Allopathy by Sainbel, its texture varying to suit the skill of Clark, Lawrence, Field, Blaine, and Coleman; yet with all their amount of talent and wisdom, their pupils must acknowledge that the melancholy triumph of disease over its victims clearly evinces that their combined stock of knowledge is insufficient 
to perfect the veterinary science. Dr. J. Bell says, "Anatomy is the basis of medical skill;" yet, in another part of his work, he says, "It enables the physician to guess at the seat, or causes, or consequences of disease!" This is what we propose hereafter to call the science - the science of guessing! If such is the immense mortality (as Mr. Youatt states) in England, - a country that boasts of her veterinary institutions, and embraces within her medical halo some of the brightest luminaries of the present century, - what, we ask, is the mortality in the United States, where the veterinary science scarcely has an existence, and where not one man in a hundred can tell a disease of the bowels from one of the lungs? Profiting by the experience of these men, we are in hopes to build up a system of practice that will stand a tower of strength amid the rude shock of medical theories. We have discovered that the lancet is a powerful depressor of vitality, and that poisons derange, instead of producing, healthy action. That they are generally resorted to in this country, no one will deny, and often by men who are unacquainted with the nature of the destructive agents they are making use of. The common practice of administering aloes, in diseases resulting from a common cold, is just as destructive as poisoning and bloodletting. Dr. J. Boutall, V. S., of London, states that "aloes given to a horse that is lahoring under a cold is likely to produce glanders."

Dr. Vines, demonstrator of anatomy in the Royal College, states that "physicking a horse when there is a discharge from the nostrils will produce glanders." The author has known death to result from the administration of a ball containing eight drachms of aloes and one drachm of calomel. A friend informed us that he occasionally puts up physic balls for horses containing three ounces of aloes. An eminent professor has said that "purgatives, besides being uncertain and uncontrollable, often kill from the dangerous irritation and debility they produce." The good results that sometimes follow the exhibition of drastic purges, antimony, \&c., must be attributed to the sanative action of the constitution of the 
animal, though it be an agent injurious in its nature, and it depends, in all cases, on the existing ability of the vital power to counteract its effects.

We are told by the professors of allopathy that their medicines constitute a class of deadly poisons, and when given in large doses, destroy life; "yet if given with a scientific hand, and in small doses, they cure disease." We deny their power to cure. If antimony, corrosive sublimate, \&c., ever proved destructive, they always possess that power, and can never be used with any degree of assurance that they will promote the healthy secretions. What difference does it make whether poisons are given by the scientific or the unscientific? Does it alter the tendency which all poisons possess, namely, that of rapidly depriving the system of vitality.

Many of the farming community, and owners of horses, to whom the author has made known his system, are in favor of the reform; they are determined to have a safer system of medication.

The author has received numerous communications, from individuals in different parts of the United States, encouraging him to proceed in the good work. The following extracts will show that there is need of reform, and that the harvest is ripe.

Extract of a letter from the Hon. H. Clay, dated

Philadelphia, Nov. 25, 1849.

There is no department in the medical world in which there is such a lamentable want of knowledge as that of the proper treatment of Horses and Cattle. Whoever shall supply this deficiency ought to be regarded as a great benefactor, and I shall be very glad if your exertions shall entitle you to that merit. With great respect, I am your ob't servant,

DR. GEO. H. DADD.

H. CLAY.

Pittsfield, Dec. 10, 1849.

Dear Sir: I received your letter explaining the princ1ples on which you propose to reform veterinary science. You 
have my thanks, and, in my opinion, are entitled to the thanks of the community for entering upon this important work. While the subject has engaged the attention of scientific men in other countries, it has been too long neglected in our own. Cruelty and ignorance have marked our treatment to diseased animals. Ignorant himself both of the disease and the remedy, the owner has been in the habit of administering the popular remedy of every neighbor who had no better powers of knowing what should be done than himself, until the poor animal, if the disease would not have proved fatal, is left alone, until death, with a friendly hand, puts a period to his sufferings; he is, however, often destroyed by the amount or destructive character of the remedies, or else by the cruel mode of administering them. I am persuaded that the community will approve of your exertions, and find it to their interest to support and sustain your system.

Wishing you great success,

I am yours truly,

G. H. DADD, M. D.

GEO. N. BRIGGS.

Latwence, Academy, Groton, Nov. 19, 1848.

Dr. DadD : Sir - Your letter and circular were duly received. In no profession, perhaps, has quackery prevailed more than in the medical, and in no branch of medicine more than in horse and cattle doctoring. But we are seeing better days; when your principles shall become known, improvement must be rapid, especially when such a wide field is open.

Very truly yours,

J. MEANS. 


\section{GENERAL HISTORY OF THE HORSE.}

Aт the head of the many varieties of the Horse stands the equus caballus, or common horse. Although there are many varieties of hoofed animals, the horse is distinguished from other animals by having the quadrupedal phalanges united and surrounded with a hoof, which does not admit of its grasping any thing. Hence these animals of the tribe ungulata, or hoofed, having but one toe, belong to the tribe solipeda, or single-hoofed.

The original country of the horse cannot now with certainty be ascertained, although many naturalists think that he is indigenous to most countries, for he is to be found in different temperatures, and varying in size and utility.

The precise time when this animal was first domesticated is very uncertain. The sacred writings inform us, that, when Jacob went into Egypt to procure corn, he sent up oxen, camels, and asses. Chariots and horses, however, appear to have been used by Pharaoh, when that prince lost his army in the Red Sea.. Greece, doubtless, amongst other things, learned the art of subduing these animals from the Egyptians. History informs us that horse and chariot races were highly esteemed at their games, and Homer mentions them as early as the Trojan war. Wild horses have been found in countless droves in the great plains of Tartary. Solomon, in his traffic with foreign nations, would have obtained Arabian horses, if in his day they had been as highly esteemed as now; but we are told that Egypt furnished him. Mahomet, at the commencement of his career, did not possess any cavalry. Indeed, we are credibly informed, that, when presents were made to the Arabian princes, even as late as the fourth century, horses were considered the most acceptable offering; from which circumstance we may conclude, that, however superior the present breed of horses in that country may be, the climate and industry have brought these animals to that esteem in which they are at present held. The Romans, in 
their conquests, extended the general use of the horse, and appear to have applied themselves to its improvement.

\section{EXTERNAL CONFORMATION OF THE HORSE.}

ThE head is one of the first parts of the horse that will convey to judges the quality of the breed. Nothing of beauty can surpass the prominent outlines of the head of the highmettled blood horse, which is small, lean, and angular; the forehead proportionally broad; the ears small and pointed; the eyes full and prominent ; the lips deep, firm, by no means hanging loose; the nostrils open and wide; and the mouth not too small.

The neck should rise from the chest with a moderate curve, and be neither too long nor too short; horses with a short, thick neck possess great strength, but are seldom noted for speed. From the top of the neck rises the mane, which nature appears to have added as an ornament and beauty to this noble animal. The shoulders should run in a slanting direction forward from the withers to the shoulder points, and should be muscular, but not heavy, as they are particularly essential to the movements of the horse. Between the points of the shoulder lies the chest, which should be moderately expansive and prominent, in order to allow the lungs to have a free action.

The trunk, from the ribs nearest the chest, should be wide towards the back, and generally deepened, in order to give the form which is termed deep in the girths; and as the ribs decrease in size, they ought to be more circular, which gives the belly a round appearance, and is more esteemed, not only for the beauty, but because it is accounted more healthy. The loins cannot be too broad and full, especially when strength is required; they should be more rounded and long; the tail should form a graceful curve with the loins. The fore legs are straight, gradually approaching each other as 
they descend to the feet; the arm should be muscular and large; when small, it generally denotes want of strength; the knee large and flat, and the shank muscular and firm, and by no means fleshy. The thighs of the horse should be exceedingly strong and muscular; the stifle should be of considerable length, as that denotes speed. The hock is the most material joint of the animal, and should be broad and wide; it is subject to many diseases, and ought to be well looked to. The feet also require attention, and are more frequently misshapen; they should not be too upright, which tends to open the heel, and thus the feet become faulty and diseased; the horn should be of considerable size, otherwise the foot is easily hurt, and rendered unhealthy. By reference to plate No. 1 , the reader may become acquainted with the bony structure of this noble animal.

On the Teeth. - A horse has forty teeth when he has completed his full number; a mare usually only thirty-six. The horse has, during life, two sets of teeth - a temporary and a permanent set. The first appears shortly after birth; the others appear gradually, as the temporary set fall out; and the change is completed about the fifth year. These two sets of teeth appear at an interval of a few years between them; yet the rudiments of both are formed nearly at the same period. It is essentially necessary that there should be two sets of teeth; for, as they grow but slowly in proportion to the jarws, had there been but one set, the disproportion in growth between the teeth and jaws must have separated and made them wide apart as the jaws increased. The manner in which the temporary teeth are removed is very curious; - it is occasioned by the pressure of the permanent teeth upon the roots of the former; this causes a gradual absorption of the roots, so that, after a time, having no support, they fall out. The teeth are covered with a hard substance called enamel ; this enamel surrounds the tooth, and is indented or sunk into it, forming a pit, or hollow, which preserves the body of the tooth from being injured. In process of time, however, the enamel is worn down below the 
hollow, and a brown mark appears on them, which indicates age. To ascertain the age of a horse, see AGE, part second.

\section{PROGRESS OF THE VETERINARY ART IN ENGLAND.}

England appears to have been almost the last, among the nations of Europe, which encouraged the study of this useful profession. In the year 1785, proposals for establishing a veterinary school in London were published by M. V. de Sainbel, who had previously received a professional education at the Royal College at Lyons. These proposals received no attention. In 1789, he published fresh proposals to read lectures on the veterinary scicnce. These met with no better success. In 1790, a plan for establishing an institution for teaching the art was published, and produced a good effect, and ultimately led to the formation of the Veterinary College of London.

Among the first of the medical profession, who subscribed towards the support of this institution, were Drs. J. Hunter and Crawford. These distinguished surgeons saw its importance, as opening a field for the cultivation of comparative anatomy, which was the canse of their rendering it all the assistance in their power.

It is also stated that the Duke of Northumberland was elected president, and contributed the sum of five hundred guineas towards the support of this most useful institution.

Among the names of the first pupils who entered the college are Clark, Lawrence, Field, and Blain. The latter was educated as a human surgeon. A medical committee was shortly afterwards appointed, consisting of the most distinguished practitioners in London, by whom the pupils were examined, and if found to have acquired a sufficient knowledge of the art, certificates were granted.

Professer Coleman likewise succeeded in procuring the patronage of govermment; and for several successive years a 
sum of money was voted by the Parliament, towards the aid of the institution. George the Third granted the rank of commissioned officers to such as might be appointed to regiments. Abont the year 1827, the directors of the East India Company, observing the good effect produced by the appointment of veterinary surgeons to the British cavalry, were likewise induced to grant the like appointment to young men who might think fit to join the native India regiments.

A course of lectures is still given by the professors throughout the season; the pupils are still examined by a medical committee. Demonstrations in anatomy, \&c., are given daily, and the pupils have the advantage of dissecting subjects themselves, and also of seeing the practice of the infirmary.

The following is from one of the works of the first professors: "We know that physicians of all ages applied themselves to the dissection of animals, and that it was almost entirely by analogy that those of Greece and Rome judged of the structure of the human body. We are told that Herophilus and Erasistratus studied anatomy on the human frame some centuries before the Christian era, and that the former even dissected living subjects, having obtained the bodies of malefactors for that purpose. On the other hand, it is abundantly proved by history, that the great progress in anatomy, till within a few centuries, was made by the dissection of brutes. A superstitions reverence for the dead, which prevailed for many centuries, confined the Greeks and Arabians to the dissection of apes and quadrupeds. Galen has given us the anatomy of the ape for that of man; and it is evident that his dissections were restricted to brutes, when he says that if learned physicians have been guilty of gross error, it was because they neglected to dissect animals. Erasistratus was the first who discovered the lacteals in kids, which he opened a short time after they had sucked. He observed the valves of the heart, and demonstrated, contrary to the opinion of Plato, that there was, behind the windpipe, a canal or passage, viz., the œsophagus, whose office was to convey food into the stomach. Rufus of Ephesus, we 
are told, described those two ducts, the discovery of which is attributed to Fallopius, and from him are called the Fallopian tubes. These he discovered in dissecting the womb of a ewe, and adds, that he strongly suspects them to be seminal vessels, and of the same nature with those of the male. Galen demonstrated, in Rome, on living animals, the organs of sound and respiration; he made several observations on the brain of animals; he also showed the effect produced by ligature on the recurrent nerves. Vesalius proved, by experiment on animals, that it was possible to restore suspended animation, by inflating the lungs artificially, which discovery has saved the lives of many individuals. Croon and Hook, two English physicians, repeated the same experiments, a century afterwards, and with success. Wharton, a physician of London, discovered the salivary glands in an ox.

In 1659, Eustachius was the first who found out the thoracic duct in the horse; a hundred years afterwards, the same canal was discovered in man by the immortal Harvey. Dr. Wren, professor of the University of Oxford, made several experiments on living animals, to be assured of the effect of different substances on the blood and solid parts, the result of which experiments was to confirm the discovery of Harvey, which for the space of forty years was strenuously opposed. Gesner Aselius, professor of anatomy at Pavia, repeated the discovery of the lacteal veins in the mesentery, in brute bodies, which had formerly been known to Erasistratus and Herophilus. Pecquet traced them to the thorax, and completed his discovery by that of the thoracic duct. It was in the body of brutes, also, that Bartholinus discovered the vasa lymphatica.

Stenon, a native of Copenhagen, but afterwards physician to Ferdinand the Second, Grand Duke of Tuscany, discovered, in 1661, the excretory ducts of the lachrymal glands in the eye of a sheep. Malpighi and Bellini, in 1665, described the organs of taste in quadrupeds. Observations on the organs of feeling were first made on the skins of brutes, and afterwards verified on the human skin. Weiff made experiments 
on the hearts of living animals, to prove that the amricles were equal. In 1641, Hoffman discovered the excretory duct of the pancreas in a turkey-cock. The peristaltic motion of the intestines was first discovered in animals. In short, the greater part of the functions in the human frame were first made known by the general analogy subsisting between the functions of animal organization. From what has been here written, though in a summary manner, it appears that the science is efficient in itself, and has given unequivocal proofs of its ability to enlarge the boundaries of general medicine.

Veterinary Surgeon Percival, in his introductory remarks to a series of elementary lectures on veterinary science, in drawing a comparison between such practitioners who have carefully studied anatomy, and those who have not, very truly observes, that no man supposes his watch can be repaired at the anvil, though there are those who send their horses to the blacksmith to be cured of their diseases. They lnow that the man is unacquainted with the mechanism of a watch; and yet they trust him with a machine, to which, in point of complication, a watch can as little be compared as a rattle can to a watch. Why, then, are men so blind? Is it that a horse is of less value than a watch? No! It is owing to the vile trash diffused as treatises on farriery, so truly disgusting to a man of common reflection, that he forms his opinion of the art by those he entertains of the book. "Miserable animal!" says Sainbel, "bereft of speech, thou canst not complain, when, to the disease with which thou art afflicted, excruciating torments are superadded by ignorant men, who at first sight, and without a knowledge of thy structure, pronounce in thy case, and then proceed with all expedition to open thy veins, lacerate thy flesh, cauterize thy sinews, and drench thy stomach with drugs opposed to the cure they engage to perform."

A veterinary school has lately been established in Scotland, where every thing that it behooves the practitioner to know is taught; and, more recently, that excellent and truly liberal institution, the University of London, has admitted a 
veterinary school under its roof; and, on the same extended plan, the bencficial results of this will be, that the diseases of cattle and sheep, hitherto so disgracefully neglected, will be better understood, and the dreadful loss which the country sustains will be materially diminished.

\section{OUTLINES OF ANATOMY IN THE HORSE.}

DESCRIPTION OF THE STRUCTURE OF THE DIFFERENT ORGANS.

The animal organization is divided into bones, muscles, arteries, veins, nerves, and viscera.

The bones are hard and durable, and are intended to form a framework for the support of the softer portions. When divested of the soft portions, they form the skeleton. The bones are united together by ligamentary and fibrous attachments, which allow free motion one upon another. The articulating surfaces of the joints are covered with a cushion or cartilage, and lubricated with a fluid called synovia, which permits them to move freely on each other, without friction. Their name and location will be found on referring to the engraving of the skeleton, accompanying page 12.

The muscles are the soft, red, fibrous masses called flesh. They are susceptible of contraction and relaxation; or, in other words, become shorter and longer, and are subject to the will of the animal: for this reason, they are termed voluntary muscles.

Besides these, there are other parts which owe their power of contraction to the vital power; yet there is a peculiar arrangement about some of their muscular fibres. Thus the heart is a muscular texture, forming a circular muscle; and the urinary bladder, stomach, intestines, \&c., - which are cnabled to contract upon their contents and expel then, whether the animal wills it or not, - are termed involuntary muscles.

The muscles of respiration, being, in some measure, under 
the influence of the will, are said to have a mixed motion. If we examine the fibres of muscles attentively, we find them not in straight, but in zigzag lines, which explains how they are able to contract and expand. These fibres may be divided and subdivided, until they are too small for the naked eye to see; they are then called fascia, and these fascia are again united to form muscle. In a work of this description, which is intended for the non-professional, the author deems it unnecessary to detail the names of the different muscles, which would involve an amount of matter incompatible with the present limits. Suffice it to say, that the names of the voluntary muscles depend on their size, form, use, the arrangement of their fibres, or their origin and insertion.

Nerves are long, firm, white cords, which ramify after the manner of blood-vessels, and are distributed to all parts of the animal. They issue from the brain, medulla oblongata, and spinal marrow. They consist of fascicula, or bundles of distinct fibres, closely connected together, and covered with a membrane called neurilema. They divide into branches, twigs, and threads, which again subdivide into filaments. They are named from their origin, use, and form. Thus those that issue from the brain are called cerebral; others, again, from the spinal cord, are called spinal; those in the region of the neck are called cervical; others, issuing from other parts of the spinal column towards the extremities, are called lumbar, dorsal, and sacral. These names correspond to their locations. See Nerves, part second.

If a nervous cord is cut through, as in nerving, or compressed with force, so as to intercept all communication with the brain, and the foot to which it is distributed, that part becomes paralyzed. In nerving horses or cattle, the sensibility of the foot is wholly or partly destroyed, according to the nature of the operation.

Veins are the vessels that return the blood to the heart. The texture of veins is much more slender than that of arteries, yet they possess considerable strength, and though sometimes distended to their utmost capacity, seldom burst. 
The veins generally accompany the arteries; but as the former are subject to pressure from the muscles, they are more numerous than arteries. The veins are provided with valves, which appear to be a duplicature of their inner coat rising into a fold. In the human subject, there are two of these folds to form a valve; but in the horse, there are three: these, when the blood by pressure, or a contraction of the capillary structure, is arrested in its course, prevent it from returning.

The arteries are vessels that carry the blood to all parts of the system, for the purpose of supplying the waste that is continually going on. They become narrower as they proceed towards the extremities, and are furnished with an elastic, a muscular, and a membranous coat. Arteries have a pulsating motion communicated to them by the impulse of the heart, by which they are distinguished from veins.

The viscera are certain organs, comprising a great part of the structure of the animal, ordinarily lodged in cavities, as in the head, the chest, the pelvis, and abdomen.

The head contains the brain, from which issue the organs of taste, smell, hearing, sight, \&c. The chest is bounded by the ribs, spinal column, breast bone, and diaphragm, called midriff. It contains the organs of respiration and circulation. The abdomen contains the organs of digestion. The pelvis contains the urinary organs, the rectum, and most of the organs of generation.

\section{PHYSIOLOGY.}

DESCRIPTION OF THE USES OF THE DIFFERENT ORGANS AND FUNCTIONS OF THE HORSE.

Nutrition. - The living body is constantly losing its constituent parts; this waste requires to be made up by the addition of new matter; and when the stomach, and other parts concerned in the process of nutrition and digestion, are 
in a healthy state, and there is a due supply of food, then this renovation is continually going on. Nutrition may be interrupted by various causes, which will be discussed in the articles Feeding, Appetite, \&c.

Digestion. - This is a chemico-vital action, and is the most extraordinary phenomenon we can contemplate, and worthy the attention of those for whom this work is mainly written. Every part of the animal is formed from the blood, which is first formed from the food.

Mastication. - The animal, by means of the teeth, grinds or breaks up the food. During the process, it is moistened by a fluid called saliva, which is secreted by glands fitted for that purpose. This moistening is essential to the passage of the food down the gullet, or œsophagus, into the stomach, and afterwards, probably, assists the process of digestion. Sometimes horses have projections on the grinding teeth, by which mastication is rendered painful and difficult; the food is imperfectly chewed, and therefore difficult of digestion. This is injurious to the stomach and bowels, and consequently the general health suffers.

Chymification. - The food, having been properly moistened with saliva, is, by means of the tongue, with the assistance of the muscles, pharynx, and gullet, conveyed into the stomach. Here the food undergoes the first process of digestion, and is converted into a pulpy mass, called chyme. The agent in converting food into chyme is the gastric juice, which is secreted from the inner walls of the stomach. This fluid has a remarkably solvent power, and when the horse is in health, acts on the ordinary articles of food. Cases are on record where the gastric juice had corroded and dissolved the coats of the stomach, after death; yet it cannot act on any thing while it retains vitality. Thus we often find bots in the stomach, and worms in the intestines, that live and generate, unhurt, by that fluid; yet the moment they are deprived of vitality, they are digested or dissolved.

As the chyme passes from the stomach through its lower orifice, called pylorus, it enters the first of the small intestines, 
called duodenum. Here it meets with two fluids, one secreted by the liver, called gall or bile, and the other secreted by the pancreas or sweetbread, called pancreatic juice. The fluids from both are conveyed into the duodenum by small tubes or canals. Immediately after the admixture of the chyme with the fluids, it begins to separate into two distinct portions, one consisting of the nutritious portion, called the chyle, and the other the refuse portion, part of which forms the excrement.

Absorption of the Chyle. - The intestines are composed, in a great measure, of muscular fibres, some of which run in a circular, and others in a longitudinal direction. When the fibres contract, the diameter of the canal is diminished; and when the longitudinal fibres are in action, the canal is shortened; and by the combined action of these fibres, the fond is gradually propelled through the whole length of the canal. The internal surface of the intestines consists of a nervous and vascular membrane, which is constantly forming a mucous substance for its own protection. In cases of constipation and colic, this secretion is so abundant as to be discharged in considerable quantity with the dung. There is also, on the inner surface of the intestines, an immense number of minute vessels, called lacteals, by which the chyle is sucked up or absorbed. The lacteals terminate on the inner surface of the intestines by small tubes, with open mouths. These tubes are full of little valves, which prevent the return of chyle. In passing through these canals, the fluid traverses small bodies, called mesenteric glands. Eventually, the whole of the lacteals terminate in a vessel called the thoracic duct, from thence into one of the jugular veins, ${ }^{*}$ into which it empties. The chyle thus mixes with the venous blood in the veins, and goes with it to the lungs, where, coming in contact with atmospheric air, it is deprived of its carbon, and assumes the character of pure arterial blood. There are other vessels that empty into the thoracic duct, called lymphatics; these, with the lacteals, form what is termed the absorbent system.

* It enters the subclavian vein in the human being. 
The lymphatics carry a fluid called lymph, which is a limpid fluid, and found in all parts of the body. They take up substances that are applied to their mouths; thus the moisture within the abdomen, and other cavities, or poisons rubbed on the hide, are taken into the system. The absorbents also assist in this process, the latter taking up all the useless matter, and conveying it into the blood, that it may be thrown off by the skin and kidneys, in the form of urine and perspiration.

The external surface of the intestines consists of peritoneum, a membrane from which the viscera of the abdomen derive their external coat. The peritoneum forms also a kind of sac, in which they are enclosed. The first portion of intestine-duodenum is about twenty inches in length. The next is named jejunum; the third illium: this terminates in the cæcum, or first of the large intestines: here there is a looseness of the internal coat, which allows it to be formed into folds, and effectually prevents the return of excrement into the small intestines. The second of the large intestines is named colon. It is small at its commencement, but soon after enlarges into a very capacious canal, which, when it has passed nearly around the abdomen, again forms a second, but slight contraction; after which it again enlarges, when, lessening a third time, it terminates in the rectum. The anus, or fundament, is the termination of the rectum, and is shut by a circular muscle, termed sphincter, which surrounds the end of the gut.

Circulation of the Blood. - Having given the reader some idea of the manner in which the blood is made, we will now consider its properties, and explain how it is propelled and distributed to every part of the animal.

The appearance of blood is familiar to most persons. We have already stated that it contains the elements for building up and nourishing the whole animal structure. On examining blood with a microscope, it is found full of little red globules, which vary in their size and shape in different animals, and are more numerous in warm than in cold blooded 


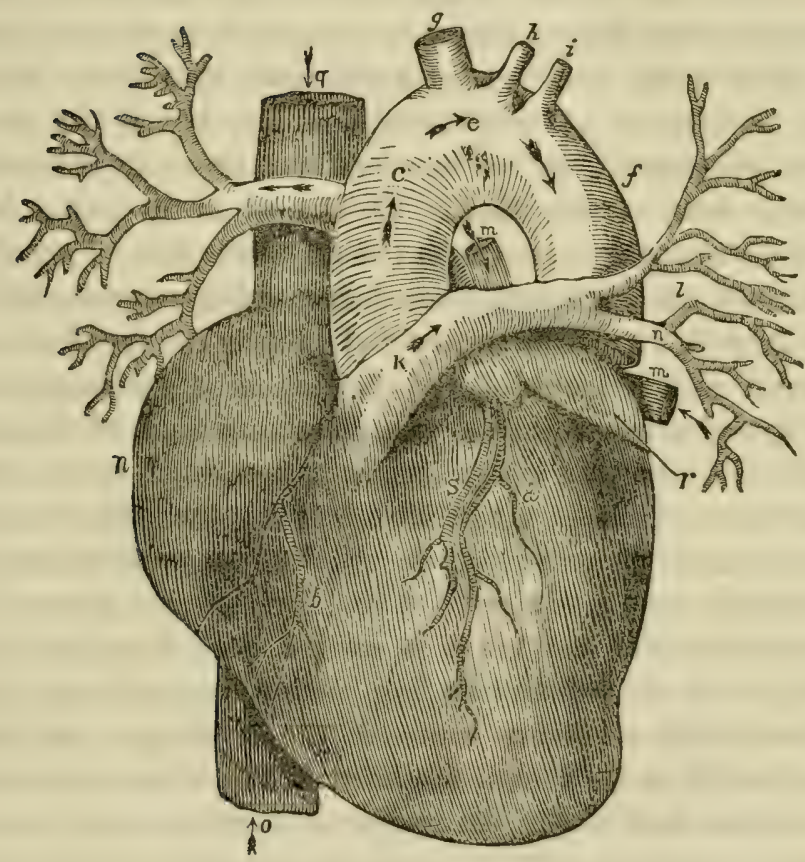

$a$, the left ventricle; $b$, the right ventricle; $c, e, f$, the aorta $g, h, i$, the carotid and other arteries springing from the aorta; $k$, the pulmonary artery; $l$, branches of the pulmonary artery in the lungs; $m, m$, the pulmonary veins emptying into the left auricle; $n$, the right auricle; $o$, the ascending vena cava; $q$, the descending vena cava; $r$, the left auricle; $s$, the coronary vein and artery. See Circulation OF THE BLOOD, on the opposite page. 
animals : probably this arises from the fact that the latter absorb less oxygen. If the blood of one animal be transfused into another, it will frequently cause death.

When blood stands for a time after being drawn, it separates into two parts. One is called serum, and resembles the white of an egg; the other is the clot or crassamentum, and forms the red coagulum, or jelly-like substance: this is accompanied by whitish, tough threads, called fibrine. When blood has been drawn from a horse, and it assumes a cupped or hollow form, if serum, or buffy coat, remain on its surface, it denotes an impoverished state; but if the whole, when coagulated, be of one uniform mass, it indicates a healthy state of this fluid. The blood of a young horse generally coagulates into a firm mass, while that of an old or debilitated one is generally less dense, and more easily divided or broken down. The power that propels the blood into the different ramifications of the animal, is a mechanico-vital power, and is accomplished through the medium of the heart, which is a powerful muscular organ contained in the chest. From certain parts of it arteries arise; in others the veins terminate; and it is principally by its alternate contractions and expansions, aided, as already stated, by the vital power, that the circulation of the blood is carried on. The heart is invested with a membranous bag, called pericardium, which adheres to the tendinous centre of the diaphragm, and to the great vessels at the base of the heart. The heart is lubricated by a serous fluid within the pericardium, which guards against friction. In dropsical affections, the quantity of this fluid is considerably increased, and constitutes a disease called dropsy of the heart. The heart is divided into four cavities, viz., two auricles, named from their resemblance to an ear, and two ventricles, (as seen in plate $3, a b$,) forming the body. The left ventricle is smaller than the right; but its sides are much thicker and stronger : it is from this part that the grand trunk of the arteries proceeds, called the great aorta, (i. e., $f$, plate 3.) The right cavity, or ventricle, is the receptacle for the blood that is brought back by the veins after going the 
rounds of the circulation; which, like an inverted tree, become larger and less numerous as they approach the heart, where they terminate in the right auricle. The auricle on the left side of the heart receives the blood that has been distributed through the lungs for purification. Where the veins terminate in auricles, there are valves placed. The coronary vein, which enters the right auricle, has its mouth protected by a valve called semilunar, or half-moon shape, which opens only towards the heart, and prevents the blood taking a retrograde course. The different tubes coming from and entering into the heart, are also provided with valves to prevent the blood from returning. For example, the blood proceeds out of the heart, along the aorta, (see plate;) the valve opens upwards, the blood also moves upwards, and pushes the valve asunder, and passes through ; the pressure from above effectually closes the passage. The valves of the heart are composed of elastic cartilage, which enables them to work with ease. In some diseases, however, they become ossified. This, of course, is fatal. The heart and its appendages are also subject to other diseases, called dilatation, softening, hardening, \&c. Now, the blood, having been brought from all parts of the system by the veins, enters into the vena cava, (see plate 3 , fig. o, $q$, ascending and descending portion,) which empty themselves into the right auricle; and this, when distended with blood, contracts, and forces its contents into the right ventricle, which, contracting in its turn, propels the blood into the pulmonary arteries, (see plate,) whose numerous ramifications bring it in contact with the air-cells of the lungs. It then assumes a crimson color, and is then adapted to build up and supply the waste. Having passed through the vessels of the lungs, it continues on, and passes into the left auricle : this also contracts, and forces the blood through a valve into the left ventricle. This ventricle then contracts in its turn, and the blood passes through another valve into the great aorta, from which it is distributed into the whole arterial structure: after going the rounds of the circulation, it is again returned to the heart by the veins. 
Respiration and Structure of the Lungs. - The organs of respiration are the larynx, the upper opening of which is named glottis, the trachea or windpipe, bronchia, and the lungs.

The air is displaced out of the lungs by the action of the muscles of respiration; and when these relax, the lungs expand by their elasticity. This may be exemplified by means of a sponge, which may be compressed into a small bulk by the hand, but, upon opening the hand, the sponge returns to its natural size, and all its cavities become filled with air. The purification of the blood in the lungs is of vital importance, and indispensably necessary to the due performance of all the functions. When the lungs, and muscles connected with them, are in a physiological state, the horse is said to be in good wind - a very desirable state for an animal to be in, whose usefulness depends on his being capable of a long continuance of quick motion. The trachea, or windpipe, after dividing into bronchia, again subdivides into innumerable other branches, the extremities of which compose an infinite quantity of small cells, which, with the ramifications of the veins, arteries, nerves, lymphatics, and the connecting cellular membrane, make up the whole mass or substance of the lungs. The internal surface of the windpipe, bronchia, and air-cell, is lined with a membrane, which secretes a mucous fluid: when, in consequence of an obstructed surface, this fluid becomes abundant, it is expelled by the nostrils. The whole is invested with a thin, transparent membrane, named pleura: the same membrane lines the internal surface of the ribs and diaphragm, and, by a duplicature of its folds, forms a separation between the lobes of the lungs.

Glandular Secretions. - Liver. This is the largest gland in the animal economy; it secretes from the blood a fluid called bile; it is conveyed by numerous small tubes into a larger one, in which they terminate: this is named hepatic, or biliary duct. In the human body, and in most quadrupeds, there is another duct, branching off from this, which terminates in a gall bladder, from which the bile is expelled; but 
in the horse there is simply one duct, which conveys the bile, as already stated, into the duodenum, where it assists in the process of chylification.

Kidneys. Their office is to convey or secrete the superfluous fluids and excrementitious parts of the blood in the form of urine. In man, the skin is the great outlet of the body, and the kidneys are one of a secondary order; but in some animals, the kidneys are the principal parts concerned in carrying off the impurities of the blood. When horses are allowed an unlimited quantity of hay and water, or when they are fed on improper food, and the skin obstructed, the urine will be voided in large quantities - thick, turbid, deficient in quality, and having a peculiar stinking smell. From a cavity in the centre of each kidney, a canal or tube proceeds, by which the urine is conveyed into the bladder. These tubes are named ureters. As the ureters enter the bladder, they pass forward a short distance between its coats; which course effectually prevents the urine from flowing back into the ureters. The urine is expelled by the muscular power which the bladder possesses of contracting upon its contents. The horse's kidneys are readily affected by diuretic medicines, and many valuable horses are ruined by the too frequent use of nitre and rosin. These articles are indirect diuretics; they cause a large secretion of urine, but do not provide for the excretion. In such cases, the bladder may be distended beyond its usual capacity; its fibres may become lacerated, and thus be incapable of contracting on its contents. Disease of the kidneys sometimes happens in consequence of excessive exertion, or strain of the loins; and sometimes peritoneal disease spreads to the kidneys.

There are other glands scattered over the system, of equal importance; yet, in the present state of veterinary knowledge, the author deems it unnecessary to refer to them.

Anatomy and Physiology of the Eye. - The parts which compose the eye are divided into external and internal. The external parts are, first, the eyelashes, or cilia, which, in the horse, can scarcely be reckoned more than one, there being 
very few hairs in the under eyelid; secondly, the eyelids, or palpebræ, upper and under: where they join outwardly, it is termed the external canthus, and inwardly towards the nose, the internal canthus: they cover and defend the eyes. The cartilaginous margin or rim of the eyelid, from which the eyelashes proceed, is named tarsus. In the tarsus and internal surface of the eyelid there are small glands, which secrete a fluid, to prevent friction of the eye and its lids, and facilitate motion. Thirdly, the lachrymal gland, which is placed on the upper part of the eyelid towards the external canthus; from this gland the tears are secreted, and conveyed to the inner surface of the upper eyelid by several minute ducts, or canals, named lachrymal ducts. There is another small body, having a glandular appearance, in the inner corner of the eye; on each side of which there are small orifices, which are called puncta lachrymalia: these are the mouths or openings of two small canals, which, joining together, form a membranous tube; and this, passing through a small opening in the bone, extends to the lower part of the nostril, where its termination may be distinctly seen in the horse. As the lachrymal gland is constantly forming tears, it must be obvious that some contrivance is necessary to convey them off, and prevent them flowing over the cheek: this purpose is answered by the canal just described.

When any irritating matter is applied to the eye, the tears are formed too abundantly to be carried off in this way; they then flow over the cheek. In the human eye, the puncta lachrymalia terminate in a small sac, from which the lachrymal duct proceeds : this is not the case in the horse. In the inner corner of the horse's eye is placed a body commonly termed the haw, no resemblance to which is to be found in the human eye. The horse has the power, by means of the muscles of the eye, to bring the haw completely over its surface ; it serves, therefore, as a second eyelid, and effectually wipes off any dust, hay, or seeds, or other matter which may have fallen upon the eye. The conjunctive membrane, or tunica conjunctiva, lines the inner surface of the eyelids, 
and covers the white part of the globe of the eye. This membrane has numerous blood-vessels, which are conspicuous when it is inflamed. The bulb or globe of the eye is composed of several coats and humors. The transparent cornea, which, in the horse, forms the front part of the eye, comprehends a larger part of the globe than in the human subject; on removing this cornea, a fluid, which is named the aqueous humor, escapes, and the iris appears. The iris is a muscular curtain, having a hole in the centre, which is termed the pupil. This divides the fore part of the eye into two parts, named chambers, which are occupied by the aqueous humor. The pupil is of a dark bluish cast; is of an oval, or rather of an oblong form. The iris regulates the quantity of light that is required to pass through the pupil. For this purpose, it is composed of two sets of muscular fibres; by means of one the pupil is enlarged, and by the other it is diminished. Thus, if the pupil is first examined in the stable, where there is a moderate light, and immediately after in the sunshine, it will be found quite altered; being so small, in a strong light, as to be nearly closed. On removing the iris, the second humor, or crystalline lens, appears : this is retained in its situation by a transparent membrane, named its capsule, between which and the lens is a minute quantity of fluid. The third humor of the eye is the vitreous. This humor is not contained in one general sac, but in numerous minute and perfectly transparent cells, and resembles pure water: this humor serves to produce a small degree of refraction in the rays of light, and occupies and distends all the posterior part of the globe of the eye. The next coat to the conjunctive is the sclerotica, or white of the eye, a strong, thick membrane, which extends from the transparent cornea to the optic nerve. The next coat to the sclerotic is the choroid. This is a delicate and very vascular membrane. In the human eye, it appears of a black color, and it is this which causes the pupil of the human eye to appear black; but the choroid coat of the horse's eye is variegated in color; in some parts black, in others blue; and in others green. The next coat is the 
retina: this is a delicate expansion of the optic nerve over the choroid coat, which it accompanies to the margin of the crystalline lens, and there terminates.

The use of the retina is to receive certain impressions made by the light reflected from objects, so as to produce in the mind an idea of their figure and color; the optic nerve being the medium of communication between the retina and brain. From the above explanation of the mechanism of the eye, it will readily appear that many circumstances may occur to render vision imperfect, or to destroy it altogether. If the transparent cornea, for example, became white, light could not pass through it, and the animal would be blind, however perfect the other parts of the eye might be. The cornea may be either too convex or too flat; in the former case, causing the animal to be near-sighted; in the latter, producing an indistinctness of vision with respect to objects that are near. The iris may, in consequence of disease, become fixed, or lose its power of motion; in which case, the pupil would be always of the same size, and the animal would not have the power of adapting it to the various distances or objects; or, as sometimes happens, the pupil may become quite closed, by which light would be perfectly excluded from the retina. Supposing the cornea and iris to be healthy, the crystalline lens, or its capsule, may become opaque, and thereby cause total blindness. But in this part, as in the cornea, we meet with different degrees of opacity : sometimes it is very slight, the pupil appearing of a lighter color, and unusually large: in this state, the pupil is said to look dull or muddy, which causes the horse to start; but when the opacity is complete, it constitutes the disease termed cataract. There is another disease, to which the reader's attention is called; it is named gutta serena, or amaurosis. This disease is known by the pupil being unusually large or open, and by its continuing so when the eye is exposed to a strong light.

Remarks on the Causes of Disease in the Eye. - Young horses, generally, are peculiarly liable to a disease called ophthalmia. Such as are got by a blind stallion, or bred from 
a blind mare, are said to be more liable to it than others; yet all horses, if pent up in hot stables, fed high, and not sufficiently exercised, are liable to disease of the eye. Sometimes a general derangement of the system, brought on by violent and excessive exertion, will terminate in a disease of the eye, or its membranes; also by standing still in cold wind or rain when the animal has been heated, and is sweating; or sluicing him with cold water, which is yery much in fashion, since the Cochituate was introduced in this city. If water is used to cleanse the horse, he should be rubbed perfectly dry, and the reactive powers provoked by friction with the brush.

Cure. - It is of the utmost importance to remove the cause, if possible : next adopt that system of management, with respect to feeding, exercise, grooming, and ventilation, laid down in this work. If the disease is hereditary, then the most scientific treatment, to say the most of it, is only palliative. The best lotion for the eye is an infusion of camomiles, or a mixture of one tablespoonful of vinegar to a pint of water, used occasionally with a clean sponge and a light hand. The horse should be kept on a light diet of scalded shorts; darken the stable, and give the animal proper attention until the disease is subdued.

\section{ANATOMY}

OF THE FEMALE ORGANS OF GENERATION.

Trre vulva, or pudendum, is the slit commencing below the anus, and extending downward, forming a fissure. This fissure is longest and most conspicuous in breeding mares. The space between the anus and vulva is called the perineum. The prominences on each side of the vulva are called the labia pudendi. They owe their bulk principally to fatty substance. 
The commissures are the parts uniting the labia above and below. The superior or upper commissure is extended to a sharp angle, and joins the perineum; the lower portion is rounded off, and is bounded by a hollow, at the bottom of which is lodged the

Clitoris. - This is brought into view immediately after staling : it bears a close comparison to the head of the male penis, and, like the latter, is susceptible of sensual enjoyment. To the clitoris belong a pair of muscles named erector clitoris. They take their origin from the perineum. Their office is to erect that body, and protrude it into the vagina in the act of coition.

The internal parts are the vagina, uterus, Fallopian tubes, fimbriæ, and ovaria. The vagina is a musculo-membranous canal, of large dimensions, extending from the vulva to the uterus or womb.

It is situated within the pelvis, having the bladder below and the rectum above it, to both of which it has cellular attachments, in addition to the reciprocal connection with the peritoneum. To the rectum it is closely and firmly attached by cellular membrane.

The figure of the vagina, when it is distended, is that of an oblong cylinder; but in the collapsed state, its sides are in contact, and it will vary its form according to the full or empty condition of the bladder. The largest part of the canal is the posterior; there it exceeds the dimensions of the bladder.

The length of the canal is about eighteen inches. Its course is horizontal, and rather shows an inclination to the curve of the rectum.

The vagina, at its commencement from the vulva, is much thicker in its walls than elsewhere; in composition, it is partly muscular and partly membranous. The orifice of it is clothed in that strong, red, circular, fleshy band, which forms the sphincter vagina; and the adjoining part of the canal is also encircled by some considerable fleshy covering, 
and thickly coated with muscular fibres. Farther forward than this the vagina is composed of membrane.

The Membrane of the Vagina. - The part of which it is constituted is one of the mucous class, and one that possesses considerable density, extensibility, and resistance. Its exterior surface is rough. Its interior is smooth, and has a pale pinkish cast ; unless the mare be under the venereal œstrum, and then its redness is heightened, and its secretion augmented. In the ordinary state, this membrane is thrown into folds, larger in breeding mares than in others, technically called rugæ.

Considerably in advance of the clitoris is an opening leading from the lower part of the canal, large enough to admit with ease any one of the fingers: this is the orifice of the meatus urinarius, or outlet of the bladder: it is guarded by a doubling of the vaginal membrane, which hangs over it, and serves the purpose of a valve.

The large and conspicuous protuberance at the bottom of the vagina, is the mouth of the uterus.

The uterus, or womb, is a hollow musculo-membranous organ, united to the anterior part of the vagina, and is destined for the reception of the fœtus. We distinguish the uterus by the body, horns, neck, and mouth. 'The body is the oblong or cylindrical part, growing out of the anterior portion of the vagina, in the centre of which it is terminated internally by the os uteri, or mouth of the womb; it gives origin, in front, to the horns. This part lies wholly within the pelvis, between the bladder and rectum, and is entirely covered by peritoneum.

The cornua, or horns, rise from the body of the uterus, and diverge towards the loins. Their length and size will be much greater in breeding mares than in others. In figure they are cylindrical; they bend upwards in their course, and terminate in round extremities, to which are loosely appended the ovaries, or testicles, through the medium of the Fallopian tubes.

The cervix, or neck, of the uterus is the rugose portion 
protruded backward into the cavity of the vagina, which has a flower-like appearanoe, and can only be seen in a virgin uterus in the undistended state: during gestation it undergoes a remarkable change.

Independently of its union with the vagina, the uterus is confined in its place by two broad portions of peritoneum, which attach it to the sides of the pelvis, named the lateral ligaments of the uterus. During the period of gestation, the uterus experiences considerable extension. The Fallopian tubes are two trumpet-shaped canals, having a remarkable serpentine course; running within the folds of the ligamenta lata, from the extremities of the horns to the ovaries.

The tube commences by an aperture in the cornu, having an elevated whitish margin, which is scarcely large enough to admit a small silver probe : from this it proceeds forward, folded in peritoneum, and extremely convoluted, until it reaches the ovary, to which it becomes attached; it then begins to enlarge in its diameter, grows less convoluted, and serpentines along the lower side of the ovary; it afterwards ends in a fringed doubling of membrane.

The internal membrane of the tubes is similar to that of the uterus.

The ovaria, or female testicles, are two egg-shaped bodies, situated farther forward than the Fallopian tubes, within the cavity of the abdomen: they receive close coverings, and are loosely attached to the spine.

These bodies are about the size of walnuts. They are not regular oviform; they have deep fissures on their sides; they bear a resemblance, at first view, to the testicles and their ducts in the male.

Internally, the ovaries are composed of a whitish spongy substance, in which are, in some instances, found little vesicles containing a yellowish glairy fluid, in others one or more dark yellow or brownish substances named corpora lutea : the vesicles are the ova, which, from impregnation, receive further development; the corpora lutea denote the parts from which vesicles have burst, and consequently only exist in the 
ovaries of those mares whose organs have been engaged in the generative process. Prior to the age of sexual intercourse, these bodies are small and white; but as soon as the season of copulation is at hand, they grow large, redden externally, and present many yellow spots or streaks through their substance.

Mamma, though unconnected with the uterus, anatomically speaking, are in function concurring to the same important end. The mammæ, vulgarly called udder, are two flattened oval-shaped bodies, depending, between the thighs, from the posterior and inferior part of the belly. In quadrupeds, with but few exceptions, this is the situation of the mammæ.

In virgin mares the udder is so small that there hardly appears to be any. In mares who have had foals, the udder remains prominent or pendulous, and has a flabby feel.

Towards the latter part of gestation, this part swells, and becomes distinctly visible. Within a few days of foaling, the udder grows turgid with milk; it does not, however, acquire its full distention until the foal has drawn it for a few days, from which time it maintains its volume, with little variation, during the period of sucking. Soon after the foal begins to forsake the teat, the secretion of milk diminishes, and is followed by a contraction of the bag, which goes on gradually, until it has resumed nearly, or quite, its former flatness.

The interior of the mammæ has a light yellowish aspect, and evidently possesses a lobulated structure, which is held together by a fine cellular tissue, interspersed with granules of fat. It is constituted of glandular masses, irregular in magnitude and form, and loosely connected one with another, each of which masses is composed of a number of lobules, closely compacted and united together. These insulated lobulous portions receive small arteries, from which the milk is secreted. The former, by repeatedly conjoining one with another, become at length several demonstrable canals, radiating from every part, and dilating to hold the milk. 
When the udder becomes charged with milk, it flows into the teat and distends it. Suction is apparently an operation purely mechanical. The teat is seized and closely compressed by the lips of the foal; and the imbibing effort which follows has a tendency to produce a vacuum, or raise the valve at the upper part of the teat, and the milk passes from the reservoirs into the mouth.

ON THE PHYSIOLOGY OF THE ORGANS OF GENERATION, MAIE AND FEMALE.

The common object in the male and female organs of generation, is the development and reproduction of new beings. The copulative act is the essential first cause that therein the action of the organs is mutual and sympathetic, and that the result is the generation of a new animal, bearing a likeness to one or both parents, the office of the testicles being to furnish the fecundating liquor, called semen. This is the most important part of the male apparatus. These organs do not descend into the scrotum for some time after birth, and do not carry on their glandular functions until the period of puberty. This epoch is marked in animals by luxuriant growth of hair, particularly in the mane and tail, a peculiar odor of the body, and lustful passions.

The semen is secreted from the blood, and is a white viscous fluid, having a peculiar faint odour, and $\mathrm{Mr}$. Percivall found it to contain myriads of animalculæ, or vermiculi. To chemical analysis, according to Girard, the horse's semen yields four fifths of a peculiar animal matter; the remaining ingredients being mucus, muriate of potass and soda, and carbonate and phosphate of lime. Castration operates in horses, not only by depriving stallions of their amorous fury, but converting the most outrageous into meek and even spiritless geldings. But the loss of one testicle does not take away either the procreative faculty, or the sexual appetite ; for rigs, as they are then called, appear to get foals as well as stallions.

In the covering season animals are found to grow restless and unruly, and unless permitted to seek their mates they 
will often refuse their tood, and even undergo considerable privations, so influential in the system is the periodical sexual passion.

By implanting such a vigorous and irresistible impulse into the sexual constitution of animals, has nature excited the congress of the sexes, and insured the perpetuation of their species; and so salutary is the moderate or seasonable performance of this act, that animals are found to be improved, both in health and strength, by it; if carried to excess, it proves highly destructive.

In the covering season the female parts are in a fit state of aptitude for giving due effect to the semen conveyed into them by the penis of the male; they show this aptitude by redness, and prominency of the vulva, and by the emission, at intervals, of a whitish mucus fluid; animals that are ill fed and hard worked, seldom show that they are horseing at all.

Impregnation ordinarily puts an end to the cstral discharge, by causing permanent closure of the mouth of the womb. The germs, or rudiments, of the future beings exist in the ovaria of the female prior to impregnation, and only require the stimulus of the masculine liquor to dislodge them and develop themselves.

STOMLACH.

By reference to the plate, it will be seen that the horse's stomach somewhat resembles a bagpipe. It is situated behind the diaphragm, principally on the left side, with its expellant orifice extending across the spine to the right. It has two surfaces, which may be called its sides, though one is posterior, and the other anterior; and two extremities, a large and small. The superior, or upper portion of the latter receives the œsophagus or gullet, and is termed its cardiac, orifice; while the lower portion, which ends in the duodenum, (see plate,) is termed its pyloric orifice. The situation of the stomach varies, in some degree, with its distention; when it is much distended, the left extremity will press upon the diaphragm, and cause heaving at the 


\section{$(50)$}

Plate No. 4.

\section{THE STOMACH OF THE HORSE.}

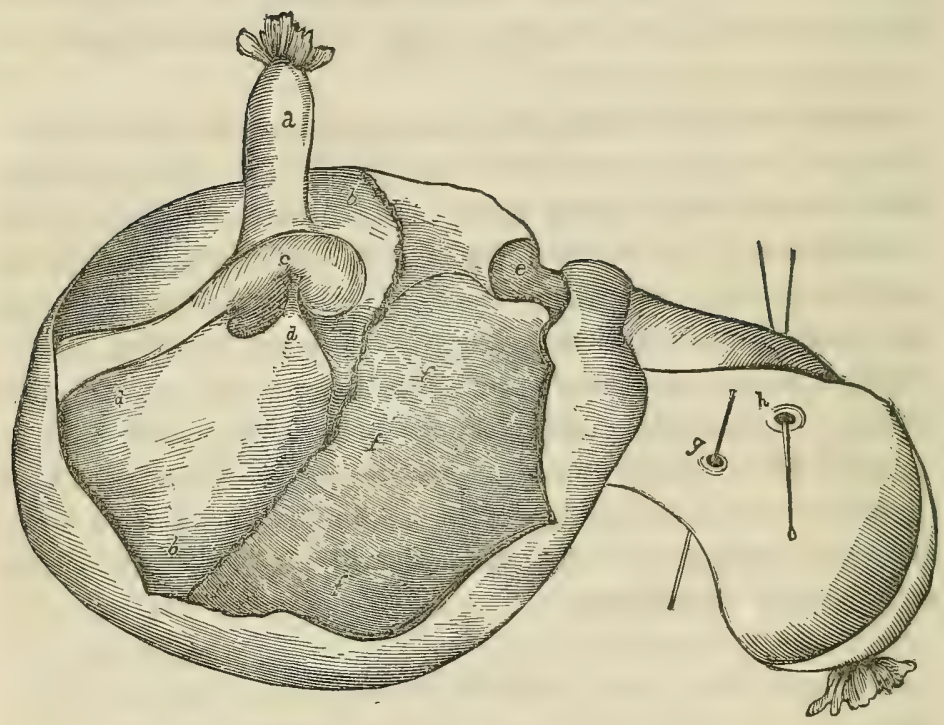

$a$, the gullet, or œsophagus, extending to the stomach: $b, b$, the margin which separates the cuticular from the villous coats of the stomach; $c$, the entrance of the gullet into the stomach; $d, d$, the cuticular portion of the stomach; $e_{3}$ the communication between the stomach and first intestine; $f, f, f$, the villous or mucous portion of the stomach, in which the food is principally digested; $g$, the small orifice through which a portion of the pancreatic juice enters the intestine; $h$, the orifice through which the bile passes into the intestine: the two pins mark the two tubes. 
flanks. In oxen and sheep, the first stomach, being very large, is found, when distended, to have its extremity carried up between the last rib and the hip, in which part it is punctured when a bullock is blown or hoven. But such an idea of the horse's stomach would be very erroneous; for, this animal having a very small one, it can never occupy a similar situation. The stomach has, externally, a covering from the peritoneum, which adheres closely to it by means of its cellular membrane. Its middle portion consists of muscular fibres, which are stronger in the horse than in oxen and sheep. These fibres run in various directions, but are principally longitudinal and circular; the latter very strong and thick at the point where the gullet terminates. The inner surface of the stomach consists of two portions, a cuticular and a villous. This kind of cuticula, covering nearly one half of the stomach, is peculiar to animals that appear destined to live on grain. It may be considered, in a slight degree, a species of gizzard, resembling the structure of those animals who have organs to make up for the want of teeth; for the horse has not the means of remastication, which oxen and sheep possess; nor does he usually masticate his food sufficiently; the wants of the constitution stimulate him to swallow it hastily; he, therefore, devours his food greedily, and if there were not some other structure than the one common to stomachs in general, it would not be sufficiently digested. The insensibility of this cuticular coat allows it to press, in some degree, on the food and perform a slight ituration without pain. The cuticular coat ends abruptly by a fringed end, and is very distinct from the villous coat. The villous coat, being much larger in extent than the muscular, is thrown into folds, which are largest towards the great extremity. Towards the first intestine they become less, and when at the lower orifice they form a valve, preventing the return of food, and its too speedy passage out. The folds not only hinder the too hasty passage of the food, but, by this means, apply the gastric juice more certainly to all its parts; but the principle end is to increase the secreting 
surfaces, which are here essentially necessary, as only half of the horse's stomach is supposed to possess the power of secreting gastric juice. We here, likewise, see the utility of the saliva; for, were the food to come into the stomach nearly dry, the gastric juice, being but a mucus, would not pervade all its parts, but would be lost upon some; nor would the mass be soft enough to spread in between its folds.

DESCRIPTION OF THE ANATONY OF THE FOOT, AND ITS DISEASES.

To a person totally unacquainted with the structure of the horse's foot, it may appear as a mass of horny, insensible matter; especially when he sees a horse-shoer cutting off large slices of it with the knife, and nailing to it plates of iron. It will be found, however, to be a very complicated piece of mechanism, but admirably calculated for sustaining the immense pressure and concussion to which it is almost constantly exposed. The horse's foot may be considered under two heads - the sensitive and the horny parts. The former consists of bones, ligaments, cartilages, membranes, nerves, bloodvessels, \&c., and is therefore susceptible of pain. The horny part, on the contrary, is void of sensibility, and serves principally as a defence to the sensitive parts, which it covers; it is endowed, however, with considerable elasticity, which enables it to yield, in some degree, to the impulse of the internal or sensitive part, in the various motions of the animal ; therefore, if, there be any disposition or tendency to contract or shrink in the horny covering or hoof, the internal, sensitive foot will be more or less compressed; and, if the horny parts lose their elasticity, the sensitive foot must suffer from concussion. So wisely, however, is every part of the foot contrived, that when it is properly managed, and judiciously pared and shoed by the smith, and when the horse is employed only by a humane man, it may be generally preserved in a sound state, perhaps nearly as long as other parts of the body. It must be admitted, that old horses, like old men, have not that ease and freedom about them which 
Plate No. 5.

\section{THE LEG FROM THE SHANK BONE.}

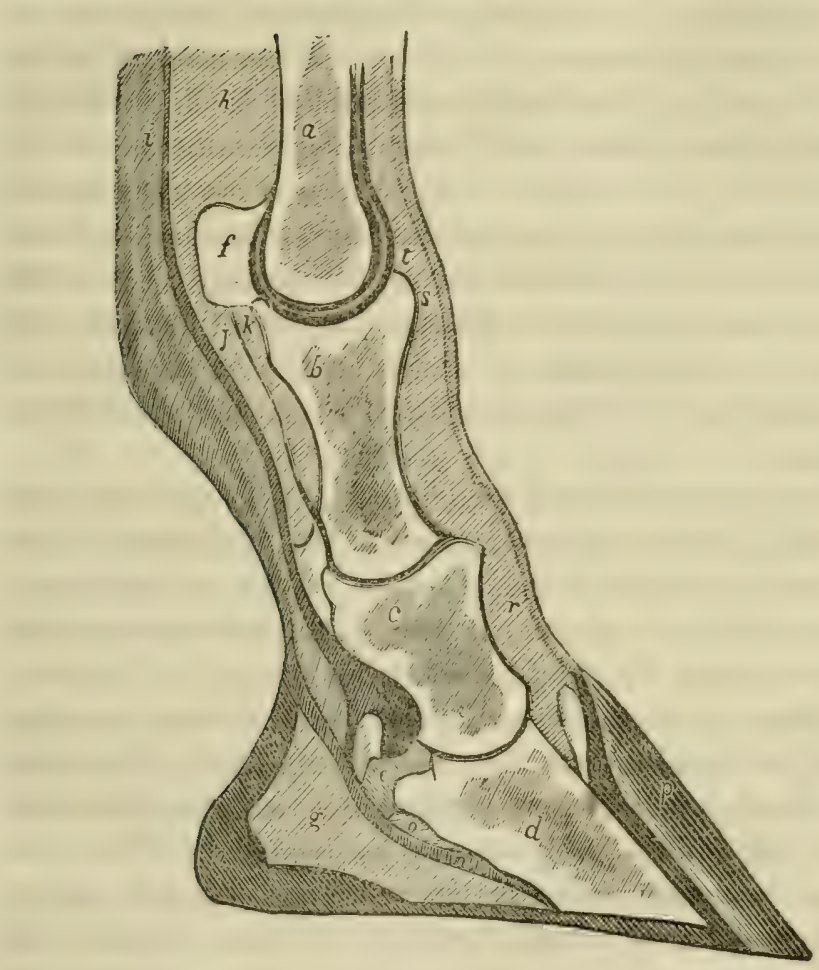

$a$, the shank bone; $b$, the superior, or large pastern bone; $c$, the inferior, or lesser pastern ; $d$, the coffin, or foot bone; $e$, the navicular, or nut bone; $f$; the sessamoid bone; $g$, the inner, or elastic frog; $h$, the suspensary ligament, inserted into the sessamoid bones; $i$, the large flexor tendon of the leg; $j$, a ligament uniting the sessamoid to the pastern bones; $l$, the short, inferior sessamoid ligament; $l$, the insertion of the flexor tendon into the small pastern; $m$, the horny frog; $n$, the insertion of the flexor tendon into the coffin bone; $o$, a ligament uniting the navicular to the coffin bone; $p$, the crust, or wall, of the foot; $q$, the sensitive lamina, uniting the crust to the coffin bone; $r$, the extensor tendon; $s, t$, the union of the upper head of the long pastern bone, and the inferior head of the shank or leg bone, forming the fetlock joint. 
they possessed in their youth; and that their feet, like other parts of the body, are subject to disease from various causes. Even in a state of unrestrained freedom, horses are found with diseased feet, that have never been shod.

The different parts that form the foot will now be noticed. By referring to the plate, figure $d$, a section of the coffin bone, will be seen, where, while it somewhat resembles the foot in shape, it contains the two principle arteries which supply the foot. They enter the lower and back part of the bone, immediately under and behind the termination of the flexor tendon. The arteries give off several branches within the coffin bone, which pass out through orifices at its lower and front part, to be distributed over its surface. The coffin bone is connected with the coronary, or small pastern, and with the navicular, (figure $e$ ) or nut bone. At the posterior, or back part, the flexor tendon (figure $n$ ) is inserted into the coffin bone.

The nut, or navicular bone, (figure $e$,) is in shape not unlike a boat. It is interposed between the flexor tendon and other bones, to remove the insertion of the tendon farther from the centre of motion; having a polished surface constantly moistened by a fluid resembling synovia, or joint oil.

The coronary, or small pastern bone, rests both on the coffin bone and navicula, to which it is firmly united by ligaments.

The great pastern, "or os suffraginis, rests on the small pastern, and is also firmly united by ligaments. The two sessamoid bones are placed at the upper and posterior part of the large pastern, to which they have a strong ligamentous attachment.

The canon, or shank bone, (figure $a$,) rests both on the great pastern and sessamoid bones. It articulates and moves easily upon them.

There are two elastic bodies attached to the upper and lateral edge of the coffin bone. They are named lateral cartilages; they occupy all the space between the extensor tendon and the back part of the sensitive frog. The lower part of these cartilages is covered by the hoof. The elastic 
membranes, or laminæ, cover all the front and lateral surface of the coffin bone; at the extremity of which they turn off at an acute angle, stretching forward to the side of the sensitive frog: here they form what have been termed the sensitive bars. The laminæ are elastic, and are said to be about five hundred in number. These laminæ are received between corresponding laminæ in the hoof; but there is a material difference between them. The laminæ of the hoof are void of sensibility; those of the coffin bone are very sensitive. These two kinds of laminæ form the connecting medium between the hoof and coffin bone; and so strong is their union, that it is found impossible to separate them without tearing or stripping off the sensitive laminæ from the coffin bone, unless the foot be placed in water for some time before it is attempted. The extensor tendon (figure $r$ ) is fixed, or inserted, into the upper and front part of the coffin bone.

The sensitive frog resembles a wedge; its point is towards the toe, whence it becomes gradually wider and larger: it is divided by a cleft in its centre, towards the hind part. The frog is made up of cartilaginous and fatty matter, and possesses considerable elasticity. Its fore part rests on that part of the flexor tendon which passes over the navicular bone, and on that which is inserted into the coffin bone. From this part its cleft or division commences; only a small portion, therefore, of the sensitive frog rests on the coffin bone and flexor tendon. The wide part of the frog projects considerably behind these, forming the bulbs of the heels, and, taking a turn forward, is blended with a ligament called the coronary. At its widest or posterior part, there is a considerable distance between the sensitive frog and the flexor tendon, the intermediate space being filled up with an elastic, fatty kind of matter. By this contrivance the frog is capable of considerable motion when it receives the pressure of the horse's weight, which it must do when its horny covering is in contact with the ground. The sensible bars are formed by an inflection of the sensible laminæ, when they arrive at the heel, whence they pass obliquely forward to the sides of the sensitive frog. 
Foot lameness. - The fore feet are more subject to lameness than any other part; and the most common cause of such lameness is a morbid irritability of the elastic laminæ, which cover the front and sides of the coffin bone and bars. The causes of this morbid state are numerous - applying a hot shoe to the foot, mechanical expansion or contraction with shoes fitted for that purpose. It may be brought on by hard riding, standing upon hot litter, and high feeding. The practice of breaking colts, and putting them to work too early, lays the foundation of foot lameness. Horses afflicted with this disease have a great degree of heat in the feet, with an unusual dryness and contraction of the horn at the heels; the frog appears to be compressed, and narrower than in the healthy foot, and sometimes ragged and discharging matter from its cleft or division. This is not always the case; sometimes the frog appears quite sound, and of the natural shape, and the form of the foot does not appear to have undergone any alteration. The lameness is often inconsiderable, and continues so for months. If the horse is worked on a soft road, very little, if any, lameness is perceptible; but the moment the animal steps on hard ground, it will be noticed. At length the horse is seen constantly resting his foot, or putting it forward, as he stands in the stable, and, when taken out to work, is found very lame. The only chance to effect a radical cure in this disease, is to turn the horse to grass in soft ground, withont shoes; and, unless this is done early, it seldom effects any permanent good.

Corns. - A disease of the horse's foot, often causing lameness. Corns generally happen in the inner heel, or in that part of the sole which lies within the angle formed by the inflection of the crust or wall of the hoof, or, in other words, between the bar and crust. In their early stage they generally cause some degree of lameness. If not attended to at this period, the horse soon becomes lame; and when the shoe is removed for examination, the horny matter in the part described will be found, upon scraping off the exterior surface, of a dark red color. If the shoe is not removed at this 
stage of the disease, continued pressure on the tender part, or corn, will at length cause matter to form, which, finding no vent beneath, ascends to the upper part of the hoof, called the coronet, where it breaks out; and this often misleads the practitioner, and the real cause is not suspected. The only proper way to proceed, is to pare out the red part, then take a small piece of tow, saturate it with tincture of myrrh, and place it on the corn; then have the animal shod with a bar shoe, and this can only be applied when the frog is sufficiently prominent and firm to receive its pressure. For, should the frog be lower than the heels, (that is, supposing the foot to be taken up, and its bottom part held upwards, ) it must be obvious that the bar shoe cannot bear upon it, and will, therefore, be useless. The only thing to be done in this case, is to pare away the crust of the tender heel, so that the heel of a common shoe may not rest upon it. The only mode by which a corn can be either cured or palliated, is to take off all pressure from the parts; and this, not only for a short time, but till the injured sensitive parts have lost their tenderness, and formed horn of sufficient strength to enable them to bear pressure. While a horse is worked, the shoe should be frequently examined; and whenever the heel appears to be so near the diseased part as to be in danger of bearing upon it, there must be a vacancy between the heel of the hoof and that of the shoe. When a horse becomes very lame from a corn, and matter is seen oozing out about the coronet, it will be advisable to leave off the shoe, and apply a poultice of shorts, or marshmallows.

\section{SHOEING.}

Many of the evil consequences of shoeing arise from the operator having but a very imperfect knowledge of the structure and various functions of the foot. (See Anatomy of the Foot.) In shoeing a strong, well-formed foot, there is very 
little difficulty, provided the smith understands his business; but in feet that are deformed, considerable skill is required, and a knowledge of the anatomy of the foot is indispensable.

The greatest evils in shoeing arise from the introduction of nails; and, notwithstanding many men of note in the veterinary art have strenuously labored to obviate the mischief, or to discover some new and better mode of fixing the shoe, their efforts have not hitherto been crowned with success.

Great ignorance was displayed in the earlier methods of shoeing; the bars were totally cut away, and the frog considerably pared down; the shoe was badly shaped, and was put on the foot red hot: the result was, what might be expected, - the functions of the bars and frog were destroyed, and the ill-shaped shoe acting with these, contraction in its worst form appeared, while the application of the hot shoe dried up the moisture of the crust.

The first who made any reformation in this method was Lafosse; he introduced the half-moon shoe. This was considered an improvement; its semicircular shape seemed to be more adapted to the healthy hoof, and not reaching beyond the middle of the foot, the nails were placed near the toe; hitherto their situation had been nearer the heels, which prevented a proper action of the sole and frog, thus destroying the natural spring and elasticity of the foot. Bracken and Bartlett made Lafosse's treatise known in England; but his method had this disadvantage, that the horses were apt to slip, and the heels were worn down very fast. To Lafosse succeeded William Osmer, who first prohibited the extensive paring of the hoof, that had as yet been practised. The crust was made smooth by rasping; the frog and bars were only to be cut when the edges were ragged; the shoe was equally thick in every part; the surface next the ground was flat, but narrower behind than before.

Many now appeared, who introduced various methods of shoeing and forms of shoes, all of which displayed more or less ingenuity. Lord Pembroke and Mr. Bracy Clark deserve 
mention. The Veterinary College threw out many hints and improvements, and Mr. Coleman labored hard to extend the knowledge already obtained.

Mr. Clark's shoe did not materially differ from that recommended by Osmer; he raised many objections against elevating the heels with calkins - preferred, however, sharp calkings in hilly roads.

Mr. Lawrence speaks in favor of the French method of driving the nails into shoes, which is in an oblique direction, so that the points come out about three quarters of an inch above the shoe.

The preparation of the foot, and the operation of shoeing, should be performed as follows:-

In taking off the old shoe, it is always necessary to raise the clenched portion of the nails, for, if neglected, the nail holes become enlarged, and not unfrequently pieces of the crust are torn off; this must naturally weaken the hold of the new nails, and injure the foot in other ways.

The edges of the crust must then be rasped, to ascertain if any stubbs remain behind; this process will likewise remove the dirt and gravel.

Paring is the next process, and perhaps the most difficult. The quantity to be cut away will vary with different horses. The flat foot needs very little paring. In the concave, or hollow foot, the horn may be cut till the sole yields to moderate pressure; when the sole appears in flakes, and thick in substance, it will be better to make the sole sufficiently hollow to admit the application of a flat shoe, as it will rest only, in that case, on the crust. But when the sole will not allow of being thus pared, the shoe must then be made concave, or hollow, on the surface next the foot.

The crust must be level all round, and the heels of the shoe should rest on the junction of the bars with the crust.

The bars should be left prominent, and never, under any circumstances, should they be cut away. If there is any one part of shoeing more important than the rest, it is to suffer the bars to remain prominent; if they are cut away, which 
is frequently done, contraction or permanent lameness is the result. The horn between the bars and crust must be removed; when this is done, and the shoe rests on the junction of the bars and crust, the horse will generally be free from corns.

The frog must be carefully pared away according to the shape and prominence of the foot, but it must be left within and above the lower surface of the shoe; if it descend lower than this, it will be injured; and if it be allowed to remain higher, it will not touch the ground, and its intention is thus rendered abortive, and its functions cannot be discharged.

For a perfect hoof, the shoe should not be more than three quaiters of an inch broad, and of the same thickness at the heel as at the toe.

The surface of the shoe that bears on the ground should be flat; that next the foot, particularly at the toe, should be hollowed; for even in good feet, the sole towards the toe is often level with the crust, and consequently would be pressed upon by the shoe, were its surface made flat. The toe of the shoe, being the part that wears most, should be formed of steel. The nails should be placed as near the toe as is consistent with the security of the shoe, that there may be as little restraint as possible upon the motion of the heels, and quarters of the hoof.

The crust of flat feet is usually weak; therefore, great care is required in nailing on the shoe; and this will appear the more necessary, when it is considered how much pain the animal must suffer, and what severe lameness may ensue, should he happen to lose a shoe during a journey. Horses that have long and slanting pasterns, with weak, low heels, require a shoe rather thicker at the heel than the toe; and when the pasterns are short and upright, and the crust of the heels deep and strong, a thin-heeled shoe is proper.

The most important object to be borne in mind, is the treatment of the foot at the time of shoeing. The blacksmith should never cut away more of the hoof than would be worn away, were the animal in a state of unrestrained freedom. 
The shoe should never be put on hot; neither should the foot be shaped to fit the shoe.

The bar shoe, which is called into use when the foot is affected with corns, sandcrack, \&c., should never be worn longer than the disease requires.

Contraction of the Hoof. - This is a very common defect in horses, and though it sometimes takes place under the best management, and even in colts that have never been shod, it is more commonly the effect of improper treatment. If we cut off the foot of a dead horse, and keep it in a dry but cool situation, so that it may not soon become putrid, it will be found to undergo but very little alteration in its form, though kept a considerable time; but, if the contents of the hoof are taken out, which may be done by keeping the foot a few days in a hot situation, the hoof will then be found to shrink or contract. This contraction will take place principally at the higher part or coronet, and towards the heels; the horn being in those parts most flexible, and containing nothing to oppose the contracting power. At the lower part, or bottom of the crust, there may be the same tendency to contraction; but there the horn is much thicker, and the contractible power is strongly opposed by the bottom of the hoof: that is, the frog, bars, and sole. If the bottom of the foot is removed, the heels will then contract rapidly. What then, it may be asked, is it that prevents contraction of the hoof in the living horse; and by what circumstances is the tendency or disposition to contract produced? The hoof, in its healthy state, is pervaded by a fluid, by means of which it is preserved in a flexible and elastic state. If, by any means, a preternatural degree of heat is excited in the foot, this fluid will be too quickly absorbed, and the supply will be diminished; the horny matter will, therefore, be disposed to contract or shrink ; and the contraction will take place more or less rapidly, according to the degree in which the disposition to contraction exists, and the resistance that is opposed to it. Contraction of the hoof sometimes depends on error in shoeing; yet the cause is often found in a morbid state of the foot, 
brought on by immoderate work, or standing idle in the stable; and sometimes depending, also, on constitutional or hereditary taint. When the nervous structure of any part of the body is impaired, it offers very little resistance to the encroachments of disease. The best means of preventing contraction of the hoof, is to breed from stallions and mares that are free from it; to break colts, and bring them into work, at a proper age; and when brought into the stable, to feed them properly, and work them with consideration. If a young horse is brought into work before he comes to maturity, there will be an undue expenditure of vital power. A horse in a state of nature takes proper and sufficient exercise, and the friction to which the feet are exposed is sufficient to wear away the useless horn; but when he is taken into the stable, his shoes nailed to the hoofs, and is made to stand for several days together without any exercise, is it strange that the feet should become diseased, or contracted? Sometimes a natural drain, or issue, is formed in one or both feet; that is, a thrush takes place; but the thrush is an evil, though less than it has a tendency to remove. (See Thrush, part Second.). The term contraction of the hoof is sometimes improperly applied; for in all those cases of chronic lameness that have been supposed to depend upon contraction of the hoof, though the contraction has been removed, the lameness has continued. The general application of the term contraction has been often the cause of obscuring the real nature of the lameness which has been so named, and has led to many contrivances, in the way of shoeing, for expanding the hoof; such as forcing it apart by means of a screw.

If we look at the real nature of contractions, we shall find that they originate, generally, in an excessive use of the organ and bad stable management; therefore the only probable means of restoration is a long run at grass. 


\section{REMARKS ON FEEDING.}

As the food of horses is well known to act considerably in maintaining health in some cases, and in others to be a serious cause of disease, it is, therefore, an important subject to the farmer and stable-keeper, and demands their serious consideration. Food may consist of two kinds, namely, natural, or such as animals are found to subsist on in a state of unrestrained freedom; and artificial, or such as man, by his own experience and observation, has found most suitable to produce health, strength, and condition, when domesticated and rendered subservient to his use. Herbage forms a great part of the food given to horses, such as grasses and clover; the different kind of grasses are usually converted into hay. Clover is given green, since it appears to be more useful in that form, for when dry it is not so easily digested, and contains less nutritive matter. The green herbage is invaluable in the cure of some obstinate cases of disease, simply by its medicinal effects. When hay is cut at the proper season, namely, before it becomes too fibrous, the greatest care is requisite in the drying process, for the most judicious persons have frequently been unfortunate enough to have their hay turn musty; in such cases it is impaired in quality. To obtain good liay, the grass should consist of various sorts; or be, as it is commonly termed, full of herbage. The soil should be well drained. The grass should be mowed early, and while in flower, and should be afterwards almost constantly attended to, if the weather is favorable; the more it is scattered about, the better will it be made, and the more effectually will its fragrance and other good qualities be preserved. The quantity is sometimes looked to more than the quality. Horses that are fed long on bad or musty hay, sooner or later suffer from indigestion, and a consequent loss of condition.

It will be seen by the annexed table, that hay contains but a small amount of nutrition in proportion to the same weight 
of grain ; therefore hay, to support life, must be given in large quantities; much time is required to digest it, and a large quantity of saliva and gastric juice to macerate it before it can be digested: all these circumstances are directly opposed to the uses of the horse, to which luxury and the wants of man have applied him. Hay, therefore, should be used as a condiment, to increase the bulk of food to a healthy distention of the stomach; and as such, very little of it should be used. The salt meadow hay has many objections; the principal one is, that it is cut too late, after the stems have become tough and fibrous. The effects of insufficient food are too well known to need much description; debility includes them all; it invades every function of the animal. And as life is the sum of the powers that resist disease, and if disease is only the instrument of death, it follows, of course, that whatever enfeebles life, or, in other words, produces debility, must predispose to disease. When horses are put to regular daily work, their vital power will be best maintained by a mixed diet, composed of shorts, meal, cracked corn, oats, and hay, the latter cut and mixed with the other articles, which must be moistened; bearing in mind, however, that horses, like ourselves, vary constitutionally, some being more readily and simply nourished than others. The principal food used in the New England States are oats, hay, and corn; the latter is ground or broken, and sometimes given whole. Oats have quite an extensive use; these, after being kept some time, give out moisture, which is supposed to render them more wholesome than new. When oats are damaged, they are unfit for the horse; if, however, they are used, they ought to be exposed to the heat of the sun, for kiln-dried oats produce disease of the bowels and skin, and of the system generally. Much has been written on the advantage of bruising oats for horses, and it has been proved by comparative tests, that a great saving may be thus effected. Some horses will not masticate the oats; hence they are swallowed whole; an examination of the excrement will prove this to be the case.

The most general roots in use are, 1. Carrots, which are 
one of the best remedial agents in our possession. When the horse is in health, they assist nature to maintain the physiological operations of all the functions. The sick horse will be improved by the use of this useful vegetable. It forms one of the best poultices, where poultices are indicated, with which we are acquainted; when cut up in small pieces, or scalded, and given to the horse occasionally, they are very acceptable to the digestive organs: in cases of chronic indigestion, and diseases of the lungs, they are invaluable. 2. Parsnips produce the same effect, and are about equal in their amount of nutritive matter. 3. Potatoes have been given to the horse, but the benefit derived from them is greater when boiled. In addition to the different diets here named, many employ other things; but this chiefly depends on the locality, and the possibility of procuring such food as is generally esteemed most wholesome.

A list, showing the relative amounts of nutritive matter contained in the following articles, taken from Sir H. Davy's work on chemistry :-

" 1000 parts of wheat contain 995 parts of nutritive matter ; barley, 920 ; oats, 742 ; peas, 574 ; beans, 570 ; potatoes, 230 ; red beets, 148 ; parsnips, 99 ; carrots, 98."

Of the grasses, 1000 parts of meadow catstail contain, at the time of seeding, 98 parts of nutritive matter; narrow leafed meadow grass in seed, and sweet scented soft grass iu flower, 95 ; narrow leafed and flat stalked meadow grass in flower, fertile meadow grass in seed, and creeping soft grass in flower, 77 ; cabbage, 73 ; crested dogstail and brome flowering, 71 ; yellow oat in flower, 66 ; yellow turnip, 64 ; narrow leafed meadow grass, creeping beet, 59 ; rough meadow grass, flowering, 56 ; common turnips, 42 ; sainfoin and broad crested clover, 52 ; lucerne, 23. Thus it appears that a horse must consume an immense quantity of the grasses, to enable the digestive organs to furnish the material for supplying the great waste that is continually going on ; therefore, however good or cheap hay may be, it is dear provender in the end. A horse will live and thrive best on a mixed diet, already 
referred to; yet an occasional run at grass will improve the condition. If indigestible substances are given to the horse, the stomach becomes overworked; and it follows that when an organ is overtaxed, other parts of the system become sympathetically affected, and the chemico-vital machinery is clogged. This is in accordance with nature's laws, which are immutable and uncompromising; whenever they are violated the penalty is sure to follow. Men who prepare horses for the market attempt to get them into condition, without any regard to their general health, the climate, quantity of food, its quality, or the state of the digestive organs. Men are very apt to think, that as long as the animal has what they term good food, and just as much as they can cram into the stomach, they must fatten; when, in fact, such an enormous quantity of food oppresses the stomach, impairs the digestive organs, and converts the food into a cause of disease. As soon as the stomach is overworked, the food accumulates; distends the viscera, interferes with the motion of the diaphragm, presses on the liver, and interrupts the circulation of the blood through that organ, seriously interfering with the bile-secreting process. Many thousands of our most valuable horses die in consequence of being too well, or, rather, injudiciously fed. Reader, if you own horses, let them have their meals at regular hours, in sufficient quantity, and no more; good straw on which they may rest their weary limbs; good stables, well ventilated; let them not be compelled to breathe the emanations that arise from the dung or urine; keep them clean, avoid undue exposure; don't work them too soon after feeding : finally, govern them in a spirit of kindness, and there will be little foothold for disease.

\section{OF STEAMING AND PREPARING FOOD FOR ANIMALS.}

"ON one occasion a number of cows were selected from a large stock, for the express purpose of making the trial : they 
were such as appeared to be of the best kind, and those that gave the richest milk. In order to ascertain what particular food would produce the best milk, different species of grass and clover were tried separately, and the quality and flavor of the butter was found to vary very much. But what was of the most importance, many of the grasses were found to be coated with silecia, or decomposed sand, and too hard and insoluble in the stomachs of the cattle. In consequence of this the grass was cut and well steamed, and it was found to be readily digested; and the butter that was made from the milk, much firmer, better flavored, and would keep longer without salt than any other kind. Another circumstance that attended the experiment was, that in all the various grasses and grain, that were intended by our Creator as food for man and beast, the various oils that enter into their composition were so powerfully assimilated or combined with the other properties of the farinaceous plants, that the oil partook of the character of essential oil, and was not so easily evaporated as that of poisonous vegetables; and experience has proved, that the same quantity of grass steamed and given to the cattle will give more butter than when the hay is given in its dry state. This fact being established from numerous experiments, then there must be a great saving and superiority in this mode of feeding. The meat of such cattle is more wholesome, tender, and better flavored than when fed in the ordinary way." Dr. Whitlaw thus describes the process of steaming: "A boiler, that will hold from fifty to a hundred gallons, should be placed in a convenient situation, upon an iron surface, so as to render it movable at pleasure, although it would be better as a permanent fixture. The boiler should have a safety-valve affixed in the middle of the lid, which should be six inches in diameter, and a screw and unscrew to the boiler, when it is necessary to replenish the boiler. The valve should be three or four inches long, one inch or more in diameter, as the size of the boiler may require, with a small bar across the bottom tube; and a small hole in the centre of the bar, to allow the stalk of the valve to pass 
through it, which must be in the form of a pencil, a few inches longer than the barrel, to allow the steam to escape; with a guard at the bottom, with a notch in it, the size of the guard, to prevent the valve flying out. There should be a concave head to the valve, to fit the tube close, and of sufficient weight to prevent its bubbling up, unless the steam be strong. Next procure a pipe resembling the neck of a goose when standing erect; the wide end to be connected with the cover of the boiler, with a screw to connect the pipe through which the steam passes into the box. The box should be made of three-inch plank, from four to six feet square, or as large as may be required; strongly dovetailed at the corners, fixed with screws, with a false bottom, and about eight inches from the true bottom: the latter should be perforated with holes, drilled about the size of a lead pencil, in order that the steam may ascend. The pipe from the boiler should enter immediately below the false bottom, through a hole made for the purpose, and of the same bore as the pipe. When thus prepared, the box should be filled with chopped hay, or whatever dry food is used, such as cornstalks, \&c. The steam should be turned on, and kept exerting its power for a short time, according to the nature of the food. When cool, a pailful of it may be mixed with a few handfuls of cracked oats, or ground corn, and should be given to each cow night and morning: half a tablespoonful of salt should be given twice a week. The cows should have, in addition, a sufficient quantity of dry hay to give them employment in chewing the cud. They must be kept perfectly clean, and be combed with a wool card every morning; for this practice will create that circulation through the skin, which is necessary to the health of the cow and the milk she gives, as a free circulation is to the lungs. Another great advantage obtained by steaming is, that it volatilizes, or throws off, the oils of many pernicious plants that may be among the hay, particularly the buttercup, and keeps the cattle from suffering from the bad effects of the poison. When potatoes are steamed, (and they never should be given without,) a con- 
siderable degree more of their dangerous powers dissipates, than would by boiling them, and consequently they are much improved for food. Having paid great attention to the cultivation of the potato," observes Dr. Whitlaw, "I may be allowed to suggest something that will be useful to the farmer. Potatoes ought to be raised on new earth - gravelly, chalky; marly, slaty, and mountainous earths. In such situations they are more mealy and wholesome; but when grown in rich manure and clayey soils, they are apt to produce disease. During the process of boiling potatoes, the poisonous or night-shade principle is so blended with the starch and gluten, that it never can be separated, so as to produce gluten and flour afterwards. If potatoes were to be raised on low grounds, and eaten in the torrid zone, in the same way they are in England, they would prove a mortal poison. Carrots, beets, and parsnips, should be raised on dry ground; particularly carrots and parsnips, as a wet soil renders them injurious, as well as all umbelliferous plants; and as they are frequently made food for cattle, they should be well steamed."

\section{WATERING.}

Although few pay proper attention to this department of stable management, yet a little reflection will prove of how much importance it is, that the horse should be supplied with such water as is most palatable to him. Horses have a great aversion to what is termed hard water, and have been known to turn away from the filthy stuff found in the troughs of some of our stables: the water of wells and purnps in our seaport towns is usually hard, and possesses a degree of coldness not at all congenial with the palate of the animal. The intense coldness of well water, in the summer months, has been known to gripe, and produce spasmodic colic, injuring the animal in other ways. 
When a horse is in health he may be frequently watered, taking care to allow but a small portion at a time. When water is drunk immoderately, it reduces the system to a condition which renders him an easy prey to the attacks of severe disease, by despoiling the structures of their elasticity and vigor. A horse that is about to perform a journey should be restrained from taking too much fluid. It is a bad arrangement to water a horse just before feeding, yet this is to a great extent a general practice.

If the animal has just arrived from a journey, or has worked hard, about two quarts may be given; yet if he is in a state of perspiration, he should be rubbed dry before partaking of any fluid. Water should always be given to a horse from a bucket, (we mean working horses,) and they never should have more than half a bucket at a time; two or three buckets a day would be sufficient for any horse.

Walking exercise is useful after watering, but trotting or galloping is dangerous. Should a horse get loose during the night, and overload the stomach with corn, then a drink of water would be equivalent to a sentence of death. The only proper course would be, to keep the animal quiet, arouse the stomach and digestive organs to action by a cordial and carminative drink; use injections ; after the danger is over, and not till then, should the horse be permitted to drink.

\section{EXERCISE.}

THIs is an essential part of stable management, and like food, it tends towards the health and strength of the animal. Daily exercise is necessary to all horses, unless they are sick; it assists and promotes a free circulation of the blood, determines morbific matter to the surface, develops the muscular structure, creates an appetite, improves the wind, and finally invigorates the whole system. We cannot expect much of a horse that has not been habituated to a sufficient daily 
exercise; while such as have been daily exercised, and well managed, are capable not only of great exertion and fatigue, but are ready and willing to do our bidding at any season. When an animal is overworked, it renders the system very susceptible to whatever morbid influences may be present, and imparts to the disease they may labor under an unusual degree of severity. The exhaustion produced by want of rest is equally dangerous; such horses are always among the first victims, and when attacked their treatment is embarrassing and unsatisfactory.

\section{WANT OF APPETITE.}

THis sometimes arises from over-exertion, or immoderate work, which produces general debility, and of course the whole functions are more or less disturbed, and take on the same morbid action: at other times it is brought on by suffering the horse to overload the stomach and bowels; by standing in the stable without exercise, and eating immoderately of hay. Want of appetite may depend on a natural delicacy of the stomach, or on the bad quality of the food.

Bad hay is often eaten with little or no appetite, especially when it has been musty. When the appetite fails, though the food is good, and the horse has only moderate work, the diet should be changed; a small quantity of straw, cut up with what is called cut feed, would be serviceable; but if the horse has been worked hard, rest probably is the only remedy necessary. Young horses sometimes refuse the hay, or mangle it, from soreness of the mouth, in consequence of changing their teeth. This is sometimes attributed to lampas, and the knife or firing iron is resorted to: this is a barbarous and cruel practice, and should never be permitted. When a young horse is changing his teeth, the whole mouth becomes red and tender, which makes him fearful of eating hay or unground corn, 
from the pain it gives him. In all such cases the horse should be kept on scalded shorts, or cut feed, until the soreness of the mouth is removed. In old horses, when the lampas are down to a level with the front nippers, the part should be washed with a strong solution of burnt alum; or make a decoction of powdered bloodroot, and wash the part night and morning. All serious internal disorders are attended with loss of appetite. Weakness of appetite is often constitutional, and cannot be cured; yet it may be palliated: when such a horse is wanted only for moderate work, his appetite may be greatly improved by careful feeding, good grooming, and a well-ventilated stable. The food must be of the best quality, and the water pure, and not too cold or hard; he should have but little food at a time, but the more frequently. He should never have more, but rather less, food put before him at a time than he is inclined to eat; and if, at any time, he is found to leave food in the manger, it should be taken out, and after keeping him without food for a short time, some fresh hay, oats, or shorts may be given. The rack, manger, and every part of the stall should be kept clean, and when taken out for exercise or work, the stall should be well swept out, the old litter spread out to dry, and that part unfit for use taken away. At night some clean, fresh straw should be placed under him. A change of food is often useful, especially when green food or carrots can be obtained. It is the custom in many stables to collect the bedding after it has been saturated with the fluids of the excrement and urine, and place it under the manger, thus submitting the horse to the noxious vapors that arise from the filthy mass. Is it to be wondered at, that the poor animals should drag out such a miserable existence?

Though a good appetite is very desirable in the horse, especially in one that works hard, yet the unlimited indulgence, as we have already shown, leads to serious consequences. Some horses will do well on less food than others; but this does not form any objection to the establishment of a fixed allowance, taking into consideration the age, size, and 
capacity of the digestive organs. The author has visited stables containing from ten to one hundred horses: out of that number no two could be found that would correspond exactly in external conformation, or muscular capacity; they weighed from seven to eleven hundred pounds. Upon a little reflection, it will be seen that some of these horses would require less food than others; yet they all had their twelve quarts, and as much hay as they could cram down. The evil consequences of overfeeding are sometimes gradual in their progress, and often so slow as to escape observation; so that when it amounts to a serious disorder, the cause is often lost sight of. Every man must be aware how important it is to know the cause of the malady before an attempt to cure is made.

Very few men notice the quantity of hay a horse eats, and there are but few who attend to its quality; yet every one will admit, that it is necessary to limit the allowance of hay, whether we regard the expense of the article or the horse's health. If a horse stands idle in the stable for a whole day, with as much hay before him as he will eat, he generally eats too much, especially if he has but little corn and too much water. The increased capacity of the stomach, which generally results from overloading that organ, is frequently accompanied with increased appetite. So craving, or morbid, is the appetite, that the animal will eat his bedding, or any thing that comes in the way, until the stomach is sufficiently filled to allay the sensations of hunger. When a horse eats an immoderate quantity of hay, he is always craving after water; so great is the thirst, that the horse generally loses that delicacy of taste and smell that is natural to him, and will drink any water that comes in his way. The best way of correcting this morbid appetite is, to turn the animal out to pasture, (if the season permits, where there is but little grass, so that he may be obliged to work for a living. Here, if it is not too late, the stomach will gradually contract; and as it diminishes in capacity, it will increase in strength. In the same ratio will the digestive organs be improved, and the 
delicacy of taste be restored. By proper attention to the appetite, not only will a horse be kept in good health, but a great saving will be effected; for it must be borne in mind, that when a horse eats more than he can digest, he does himself harm, and occasions a great waste of food.

\section{ON STABLE MANAGEMENT.}

As the construction and management of the stable are materially connected with the prevention of disease, it is necessary that every farmer should pay particular attention to this important branch, since to negligence in this department may be traced many of those diseases which derange the natural functions of the body. When a horse is roaming at liberty in the forest or field, he enjoys all the advantages of fresh and pure air, and no restriction of light. The reader's attention will be first called to construction and ventilation of the stable.

Situation is very important; yet in crowded cities the stablekeepers have but little choice. An elevated spot should be selected, if possible; low, damp, or marshy ground is very prejudicial to the comfort and health of the horse; all low situations are apt to exhale gases that are more or less destructive. A moist, chilly air will engender rheumatism, stiffness of the joints, colds, or common catarrh.

Lofiness is very essential; it prevents injury of the poll, called poll evil, and provides for a larger supply of pure air for the support of respiration.

In all cases it is necessary to have the ceiling tight; it keeps the bad atmosphere of a close stable from injuring the hay: by neglecting this precaution the food is rendered highly injurious and unwholesome.

The size of the stable must vary according to the number of horses it is intended to contain. The stalls should be six feet wide, so as to allow the horse to lie down, and nine feet 
in length, with a declivity of one or two inches, so as to allow the urine to run off. Too many should not be kept in the same apartment : not only is the air thereby vitiated, but the rest and sleep, so necessary to invigorate the animal, are thus prevented or disturbed. Some horses will not lie down; in fact, there is not room for them to do so in many stables. Some men actually believe that a horse is as insensible as a stone, and that any thing is good enough for him; that he is not entitled to any consideration or mercy; and he stands in a narrow-contracted, filthy stall, until the muscles and ligaments around the joints become so stiff and callous, that the poor brute is unable to rest his weary limbs. Some horses will not sleep, or lie down, unless perfectly at their ease; hence the frequent entrance of stablemen and other persons, with lights, must be a great disturbance to horses that are fatigued and irritable.

A large manger will be preferable to the rack; it will prevent the hay seeds and dust from falling on the head, to the frequent injury of the eyes. The length of the halter should be sufficient to allow the animal to lie down.

The floors of stalls are made of various materials : hard pine planks are the best, as they preserve an equal temperature. A small quantity of dry straw is absolutely necessary, as it prevents many diseases of the feet; but the feet need not sink so deep in it that their temperature should be affected.

On Ventilation and the Admission of Light into the Stable. - In a close stable the air is not only hot, but loaded with impurities; the breath of the animal corrupts it, and renders it unwholesome. The author has often visited stables early in the morning, and found the atmosphere very oppressive, and the smell intolerable. From this hotbed of corruption the animals were brought forth to their daily work: the natural consequence of such sudden transitions must sooner or later be disease. The effluvia of animal bodies are constantly rumning into a putrefactive state, and this must point out very forcibly the necessity of a proper ventilation in stables, especially when it is considered that the dung and urine add to 
the evil. Stables that are kept hot, and not sufficiently ventilated, are always damp. This arises from the breath and vapor of the horse's body becoming condensed. When the moisture has remained for a certain length of time, it acquires an unpleasant smell, which must be peculiarly offensive to an animal destined, in a state of nature, to be surrounded with pure and wholesome air. In a state of health, a certain evaporation from the surface of the body is constantly going on : this is called insensible perspiration; it unloads the vessels of the skin, invigorates the circulation of the blood, and gives tone and health to the whole animal; hence the necessity of attending to the proper means of ventilation in the construction of stables must be sufficiently evident.

The best mode of ventilation is to have a tube, which may be constructed of four boards nailed together, so as to form a hollow box: this is carried from the centre of the ceiling through the roof; a small ventilator may then be placed on it above the roof; or a more simple and less expensive method is, to furnish the tops with slanting caps, leaving sufficient space for the hot air to pass off : this will prevent the rain passing into the stable.

On the Admission of Light. - Nothing is so detrimental to the eyes as sudden transitions from darkness to a glaring light; and yet this is heedlessly disregarded. Many of our city stables burn lamps during the day, (probably preferring darkness to light.) It is well known, and most persons have experienced the very unpleasant sensation of a mingled pain and giddiness, which is not readily dismissed, after emerging from a dark room or passage, and suddenly coming in contact with the light. Daily repetitions of this would gradually injure the eyesight, and probably blindness would be the result. On the other hand, too much light is equally injurious. The windows should be sashed so as to draw down from the top; and when the horse is at work, both these and the doors should be open.

The brush and currycomb are highly necessary for horses kept in stables. Good rubbing promotes circulation of the 
blood, determines morbific matter to the surface, relieves congestions, and is a substitute for exercise. Without a clean skin no horse can be expected to have a fine coat.

In fair weather the horse should be cleaned in the open air, and not in the stable; a brush, or a wisp of straw, is the most beneficial and effective. The currycomb, when immoderately used, is decidedly injurious.

Neatness is always requisite in stables, and in that case the appearance is more healthy and comfortable. Every article should be hung or laid in its proper place.

We cannot close this subject without referring to the evil practice of allowing the manure to accumulate under the stable floor : how long this practice will be continued remains to be seen. The subject of ventilation is but just in its infancy; many have yet to learn, that the very existence of their animals depends on a proper supply of pure, uncontaminated atmospheric air: when they are convinced of this fact, and not till then, do we expect a reformation. The litter and dung should be removed into the open air; nothing is lost by taking away that which is bad or unwholesome.

\section{ON THE ILL EFFECTS OF MANURES}

OF LARGE CITIES ON THE QUALITIES OF PLANTS.

DR. Whitlaw observes, "Among the fertilizers of the soil, high importance is attached, and deservedly, to that mass of matter which results from the process of putrefaction upon organic substances undergoing corruption after death. $\mathrm{By}$ reason of its efficacy, it is assiduously procured to fertilize poor soils, to renovate exhausted ones, and prevent good ones from wearing out. Animal manures have a peculiar rankness; some of them stimulate, or, it may almost be said, cauterize with vehemence. Hence they require admixture of milder materials to mitigate their force. Yet after this offal and 
scrapings of large cities have been mingled with soil, in such proportion as not to destroy the life of the plants, but to promote their vegetation, they have been considered as communicating, in many cases, a disgusting or offensive quality to some of the vegetables they nourish. They have been charged with imparting a biting and acrimonious taste to radishes and turnips. Potatoes have been observed to borrow the foul taint of the ground." This may readily account for the disease found in the potato. That the potato, in several sections of the United States, is fast degenerating, every one will admit; and they will continue to do so just so long as the farmer uses animal manure, and suffers rank and poisonous weeds to vegetate on his lands.

Millers observe a strong, disagreeable odor in the meal of wheat that grew upon land highly charged with rotten recrements of cities; the like deterioration of quality has been remarked in tobacco raised in cow-pens. And stable dung has been accused of imparting a disagreeable flavor to asparagus. It seems that some portion of the foul matter of manure is absorbed by the radicles of vegetables, and, after passing unassimilated through the sap-vessels, is communicated by the process of nutrition to living substances. This is not to be wondered at when we know that the principal constituents of animal and vegetable life are nearly the same; or the different compounds are all produced by the same elementary principles. Vegetables consist of carbon, hydrogen, and oxygen, and the same substances, with the addition of nitrogen, are the principal constituents of the most important compounds found in the animal creation. "It may be illustrated in the animal kingdom. Ducks are rendered so ill tasted, from stuffing down garbage, as sometimes to be offensive when brought as food to the table; the quality of pork is known to be modified by the food of the swine; the bitterness of partridges has been ascribed to the buds on which they live; and the peculiar flavor of piscivorous fowl is rationally traced to the fish they devour. Thus a portion of nutrimental matter passes into the living 
bodies of plants and animals, in certain proportions, without having been entirely subdued or assimilated. It becomes, therefore, a subject of curious and important reflection. The horticulturist mostly calculates on the quantity of his crops. It is, however, a becoming subject of research, that he should likewise attend more to the quality; or, perhaps, the consumer may inform him that an offended palate, and injured health, will induce a careful provider to seek uncontaminated articles for his table."

Dr. Whitlaw continues: "I have labored with the most unwearied zeal to point out to agriculturists the evil effects of the corrupted soil arising from improper manure, in producing diseased crops; and, consequently, diseasing animals and man fed on them likewise. I have urged my belief that even the most wholesome vegetables are changed by rank manures, so as to cause many diseases."

I hope the horticulturists and agriculturists in America will profit by the doctor's advice and prevent, not only noxious, but likewise wholesome, vegetables from imbibing poisonous qualities, corrupted by bad manures, and more palticularly as the heat of that climate renders poisonous plants much more active than in England; otherwise they will soon exceed the latter in respect to diseases, at least in dyspepsia, with its long train of awful attendants. "Putrid animal matter is offensive to many animals. Dr. Rudge says that there was an enclosure, near Arlington, close to which was a dog kennel. Eight cows out of twenty miscarried, in consequence of frequent exposure to flesh, and the skinning of dead horses, so near them. The remainder were removed to a distant pasture, and did well. Most veterinary writers recommend that when a cow has aborted, the fœtus and afterbirth should be buried deep and away from the pastures. Sad experience has taught them, that putrid animal matter is as destructive as the pestilential sword. The smell of any putrid substance will cause sheep to miscarry."

Let our landowners and farmers appropriate the best calculated situations for raising grain, clover, and grass seed of the 
most approved kind, in order to supply the cattle-growing jnterest. These should have their lands well cleaned by cropping, and well prepared for laying them down into pasture. All the manure that is to be put on the land should, the year previous, be made into compost with lime and other earth, well mixed by turning it over two or three times in summer; by this means all the insects, seeds, and roots in the manure will be destroyed by the lime. This plan will insure a good crop of grain and grass, adequate to the expense of the manure. The ditches should be cleaned, and the dirt laid in heaps; both the common and rich earths made from the decayed leaves, should be prepared to mix with the manure and lime. In cases where the soil is light, lime, chalk, and marl are the best manure. In clay soils, sand and carbonaceous earths are proper. The land should be ploughed deep, so that the soil that has been subject to cultivation should be turned down to rest and recrystallize. Upon this principle, the people would be living upon provisions raised from virgin earth, which would indeed be a blessing to them; for then there would be few diseases, and the farmer would contribute to the wealth of the country. Paring and burning are good methods of getting the fields cleared of buttercups, poppies, dandelions, and other noxious plants, whose roots do not run deep into the soil. The flavor of all grains, fruits, and vegetables are much improved by being manured with burnt earth and vegetable ashes.

\section{ON ANIMAL MATTER.}

All bodies endowed with life, and with spontaneous motion, are called animals. These are all capable of reproducing their like in life. Some, by the union of the two sexes, produce small living creatures; others lay eggs, which require a due temperature to produce young; some multiply without 
conjunction of sexes; and others are reproduced when cut in pieces, like the roots of plants.

All animals are fed on vegetables, either directly or by the intervention of other animals.

As the animal, then, is derived from the vegetable matter, we find, accordingly, that the former is capable of being resolved into the same principle as those of the latter. Thus, by repeated distillations, we obtain from animal substances water, oil, air, and easily destructible salt and charcoal. These secondary principles are, by further processes, at length resoluble into the same proximate principles which we find in vegetables, viz., air, earth, and water, and the principle of inflammability.

But though the principles of vegetable and animal substances are fundamentally the same, yet these principles are combined in a different manner. It is exceeding rare that animal substances are capable of the vinous or acetous fermentation; and the putrefactive, into which they run remarkably fast, is also different in some particulars from the putrefaction of vegetables. The smell is much more offensive in the putrefaction of animal than of vegetable substances. The putrefaction of urine, is, indeed, accompanied with a peculiar fetor, by no means so intolerable as that of other animal matters; this is probably owing to the pungency of the volatile alkali, and also to the urine containing less inflammatory matter than the blood and other fluids. When analyzed by a destructive heat, animals afford products very different from those of vegetables; the oil has a particular and much more fetid odor, and the volatile salt, instead of being an acid, found as it is in most vegetables, is found in animals to be a volatile alkali.

Chemists have spoken of an acid procurable from animal substances, and, indeed, certain parts of animal bodies are found to yield a salt of this kind; but it by no means is the case with animal substances in general. In some animals an acid exists uncombined and ready formed in their bodies. This is particularly manifest in some insects, especially ants, 
from which an acid has been procured by boiling them in water.

The solid parts of animal bodies, as the muscles, teguments, tendons, cartilages, and even the bones, when boiled in water, give a gelatinous matter, or glue, resembling the vegetable gums, but much more adhesive. We must, however, except the hair. The acids, the alkalies, and quicklime are found to be powerful solvents of animal matter. It is from the solids that the greatest quantity of volatile alkali is obtained; it arises along with a very fetid empyreumatic oil, from which it is in some measure separated by repeated rectifications. This salt is partly in a fluid, and partly in a solid state; and from its having been formerly prepared in the greatest quantity from the horns of the stag, it has been called salt or spirits of hartshorn. Volatile alkali may be procured from many animals, and from almost every part, except the fat. Though we are sometimes able to procure the fixed alkali from animal fat burnt to a cinder, yet it is probable that this salt did not make any part of the living animal, but rather proceeded from the introduction of saline matter, incapable of being assimilated by the functions of the living creature.

In speaking of the fluid parts of animals, we should first examine the general fluid, from whence the rest are secreted. The blood, which, at first sight, appears to be a homogeneous fluid, is composed of several parts, easily separable from each other, and which the microscope can even perceive in its uncoagulated state. On allowing it to stand at rest, and be exposed to the air, it is separated into what are called the crassamentum and the serum. The crassamentum consists chiefly of the red globules, joined together by another substance, called the coagulable lymph. The serum is a yellowish fluid, having little sensible taste or smell ; at the heat of $160^{\circ}$ Fahrenheit's thermometer, it is converted into a jelly. This coagulation of the serum is also owing to its containing a matter of the same nature with that of the crassamentum, viz., the coagulable lymph: whatever, then, coagulates 
animal blood, produces that effect on this concrescible part. Several causes, and many different, are capable of effecting this coagulation; such as contact of air, heat, alcohol, earth, alum, and some of the metallic salts. The more perfect neutral salts are found to prevent coagulation, such as"common salt and nitre.

Of the fluids secreted from the blood, there a great variety in men and other animals.

The excrementitious and redundant fluids are those which afford, in general, the greatest quantity of volatile alkali, and empyreumatic oil. There are, also, some of the secreted fluids which, on a chemical analysis, yield products in some degree peculiar to themselves. Of this kind is the urine, which is found to contain phosphoric acid and volatile alkali.

The fat, too, has been said to differ from other animal matters in yielding, by distillation, a strong acid, but no volatile alkali. There is also much variety and state of the combinations of the saline and other matters, in different secreted fluids.

Animal oils and fats, like the gross oils of vegetables, are not soluble in water, but may be united with water by the intervention of gum or mucilage.

Most of them may be changed into soap by fixed alkaline salts, and may thus be rendered mixible with both spirit and water.

The odorous matter of some odoriferous animal substances, as musk, civet, castor, is, as well as essential oil, soluble in spirit of wine, and volatile in the heat of boiling water.

It is said that an actual essential oil has been obtained from castor in a very small quantity, but of an exceedingly strong, diffusive smell. The blistering matter of cantharides, and those parts of sundry animal substances in which their peculiar taste resides, are dissolved by rectified spirit, and seem to have some analogy with gummy resins.

The gelatinous principle of animals, like the gum of vegetables, dissolves in water, but not in spirit or in oils; like gums, also, it renders oils and fats mixible with water into a 
milky color. Some insects, particularly the ant, are found to contain an acid juice, which approaches nearly to the nature of vegetable acid. There are, however, sundry animal juices which differ greatly, even in these kinds of properties, from the corresponding ones of vegetables. Thus animal serum, which appears analogous to vegetable, gummy juices, has this remarkable difference, that though it mingles uniformly with cold or warm water, yet, on heating the mixture, the animal matters separate from the watery fluid, and concrete into a solid mass.

Some have been of opinion, that this heat of the animal body, in certain diseases, might rise to such a degree as to produce this dangerous concretion of the serous humors; yet the heat requisite for this effect is greater than the system seems capable of sustaining. The soft and fluid parts of animals run quickly into putrefaction; at least, much quicker than vegetable matter, and when corrupted, prove more offensive. This process takes place, in some degree, in the bodies of living animals; as often as the juices stagnate long, or are prevented by an obstruction of the natural outlets from throwing off the more volatile and corruptible parts. During putrefaction a quantity of air is generated, all the humors become gradually thinner, and the fibrous parts more lax and tender; hence the distention which succeeds the induration of any of the viscera, or the imprudent suppression of dysenteries by astringents. The crassamentum of human blood, as well as that of quadrupeds, changes, by putrefaction, into a dark livid color, a few drops of which tinge the serum with a tawny hue, like the ichor of sores and dysenteric fluxes; as also the white of the eye, the saliva, the serum of blood drawn from a vein, \&c. The putrid crassamentum changes a large quantity of recent urine to a flame-colored water, so common in diseases where febrile symptoms are present. The mixture, after standing an hour or two, gathers a cloud resembling what is seen in the crude water of acute distempers, with some oily matter on the surface, like the scum which floats on scorbutic urine. The serum of the blood 
deposits, in putrefaction, a sediment resembling well-digested pus, and changes to a faint olive-green. A serum so far putrefied as to become green, is frequently to be found in parts that are bruised, and in gangrene. In dead bodies this serum is to be distinguished by the green color the flesh acquires in corrupting. In salted meat, this is commonly ascribed to the brine, but erroneously; for it is known to resist putrefaction. It has no power of giving this color, but only of qualifying the taste, and in some degree, the ill effects of corrupted aliments. In foul ulcers, or in other sores where the serum is exposed, the matter is likewise found of this color, and is then always acrimonious. The putrefaction of animal substances is prevented, or retarded, by most saline matters; even by the fixed and volatile alkaline salts, which have often been supposed to produce a contrary effect. Of all the salts that have been tried, sea salt seems to resist putrefaction the least ; in small quantities it even accelerates the process. The vegetable bitters, such as balmony, gentian, \&c., charcoal, cayenne, gum myrrh, \&c., are among the best antiseptics, not only for preserving the flesh long uncorrupted, but likewise correcting it, in a measure, when putrid.

It has been found, that when animal flesh in substance is beaten up with bread, or other farinaceous vegetables, and a proper quantity of water, into the consistence of paste, this mixture, kept in a heat equal to that of the human body, grows in a little time sour; while the vegetable matters, without the flesh, suffer no change. Some few vegetables, in the resolution of them by fire, discover some agreement in their matter with bodies of the animal kingdom; yielding a volatile alkaline salt in considerable quantity, with little or nothing of the acid of fixed alkali, which the generality of vegetables afford. 


\section{ON BREEDING.}

The choice of a sire and dam is a point of the utmost consequence in breeding horses, (or indeed any other animal,) as the offspring will be found, in almost every instance, to inherit the qualities of its parents: peculiarity of form and constitution is inherent, and descends from generation to generation. Hence the necessary attention to those niceties which breeders are often apt to forget. Nor is it sufficient that one of the parents be good, and the other indifferent; for the perfection of the sire may be lost through the deficiencies of the mare, and vice versa.

In the selection of a stallion, many things should be observed. There should be general uniformity and compactness in every part. The height should depend on the occupation the foal is destined to fill. The legs should be particularly examined, and disease should pervade no part of the system. Fat, heavy horses, with thick legs, and coarse, unseemly heads, should always be avoided. Horses should be free from specks on the eye - partial or total blindness. Temper is an essential point, for vice is sometimes hereditary. Stallions that cover too many mares in a season, in the latter period produce weak offspring.

As regards the mare, it is well known that the dam contributes more to production of the offspring than the sire. It is essential that she be in full possession of her natural strength and powers : the vigor of the constitution determines much in favor of the foal. It is a great error to suppose, that a mare that has once been good, and capable of great exertion, should, when old, and no longer fitted for work, produce offspring equally efficient as when in her prime : the foal will certainly inherit some of the weakness of the present nature and broken-down constitution. Mares should never be put to the stallion until they have arrived at maturity, which takes place about the fifth year. Mares will, and are bred from, earlier, but it is a bad practice, for strength and beauty 
are absent; and thus not only is the dam rendered inefficient sooner than in one that is allowed to come to maturity, but the foal can never be expected to be either healthy or strong in constitution. The period of going with foal is eleven months: after the sixth month, great care and gentleness should be exercised towards them; moderate exercise is essential; hard work in haruess, over bad roads, is likely to produce abortion ; and mares that have once aborted are very liable (if the same causes are in operation) to a recurrence of the same. (See Aвortion, part second.)

The proper time for copulation is when there is a discharge of a whitish fluid from the vagina. She neighs frequently, and exhibits great desire for the horse: when she has conceived, she shows no further desire, and the discharge from the vagina stops.

Some writers recommend the mare to be put to the stallion early after foaling : this is improper, for the simple reason that the dam has to nourish two, viz., the foal and the embryo: this is excessively weakening, and liable to injure one or the other.

Disproportionate copulations are also bad, as a large horse and small mare : the size of the horse should be produced by gentle gradations, and this is evidently a better way to arrive at beauty as well as strength.

The best mode of preserving the breed and making improvements, is to make selections of the best on both sides. Much judgment and circumspection is necessary at all times in crossing the breed; and many errors arise in consequence oi a want of knowledge in the breeders.

When the period of foaling draws nigh, the mare should be separated from other horses. Having foaled, turn her into a fine pasture, where there is a barn. The foal may be weaned at six months. If the foal dies, or is taken away from the dam, humanity would suggest the propriety of a few weeks' rest, to enable the animal to recover from the effects of parturition. 


\section{REMARKS 0N BLOODLETTING.}

IN justice to the veterinary surgeons of this country, the author would inform the reader that professional bleeding is very rarely resorted to. To bleed a horse in the present enlightened age, when he is in a state of plethora, or the blood in a morbid state, would be bad practice, for we cannot purify a well of water by withdrawing a bucket; neither can we purify the whole mass of blood by abstracting a portion. The author has seen several cases where the poor animal (a victim to science) had been so far and fatally drained of the living principle, that there was not sufficient blood left in the system to produce reaction. We have profited by the fatal errors that have been committed under our own observation, and have never drawn a drop of blood from a horse, (except in surgical operations, when it could not be avoided,) neither will we ever, under any circumstances, resort to the lancet; for we are convinced that bloodletting is a powerful depresser of the vital powers.

Blood is the fuel that keeps the lamp of life burning: if the fuel is withdrawn, the lamp is extinguished; hence, if "life is the sum of the powers that resist disease," then whatever enfeebles life must produce disease and death.

An eminent physician has said, that "after the practice of bloodletting was introduced by Sydenham, during the course of one hundred years, more died of the lancet alone than those who in the same time perished by war."

Dr. Hunter says, in relation to the human being, - and the same applies to the brute, - that "bloodletting is one of the greatest weakeners, as we kill thereby."

Professor Lobstein says, "So far from bloodletting being beneficial, it is productive of the most serious consequences a cruel practice, and a scourge to humanity. How many thousands are sent by it to an untimely grave! Without blood there is no heat, no motion in the body." For more important information, see Good's Study of Medicine, vol, i. 
p. 407. Hence to bleed, as taught by the works found in this country, is to bleed until the horse gives signs that the vital principle is about deserting her empire.

Dr. White relates a case: the same takes place every day; the author has seen several in one day. "A horse was brought to be bled, merely because he had been used to it at that season of the year. I did not examine him minutely; but as the groom stated there was nothing amiss with him, I directed a moderate quantity of blood to be drawn. About five pints were taken off ; and while the operator was pinning up the wound, the horse fell. He appeared to suffer much pain, and had considerable difficulty of breathing. In this state he remained twelve hours, and then died. Judging from the appearances at the post mortem examination, it is probable that the loss of a moderate quantity of blood caused a fatal interruption of the functions of the heart." It is surprising that such cases as these do not compel men to acknowledge that there is something wrong in the theory of disease, or its treatment. Here is an unanswerable argument against bloodletting; for as the blood, which is the natural stimulus of, and gives strength to, the organs, is withdrawn, its abstraction leaves all those organs less capable of self-defence. And if one part is more delicate than the rest, the abstraction of the blood from the circulation that pervades the whole, instead of benefiting the part, will be more sensibly felt by it. Drs. White, Youatt, in fact most veterinary writers, recommend bleeding when the horse has been fed too liberally, or the secretions vitiated. This has led men to commit great errors, and caused great destruction of property. If the horse has been too well fed, reduce the quantity of food, or, in other words, remove the cause. If the secretions are vitiated, then regulate them, not take away the blood on which their vitality depends. If the different parts had between them partitions impervious to fluids, then there would be some sense in drawing out of the vessels over filled; but unfortunately, if you draw from one, you draw from all the rest.

Again. The authorities above named recommend bleeding 
when there is too much blood, There may be at times too much blood, or at others too little; but suppose there is, has any body found out any other process of making blood, other than the slow process of nature, as exhibited in the process of circulation, digestion, and nutrition? Have they discovered any artificial means of restoring the blood to its healthful quantity when it is deficient? Have they found any other means of purifying the blood, save the healthful operations of rature's secreting and excreting laboratory? Have they found any safety-valve or outlet for the reduction of what they please to term an excess? And if they have, are they better able to adjust the pressure on that valve than he who made the whole machinery, and knows the relative strength of all its parts?

In an article on bloodletting found in the Farmer's Encyclopædia, the author says, "In summer, bleeding is often necessary to prevent fevers, " always choosing the cool of the morning for the operation, and keeping the animal cool the remaining part of the day. Some farriers bleed horses three or four times a year, $\dagger$ or even oftener, by way of preventive, $\ddagger$

* We of the physiological school deny that fever is disease : it is simply an effort of the vital power to regain its equilibrium, and it does this by means of the fever; therefore it should never be subdued. (See Fever.)

$\dagger$ This gives to the blood-vessels the power to contract and adapt themselves to the measure of blood that remains. Common sense will teach men that frequent bleedings must impoverish the blood. It leads to hydrothorax, or an accumulation of water in the cavity of the chest, and materially shortens life. Mackintosh says, "Some are bled who cannot bear it, and others who do not require it ; and the result is death."

$\ddagger$ Nature's preventives are air, exercise, and water. Dr. Warren says, "In attempting to prevent or cure disease, we must imitate nature." Now, the proper mode of imitating nature is not by bloodletting, but by the rules we have laid down in articles Feeding, Watering, Ventilation, \&c. If the means of prevention recommended by the Cyclopædia were fully carried out, the stock of our farms would be swept away as by the blast of a tornado. Such a barbarous system would entail universal misery and degeneration; and well might we exclaim, They are living, yet half dead, in consequence of an evil system of medication. But thanks to a discerning public, they just begin to see the absurdity and wickedness of draining the system 
taking only a small quantity at a time." * Then the author winds up by saying, "There is, however, this inconvenience from frequent bleeding, that it grows into a habit, $\dagger$ which in some cases cannot be easily broken off; besides, horses become weak from frequent bleeding." $\ddagger$

"Bleeding," says Youat, "lessens the quantity of blood in the vessels, and diminishes nervous power," (and destroys life, he ought to have added.) He recommends it when animals rub themselves, and the hair falls off, when the eyes appear dull and languid, red or inflamed, the breath hot, and the veins puffed.

In all inflammatory complaints, as of the brain, lungs, kidneys, bowels, eyes, womb, bladder, and joints ; in all bruises, hurts, wounds, and all other accidents.

In cold, catarrh, constipation, and paralysis, and lockjaw, this indiscriminate use of the lancet is calculated to do a vast amount of injury if it is followed up.

The author qualifies his remark as follows: "No man, however wise, can tell exactly how much blood he ought to take in a given case."

of the living principle: medical reform has germinated, and struck its roots deep into the minds of a class of men who have the means and power of preventing much barbarity and suffering among our domestic animals, and they will use those means to their own interest and the welfare of their stock.

* Small bleedings tend to an unequal distribution of the blood, and diminish its conservative power; the disease must be prevented by the promotion of the equilibrium of the circulation, not its destruction.

\section{† A habit confined to the operator.}

$\ddagger$ If horses become weak from bleeding, then we have another unanswerable argument against the practice. For all means or processes that are calculated to debilitate the general system will shorten life; thus attempts to cure disease are made with the instrument of death.

\$ True; but the animal lives out his existence in about half the usual time allotted by the Creator, and drags out a miserable life of toil. The conservative power of life always operates in favor of health, and remedies the encroachments upon her province with all her might, and frequently recovers the dominion, but by frequent bleedings. She has become exhausted; and upon taking a little more blood than usual, the animal drops down and dies; and the owner of the animal attributes to disease what, in fact, is the result of his evil practice. 
In cases of congestion, or inflammation, the equilibrium of the circulation is disturbed, the capillary structure is contracted, and the mouths of the absorbents are closed. The draining of blood from a vein, though it diminishes the force of the congestion or inflammation, does not mend the matter, for it also diminishes the power of the whole system, and thus gives to cold and atmospheric pressure the ascendent influence. A collapse takes place, the secretions become impaired; thus destroying the power of all parts to recover their reciprocal equilibrium. How can it be expected that a practice which will make those forms of disease, should ever be supposed to cure them. The only rational treatment consists in producing a relaxation and expansion of all parts of the system, and keeping up this relaxation, by warmth and moisture, till, by friction and counter irritation, and the removal of obstructions to vital action, the healthy equilibrium is restored.

"Bloodletting," writes the editor of the London Lancet, "has most serious disadvantages; it invariably renders convalescence more tedious." Horses that have been bled generally require several weeks' run at grass to get them into working condition. Dr. White relates a case which proves the truth of our position. "A horse was bled from the neck for lameness, without any benefit; the vein was opened a second time, but very little blood could be obtained; the temporal artery was then opened, and two gallons (of arterial blood) drawn! The next morning it appeared necessary to take another gallon from the other temporal artery! When sufficiently recovered, he was turned to grass; and about four months afterwards, he was as lame as ever, and quite useless."

This is one among the many thousand similar cases that have come under the author's observation, in the course of a few years.

The same author above quoted writes, "The value of a horse depends on his strength and spirit; and whatever tends to diminish these will produce a proportionate diminution in his value. The muscular power and nervous energy are 
derived from the blood." If the latter are derived from the blood, (and we know it is so,) then what inconsistency there is in medical authors to recommend bloodletting, with a view of improving the strength and spirit, when they are depriving the system of that on which the very life of the animal depends.

Our readers may say, horses and cattle are bled and get well. Suppose they do, - is it thus proved that more would not get well if no blood were drawn from any? If the abstraction of a certain number of gallons of blood will kill a strong horse, then the abstraction of a small quantity will injure him proportionally. We have already shown that there is in the animal economy a power which always operates in favor of health; if the provocation is gentle, this power may overcome both it and the disease, and the animal is considered cured merely because the symptoms that marked the character of the malady disappear. The appearance of symptoms of another order, and perhaps not so alarming in their nature, lead men to suppose they have performed a cure ; when, in fact, they have just sown the seeds of a future disease.

We do not propose to show definitely how a horse gets well in spite of bloodletting. It is enough for us to prove that this operation always tends to death, which can easily be done by conducting the process till no blood remains.

In cases of congestion, or a determination of blood to a vital organ, we find a want of action on the surface and at the extremities. The course we invariably pursue is to equalize the circulation, and invite the blood to the surface by warmth, moisture, friction, and counter irritants, and maintain it there by the administration of relaxants and diffusible stimulants. These latter must be of a harmless nature, as we find them compounded in the forest and field, by the Great Physician, the All-wise Creator.

Many interesting experiments have been made to estimate the quantity of blood contained in an animal. "The weight of a dog, says Mr. Percival, being ascertained to be 79 
pounds, a puncture was made with the lancet into the jugular vein, from which the blood was collected. The vein having ceased to bleed, the carotid artery of the same side was divided, but no blood came from it; in a few seconds afterwards the animal was dead. The weight of the carcass was now found to be $73 \frac{1}{2}$ pounds; consequently it had sustained a loss of $5 \frac{1}{2}$ pounds, precisely the measure of the blood drawn. It appears from this experiment, that an animal will lose about one fifteenth part of its weight of blood before it dies; though a less quantity may so far debilitate the vital powers, as to be, though less suddenly, equally fatal. In the human subject, the quantity of blood has been computed at about one eighth part of the weight of the body; and as such an opinion has been broached from the results of experiments on quadrupeds, we may fairly take that to be about the proportion of it in the horse; so that if we estimate the weight of a horse to be 1344 pounds, the whole quantity of blood will amount to 84 quarts, or 168 pounds; of which about 45 quarts, or 90 pounds, will commonly flow from the jugular vein prior to death; though the loss of a much less quantity will deprive the animal of life.*

"It is well known that young animals possess more blood than old, and that they will, perhaps on this account, sustain greater bodily injuries, and bear larger hemorrhages. In the latter, when the body is gradually decaying, and the powers of life declining, the quantity of blood becomes reduced. Mr. Wilson, in his lectures on the blood, \&c., says that 'fat animals are found to possess less blood than leaner animals; and tame animals, which are confined, less blood than wild ones.' The quantity of blood contained in the body of a man, supposing his whole weight to be 168 pounds, may be rated at 21 pounds, or 2 gallons, 2 quarts and 1 pint. Again, granting that a dog weighs 40 pounds, the amount of his blood will be 5 pints; hence we may reckon the loss of a pint from

* The author of Hinds's Farriery is in error when he states that two hundred and twenty quarts are calculated to reside in a middling-sized horse. 
a man to be equivalent to that of a gallon from a horse, or to 4 ounces from a dog, and vice versa; selecting individuals from each class at about the respective weights here set down." (See Percival's Lectures, p. 9, vol. i.)

\section{ON THE THEORY OF HEALTH, DISEASE, FEVER, AND INFLAMIMATION.}

The Healthy or Physiological State. - When all the different tissues and organs of the animal are sound, unobstructed, and unwearied, - when the living principle has free action through each and every one, according to the degree that it is designed to sustain, - then the animal is in health.

Disease. - Any injury done to the different structures of organs, which does not amount to the total destruction of its vitality, - or, in other words, the inability of an organ, or organs, to perform the natural functions, is termed disease.

Fever. - Fever and inflammation are one and the same thing. They are not disease, and never should be treated as such. It is the accumulated action of the vital system, for the purpose of warding off or removing the causes of disease, and restoring the healthy action of the organs.

Let us suppose a horse has been exercised: there is a determination of heat and fluids to the surface, the pores of the skin expand: now, if the horse is put into the stable, or the exercise suddenly ceases, the heat escapes too fast, and leaves the surface cold. For want of heat to keep them open and active, the pores become constricted, so that after the organs of circulation become rested from their fatigue, they commence a strong action again, there is not room for the escape of the fluids at the surface, the skin becomes dry and harsh, the coat stares, and the animal has, in common parlance, taken cold, and it has thrown him into a fever. Now, the cold is the real enemy to be overcome, and the fever should be aided by warmth, moisture, friction, and diffusi- 
bles. If at this stage the cold is removed, the fever will disappear; but if the disease (the cold) has been allowed to advance until a general derangement or sympathetic action is set up, and there is an accumulation of morbific matter in the system, then the restorative process must be more powerful and energetic; constantly bearing in mind that we must assist Nature in her endeavors to throw off whatever is the cause of her infirmities. Instead of attacking the disease with the lancet, and poison, - which is on the principle of killing the horse to cure the fever, - we should use remedies that are favorable to life. It matters not what organs are affected; the means and processes are the same, and therefore the division of inflammation and fever into a great number of parts designated by as many names, and indicated by twenty times as many complications of symptoms which may never be present, only serve to bewilder the practitioner, and render his practice ineffectual, or, as Dr. Bigelow calls it in human practice, "learned quackery." We have said, fever and inflammation are one and the same thing; when the fever is confined to a small space, it is called inflammation. "Inflammation is rather an effort of nature than a disease." (Hunter, vol. iv. p. 293.)

As inflammation is an action produced for the restoration of the most simple injury in sound parts, which goes beyond the power of union by what is termed first intention, we must look upon it, in such instances, as one of the most simple operations in nature. Therefore inflammation in itself is not to be considered a disease, but a salutary operation consequent to either violence or disease. (Ibid. vol. iv. p. 285.) Hence, when men cease to consider, and to call fever and inflammation "diseased action," they will begin to learn to heal disease aright, and not till then.

Dr. White writes thus: "Though horses and other domestic animals are liable to fever, there is not that variety in the disease, nor is it by any means so intricate as it is in the human subject. Some practitioners do not admit the existence of fever in the horse, as a primary disorder, but consider it as symp- 
tomatic, or dependent on internal disease." Then why not attempt to cure this internal disease, and let the fever alone? The same author remarks, "The same applies to cattle; for it is of very little importance whether we call it fever or inflammation." It is clearly evident that there is but one cause of fever, viz., the natural motive power of the system, and but one fever itself, viz., accumulated vital action; yet the causes of disease are numerous, and many a tissue to be obstructed, and if the disease were named from the tissue or organ, as nervous, pulmonic, \&c., it would have as many names as there are tissues or organs to be affected; if it be named from the symptoms, it would be numberless and boundless. But of what use is it to decide what particular nerve, blood-vessel, or muscle is contracted, or compressed, seeing that the proper and only rational treatment consists in acting on the whole, nerves, tissues, and blood-vessels, by relaxing them, and equalizing the circulation? But suppose we do ascertain exactly what part of the alimentary canal is contracted in a given case of constriction; what advantage is it to us? Suppose we find it in the duodenum, - have we any specific that will act upon it, other than through the healthy operation of nature's secreting and excreting process? Therefore the symptoms produced by medicines ought always to be those of health : hence those who treat disease according to the principles we have laid down, must not expect to see, in the progress of the disease, the same train of symptoms that are given in works hitherto published on veterinary practice.

Suppose two cases of enteritis (inflammation of the bowels) were put into the hands of two different men, one of the physiological school, and the other of the allopathic. The latter would, if he practised according to the principles taught by the professors of veterinary surgery, proceed thus. (See Youatt, p. 208.) "From six to ten quarts of blood should be taken as soon as possible, and the bleeding repeated to the extent of four or five quarts more, if the pain is not relieved. The speedy weakness that accompanies this disease should not 
deter from bleeding largely. It is the weakness that is the consequence of violent inflammation of these parts, and if that inflammation be subdued by the loss of blood, the weakness will disappear." How weakness can disappear by the loss of blood we are at a loss to conceive. All men agree that the abstraction of blood will produce fainting, and coldness of the extremities. Dr. Hunter, already quoted, says, "Bloodletting is one of the greatest weakeners."

"Next," continues the author, "a blister should be resorted to. The tincture of Spanish flies, whether made with spirits of wine or turpentine, should be well rubbed in." It is a wellknown fact that the application, and final absorption, of Spanish flies will produce strangury in its worst form: aside from this it is an acrid animal poison, being taken up by the absorbents, it enters the circulation, and is often fatal in its result.

Now for the physiological practice. "The extremities are cold; " then we should proceed to warm them by hot vapor, stimulating liniments, and by friction with the brush; the belly should be fomented with flannels wrung out in warm water: this process will relax the capillary structure, and equalize the circulation, and relieve the engorged vessels of the intestines: then give an antispasmodic drink. (See Antispasmodic, part second.) If the borvels are constipated, the following aperient may with safety be ventured on: Take half a pint of linseed oil, beat up in it the yolk of two eggs, and administer it with a common junk bottle ; then use injections. (See Appendix.) The animal is usually clothed with a blanket. We believe it is the duty of the physician to aid nature in removing from the animal economy all the causes of disease. We therefore adopt the most efficient, yet innocent instruments and processes of cure, and totally reject, in all cases and stages of the treatment, all violence, poisons, and the lancet. If bleeding could be practised with impunity, such assistance might be proper in the above case; but as the vital force (whose diminution is the proximate cause of enteritis) is itself dependent upon the blood, increased debility is the necessary consequence of its abstraction. Hence, 
when horses are bled, their convalescence is very tedious. All medical men agree that inflammation is favorable to the healing process, and without it no wound could be healed. How, then, can it be called disease, but by an oversight of the vital aid which it gives to the different organs?

Causes of Disease. - These are numerous. Any thing that can in any way disable an organ to perform its proper function, is a direct cause of disease. There are other causes, as hereditary taints, sudden changes from heat to cold, overexertion, and want of proper exercise. Overfeeding is one of the principal causes of disease ; the bad quality of the hay or oats, bad water, and inattention to ventilation; the unnecessary dosing with improper medicines.

Poisons - Either taken into the alimentary canal, or by absorption through the external surface, or the lungs; bloodletting, and sluicing cold water on the animal after active exercise.

The indications of cure are to relax spasm, as in lockjaw, or in obstructed surfaces, constipation of the bowels, \&c.; to contract and strengthen relaxed and weak organs, as in general debility, diarrhœa, scouring, lampas, \&c. ; to stimulate inactive organs; to remove all obstructions to the free action of all the organs; to equalize the circulation, and distribute the blood to the external surface and extremities, as in congestions; to furnish the animal with sufficient nutriment to build up the waste, and prevent friction.

No matter what be the nature of the disease, our treatment is always conducted on these principles.

Dr. Curtis observes, "All the fluids of the system are moved through it by the alternate contractions and relaxations of the vessels from which they are sent, and in which they are transmitted; thus the blood is thrown by these actions of the heart and arteries, and returned by the same movements. The chyle is absorbed or elaborated, and carried to the circulation; and the lymph is taken up and united with it by the alternate contractions and relaxations of the fibres which compose the coats of the tubes through which 
they pass. All the voluntary and involuntary motions of the body are performed by the alternate contractions and relaxations of the fibres; and the food is masticated, swallowed, and moved through the system by the same process. To relax, to contract, to stimulate, and to furnish the system with the proper materials for nutrition, constitute the whole modus operandi of the medical art."

"All experience has proved that warmth and moisture relax all animal fibre ; that dry heat or dry cold contracts it ; and that some medicines do one, and some the other; that certain articles and processes stimulate the organs to high action, and that nutritious food aids them in building up the wastes and restoring injuries."

Congestion of the Brain, \&.c. - In diseases bearing a proximity to apoplexy, they manifest themselves in different forms, according to the amount of vital resistance that the animal possesses. Thus we have stomach staggers, congestion of the brain, vertigo, disease of the brain called hydrocephalus. Now, although we observe alarming symptoms in the region of the brain, it is no more a disease of that organ than it is of impaired digestion, circulation, absorption, secretion, \&c. ; for the latter are all involved in a deficiency of physiological action, and the cure of stomach staggers is the cure of every other form of disease. The different forms of disease supposed to be in the brain of horses, are, nominally, impaired digestion, and result from overtaxing the latter function, constipation, want of pure air and sufficient exercise, bad food, \&c.: these are chiefly the causes that produce staggers. A primary congestion of the brain, or spinal marrow, is often produced by vitiated and irritating mucous secretions, and indigestible and feculent matter in the intestines, producing, in common parlance, "a determination of blood to the head." (For treatment, see Appendix.)

The author has consulted several works on the treatment of apoplexy, congestions, \&c.: they all agree in bleeding, blistering, and purging. Mr. Youatt says, "The treatment adopted by the best practitioners is too often unsuccessful. 
The horse should be bled until he faints or drops! Both the neck veins should be opened at once, and the fulness of the stream, or the quickness with which it is taken, is almost as important as the quantity. After purging is effected by large doses of aloes." He then recommends foxglove and tartar emetic in doses of a drachm each, three or four times a day. "The head should be blistered : rowels and setons give useless pain, for the horse is either cured or dead before they perceptibly begin to act." (See Youatt, p. 105.)

It is surprising that such a man as Mr. Youatt could not perceive the reason why "the treatment is too often unsuccessful." The means recommended are calculated to kill, not to cure: hence, if the disease did not carry the animal off, the treatment would. Why draw away the blood from the poor animal, when all that is needed is to give it equal distribution, and rid the stomach and alimentary canal of offending matter? Dr. Hinds observes, "In all ordinary cases of staggers and congestion of the brain, simply opening the bowels will effect a cure, nine cases out of ten. I have known violent cases of staggers cured by injections and a dose of physic."

The whole train of maladies, viz., staggers, \&c., can be traced to acute or chronic indigestion, or an obstructed surface, accompanied often by the retention of a great mass of indigestible food in the stomach and intestines. How on earth bloodletting can relieve the stomach and intestines of this load, we should like to know. Bloodletting may give a momentary respite to the distended vessels of the brain, in apoplexy, and the animal appear relieved ; but, by destroying, in a certain degree, the vital energies, it also admits of a still further reaction, which is favored by the pressure of the atmosphere on the extreme vessels of the external surface ; and thus the advocates of bleeding find a repetition of the practice still more necessary than at the commencement. Dr. White says, "If no relief is obtained by abstracting seven or eight quarts of blood, take away five quarts more !" Now, it is evident, that if we were to draw out all the blood, the 
animal would die; as it is, they try to leave just enough to keep up a low form of vitality. Most authors agree that in "megrims, mad staggers, stomach staggers, apoplexy, and congestions, there is a determination of blood to the head, and may be produced by causes that mechanically impede, or obstruct, the flow of blood." Then they should be removed by regulating the unequal distribution. If a horse has too much blood in the head, he will have too little in the tail and extremities. The difference of symptoms in the derangements just enumerated, differ only according to the state of the organs, and the manner in which the blood is thrown on the brain, and retained there. There is no real difference in the nature of the malady. The same indications of cure are to be fulfilled that we have just laid down, viz., to relax the whole horse, and remove obstructions from the alimentary canal and external surface.

Dr. Marshall Hall says, "Physical impediments to the return of blood by the veins will cause congestion." These impediments consist in any thing that weakens the force of the circulation, as bloodletting, narcotizing, calomelizing, \&c., as practised by the disciples of Sainbel. Few cases of disease occur without the parentage of some of these Samsons of the regular school. The veins, having but little forcing power at their base (like the arteries) to propel the blood back to the heart, are the first to feel the impediments and compel the blood to accumulate; hence congestions.

Professor Coleman considers that this disorder takes its rise from over-distention of the stomach. He was once consulted about some horses, among whom there had been a strange mortality; and he found that they were in the habit of continuing at work for ten hours together, during the day, and on their return home at night were abundantly supplied with food. The professor soon discovered the source of the evil, and ordered, for the future, that the horses should be fed in the middle of the day also, by means of nose-bags; which salutary practice put flight to the epizootic. Now, this is 
certainly a strong case to show the stomachic orlgin of the malady.

Mr. Blain says, "The treatment of staggers has been notoriously unsuccessful. I never witnessed a successful issue, and think that men have strangely erred in pointing out remedies for this malady. Phlebotomy will certainly tend to relieve congestion or inflammatory action, that may exist in the brain; but the main question for us to consider, is, whether it can have any effect in unloading the stomach. Practitioners are in the habit of expressing their surprise at the obstinate apathy of the bowels ; whereas, is it unreasonable to suppose that 12 or even 20 drachms of aloes can have any effect, when they can pass no farther than the stomach? It is possible that active stimulants may have such an impression upon the stomach, as to excite contraction in it. [Then why not use them?] The state of the brain in staggers, generally speaking, appears to be, in the beginning, that of simple congestion, or unequal distribution of the blood. [Then equalize, instead of abstracting it.] In most of the heads I have examined, vascular distention of the membranes was found, with minute bloody specks upon the divided surfaces of the brain."

From the professor's remarks we are led to conclude, that prevention is more valuable and successful than their attempt at cure. The reason why their treatment is "notoriously unsuccessful," the reader can readily perceive, when he takes into consideration the destructive nature of the treatment, which is as follows: "Bleed profusely; most of those subjects will bear to lose six or eight, and some even ten quarts of blood. The next consideration is purgation. The common saying is, Purge a horse with staggers and you cure him; and there is much truth in the observation, for we know that hardly any one thinks of purging before he has bled the animal, so that the purge is acting under the most favorable circumstances. [Unfavorable he ought to have said.] Two drachms of castor nut, and a small quantity of calomel, are to be given in a bolus; promote the action by aloetic injections, 
and follow up the purgative medicine by diminished doses. In the intervals between the repetition of the purges, hellebore [poison] should be administered every six hours, in doses of half to a drachm, provided the first quantity make no impression; nothing, bleeding excepted, operates more effectually in diminishing the force of blood to the head, than the excitement of nausea at stomach. Having, by these means, sensibly weakened the impulse of the circulation, the head should be shorn, and blisters applied over the forehead, the occiput, and temples, and should be renewed every six hours, until vesication is abundantly produced,"

This is a specimen of scientific doctoring. Many of our farmers could scarcely believe that men could be so cruel. It is passing strange that the regular faculty, with all their advantages of numbers, learning, and respectability, have only learned how to kill, instead of cure.

How to avoid Congestions, Staggers, and Apoplexy.Never permit an animal to eat too great a quantity of food at one time. Let him have less than usual after being worked hard. Buy the best food in the market, for cheap fodder is dear at any price. Attend to the directions we have laid down in the articles Feeding, Watering, \&c.; lastly, avoid the lancet and poison.

\section{INHUMAN TREATMENT OF HORSES IN ENGLAND.}

"THe object of the veterinary profession," says Dr. White, " is to remove the pains and diseases of our domestic animals. Can we honestly, heartily, succesfully employ ourselves, if we do not sympathize with them? if we do not love to see them happy, and contemplate their sufferings with regret? Can the brute who regards them as mere machines, devoid of rights, placed without the pale of justice, created merely for our purposes, and to be sacrificed without crime to our caprices ; 
- can he so identify himself with his profession, as to neglect no opportunity to mitigate pain, and to spare no exertion to increase enjoyment? This is the duty, and ought to be the pride and pleasure, of every veterinary surgeon. Regard to reputation, and sense of duty to our employer, are powerful principles of action.

"Dare we trace the education of the veterinary surgeon as far as humanity is concerned? See him at the college attending a necessary, but severe operation, jostling and wrestling with his fellows for the best view; execrating the struggles of the agonized animal, and mocking its groans; not one expression of commiseration heard; not one calculation, how far a part, at least, of the torture may be saved, consistently with the object of the operation; the loud laugh, and the ribald joke, drowning the voice of the operator, - or the operator himself, when not too much annoyed by the shameless indecency of the scene, pausing in the midst of his work, and joining in the laugh. We have sometimes thought, that if a stranger were present at this unnatural exhibition, he would imagine that we were training for purposes of brutality, and not of humanity, and be very cautious how he intrusted a valuable and generous animal to our tender mercies. And sure we are, that scenes like these are more calculated to train us to become butchers than surgeons; and hence, in a great measure, it is that so many of our operations are performed in a butcher-like manner. We are aware that one of the most important requisites in a surgeon is self-possession; and that the feelings of the patient should not for a moment merge in the important object of the operation; but this is different from those exhibitions in which there is no previous comparison of suffering and advantage, and no subsequent commiseration. It cannot be denied, that circumstances do sometimes attend the operations of veterinary surgery, which would meet with universal execration in the theatre of the human surgeon. The inevitable consequences of this on the mind of the young practitioner have not been sufficiently calculated; or, rather, the 
error has been, that we have not felt ourselves bound to regard the feelings and the sufferings of the animal given to our care.

"A knot of young pupils go to the knacker; they bargain for some poor, condemned animal ; they cast him, and they cut him up, and torture him alive. They perform the nerve operation on each leg; and on each side; they fire him on the coronet, the fetlock, the leg, the hock, and the round bone; they insert setons in every direction; they nick him, they dock him, they trephine him: when one is tired of cruelty, another succeeds him: and at length, perhaps, they terminate his sufferings by some new mode of destroying his life. Did the great surgeons of the present day thus acquire precision and judgment? or, if they did, would they not have been supposed to have been qualifying themselves for the office of familiars at the Inquisition, rather than of humane surgeons? Would they not have been detested while living, and held in lasting execration when dead? But these operations on the living subject teach the youngster how to accommodate himself to the struggles of the animal, how to feather his lines with mathematical exactness, and to acquaint himself with the true color produced by the iron when it has seared the skin sufficiently deep! Would not one or two operations on the real patient have given all the information that would be necessary, without engaging the conservators of the health and enjoyment of the horse in the functions of demons, and giving them an indifference to suffering, and a callousness of feeling which taints the whole course of their after practice?

"That school wants reform that tempts pupils to the commission of atrocities like these. Every pupil, after having been compelled to operate once, or twice, or thrice, on the dead subject before the professors, should in his turn be called on to operate on the different cases which are brought to the colleges. Under the immediate inspection of the professor there could be no danger to the patient; and one operation, every step of which was guided and directed by the professor, would be more useful to the student than a hundred at the 
linacker's yard; but, according to the present system, nearly all the operations are performed by the assistant professor, and the demonstrator and the pupils are permitted only to look on. Some alteration is here imperiously required."

Mr. Blane experienced in his own person the results of this imperfect system of teaching. He was sent for to fire a valuable horse, and gives the following account of it: "It was my first essay in firing on my own account, and fired as I was with my wishes to signalize myself, I labored to enter my novitiate with all due honor. The farrier of the village was ordered to attend, a sturdy old man, civil enough, but looking as though impressed with no very high respect for a gentleman farrier's linowledge. The horse was cast, (awkwardly enough,) and secured, as will appear, even more so. I, however, proceeded to show the superiority of the new over the old schools. I had just then left the veterinary college, not as a pupil, but as a teacher, [licensed to kill, and no questions asked,] which I only mention to mark the climax. On the very first application of the iron, up started my patient, flinging me and my assistants in all directions from him, while he trotted and snorted round the yard with rope, \&c., at his heels. As may be supposed, I was taken aback, and might have gone back as I came, had not the old farrier, with much good humor, caught the horse round the neck with his arms, and by some dexterous manœuvre brought him on his knees; when, with a jerk, as quick as unexpected, he threw him at once on his side, when our immediate assistants fixed him, and we proceeded. It is needless to remark that I retired mortified, and left the village farrier lord of the ascendant."

"It cannot be doubted that the best operators in this case are always the common country farriers, who, from devoting themselves entirely to the occupation, soon become proficients." *

* This admission on the part of a regular graduate of a veterinary institution of London shows that the veterinary science, as taught at the present 


\section{ON RABIES, OR MADNESS,}

\section{AND THE EFFECTS OF THE MILK OF RABID AND DISEASED ANIMALS.}

Mr. Youate says that "the poison of all rabid animals seems to reside in the saliva." Who ever heard of the animal's horns, the teeth, or saliva being mad, without the whole animal being sympathetically affected? Is not the saliva a secretion from the blood, (secreted by the salivary glands,) and is not the virus first absorbed and taken up by the lacteals, from thence going the rounds of the circulation? When any kind of poison is absorbed, the whole secretions become vitiated: thus the bile, blood, urine, and milk, all become deranged. For proof of this, see B. M. Recorder, vol. vii. p. 101. "If the Rhus Toxicodendron, called poison sumac, poison oak, \&c., is eaten by cattle or horses, the males usually die, the females sometimes escape; the animals that drink of their milk, or eat butter or cheese made from it, usually have the disease ; and the dogs, hogs, buzzards, \&c., that eat the fiesh of these animals, die of it. And the fumes of the candles made of the tallow of the cattle that have died of it frequently communicate the disease. Persons who skin the animals often take it." What folly, then, to prate about the salivary glands being inoculated, to the exclusion of other

day, is a matter for reproach. The melancholy triumph of disease over its victims (in England amounting in neat cattle to $\$ 50,000,000$ ) shows that the science is mere moonshine; that in regard to its most important objects, (the cure of disease, it is mere speculation, rich in theory, but poverty-stricken in its results. Hence we have not only proof that the American people ought to be reformers, but, as interested individuals, we have great encouragement to be such. The author dates his conversion to the true, or physiological faith, up to the moment when he emancipated himself from the theory of the popular schools. The superiority of our practice consists in the agents used, which are harmless and efficient; whereas the agents which he formerly used constituted a class of deadly poisons. For the proof of the success of our present system over that of the old, we refer the reader to some of our patrons, whose names will be found in the Appendix. 
parts of the animal. Who ever heard of a man's head being drunk, and not the whole man being more or less affected? Our object is to show that the milk of a rabid cow cannot be drank with impunity, notwithstanding Mr. Youatt's assertion to the contrary, who maintains that the milk of the rabid cow may be drank with safety, for the poison is confined to the saliva. Dr. Pereira says the morbid changes produced in the quality of the milk by diseased conditions of a cow, have recently attracted considerable attention in Paris, owing to the prevalence of a malady, called the cocote, among the cows in that capital. Those which have been recognized are, want of homogeneousness, imperfect mobility, or liquidity, capable of becoming thick or viscid, on the addition of ammonia, and containing certain properties not found in healthy milk. Labillardiere states that the milk of a cow affected with consumption contained seven times more phosphate of lime than usual.

The influence which many medicines, taken by the parent, have over the offspring, is well known, though Cullen denies it. We can modify the color of the milk by mixing madder or saffron with the food; the odor may be affected by garlic; the taste may be affected by the use of wormwood; and lastly, the medicinal effect may also be influenced. The fact thus established, that the milk can be altered by disease, leads us also to conclude that it can be altered by rabies, or madness. We do not wish to give the reader an idea that the milk of a rabid animal will produce hydrophobia; all we desire to promulgate is, that it will produce disease. If it has not accomplished this in all cases, it is because the vital energies of the system, into which it was introduced, encountered, and eventually resisted the foe.

Mr. Clater observes that "rabies has but one origin, and that is inoculation." Can Mr. C. tell who inoculated the firstdor? We hear the free use of horse flesh, in keeping dogs in England, charged as one main cause for engendering rabies. Dr. Hinds observes, that "this appalling disorder is comparatively small in those parts of the world where horse 
flesh is less used." Dr. C. M. Wood, of this city, observes, that "the putrid, filthy food given to dogs in the hot season may engender rabies, or a disease analogous to it, especially when the organs of digestion are deranged."

It has been supposed by M. Husart, and others, that "hydrophobia, communicated by a dog to horses, sheep, and cattle, undergoes a change, and is modified in the system of the latter, so that it may be deprived of its virulence; and that these animals do not possess the power of communicating the disease, by bite, to other animals, even though laboring under the highest degree of hydrophobia" - a proposition the author does not vouch for.

We advise those who are disposed to attempt a cure in hydrophobia to use lobelia, scutellaria (skullcap,) plantago, (plantain,) either of which, given freely in the form of infusion, assisted by injections of a decoction of milkweed, (known as Indian hemp,) will cure this dreadful malady. In the latter stages of hydrophobia, when the throat is sore, the eyes affected, sight impaired, and intestinal disease has set in, the author would not attempt a cure.

\section{PRELIMINARY REMARKS}

ON THE DISTRIBUTION OF THE ARTERIES, VEINS, \&C.

The agricultural societies of this country are now making efforts to induce their respective legislatures to grant assistance for the purpose of establishing agricultural colleges, and we have no doubt of the result; and we predict that the veterinary science will there receive its origin; for the agriculturist will not only confine himself to the improvement of "the soil and the mind," but the improvement of his domestic animals will receive a share of his attention. It appears to us that the community require practical information for its attainment, and a knowledge of the organs of locomotion, 
blood-vessels, brain, nerves, viscera, \&c. For this reason, and in order to render assistance to those desirous of practising the veterinary art, the author has thought proper to introduce a description of these vessels. We are compelled from long usage, and because the English language will not furnish us with suitable terms to express in all cases our meaning, to adopt technicalities, which at first sight may appear superfluous and unsurmountable; yet it has ever appeared to us that this is the best system. For students we principally design this part of the work : should it be deemed worthy the attention of the farmer and stable keeper, we shall feel amply repaid for our trouble.

To compose this part of the work, we have availed ourselves of Professor Percival's lectures. The same talented author, in his introductory remarks, says, "The theory of medicine in the human subject is the theory of medicine in the brute; it is the application of that theory - the practice alone - that is different. Whether we prescribe for a man, or a horse, a dog, or a cat, the laws of the animal economy are the same in all; and one - and that an unerring system of principles, built upon ascertained and established truths - is to dictate our practice in all. We might as well, in reference to the principles of each, attempt to separate surgery from medicine, as insist that either of these arts, in theory, is essentially different from the veterinary: every day's experience serves to confirm this our belief, in showing us how often the disease of a. horse arises from the same causes as those of a man, exhibit the same indications, and require a similar method of cure. "To the old practitioner we would fain hint, that nothing is so effectual a barrier to advancement, nothing so prejudicial to the art, as to continue the use of remedies purely because they were the infallibles of those who went before: let him be wary how he vainly piques himself of his experience."

An accurate examination of the interior parts of animals, a- studious survey of the arrangement, structure, form, connection, use, and relation, of these parts, and of the laws by which they are intended to act, as also of the nature and 
property of the various foods, and other agents, which the earth so liberally provides for their support and cure: these form, in a great measure, the sound and sure foundation of all medical science, whatever living individual animal is the subject of our consideration."

\section{DISTRIBUTION OF ARTERIES.}

The blood is propelled by the heart through the great aorta, which rises out of the base of the left ventricle, in the space between the left auricle and the pulmonary artery. The branches furnished by the main trunk are the coronary arteries. The right coronary artery emerges from between the pulmonary and right auricle, winds round the fissure separating that cavity from the right ventricle, and turns down under the termination of the vena cava; and distributes ramifications in its course, which penetrate the substance of the parietes, and end in spiral branches. The left coronary artery, in passing out between the pulmonary artery and left auricle, sends off a large branch, which encircles the other auricle ; it then takes its course downward, and ends in spiral ramifications.

ANTERIOR AORTA.

This is a shorter division of the main trunk. The course of this vessel is under the windpipe; it gives origin to those large arteries which are distributed over the breast, head, neck, brain, and anterior extremities. It divides, at a short distance from the heart, into the right and left arteria innominata; the right is considerably longer than the left, and measures nearly as much again in circumference; it forms the trunk from which the two carotid arteries spring; the left terminates in the following vessels : -

1. The dorsal artery. 2. Posterior cervical. 3. Vertebral. 4. Internal pectoral. 5. External pectoral. 6. Inferior cervical. 7. Axillary. Each of these arteries ramify and anastomoze with others, and are distributed to muscular and adipose 
substance. From the axillary artery spring all the arteries of the fore extremity. This vessel can only be seen by detaching the shoulder from the body. It arises within the chest, from the arteria innominata; gains exit by making a sudden turn around the first rib, rather below its middle, crossing the lower border of the scalenus in the turn; it is first directed outward in this flexure, and then backward, and at length reaches the inner part of the head of the humerus, where it makes another turn backward, and afterwards takes the name of the brachial artery. Its branches are -1 . The external thoracic. 2. The humeral thoracic, which runs to the point of the shoulder, and gives its branches to the levator humeri and shoulder joint. 3. The dorsalis scapulæ ascends, in a flexuous manner, to the shoulder joint, crossing the insertion of the subscapularis. It runs for a short distance along the ribs. 4. The subscapularis, a large artery, which also arises from the upper part of the trunk, but near to its termination. It passes along the ribs, screened from view by the edges of the subscapularis and teres major, to both of which muscles it detaches several small branches, and ends near the lower angle of the bone; it also gives off several branches to the triceps and panniculus.

The humeral artery descends from the inner and back part of the head of the os humeri, in an oblique direction on the body of the bone, where it divides into the ulnar, spiral, and radial arteries. On its inner side, it has the spiral and ulnar nerves; in front, the radial nerve; and behind, the humeral veins; and it is covered internally by the large pectoral muscle, to which it sends some small branches. But its principal branches are -1 . One near its origin, which crusses the bone to get to the flexor brachii, and sends twigs to the shoulder-joint. 2. A posterior branch, arising a little lower down, which enters the muscle called triceps. 3. Near its termination, another branch to the flexor brachii. Where the artery divides, it is covered by the humeral plexus of veins, and by the absorbent glands of the arm.

The ulnar artery consists of a common root, from which 
spring three or four vessels of considerable size, rumning in waving lines upon the inner side of the lower end of the humerus. The upper one is directed to the ulnar, splitting before it reaches the bone, and sending one branch uptward upon the elbow, and another downward to the heads of the flexors; to which muscles the other branches of this vessel are distributed.

The spiral artery, the outermost division, turns round the os humeri, passing under the flexor brachii, and sending a recurrent branch to it, to arrive at the front of the radius, where it splits into several branches, of which - 1. Some run into the elbow joint. 2. Others, larger and more numerous, penetrate the heads of the extensors. 3. Two long, slender ones descend upon the radius, and give branches, in their course, to the extensor muscles as low as the knee, and there end in ramifications about and into the joint joining with others coming from the radial.

The radial artery, the principal division humeral, continues its descent along the radius, about the middle of the arm; the nerve accompanies it first on its outer side, and subsequently behind it. A short way above the knee, it splits into the metacarpal arteries.

The small metacarpal artery descends, within a cellular sheath, along the inner and back part of the knee. It continues its descent along the metacarpal vein, (which runs to its inner side,) till it gets below the knee, and then transmits its divisions down the front of the suspensary ligament; between it and the canon bone, it sends off branches over the front of the knee, the canon, and suspensary ligament.

The large metacarpal artery, a continuation of the radial trunk, continues its course down the leg, by the side of the tendo perforatus, passing under the posterior annular ligament, approaches the fetlock just above the joint, and then splits into three vessels; from the middle division three recurrent arteries are given out; the side divisions become the plantar arteries. From the arch below come off two other branches, which descend into the joint. The plantar arte- 
ries, external and internal, in the fore extremity, result from the fork of the metacarpal ; in the hind, from that of the metatarsal. (Their general distribution is the same, both in the hind and fore feet.) They descend the fetlock upon the sides of the sessamoids, in company with the veins which run in front of them, and with the plantar nerves which proceed behind them; the artery then passes down to, and into the substance of what is called the "fatty frog;" it next passes the inner and upper extremity of the coffin bone, and afterwards to the foramen of the posterior concavity of the bone. The branches of the plantar artery are many and important. After detaching some small ramifications inwardly to the fetlock, posteriorly to the flexor tendons, and anteriorly to the extensor tendon, it then sends off -1 . The perpendicular artery. 2. The transverse artery. 3. The artery of the frog. 4. The lateral laminal artery. 5. The circulus arteriosus. From the latter arise two principal sets of vessels - 1. The anterior laminated arteries. 2. The inferior communicating arteries, "thirteen, and sometimes fourteen, in number." 3. The circumflex artery. Then, again, from this vessel spring the solar arteries, which may be so named from their radiated arrangement. These latter are destined for the supply of the sole, upon which they run in radii at equal distances, whose common centre is the toe of the frog, where they end in communications with the arteries of that body.

THE CAROTID ARTERY.

The right arteria innominata, having detached seven important branches, which vary but little in their mode of origin, general course, and distribution, from the several arteries into which the left division resolves itself, become the common carotid - a large vessel emerging through the upper opening of the chest ; it divides, as it quits the chest, into two branches, called the right and left carotids. These arteries ascend, and having reached the top of the larynx, the carotid of either side branches into three divisions - the external and inter- 
nal carotids, and the ramus anastomoticus : here, though the trunk itself becomes deeply lodged in soft parts, its situation is well indicated by the larynx, with which it is in contact. This vessel detaches - 1. Several unimportant muscular branches in its progress up the neck. 2. The thyroideal artery, which furnishes the laryngeal, a small artery that perforates the ligament uniting the cartilages of the throat.

The external carotid artery is the large division, which may be regarded as the continuation of the carotid itself. This artery is embedded in glandular substance, surrounded by venous and nervous trunks, and protected by bony prominences and muscles. The first branch of the external carotid is the submaxillary artery; it comes off behind the horn of the ox hyoides, just as the carotid makes its second curve, and ranks next in size to the trunk itself. After reaching the lower jaw, (about one third of its length downwards,) it arrives upon the face; here it becomes subcutaneous, it ends in an equal division, called the facial and inferior labial arteries. Its branches are, the ascending laryngeal, pharyngeal: smaller branches go to parotid gland, and a large branch, called the lingual. The latter detaches a few twigs into the submaxillary space; it then branches into two arteries, the ranine and the sublingual. The ranine, apparently a continuation of the lingual, passes along the under part of the tongue, and transmits branches to the interior, and continues of large size even to the tip of the organ, wherever its extreme ramifications are expended. The sublingual artery winds along the under and outer border of the tongue, preserving a more superficial course than the former. It supplies the sublingual gland, and distributes branches over the membrane of the tongue. The submental artery leaves the submaxillary, follows the course of the branch of the jaw, and detaches twigs to muscles; it then transmits its ramifications into the gums internally. The anterior masseter branches pass on the external side of the jaw.

The inferior labial artery courses the side of the jaw, invested in the cellular and fleshy substance belonging to the 
buccinator. It gives off slender ramifications to the investing cellular substance, also the buccinator arteries; the buccal twigs bifurcate, sending their divisions respectively to the upper and under lips; these form the superior and inferior coronary arteries of the lips.

The facial artery ascends upon the side of the face, crosses the buccinator; then, having run as high as the bony ridge, from whence the masseter arises, it detaches a large branch, and then expands upon the upper and fore part of the face; its terminating ramifications are in the cellular substance and skin covering the fore part of the face.

The posterior auricular gives branches to the parotid gland, and to the different muscles of the ears.

The temporal artery, the anterior auricular, and the internal maxillary, may be considered as the terminating branches of the external carotid. 'The internal maxillary gives off deep temporal branches, long slender twigs, to the soft palate, to the ear, and to the articulation of the jaw ; the facial artery also gives off the inferior maxillary, the supra-orbitar, the ocular, the infra-orbitar, and the palate maxillary. The second and smallest divisions of the carotid is the

\section{RAMUS ANASTOHOTICUS.}

It leaves the trunk of the carotid, joins the vertebral, and from it arises the occipital artery, which gives off twigs to be dispersed upon the dura mater, temporal muscle, and muscles of the occiput.

\section{INTERNAL CAROTID.}

This vessel, whose calibre is not more than half that of the external carotid, ascends to the base of the skull: at its entrance into the skull, a vessel comes off named the arteria communicans : after having given off this vessel, the internal carotid pierces the dura mater, takes its course up near the optic nerve, and branches into four divisions, which supply the cerebrum with blood. 
The remaining vessels of the brain are derived from the vertebral artery, which gives off posterior arteries to the dura mater, and ramifications to the medulla oblongata.

The basilar artery sends off branches to the cerebellum.

THE POSTERIOR AORTA.

Considerably longer and larger than the anterior is the main trunk, from which are derived the artery of the abdomen, pelvis, and posterior extremities, in addition to the posterior intercostals, and some few of the thoracic arteries. It commences opposite the fourth dorsal vertebræ: from its origin it courses first upward, and then backward, having the pulmonary artery on its left, the termination of the windpipe on its right, then takes a course along the spine, inclining to the left side. From the inferior part of the curvature of the aorta arise the right and left bronchial arteries: these vessels penetrate the lungs in company with the bronchia, to the branches of which they cling in the course of their ramifications within the substance of the lungs.

The æsophogeal also spring from the concavity of the arch near to the former, and proceed backward to the æsophagus, where it divides into an inferior and superior artery. The intercostal, the remaining branches, come off in pairs from the sides of the vessel, to supply all those intercostal spaces posteriorly to the last. These arteries run along the lower borders of the ribs, and end about the inferior parts of the chest and abdomen. They furnish, near their origin, small branches, which enter the vertebral canal. Having detached these small vessels, the posterior aorta continues its passage into the abdomen. In making its exit from the chest, it gives off the phrenic or diaphragmatic arteries.

Within the abdomen, the aorta continues to be firmly fixed to the spine, by its several cellular attachments, as far as the lumbar vertebra, under the body of which it branches into four large arterial trunks. Prior to this division, the abdominal aorta gives off the cœliac artery, which is 
nothing more than the common root of the splenic, gastric, and hepatic - arteries that in some instances have separate origins.

The splenic artery, after passing between the stomach and spleen, ends in the left gastric artery. In its course it gives off several branches to the pancreas, called pancreatic arteries.

The gastric artery, the smallest of the cœliac divisions, runs forward to the small curvature of the stomach, between the layers of the omentum, branching, before it reaches this organ, into two vessels, called inferior and superior gastric, which finally ramify upon the upper and under surface of the stomach.

The hepatic artery, the largest of the cœliac division, proceeds before the pancreas to the right side of the cavity, and passes over the pyloric end of the stomach, and gives off small branches to the pancreas. Near the pylorus, it sends a branch to the duodenum, which, as soon as it reaches the intestine, divides : one division - the duodenal- retrogrades along the gut, and ends in anastomosis, with branches coming from the anterior mesenteric; the other - the right gastric - crosses the gut, proceeds to the great curvature of the stomach, where it inosculates with the left gastric. The hepatic artery itself is continued forward to the porta of the liver, where it divides into the right and left hepatic; the right, - the larger and shorter one, - after giving off a considerable branch to the portio media, turns back to reach the right lobe; the left, after giving off a branch or two to the middle portion, penetrates the left lobe.

The anterior, or great mesenteric, is the next vessel to the cœliac, and arises from the under part of the posterior aor. ta. From its origin, it passes downward within the layers of the mesentery, detaching some small twigs to the pancreas; it then separates into larger vessels, (commonly from eight to twelve in number,) from which are derived a branch that runs to the duodenum; several other branches encircle and ramify on and around the intestines. 
The renal or emulgent arteries leave the aorta at right angles just below the preceding vessel; they each pass into the respective kidneys, and therein divide into branches that penetrate the glandular substance.

The spermatic arteries, right and left, originate from the under part of the aorta; they pass out of the abdomen, at the abdominal ring, to the testicles. In the female, they pass to the ovaries, Fallopian tubes, and horns of the uterus.

The posterior aorta also gives off the small mesenteric, and five or six pairs of lumbar arteries. Under the last lumbar vertebræ, the aorta gives off two pairs of arterial trunks, called the external and internal iliacs.

The internal iliacs give off a branch called the artery of the bulb, and afterwards branch into three divisions - the obturator, gluteal, and lateral sacral arteries:

The artery of the bulb passes to the bulb of the penis, where it terminates. In the female, this artery sends its terminating branches to the vagina. It gives off the fotal umbilical artery. In leaving the pelvis, the prostatic artery, which detaches tivigs to the vesiculæ seminales, also distributes its ultimate ramifications to the prostate gland. It also gives off divers branches, anal and perineal, to the posterior portion of the rectum, anus, and parts comprising the perineum.

The obturator artery is the lowest of the divisions of the internal iliac. Its branches are the arteria innominata, and ramifications to the obturator muscles and ligaments. Its divisions are the ischiatic, which distributes its branches to the triceps; next, the pubic: the internal pubic artery gives two sets of branches, which pass to the penis.

The gluteal artery is destined principally to supply the gluteal muscles.

The lateral sacral artery, having reached the coccyx, divides into two branches. It furnishes the sacro-spinal branches, five or six in number, and the perineal artery. It soon divides into several ramifications, of which many run into the gluteal muscles; others descend on the back of the thigh, and others are distributed to the anal muscles, and to the 
skin and cellular substance of the perineum. The lateral sacral also furnishes the lateral coccygeal, and the inferior coccygeal.

The external iliac artery, right and left, results from a branch of the posterior aorta, which takes place under the body of the last of the lumbar vertebræ, and passes into the muscles, forming the inside of the thighs. The vessel gives off the circumflex artery of the ileum, the artery of the cord and the arteria profunda: the latter having reached the posterior quarters, it sends its ramifications into the biceps. Before this ressel dips into the substance of the thigh, it gives rise to a large branch, called the epigastic artery.

The epigastic artery, in passing the margin of the internal ring, forms a branch which divides into several small arteries; of these a twig runs to the groin, and ramifies among the adipose membrane and absorbent glands; then next, a slender branch to the cremaster, and a subcutaneous twig to the thigh, and lastly, the external pudic artery.

The femoral artery. Regarding the profunda femoris as a limb of the external iliac, we descend to the femoral artery, the subsequent contination of the same trunk. This artery proceeds in an oblique direction down the haunch, preserving nearly the line of its middle; opposite to the head of the tibia, it branches into the anterior and posterior tibial arteries; the anterior tibial gives off the inguinal artery, also three or four branches to the sartorius, and one to the side and front of the stifle. Its posterior branches are a large artery to the gracilis, (which detaches twigs to the long and short heads of the triceps,) also one to the biceps. At the back of the stifle come off the popliteal branches, four or five in number, taking opposite directions, which are destined for the supply of the joint; one runs down upon the posterior tibial muscles; another - the recurrent branches - climbs the back of the os femoris, and anastomozes with the descending ramifications of the profunda femoris.

The tibial arteries are a continuation of the femoral trunk, which branch of into tibial arteries at the head of tibia. 
The posterior tibial artery, the smaller of the two, passes along the posterior deep region of the thigh, to the hock, where it ends in bifurcation. Its branches are, one that runs into the flexor pedis; another to the upper and back part of the tibia; and small twigs to both the flexors. There are several terminating branches, some ramifying subcutaneously, others continuing down the leg internally over the tendon of the flexor pedis, and ending at the lower part of the cannon in divers small ramifications.

The anterior tibial artery, after leaving the trunk, passes down the fore part of the thigh, to the hock and metatarsal bone, where it becomes the metatarsal artery.

The metatarsal artery pursues its course downwards to about two thirds the length of the leg; it then gains the posterior part of the latter; a little above the fetlock, it divides into three vessels: one forms an arc, (as in the fore extremity,) from which come off the recurrents, and they anastonoze with the posterior tibial artery; the lateral divisions become the plantar arteries.

\section{DISTRIBUTION OF VEINS IN THE HORSE.}

The two main venous trunks, the vence cavce, anterior and posterior, correspond to the anterior and posterior aortæ.

\section{THE ANTERIOR VENA CAVA}

Forms the main trunk of the veins, returning the blood from the head, neck, chest, and fore extremities. It is principally formed by the concurrent union of the jugular and axillary veins, and is situated at its formation in the space between the two first ribs, about midway between the sternum and vertebræ; it also receives the pectoral, vertebral, dorsocervical, and inferior cervical veins, and the vena azygos.

THE JUGULAR VEIN.

It passes behind the condyle of the lower jaw, under the parotid gland, and joins the external carotid artery, and 
continues its course down the neck with the latter. It now receives the auricular veins, anterior and posterior, and also internal. The next is the temporal, the third is the internal maxillary; the latter in its course receives the blood of many small veins, - the palato-maxillary, infra and supra orbitar, ocular, inferior maxillary, and deep temporal; the fourth branch, received by the jugular vein, is the parotideal, and the last branches from the masseter muscles.

THE OCCIPITAL VEIN

Descends from the head, along with the occipital artery. It brings blood from the occipital sinuses, receives veins from the posterior lobes of the cerebrum and cerebellum; also from the dura mater.

The submaxillary vein, a large branch of the jugular. It is formed upon the side of the face by the concurrence of the facial, labial, and varicose veins. It joins the trunk by the side of the trachea, just below the parotid gland. In its course it receives a number of veins; the principal are - the submental, sublingual, lingual, pharyngeal, and superior laryngeal veins. The facial vein results from an expansion of small veins upon the side of the face, one of which is the varicose from the masseter. The labial vein is formed by the union of a plexus of venous branches, coming principally from the angle of the mouth, joined by others both from the upper and lower lips. The varicose vein is buried in the masseter.

The jugular trunk having received the submaxillary, proceeds down the neck, and terminates in the anterior vena cava, within the space between the two first ribs. Near the junction of the submaxillary the jugular receives the small thyroideal, cutaneous, muscular, and tracheal veins. Near its termination it receives a branch of the superficial brachial, and plate or plat vein.

The vertebral vein runs the same course as the artery, through the foramina, in the transverse processes of the cervical vertebræ, with the exception of the last. This vein has 
communications with the occipital sinus and posterior cerebral veins, medulla oblongata, and spinal marrow; it also receives vessels from the deep-seated muscles in the vicinity, and ends in the anterior vena cava, just behind the first rib.

The axillary vein returns the blood distributed by the axillary artery to the various parts of the fore extremity; there is a superficial and deep-seated set; the former run under the skin, the latter among the muscles. The plantar veins are an intricate network of small veins, and cover the foot with a venous netting. The veins of the sole pour their blood into the veins of the lamina; the latter increase in size towards the coronet, and gradually unravel themselves, so as to collect in a great many branches; these run upward, through the substance of the coronary ligament, and form the superficial coronary vein; from them other branches proceed and join the deep coronary, and afterwards unite in a single vein opposite the pastern joint.

The veins of the frog, after ramifying in the form of network over that body, ascend into the heel, growing larger as they leave the foot; they make a single branch at the pastern joint, then unite with the vein coming from the lamina, thereby forming the plantar vein. The plantar vein ascends, unites with other vessels, and becomes metacarpal.

The metacarpal veins, two in number, result from the union of the plantar; these veins pursue their course up the leg, one on either side, to the back of the knee, where they end in anastomosis. The internal metacarpal vein preserves the line of the splint bone. These vessels receive in their course cutaneous veins from the front of the cannon, and one or two descending veins from the back of the leg; it afterwards forms the deep-seated veins of the arm.

The superficial brachial vein ascends along the inner side of the radius to the elbow-joint; here it crosses over to the front of the biceps and pursues its ascent upon that muscle towards the point of the shoulder, and then passes inward to the jugular vein. In its course to the latter, it receives numerous cutaneous and muscular branches, communicates with 
the humeral vein, and anastomoses with other veins of the arm.

The radial veins, two in number, arise from the junction of the metacarpal veins above the knee; they take the course of the radial artery, and receive anastomosing vessels as they ascend from the ulnar and superficial veins.

The ulnar veins (with one exception) end in the common trunk of the humeral vein.

The humeral vein accompanies the artery; it receives small veins from the muscles.

The axillary vein is the continuation of the humeral, augmented by the accession of the triceps vein. Its branches are, the subscapular vein, and dorsalis scapular; the latter terminates about midway between the chest and shoulder. The remaining branches of this vein are the humeral thoracic, and the external thoracic; it also receives other small veins, which contribute more or less to its volume.

The pectoral vein runs the course of the pectoral artery. It originates in branches from the abdominal parietes, continues to receive accessory vessels in its course, and ascends along the inner and lower border of the first rib.

The dorso-cervical vein consists of two divisions, ramifying with the dorsal and posterior cervical arteries; it receives the anterior intercostal vein.

The inferior cervical vein runs down the lower part of the neck in company with the artery; the principal branches are muscular, though some come from the skin and absorbent glands in the vicinity.

The vena azygos ends just as the trunk opens into the auricle; it returns the blood from the lower intercostal veins.

THE POSTERIOR VENA CAVA.

This is the corresponding venous trunk to the posterior aorta, returning the blood from the parietes of the abdomen and pelvis, the urinary and genital organs, and the posterior extremities. It takes its course under the bodies of the lumbar vertebræ, runs along the great fissure of the liver, perfo- 
rates the cordiform tendon, and pursues its way directly across the cavity of the chest to the lower part of the right auricle: in its passage it is joined by the lumbar spermatic, renal, hepatic, and diaphragmatic veins.

The common iliac veins are formed under the sacro-iliac, symphysis, by the union of the external and internal iliacs; they receive a vein from the psoæ and iliacus, circumflex vein of the ileum, middle sacral, and azygos.

The ischiatic vein, situated upon the side of the pelvic cavity, midway between the external iliac and lateral sacral veins; external and internal branches unite to form it. The internal comprise veins coming from the bladder, anus, perineum, and, in the male, from the bulb and prostate: in the female, from the vulva and body of the vagina. The external come principally from the gluteal and obturator muscles.

The lateral sacral vein comes from the tail formed by coccygeal veins; it runs forward to the sacrum, and receives in its course the perineal and sarco-spinal branches.

The external iliac vein takes the same course as the artery; as it departs from the belly, this vessel receives

The inguinal vein, (coming from the groin,) also a superficial or cutaneous abdominal vein, known as the milk vein in cattle.

The femoral vein is the continuation of the iliac trunk below the brim of the pelvis; and is the main channel into which the deep-seated veins of the hind extremity pour their blood. We commence the description as in the fore extremities, at the leg.

The large metatarsal vein ascends the canon by the side of the flexor tendons, and passes over the front and inner part of the hock; it sends out branches, from which result the

Anterior tibial veins, which run between the tibia and fibula to the back and lower part of the os femoris, and then are joined by the posterior tibial vein, and all three unite to form the femoral.

The posterior tibial vein is a continuation of the small metatarsal vein, and corresponds in size to the small metacarpal. It runs in company with the posterior tibial artery, 
receiving various muscular branches in its course, also the medullary vein of the tibia.

The femoral vein results from the two last named vessels; runs behind the femoral artery, and ends in the external iliac vein. It receives muscular veins, as well as veins from the stifle joint, and the medullary vein of the os femoris; also, about two thirds of its length upwards, it is joined by the saphena vein.

The vena saphena major results from the large metatarsal vein; at the hock it anastomoses with the anterior tibial vein; it also receives cutaneous and muscular branches in its course.

The vena saphena minor springs from the small metatarsal vein; it runs up the back of the hock, over the root of the os calcis, and ultimately reaches the femoral vein.

The vena porta circulates the blood through the liver, and is principally formed by the union of the splenic and mesenteric veins.

THE BRAIN AND ITS APPENDAGES.

The cerebrum, cerebellum, and medulla oblongata, and medulla spinalis are invested with three membranes: the dura mater, pia mater, and tunica arachnoides. Of these the exterior is the dura mater: which, though called a membrane, is of a dense, tough, and inelastic texture. It is so firmly adherent, by means of numerous little prominences, to the sutures of the cranium, that it is difficult to separate them; this membrane is to the internal cranium what the pericranium is externally. The inner surface of the dura mater is lubricated by a fluid furnished by its own blood-vessels.

The pia mater is that membrane which closely envelops the substance of the brain, and dips down between its convolutions, and adheres to its surface by numberless minute blood-vessels. It differs in its appearance and texture from the dura mater; presenting a smooth surface exteriorly, but a rough and villous one next to the brain, and being composed of a beautiful network of blood-vessels united together by a delicate cellular tissie. 
The third membrane has been compared to a spider's web, in allusion to which the name of membrana arachnoides has been given to it. It is placed between the pia and dura mater.

The arteries which supply the brain with blood are the two vertebrals, besides two other branches called the internal carotids. Its blood is returned from the sinuses of the dura mater by the vertebral and jugular veins.

It is on the supply of the vertebral arteries, however, that the brain mainly depends for its supply, for if ligatures are placed on these arteries, the animal dies; whereas, both the carotids may be tied without occasioning any apparent ill effects. If our memory serves us, Dr. J. C. Warren, of this city, has performed the latter operation on the human subject with success.

In raising the bony covering of the brain, we meet with two processes, called the falx, or longitudinal process, and the tentorium, or transverse process. The former resembles the blade of a scythe, hence its name. These processes are formed from duplicatures of the dura mater; the first descends for a short distance between the lobes of the cerebrum. It takes its rise from the crista galli, and terminates on the os occipitis.

The tentorium is extended from the inner plate of the os occipitis along the sides of the cranium to its base, whence it may be traced to the sphenoid bone, and is lost in the common covering of the dura mater. It is composed of two laminæ: one is continuous with the falx: the other forms that portion of the membrane which covers the cerebellum. The tentorium is equally divided by the falx into two lateral portions.

The sinuses. - The superior, or longitudinal sinus, runs within the duplication of the falx, along its superior border.

The two lateral sinuses are formed within the duplicature of that part of the tentorium which is attached to the temporal and occipital bones; one extending to the right, and the other to the left. They receive veins both from the cerebrum and cerebellum.

The cavernous sinuses, so named from the cavernous ap- 
pearance of their interior: they receive some important nervous trunks in their passage from the brain, and for lodging the terminations of the internal carotid arteries. They commonly communicate with the sub-occipital sinus; these are also of membranous formation, and are found upon the cuneiform process of the os occipitis, running longitudinally to the foramen magnum. They receive veins from the cerebellum and posterior parts of the cerebrum.

Cerebrum. - The largest portion of the cerebral mass, and that which presents itself to our view in raising the skull, is the cerebrum. It is equally divided by a longitudinal fissure along its middle, into which the falx cerebri descends; and its divisions, which are symmetrical, both internally and externally, are denominated hemispheres.

Cerebellum. - The cerebellum is at once distinguished from the cerebrum by its being only one sixth the size of the latter. Its figure is irregular : it has two oval ends, and its lateral dimensions exceed its longitudinal. It is divided into three oblong lobes - a middle and two lateral.

Medulla oblongata, the smallest division of the cerebral mass. It rests on the cuneifoim process of the occipital bone, and is continued upward and backward to the foramen magnum.

The upper surface of the medulla oblongata forms, with the tuber annulare, the floor of the fourth ventricle.

Pituatary gland, a red body, of an egg form, seated upon the sella tursica, within a fold of the dura mater. It has a membranous capsule, surrounded by cellular adhesions, by which it is firmly retained in its place.

Medulla spinalis. - The spinal marrow is that extended portion of brainlike substance which is continued from the posterior part of the medulla oblongata through the entire length of the spinal canal. It is enclosed in the same membranes that envelop the brain; but, in addition to them, the superior ligament of the spine serves as a covering and defence to it below. To this, and to the periosteum lining the canal, its proper theca is loosely attached by cellular, adipose, 
and gelatinous matter. Its dura mater is derived from that which covers the brain: in being continued through the foramen magnum, the membrane is contracted into a cylindrical sheath, which loosely encases the marrow, and is generally described under the denomination of theca vertebralis. The arachnoid membrane and pia mater have the same relation to the marrow that the same membranes have to the brain, of which they may be considered prolongations.

\section{ORIGIN AND DISTRIBUTION OF THE NERVES.}

THE nerves being symmetrical in number and distribution on either side of the body, take their origin in pairs, and these pairs are numbered, and so distinguished from one another, according to the order in which they arise. There are forty-six pairs of nerves; ten, coming from the brain, are distinguished as the cerebral nerves; thirty-six, from the spinal marrow, denominated the spinal nerves.

\section{CEREBRAL NERVES.}

First pair, or olfactory nerves, arise from the corpora straita, along the posterior borders of which bodies the medullary bands or roots of them may be traced as high up as the middle lobes of the cerebrum. These are the largest of the cerebral nerves, are bulbous at their origin, pulpy in texture, and exhibit, when cut into, comparatively to their size, large cavities, which are walled in by a layer of medullary matter, enclosed within a thinner one of cortical substance.

Second pair, or optic nerves, arise from the thalamia nervorum. They leave the cranium through the optic foramen, and pass to enter the globe of the eye, within the interior of which it expands, and forms the retina. In its whole course, it is enclosed within a sheath prolonged from the dura mater.

Third pair, or motores oculorum, take their origin by several filaments, from the inward parts of the crura cerebri. The trunk of the nerve first runs obliquely outward, across the back of the crus, then turns downward and enters the 
cavernous sinus, on through the foramen lacerum-orbitale. In entering the cavity, the nerve divides into two branches. The smaller is generally received by the levator oculi. The larger branch subdivides into several others; the longest of these runs round the eyeball, and penetrates the oblique muscle. Two or three others run to the abductor and depressor muscles.

Fourth pair of pathetic. These take a filamentous origin, and pass the border of the tentorium, entering the cavernous sinus, from thence to the orbit. Its destination is the superior oblique muscle of the eye.

Fifth pair, or par trigeminum. These are the largest nerves of the brain. They take their origin by filaments from the crura cerebelli, and pierce the dura mater. Each nerve appears to form a ganglion; from this ganglion, we say that three nerves depart: one is called the ophthalmic; the second, the anterior maxillary; the third is the posterior maxillary nerve. The ophthalmic nerve is the smallest of the three divisions; as it emerges from the orbit, it divides into three branches, called the lachrymal, the super-orbitar, and the lateral nasal branch.

The second division, or anterior maxillary nerve, leaves the cranium through the hole, called foramen rotundum, of the sphenoid bone, and takes its passage through the inferior orbital canal, whence it emerges, covered by the levator labii superior, upon the face; here it splits into several large branches, denominated the facial nerves. But prior to its entering this canal, it detaches several important branches to the eyelid, lachrymal duct; also several long filaments which descend on the tuberosity of the anterior maxilla, penetrate the bone, and furnish twigs to the antrum, and the two superior molar teeth. The largest branch is the spheno-palatine, or lateral nasal nerve, to which the foramen spheno-palatine gives passage into the nose, wherein it divides into two sets of filaments. One of these is spread over the lateral parietes of the nasal cavity; the other ramifies over the sinuses, and sends a filament to the lower border of the septum. A branch 
also goes to the velum palati, and another branch accompanies the palatine blood-vessels, and ramifies over the soft palate.

The facial branches of this division terminate on the front and sides of the face, and receive communicating filaments from the anterior facial branch of the portio dura, and with them form a plexus.

The third division, the posterior maxillary nerve, gives off a branch which runs up in front of the parotid gland, and joins the portio dura; also branches called the buccal nerve, pterygoideus, and gustatory. The latter descends by the side of the tongue, penetrates that organ about its middle, and vanishes in its tip. It also sends ramifications to the roots of the incisive teeth, and to the under lip.

Sixth pair, or abducentes, arise by means of filaments from the medulla oblongata; this nerve gives off two or three filaments to the retractor oculi; but its principal destination is to the abductor, along the fascicula, of which its ramifications are equally distributed.

Seventh pair, or auditory nerves. - This pair includes two separate nerves on either side; one, from its remarkable softness, is denominated the portio mollis; the other, in contradistinction, the portio dura. The portio mollis enters the organ of hearing, and is distributed to the labyrinth.

The portio dura arises from the medulla oblongata, and passes to the internal part of the ear, the tympanum and eustachian tube. It is also distributed to the temples, eyelids, nose, lips, cheek, and neck.

Eighth pair, or par vagum. - At its commencement it consists of two separate portions; the first called the glossopharyngeal nerve, and the second the true par vagum. They arise from the corpora olivaria, and make their exit through the base of the cranium. The glosso-pharyngeus gives off branches, which join the portio dura, to the constrictors of the pharynx, and form branches which ramify in the base of the tongue.

The proper par vagum, having disunited from the glossopharyngeal nerve, proceeds downwards to join the carotid 
artery, and takes its course along the neck to the chest. Its filaments are -1 . To the cervical ganglion. 2. The pharyngeal branch, whose filaments pass to the œsophagus and larynx. 3. Two slender branches to the carotid artery, which form a plexus. 4. The laryngeal branch.

At the back part of the neck the par vagum inclines upwards, and is found above the carotid artery; it then passes between the two first ribs, into the chest. Having entered the thoracic cavity, it runs within the superior mediastinum; the right nerve adheres to the trachea, crosses above the root of the right lung, alongside of the œsophagus, and gains the under side of that tube before it leaves the chest. On the left side the nerve accompanies the anterior aorta, and crosses the root of the posterior aorta, and also reaches the osophagus. Its branches within the chest are filaments to the tracheal and cardiac plexuses; also, a branch called the recurrent nerve: branches to the pulmonary plexus, and also two cords that branch out and penetrate the walls of the auricles. The recurrent nerve of the left side originates from the par vagum, by the side of the anterior aorta, and coils round the root of the posterior aorta.

The recurrent nerve, so denominated from its retrograde course, passes upwardly and outwardly, and is found between the carotid artery and the trachea; having reached the top of the latter, it spreads into fine terminating branches, several of which run to the muscles of the larynx and thyroid cartilage, and end in ramifications upon the membrane of the glottis. Its branches are filaments to the pulmonary plexus, cardiac plexus, posterior cervical ganglion, and branches to the œsophagus and trachea.

The par vagum runs to the stomach. The left nerve sends filaments to the heart, and others along the small curvature, which communicates with the ramifications of the right nerve; the other crosses to the left side, and joins the great semilunar ganglion. The right nerve, as soon as it reaches the heart, divides into numerous branches, which join the left, and spread their ramifications upon the under part of the 
heart; some run to the pylorus, and others join the hepatic plexus.

Accessory nerves to the eighth. - These nerves are considered as accessory to the eighth, in consequence of their being found in close connection in issuing from the cranium; it originates in the vertebral canal, by the union of several filaments. In its course into the cranium it receives many other fine threads, and in that cavity joins the par vagum. Beneath the atlas, the accessory nerve divides; the front division runs downward, and penetrates the belly, transmitting side twigs in its course. The posterior division turns round the transverse process of the atlas to the scapula, near which it is lost in muscular substance. The branches of the accessory pass to the par vagum, anterior cervical ganglion, and communicate with the sub-occipital nerve.

Ninth pair, or linguales, arise behind the eighth pair, from the corpora olivaria; it is found in company with the par vagum, near the coranoid process. The nerve passes down the lower jaw, between the muscles forming the root of the tongue, and ends in the tip of the latter. It sends branches to the lingual muscles, and to the hyo-glossus longus.

Tenth pair, or sub-occipital nerves. - They arise from the medulla oblongata, and beginning of the spinal marrow; they pass out through a hole in the fore part of the body of the atlas. It then branches into a superior and inferior division. The superior is distributed to the extensor muscles of the head and neck. The inferior branch goes to the trachea, lymphatic glands, and muscles of the neck.

CERVICAL NERVES.

These consist of seven pairs, originating from the cervical portion of the spinal marrow. Each nerve, as soon as it issues from the spinal canal, forms two nervous filaments, one superior, the other inferior.

The first cervical nerve makes its exit between the first and second cervical vertebræ. It sends branches to different muscles, and communicates with the 
Second cervical nerve, which makes its appearance between the second and third vertebræ. Its superior filament sends branches to the muscles of the neck, and levator humeri, communicates with the accessory nerve, and

Third cervical. This also send branches and twigs to the different muscles of the neck, and communicates with the fourth.

The fourth, fifth, sixth, and seventh pairs pass from the spine, between their respective vertebræ, and send branches to the phrenic nerve, and ramifications to the muscles, sympathetic nerve, and unite with the dorsal.

THE DIAPHRAGMATIC, OR PHRENIC NERVE.

This is formed by branches from several of the cervical nerves. It takes its course down along the inferior border of the scalenus muscle. It terminates by numerous ramifications on the tendinous parts of the diaphgram.

\section{DORSAL NERVES.}

These consist of eighteen pairs. They pass from the vertebral canal in the same manner as the cervical, having superior and inferior branches. The inferior branches follow the course of the intercostal blood-vessels, and are called intercostal nerves. The superior branches are distributed to the back and loins.

\section{LUMBAR NERVES}

Consist of five pairs, (corresponding to the number of the lumbar vertebræ.)

The first nerve ends in ramifications near the stifle, and gives off branches to the last dorsal nerve, to the sympathetic, and to the second lumbar nerve.

The second nerve has communication with the first nerve, and sympathetic; also the crural. It sends one division to the fore part of the haunch, where it becomes sub-cutaneous, and ramifies over the stifle. The other division crosses the 
ilio-lumbar artery, just below its origin, and takes nearly a similar course to the inward part of the haunch, and then ramifies upon the skin; in its way it detaches a considerable branch, called the spermaticus externus, which passes through the abdominal ring, and sends twigs, in the male, to the scrotum and testicle; in the female, filaments go from it to the uterus, udder, and external labia.

The third nerve contributes to form the crural and obturator. It sends small branches to the sympathetic, psoas, and obturator nerves.

The fourth nerve sends a branch to the sympathetic, contributes to the production of the crural; and also sends a branch to the obturator.

The fifth nerve communicates with the sympathetic, crural, and sciatic plexus.

\section{SACRAL NERVES}

Consist of five pairs; a superior and inferior fascicula. The superior make their exit through holes upon the upper part of the sacrum, and are there buried under a thick mass of muscle, and become cutaneous upon the outer part of the haunch.

The inferior fascicula. The first nerve largely contributes to the origin of the sciatic plexus, and sends a branch to. the gluteal nerve; also to the sympathetic and second lumbar nerves. The second nerve communicates with the third and sympathetic, and sends branches to the surrounding muscles and sciatic plexus. The third and fourth have similar connections. The fifth passes into the coccygeal muscles.

COCCYGEAL NERVES.

These issue from the spine, in the same manner as the last described. They communicate with one another, are distributed to muscles in the vicinity, and end in filamentous ramifications at the end of the tail. 


\section{NERVES OF THE FORE EXTREMITY.}

The fore extremity receives its nerves from the axillary or humeral plexus, and this plexus is formed by the union of portions of the sixth and seventh cervical nerves, and a division of the first dorsal nerve.

The external thoracic nerves, six or seven in number, arise from the humeral plexus, and are distributed to the pectoral, triceps, and other muscles; they finally ramify into the skin.

The scapular nerves are called anterior, posterior, and subscapular. The former sends its ultimate filaments to the triceps.

The posterior scapular nerve sends branches to the subscapularis, triceps, teres minor, and shoulder joint, and ends in the insertion of the levator humeri.

The subscapular nerves run upward between the shoulder and chest, and enter the subscapularis.

The spiral or external cutaneous nerve is furnished by the axillary plexus ; arises behind the humeral artery, and passes between the os humeri and the head of the triceps, through the extensors, to the external flexors of the cannon. It gives off several branches to the triceps, ramifies on the fore and outward part of the knee, and sends branches to the heads of the extensor muscles.

The radial nerve descends with the humeral artery to the inward side of the elbow joint, and runs along the back part of the radius to the knee; passing under the annular ligament, it descends to the leg, and takes the name of the internal metacarpal nerve. It gives off numerous twigs to the muscles, and finally becomes subcutaneous.

The ulnar nerve originates from the humeral plexus. It passes down the radius, under the annular ligament, to the tendo perforans, and there becomes the external metacarpal nerve. It gives off internal cutaneous and subcutaneous branches, ramifies into cellular substance, penetrates the heads of the flexors, and finally disperses its ramifications in front of the leg. 
The metacarpal nerves continue down the leg, over the fetlcck joint, where they become the plantar nerves; these pursue their course behind their corresponding blood-vessels to the back part of the foot, which they penetrate to the inner sides of the lateral cartilages.

The plantar nerve detaches a branch from the fetlock to the lateral cartilage; another passes to the fatty frog. The final branch enters a hole in the back, and lower part of the coffin bone, in company with the plantar artery, and there divides and distributes its ultimate branches around the edges of the sole.

NERVES OF THE HIND EXTREMITY.

The crural nerve is derived partly from the second, third, fourth, and fifth lumbar nerves. It makes its appearance under the transverse process of the loins, and proceeds in a line with the external iliac artery. It gives off filaments to the psoas magnus, iliacus, rectus, and vastus internus muscles. It also gives off cutaneous filaments: one runs to the stifle, and ends in ramifications upon the fore part of the thigh. The other continues down the leg, and can be traced as low as the fetlock.

The obturator nerve, contributed to by third and fourth lumbar nerves, sweeps round the brim of the pelvis, and detaches twigs to the obturator muscles. Its ultimate filaments are expended on the triceps and gracilis.

The gluteal nerve, after leaving the cavity of the pelvis, accompanies the gluteal artery, and passes into the substance of the gluteal muscles.

The sciatic nerve derives its origin from the sacral and last of the lumbar nerves; after leaving the cavity of the pelvis, passes between the hip joint and the tuberosity of the ischium, and plunges into the substance of the haunch. Here it divides into branches called the popliteal nerves. At the hock its principal branch separates into the external and internal metatarsal nerves: the former runs over the flexor pedis to the os calcis. Their subsequent course and ultimate distri- 
bution are the same as those of the plantar nerves of the fore extremity. The second popliteal nerve passes between the bellies of the gastrocnemii, above the first, detaching twigs to them in its passage, and then spreads into many branches, which penetrate the heads of the flexor muscles of the foot, and sends filaments into the stifle joint.

\section{SYMPATHETIC NERVE.}

This nerve derives its name from the universal influence which it has on the nervous system. It communicates with the head, neck, chest, pelvis, and abdomen, by its frequent intercourse and connection with their respective nerves. It is supposed by some writers to be a nervous system of itself. It has, at different distances, a great number of gangliform tubercles, from which ramifications proceed forward, as well as filaments backward, to the ganglia of the nerves of the medulla spinalis. It is considered generally as beginning from a branch of the fifth and sixth pair, given off at the base of the cranium. The ganglionic structures, and the different plexuses are named from their form, location, and distribution; hence we have the cervical ganglion, semilunar, sacral, \&c. From the semilunar ganglion nervous filaments shoot in various directions, which, from their being compared to the rays of the sun, are denominated the solar plexus. From the divergent filaments of the latter, the several smaller plexuses of the abdomen may be said to derive their formation, taking names according to the viscera they are particularly designed to furnish with nerves; hence we have the splenic plexus, that sends filamients to the spleen, the hepatic plexus, mesenteric, aortic, hypogastric, and renal plexuses. The sympathetic nerve in the abdomen travels over the sides of the bodies of the lumbar vertebræ, below the articulations of the ribs, and pursues its course into the pelvis. Here, also, it forms ganglia, which correspond in number to those of the lumbar nerves; and from every ganglion come off two filaments; one which runs to the corresponding lumbar nerve; the other crosses the aorta, and by joining the aortic plexus, 
communicates with nerves coming from the sympathetic of the other side.

From the loins, the sympathetic descends into the pelvis, and takes its course along the side of the sacrum, and forms five ganglia, corresponding to the sacral nerves; it finally terminates by forming a union with its fellow.

\section{ORIGIN, INSERTION, AND USE OF THE DIFFERENT MUSCLES OF THE HORSE.}

TRAPEZIUS,

Or triangular muscle, is in the region of the withers.

Origin. - From the processes of several dorsal vertebræ, and from the fascia covering them. Its fleshy fibres pass over the shoulder bone, and there unite in a tendon.

Insertion. - Into the spine of the scapula.

Use. - It elevates the shoulder blade, and inclines it backward.

\section{LATISMUS DORSI.}

Origin. - By a broad expansion over the posterior part of the back and loins. Its fleshy fibres appear upon a level with the top of the shoulder bone, and converge, in their course downwards and forwards, over the ribs, to which they are loosely attached.

Insertion. - Into the inner and upper part of the os humeri.

Use. - To draw that bone backwards and upwards.

RHOMBOIDEUS BREVIS.

Origin. - From the dorsal spines. In passing downwards to the scapula, it unites with the longus.

Insertion. - Into the costa of the shoulder bone.

Use. - To draw the shoulder bone directly upwards. 
RHOMBOIDEUS LONGUS.

Grigin. - From the side of the subflavum, near its attachment to the second cervical vertebra.

Insertion and Use. - The same as the last described muscle.

\section{LEVATOR HUMERI.}

Origin. - From the tubercle of the occiput, and mastoid process of the temporal bone; also from the transverse process of the atlas, and third and fourth cervical vertebræ.

Insertion. - Into the fascia covering the muscles of the shoulder blade: thence it is continued down to the body of the os humeri.

Use. - To raise and draw forwards the shoulder. When both muscles act, they depress the head.

\section{MUSCLES OF THE NECK.}

\section{SPLENIUS.}

Origin. - By tendinous fibres, and fleshy ones between the occipital bone and the fifth dorsal spine.

Insertion. - Into the transverse processes of the six lower cervical vertebræ; also into the atlas and mastoid process of the temporal bone.

Use. - To erect and uphold the head when the pair act : one contracting alone will incline those parts to one side.

\section{COMPLEXUS MAJOR.}

Origin. - By short tendinous slips, from the spines of the four or five anterior dorsal vertebræ; also from the same processes of the lower five cervical.

Insertion. - Into the tubercle of the occipital bones, by the side of the ligamentum subflavum.

Use. - To erect the head. 
COMPLEXUS MINOR.

Origin. - From the spinous process of the vertebra dentata. Insertion. - Along with the complexus major.

Use. - To assist that muscle in erecting the head.

RECTUS CAPITIS POSTICUS MAJOR.

Origin. - From the spine of the vertebra dentata. Insertion. - Into the occipital bone.

Use. - To pull the head backwards.

RECTUS CAPITIS POSTIBUS MINOR.

Origin. - From the body of the atlas.

Insertion. - Along with the last-described muscle.

$U$ se. - To raise the head.

OBLIQUUS CAPITIS SUPERIOR.

Origin. - From the superior border of the transverse process of the atlas.

Insertion. - Into a ridge extending from the occipital tubercle.

Use. - When both act, to assist in pulling up the head; singly contracting, they will turn it to one side.

\section{OBLIQUUS CAPITIS INFERIOR.}

Origin. - From the spine of the vertebra dentata.

Insertion. - Into the superior parts of the transverse process and body of the atlas.

Use. - When both contract, the atlas, and the head with it, will be raised. It also gives a rotary motion to the head.

\section{SPINALIS COLLI.}

Origin. - From the anterior oblique processes of the curved vertebræ, and from that of the first dorsal, by tendinous and fleshy slips.

Insertion. - Into the spines of the cervical vertebræ, with the exception of the atlas.

Use. - To elevate the head, and flex the neck backwards. 
ANTERIOR CERVICAL REGION.

\section{STERNO-IMAXILLARIS.}

Origin. - Fleshy and tendinous, from the cartilage projecting in front of the sternum. Its belly is compact, rounded, and of inconsiderable breadth in comparison to its length. About three fourths of its length upwards, it terminates in a flat tendon, which insinuates itself between the parotid and submaxillary glands.

Insertion. - Into the angle of the posterior jaw.

Use. - To draw the head towards the chest. They also assist the occipito-maxillaris in opening the mouth.

STERNO-THYRO-HYOIDEUS.

These muscles are said to clothe the upper and front parts of the trachea.

Origin. - From the front cartilage of the sternum, above the sterno-maxillaris.

Insertion. - The main part of this muscle, having crossed the front of the larynx, is inserted into the neck or spur of the body of the os hyoides. A small tendon is also fixed in the lower border of the thyroid cartilage.

Use. - To draw the os hyroides, and larynx with it, downwards and backwards.

SCALENUS.

Origin. - From the middle of the first rib.

Insertion. - Into the bodies and transverse processes of the fifth and sixth cervical vertebræ.

Use. - To straighten the neck.

RECTUS CAPITIS ANTICUS MAJOR, MINOR, OBLIQUE, AND LONGUS COLLI,

Are all inserted into the occipital region, and assist in flexing and bending the head. The latter muscle, in addition to its insertion into the body of the atlas, is also inserted into the transverse processes of the six posterior cervical vertebræ. 


\section{MUSCLES OF THE HEAD.}

Epicranius and Temporalis. Mr. Percival writes, "These are the only two that can be considered as cranial muscles." The former is expanded over the os frontis. Its origin is almost imperceptible. It raises the upper eyelid. The temporalis occupies the side of the skull, and is demonstrable in the living horse.

Origin. - From the temporal bones, and the fascia covering it.

Insertion. - Into the coronoid process of the lower jaw.

Use. - To shut the mouth.

\section{AURAL REGIOP}

As these muscles are not so important as others we shall enumerate, we merely name them. Attollentes aurem consists of four muscles, viz., the attollens maximus, minimus, inferior, and superior. These muscles all coöperate in the erection of the ears.

THE PROPER MUSCLES OF THE CONCHÆ

Are the anterior conchæ, rectus, oblique, and internal conchæ. The first three assist in the erection of the ears. The internal conchæ rotates the ear backwards.

RETRAHENTES AUREM.

These are the retrahens superior, inferior, and medius. They retract and rotate the ears.

FACIAL REGION:

The muscles in this region are numerous, and some of: them complicated.

\section{ZYGOMATICUS:}

A long slender muscle traversing the cheek.

Origin. - By tendinous fibres, from the lower edge of the zygomatic process of the os malæ.

Insertion. - Into the angle of the mouth. 
Use. - To extend this angle, by drawing it upwards and backwards.

\section{LEVATOR ANGULI ORIS.}

Upon the fore part of the cheek.

Use. - To retract the angle of the mouth, assist in the elevation of the upper lip, and dilate the nostril.

\section{RETRACTOR LABII SUPERIORIS.}

Insertion. - Into the side of the upper lip, and lower part of the nostril.

Use. - To retract those parts, and thus assist in raising the upper lip, and dilating the nostril.

\section{LEVATOR LABII SUPERIORIS.}

Use. - To raise the upper lip and dilate the false nostrils. If one contracts, the lip will be distorted.

\section{BUCCINATOR.}

Origin. - From the lower jaw.

Insertion. - Into the buccal membrane, and into the angle of the mouth.

Use. - To contract the jaws, and retain the food for mastication.

ORBICULARIS ORIS.

The use of this muscle is to close the lips.

DEPRESSOR LABII SUPERIORIS.

Use. - To depress the lip, and project it forwards, and to assist in dilating the nostril.

LEVATOR LABII INFERIORIS.

Use. - To raise the lip, and project it forwards.

\section{HYOIDEAL REGION}

Comprehends the digastricus, mylo-hyoideus, genio-hyoideus, and hyoideus muscles. 
Use. - They are more or less engaged in moving the os hyoideus in different directions.

GLOSSAL REGION.

These muscles, by their union, compose that fleshy body called the tongue.

They are named genio-hyo-glossus, hyo-glossus longus, hyo-glossus brevis, and lingualis.

MAXILLARY REGION

Comprehends three strong and well-defined muscles.

1. The masseter.

Origin. - From the under part of the zygomatic arch, and from the superior maxillary bone.

Insertion. - Into the rough border, around the angle of the jaw.

Use. - To act, in conjunction with the temporalis, in the elevation of the jaw.

2. The stylo-maxillaris. A round and compact muscle, found above and behind the jaw.

Origin. - From the styloid, or coronoid process.

Insertion. - Into the angle of the jaw.

Use. - To pull the jaw backwards, and depress it.

3. The pterygoideus. It takes the same course inwardly, to what the masseter does outwardly.

Use. - To close the jaws. It also gives a lateral motion to the jaws.

\section{PHARYNGEAL REGION}

Comprehends six pairs of muscles, belonging to the pharynx. They are named as follows:-

Hyo-pharyngeus, Constrictor pharyngeus inferior.

Palato-pharyngeus, " " " " superior.

Stylo-pharyngeus, " " " medius.

Use. - To dilate and contract the pharynx. 


\section{MUSCLES OF THE TRUNK.}

PECTORAL REGION.

The pectoral muscles constitute the breast.

They are named - Pectoralis transversus,

Pectoralis magnus,

lar.)

Pectoralis parvus, (or Depressor scapu-

The first is inserted into the fascia of the arm, extending from the elbow nearly half way down to the knee. It confines the arm to the side in its motions.

The magnus originates from the sternum, is inserted into the os humeri, and serves to pull the point of the shoulder backwards.

The parvus, or depressor, originates from the inferior part of the sternum, is inserted into the muscles covering the shoulder joint, and assists the last named muscle.

\section{COSTAL REgION. - SERRATUS MAGNUS.}

Origin. - From the bodies and transverse processes of the fourth, fifth, sixth, and seventh cervical vertebræ; and from the eight anterior true ribs, as low down as their cartilage.

Insertion. - By strong fascicula, into the upper and inward part of the scapula.

Use. - It constitutes the main attachment of the scapula to the trunk, and is more or less concerned in all the motions of the shoulder blade.

The costal muscles are - Superficialis costarum,

Transversalis costarum,

Intercostalis externi,

$$
\text { " interni. }
$$

They are all, more or less, concerned in dilating the thorax.

\section{STERNAL REGION}

Comprehends two small muscles that are employed in the contraction of the chest, or raising the sternum, and contracting the cartilages.

They are named lateralis sterni, and sterno-costalis externi. 
DORSAL REGION.

These muscles are connected with the vertebræ of the back.

LONGISSIMUS DORSI.

Origin. - From the six posterior dorsal spines, and by lumbar fascia, and from the crest of the ileum.

Insertion. - Into the posterior angles of the ribs, viz., the twelve last ribs, and three or four hindermost cervical vertebræ, and all the dorsal.

Use. - The motions of the back and loins are mainly produced by it. It is a principal agent in kicking and rearing.

SPINALIS DORSI, AND SEMI-SPINALIS DORSI.

These muscles are both inserted into the dorsal spines; the former is also attached to three or four posterior cervical.

Use. - To writhe the back, or bend the withers; to incline the spines backward, and to coöperate with the longissimus dorsi.

\section{LEVATORES COSTARUM.}

These are prominent bundles of fibres, which take a similar course to the intercostalis externi.

Use. - They assist the intercostalis, and contribute to the elevation of the ribs.

LUMBAR REGION.

SEMI-SPINALIS LUMBORUM.

These are similarly distributed in the loins, to what those of the semi-spinalis dorsi are in the back.

INTERTRANSVERSALES LUMBORUM.

These run from the edge of one transverse process to that of the next.

Use. - To approximate these processes.

SACRO-LUMBALIS.

They traverse the under surface of the loins. 
Origin. - From the anterior and lateral part of the body of the sacrum, and last lumbar vertebræ.

Insertion. - Into the fibres that traverse the loins, and into the last rib.

Use. - They assist the intertransversales lumborum.

\section{PSOAS MAGNUS}

Runs along the inner part of the loins above the kidney.

Origin. - From the inward surfaces of the two last ribs, close to their articulations with the vertebræ; and from the bodies and transverse processes of the last dorsal vertebræ, and all the lumbar vertebræ. In its passage to the thigh, some of its fibres are blended with those of the iliacus.

Use. - To bend the femur upon the pelvis; to pull the haninch forwards in progression.

\section{PSOAS PARVUS.}

A smaller muscle than the last, placed between it and the spine.

Origin. - From the heads of the sixteenth, seventeenth, and eighteenth ribs, from the bodies of the three posterior dorsal, and from those of the lumbar, vertebræ.

Insertion. - By a tendon into the rough surface upon the os innominatum, below the acetabulum.

Use. - To draw the pelvis forward. When one acts, it may incline it to one side. It also assists the psoas magnus in arching the spine.

\section{ILIACUS.}

A muscle of considerable substance and power, placed above and in part exterior to the psoas magnus.

Origin. - From that part of the crest of the ileum that has no bearing upon the sacrum, and from the anterior spinous process, and inferior edge of the bone.

Insertion. - It passes down the thigh in company with the psoas magnus, with which it is inserted.

UTse. - To advance the haunch. 
INTERNAL COSTAL REGION.

DIAPHRAGM.

The diaphragm is that fleshy and tendinous expansion which divides the cavity of the chest from that of the abdomen.

Origin. - It arises by fleshy digitations from the cartilages of the eighth, and those of all the posterior ribs, with the exception of the two last; also from the ensiform cartilage. From these points of attachment, they converge like the radii of a circle, and terminate about midway between the ribs and spine, in a thin expansion of tendon. The crura, or appendages of this muscle, are two in number, and lie by the side of the aorta, which vessel takes its course between them; the right, much the longer of the two, arises above the artery, from the inferior part of all the bodies of the lumbar vertebræ; the left, or shorter, has a tendinous origin from the under part of the body of the first lumbar vertebra, and by a separate tendinous slip from that of the second. They unite and decussate each other opposite to the seventeenth dorsal vertebra, form a fleshy belly, and this again separates into two portions previously to its insertion, in order to admit of the passage of the csophagus.

Insertion. - Into the upper part of the cordiform tendon. About the centre of this tendon, is a perforation for the passage of the vena cava posterior; so that there are, all together, three openings in the diaphragm.

Use. - It acts in opposition to the abdominal muscles in the act of respiration.

\section{STERNO-COSTALIS INTERNUS.}

This muscle lines the sternum inwardly; it is interposed between it and the cartilages of the ribs and pleura.

Origin. - By tendinous roots from the upper half of the sternum.

Insertion. - Into the cartilages of the true ribs.

Use. - To contract the cavity of the chest. 
THE ANAL REGION

Includes a pair of muscles and a single one.

RETRACTOR ANI,

Which retracts the anus - draws it within the pelvis.

SPHINCTER ANI,

Which closes the anus, after the expulsion of the fæces.

COCCYGEAL REGION

Includes the erector coccygis.

Use. - To elevate the tail.

DEPRESSOR COCCYGIS.

Use. - To depress the tail.

CURVATOR COCCYGIS.

Use. - To incurvate the tail, or laterally flex it around the quarters.

COMPRESSOR COCCYGIS.

Use. - To assist in depressing the tail, and to maintain it forcibly pressed against the anus.

MUSCLES OF THE TRUNK.

ABDOMINAL REGION.

The white line, (or linea alba, extending from the ensiform cartilage to the pubes, marks the place of junction of the tendons of three pairs of muscles, and is perforated near the middle by the umbilicus or navel; through which, in the fœtus, passes the umbilical cord. On either side of this line is another, taking a curvilinear course, called the linea semilunaris: this is the line of demarcation between the oblique and transverse muscles and their tendons, denoting where the one substance begins and the other ends. Running transversely between these are several white lines, to which the 
name of linea transversales is given : they consist of many tendinous intersections in the straight muscles.

OBLIQUUS EXTERNUS ABDOMINUS. - OBLIQUUS INTERNUS ABDOMINUS. - TRANSVERSALIS ABDONINUS. - RECTTIS ABDOMINUS.

These four pairs of muscles are inserted into the lines we have just described; the latter muscle is also inserted into the pubes. These muscles contribute largely to the formation of the under and lateral parts of the abdominal parietes, and to give support to the contained viscera. They also compress the bowels, and by that means assist in the evacuation of the fæces and urine, and the expulsion of the fœtus.

The use of the last muscle - rectus abdominus - appears to be that of strengthening the middle parts of the belly, and thereby of counteracting that tendency to relaxation which must exist from the constant dependence of the bowels.

MUSCLES OF THE FORE EXTREMITY.-EXTERNAL SCAPULA REGION.

ANTEA SPINATUS.

Origin. - The anterior and superior spinatus fills up the fossa antea spinata, from which it arises, as well as from the spine and anterior costa of the scapula.

Insertion. - Into the summits of the greater and lesser tubercles of the os humeri, and into the capsular ligament of the shoulder joint. At the point of the shoulder it sends off a tendinous expansion over the joint, between which and the tendon of the biceps we find a bursa mucosa.

Use. - To extend the os humeri on the scapula; at least, as far as that motion is admitted of.

POSTERIOR SPINATUS.

Origin. - From the fossa postea spinata, and from the spine of the bone.

Insertion. - Into the outward part of the great tubercle of the os humeri. 
Use. - To assist in the flexion of the humerus.

TERES IIAJOR AND TERES MINOR.

Origin. - From the posterior angle and costa of the scapula.

Use. - These muscles assist in bending the shoulder joint, and roll it outwards and inwards.

SUBSCAPULARIS.

A muscle of triangular figure, filling up the hollow of the scapula.

Origin. - From the surface and circumference of the subscapular fossa.

Insertion. - Into the small tubercle of the os humeri.

Use. - To assist in the extension of the shoulder joint, and to turn the humerus inwards.

\section{POSTERIOR HUMERAL REGION.}

TRICEPS EXTENSOR BRACHII.

This muscle consists of three distinct portions, called its heads. The first takes its origin from the posterior costa of the scapula; from which its fibres run to the point of the olecranon. The second takes its origin from the outward sides of the neck and body of the os humeri, and unites with the former. The third arise from the inward part of the os humeri, and unites with the others prior to their insertion.

Insertion. - By a strong but short tendon, into the olecranon of the ulna: some of its fleshy fibres are continued down upon the fascia of the arm.

Use. - To extend the arm.

ANTERIOR HUMERAL REGION

Comprehends those muscles which are seen in front of the humerus. 
CORACO HUMERALIS.

Origin. - By a slender tendon, from the coracoid process of the scapula.

Insertion. - Into the inner and fore part of the body of the os humeri.

Use. - To assist in extending the shoulder joint, and turning the humerus inwards.

\section{FLEXOR BRACHII.}

Origin. - By a strong, round tendon, from the coracoid process of the scapula.

Insertion. - Tendinous into the inward parts of the head and neck of the radius, where it adheres also to the capsular ligament of the elbow joint: from it an expansion is sent off to the fascia of the arm.

Use. - To bend the arm by carrying it forwards and upwards.

\section{HUMERALIS EXTERNUS.}

Origin. - From the lower and inner border of the neck and body of the os humeri.

Insertion. - Into the inner and upper body of the radius.

Use. - To bend the arm.

MIUSCLES OF THE ARM.

\section{FLEXOR METACARPI EXTERNUS}

Is situated on the outer side of the other superficial flexos.

Origin. - From the outer and back part of the external condyle. It has two tendons; one is fixed in the os trapezium; the other passes on through a tendinous sheath to be inserted into the head of the outer small metacarpal bone.

Use. - To bend the leg.

Passes along the middle and back part of the arm. It 
arises from the internal condyle of the os humeri, and is inserted into the os trapezium.

Use. - To bend the leg.

\section{FLEXOR MIETACARPI INTERNUS}

Takes its course along the inner and back part of the leg. It originates from the internal condyle of the os humeri, adhering to the capsular ligament of the elbow joint.

Insertion. - Into the head of the internal small metacarpal bone.

\section{DEEP POSTERIOR BRACHIAL REGION.}

The following muscles constitute the deep-seated flexors; they lie anterior to, and are concealed by, the superficial.

FLEXOR PEDIS PERFORATUS. - FLEXOR PEDIS PERFORANS.

Both these muscles originate from the internal condyle.

Insertion. - The former, at the pastern joint, divides into two parts, which are fixed into the upper and back part of the os coronæ.

The perforans continue over the os naviculare - having a bursa between them; an expanded termination passes to the concavity of the os pedis.

ANTERIOR BRACHIAL REGION.

These muscles form the prominent part of the arm in front, take their origin from the external condyle, and operate in the extension of the leg and foot.

EXTENSOR DIETACARPI MIAGNUS.

Origin. - From the external condyle of the os humeri: its fibres also adhere to the capsular ligament; at the knee its tendon passes under the annular ligament, within a synovial sheath, where we find a bursa mucosa.

Insertion. - Into the front and upper part of the large metacarpal bone.

Use. - To extend the leg. 


\section{EXTENSOR PEDIS}

Takes the same course as the last described muscle. In passing over the front of the cannon, it is tied down by cellular membrane, and in front of the fetlock and pastern; it adheres to and strengthens the capsular ligaments of those joints.

Insertion. - By an expansion of its tendon, into the lower end of both pasterns, and coffin bone.

Use. - To extend the foot and pasterns, and assist in the extension of the knee.

EXTENSOR SUFFRAGINIS.

Origin. - From the upper and outer part of the radius and ulnar.

Insertion. - Into the upper end of the large pastern.

Use. - To assist in extending the knee and fetlock.

EXTENSOR METACARPI OBLIQUE.

Origin. - From the outward part of the body of the radius.

Insertion. - Into the upper part of the os metacarpi.

\section{MUSCLES OF THE HIND EXTREMITY}

Are invested with a dense, strong, and tendinous fascia upon the fore, outer, and back parts ; but it is thin, weak, and cellular upon the inside of the limb. Its chief attachments are to the ileum, the pubes, the ossa coccygis, and the stifle; it is continuous superiorly with the aponeurosis of the external oblique, and with the fascia lumborum.

MUSCLES OF THE HAUNCH.

ANTERIOR FEMORAL REGION. - TENSOR VAGINA.

Origin. - From the anterior spinous process of the ileum and fascia lata. About midway between the pelvis and stifle, 
it sends off a thin expansion of tendon, by which it is inserted.

Insertion. - Into the tendons of those muscles that are fixed to the patella. It is also connected to the trochanter minor externus, and fascia lata.

Use. - To assist in drawing the haunch forwards and upwards, and extend the thigh.

\section{RECTUS.}

Origin. - In part concealed by the iliacus, by two broad, flat tendons, from the dorsum of the ileum, anteriorly to and above the acetabulum.

Insertion. - Into the upper and anterior, parts of the patella.

\section{VASTUS EXTERNUS}

Runs along the outward side of the rectus.

Origin. - From the inferior part of the root of the trochanter major and minor, and outward surface of the os femoris.

Insertion. - With the rectus, into the upper and outer part of the patella.

\section{VASTUS INTERNUS.}

Origin. - From the inward part of the neck of the os femoris and root of the trochanter minor internus, and from the inward part of the body of the bone.

Insertion. - Into the patella.

\section{INTERNAL FEMORAL REGION.}

\section{SARTORIUS}

Is a long, thin muscle, crossing obliquely over the inward side of the haunch, immediately under the fascia lata.

Origin. - From the brim of the pelvis. In its course it passes over part of the psoas magnus, and obliquely crosses the vastus internus; at the inward part of the stifle it ter- 
minates in a thin, delicate tendon, which unites to the gracilis.

Insertion. - Into the inner and upper part of the tibia.

Use. - To assist in bending the leg; and, when bent, to rotate the head of the tibia inwards.

\section{GRACILIS.}

Placed upon the inside of the haunch.

Origin. - Tendinous and fleshy, from the symphysis pubis, and inner edge of the descending ramus of the pubis. It forms that remarkable prominence upon the inside of the thigh.

Insertion. - Into the inner and upper part of the tibia.

Use. - To flex and rotate the tibia inwards.

\section{PECTINEUS.}

Origin. - From the upper margin of the pubis, near the symphysis.

Insertion. - Into the trochanter internus.

Use. - To flex the haunch, and at the same time abduct it.

\section{TRICEPS FEMIORIS.}

It has, as its name implies, three heads, which are called abductor brevis, abductor longus, and abductor magnus.

Insertion. - Into the pubes and tuberosity of the ischium, tibia, and expansions of the gracilis and sartorius.

Use. - They act as abductors.

\section{GLUTEAL REGION}

Includes the three gluteal muscles, and they compose the upper part of the quarter.

\section{GLUTEAL EXTERNUS.}

This muscle corresponds, as far as regards its relative situation, to the gluteus maximus of the human subject.

It originates from the third spinous process of the sacrum, 
and from the fascia lumborum, and is inserted into the trochanter and fascia.

\section{GLUTEUS MAXIMUS.}

Origin. - From the spinous and transverse processes of the two or three last lumbar vertebræ, from those of the two or three upper sacral, and from the fascia lumborum; from the crest of the ileum, and from its dorsal and posterior spinous processes, and from the sacro-sciatic ligament. From these origins its fascicula run in a convergent manner towards the trochanter major.

Insertion. - Into the sides of the trochanter major.

\section{GLUTEUS INTERNUS.}

Origin. - From the dorsum of the ileum.

Insertion. - Into the anterior and less projecting part of the trochanter major.

$U s e$. - The gluteal muscles are extensors of the os femoris. - In rearing and kicking they are in violent action.

\section{PELVIC REGION.}

These muscles, mostly small ones, run from the pelvis to the upper end of the os femoris: they are called -
Pyriformis,
Obturator externus,
Obturator internus,
Gemini.

POSTERIOR FEMORAL REGION.

These muscles are found upon the outer and back part of the haunch.

BICEPS.

A large fleshy mass forming the outermost part of the quarter.

Origin. - From the lateral and posterior parts of the sacrum, and from several of the ossa coccygis; from the great 
sacro-sciatic ligament; from the tuberosity of the ischium, and from the fascia lata.

Insertion. - Into the outer border of the patella, and to its external ligament.

Use. - The heads of the biceps, from having different insertions, will perform different uses. The anterior, or upper one, will assist the rectus and vasti in extending the thigh; but the posterior will aid in its flexion; they will both have some effect in abducting the limb, and in rotating it inwards - the hock at the time turning outwards.

SEMI-TENDINOUS AND SEMI-MEMBRANOUS.

These are placed behind the biceps, and originate from the bones of the coccyx, fascia lata, and tuberosity of the ischium.

Use. - To flex the leg and turn the stifle inwards.

MUSCLES OF THE THIGH.

These muscles are included between the stifle and hock; they are all fixed to the os calcis.

\section{GASTROCNEMIUS EXTERNUS.}

Origin. - By two heads, the outer one from a rough hollow just above the external condyle of the os femoris.

\section{GASTROCNEMIUS INTERNUS.}

Origin. - From a little above the external condyle of the os femoris. In passing over the hock it expands, and is implanted around the summit of the os calcis; thence it is continued down the back part of the leg, and here takes the name of tendo perforatus.

Use. - To extend the hock, and to flex the fetlock and pastern.

PLANTARIS.

A slender muscle passing along the outer and back part of the thigh. 
Origin. - In common with the flexor perforans, from the head of the fibula.

Use. - To assist the gastrocnemii in extending the hock.

\section{POPLITEUS.}

The following muscles lie deep-seated, close to the tibia, between it and the gastrocnemii.

The popliteus is placed at the back of the stifle joint.

Origin. - By a short, round tendon, from the outer and under part of the external condyle of the os femoris. Its fleshy fibres, which are attached to the capsular ligament, run obliquely to the inner and back part of the head of the tibia.

Insertion. - Into the inner and upper part of the body of the tibia.

Use. - To assist in bending the stifle, and to roll the head of the tibia inwards.

\section{FLEXOR PEDIS ACCESSORIUS}

Arises just below the popliteus.

Origin. - From the outer part of the head of the tibia.

Use. - To assist the flexor pedis in bending the pastern and coffin joint.

\section{FLEXOR PEDIS}

Courses the back part of the tibia.

Origin. - From the outer part of the head of the tibia, from the upper half of the body of the bone posteriorly, and from the fibula. At the back part of the hock joint it sends off a strong round tendon, which passes within a groove upon the inward surface of the os calcis, to the posterior part of the leg, where it is connected with the tendons of the flexor accessorius and gastrocnemius internus; with the former it unites, and the two become one and the same tendon; but with the latter it is only connected by cellular membrane. 
ANTERIOR CRURAL REGION.

\section{FLEXOR METATARSI}

Lies in contact with the anterior part of the tibia.

Origin. - By a tendon blended with the extensor pedis, from the lower part of the external condyle of the os femoris, and by fleshy fibres from the fore part of the tibia.

Insertion. - Into the head of the large metatarsi. The tendon itself, as it emerges from the theca, splits into two: the smaller one is implanted into the large metatarsi; the larger winds round the inward part of the hock, and is fixed on the os metatarsi.

Use. - To bend the hock and turn its point inwards.

EXTENSOR PEDIS.

Origin. - From the upper and fore part of the tibia, and lower part of the external condyle of the os femoris. Its fibres end in a flat tendon, a little above the hock, just as it descends in company with the peroneus to the large pastern joint; above the latter, they disunite, and run separate: in their course, both are invested in a cellular sheath. In front of the fetlock joint this tendon spreads out, and its fibres continue to expand in its passage over the pastern and coffin joints.

Insertion. - Into the coronal process of the os pedis, and along the upper edge of the bone between the attachments of the lateral cartilage.

PERONEUS.

Origin. - From the head of the fibula, and the whole length of the bone.

Insertion. - With the former muscle. 
THE MECHANISII AND FUNCTIONS OF THE JOINTS.

\section{ARTICULATIONS OF THE TRUNK.}

Ligaments of the spine. - Those between the head and first and second vertebræ are,

Lateral ligaments, one on each side, that run from the coronoid processes of the occipital bone to the fore part of the atlas, and are fixed in the roots of the transverse processes.

Suspensory ligament of the head is a broad ligament enclosed within the capsular. It proceeds from the body of the atlas to the occipital bone.

Capsular ligament is attached to the occipital bone, around the roots of the condyloid process, and to the anterior articular processes of the atlas.

Superior ligament runs from the long ring of the atlas to the spine of the vertebra dentata.

Odontoid ligaments are three in number: the two long pass from the sides of the process dentata, to the occipital condyles; the last runs from the point of that process to the anterior and inferior parts of the atlas.

Inferior ligament runs from the inferior spinous process of the first to the second vertebra.

'The ligaments common to the spine are,

Intervertebral ligaments. - They are the chief bond of union by which one vertebra is bound to another.

The common inferior and superior ligaments. - The former passes obliquely along the inferior parts of the vertebræ; and the latter runs within the spinal canal.

Capsular ligaments surround the smooth cartilaginous surfaces of the articulatory processes.

Intertransverse ligaments fix the transverse processes of the dorsal vertebræ together.

Interspinous ligaments are found between the spinous processes of the back and loins.

Ligamentum subflavum (or nuchæ) extends from the oc- 
cipital bone to the tail. It covers and connects the spinous processes of the back, loins, sacrum, and coccyx. This ligament forms a strong connecting medium between the spines of the vertebræ.

Ligaments of the pelvis. - Two superior transverse ligaments are fixed to the transverse processes of these bones above; two inferior, below, run from the fourth and fifth transverse processes of the loins to the crest of the ileum. Sacro-iliac symphysis consists of a cartilago-ligamentous substance interposed between, and firmly adherent to, the transverse processes of the sacrum, and the inward part of the ileum. This union is strengthened by ligamentary bands, which run from the posterior spine, and border of the ileum, to the transverse process of the sacrum.

Sacro-sciatic ligaments are broad expansions, stretched across the sacro-sciatic notch. They arise from the transverse processes of the sacrum, and those of two or three uppermost bones of the coccyx, and are extended to the posterior parts of the ileum and ischium, and to the tuberosity of the latter.

Obturator ligament is an expansion, thinner than the last, which passes across the foramen magnum ischii.

Ligament of the symphysis is the cartilago-ligamentous substance which unites the pubic bones.

Ligaments of the ribs. - Every rib is connected to two vertebræ by four ligaments, viz., two cxpsular internal and external ligaments.

Capsular ligament of the head invests and holds it within the vertebral socket. Two articular cavities are found within it, one with each vertebra, which have separate synovial linings.

Capsular ligament of the tubercle surrounds it at its articulation with the transverse process of the vertebra.

External and internal ligaments consist of strong fibres, which connect the neck of the rib, above and below, to the spine.

Intercostal ligaments are broad fibrous bands which run 
obliquely across the intercostal spaces, and hold the ribs and their cartilage firmly together.

Sternal ligaments. - These several pieces of the breast bone are united to each other by intervening cartilaginous substance ; in addition to which they are connected by ligamentary bands, both inwardly and outwardly. The fore part of it is surmounted by a broad portion of cartilage, which runs along its under part.

ARTICULATIONS OF I'HE FORE EXTREMITY.

Shoulder joint. - The capsular ligament around this joint is strengthened in many places by additional fibres dispersed upon its exterior. It is fixed to the rough margin of the glenoid cavity, and to the neck of the os humeri. A synovial membrane lines it, which may be followed upon the cartilaginous surfaces of the bones. Externally, this ligamentous capsule is clothed on every side by muscle; and to them is attributed the main strength of the joint.

Elbow joint. - The ligaments of it are two lateral and a capsular.

Knee joint. - In the knee there are five distinct articulations; one between the radius and the three small bones of the upper row; a second between the small bones, above and below; a third between those of the lower row and the metacarpal bones; a fourth between the os trapezium and the os cuneiforme; and a fifth between the os pisiforme and os trapezoides: they have all separate capsular ligaments and synovial linings.

The ligaments of the linee, and the tendons passing over it, are girt by broad, glistening, ligamentous bands, which retain the latter in their places, and render the joint stronger and more compact. Between these ligaments, fascia, and the extensor tendons, are some small bursæ.

External lateral ligament runs from a tubercle upon the radius to the head of the external metacarpal bone.

Internal lateral ligament consists of two parts, which 
proceed from a similar tubercle upon the inside, and from the body of the radius. The longer is fixed to the inner head of the metacarpal bone, and the shorter to the fore part of the metacarpal.

Ligamentum annulare passes from the os trapezium to the ossa scaphoides and cuneiform : it confines the flexor tendons.

Fetlock joint. - Capsular ligament is attached to the articulatory surfaces of these bones; and the synovial membrane, after having lined it, is reflected upon their cartilages : it is guarded in front by the extensor tendon.

Long lateral ligament is fixed to a projection upon the side of the metacarpal bone, and to the os suffraginis.

Short lateral ligament runs underneath the latter. These ligaments prevent motion sideways.

The ligaments of the sessamoid bones are seven, viz. : superior suspensory, the long inferior, the short inferior, the two lateral, and the two crucial.

Pastern joint is formed by the adaptation of the ossa suffraginis and corona. It has a capsular, and two pairs of lateral ligaments.

The capsular ligament is inserted into the smooth cartilaginous ends of these bones: it is blended with the extensor tendon in front, and behind with the long inferior ligaments of the sesamoids's.

The lateral ligaments are inserted on the sides of the os coronæ and suffraginis.

Coffin joint is made up of three bones: the ossa coronæ, pedis, and naviculare.

Capsular ligament envelops the articulatory surfaces, and is inserted beyond their limits ; in front it is united with the extensor tendon; behind it is strengthened by the tendo perforans. In addition to the capsular, there are three pairs of ligaments.

The first pair passes from the superior edges of the os pedis to the lateral parts of the os corona, and are inserted about its middle.

The second pair is stretched from the extremities of the os 
pedis to the os corona, and are fixed below and behind the first.

Third pair arise from the sides of the coronal process, and terminate in the cartilages.

The ligaments of the os naviculare are four, viz., two single, and one pair.

Superior ligament runs from its upper and posterior part to the tendo-perforans.

Inferior is a very broad ligament, arising from the whole of the lower edge of the bone, and thence extending to the os pedis, above the long extensor tendon.

Lateral ligaments fix the os naviculare, by its two ends, to the sides of the os corona.

\section{ARTICULATIONS OF THE HIND EXTREMITY.}

Thigh joint is formed by the reception of the head of the os femoris into its socket.

Capsular ligament is attached around the cervix of the os femoris and the margin of the acetabulum; it is thickly clothed on every side by muscle, which assists to maintain position.

The acetabulum is surrounded by the circular ligament, whose border turns inward to embrace the cartilaginous head of the os femoris.

The notch in this cavity, to its inward side, is crossed by the transverse ligament, which here makes up for the deficiency in the bone.

Ligamentum teres consists of a bundle of ligamentous fibres enclosed in a sheath, which proceed from a pit in the inner and upper part of the ball to a similar one in the roof of the socket. Another portion of it leaves the cavity under the transverse ligament, and is implanted in the pubes. The synovial membrane lines the socket, and is reflected over these parts.

Stifle joint is composed of the os femoris, the tibia, and patella. 
Ligamenta patella are composed of four strong cords, which descend over the condyles of the os femoris, and are inserted into the tubercle of the tibia. The external one passes upon the outer and anterior part of the external condyle; the internal, upon the inward part of the internal condyle; and the middle one, between them; they approach each other in their descent. Concealed by the external one is the fourth ligament of the patella; it runs to the outward part of the tibia.

The patella, with its articulatory surface of the condyles in front, forms a joint of its own, perfectly distinct from that between the tibia and os femoris.

Its capsular ligament is fixed to its surrounding border.

Internal lateral ligament descends from the internal condyle to the inner and upper part of the tibia.

External lateral ligament - stronger than the internal runs from the external condyle to the upper end of the fibula.

Crucial ligaments, short and strong, and deeply buried within the joint, run from the space within the condyles to the tibia.

The synovial membrane, after having lined the capsule, is reflected upon the cartilages and ligaments included within it.

Hock joint has four lateral ligaments, two on each side, called internal and external.

Capsular ligament includes the lower end of the tibia, and the pully-like part of the astragulus; to both of which, and the lateral ligaments, and to the os calcis, it is firmly attached.

The os calcis forms a joint with the os cuboides, and the ossa cuneiforme are also a joint, and the middle and small bones make joints with the cuboid above, and the metatarsi below; hence, there are six articulations in addition to what we commonly understand by the hock joint, that between the tibia and astragulus. 


\section{A TABLE OF THE BONES IN THE STRUCTURE OF THE HORSE.}

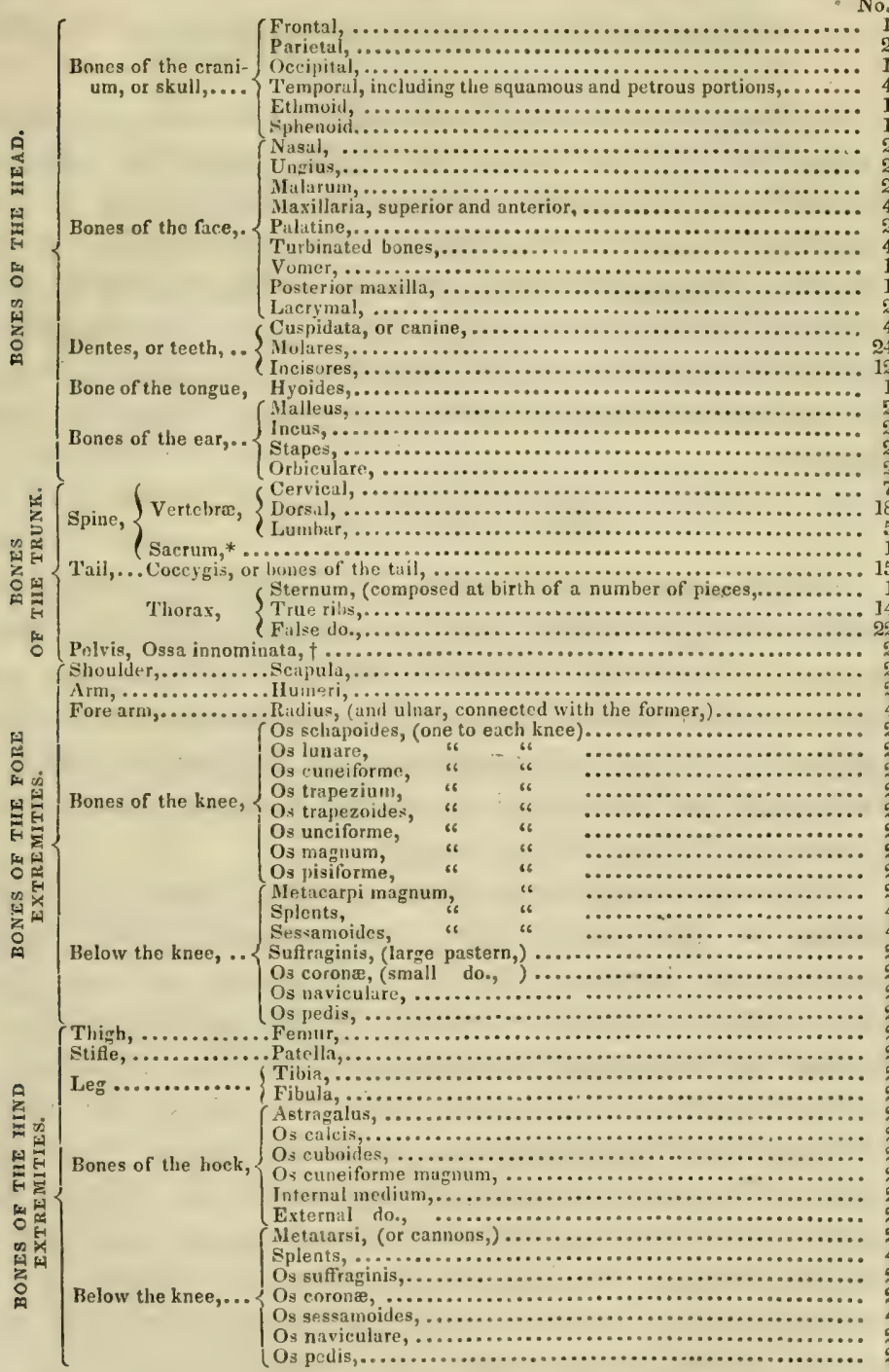

Total, ..................... 244

Dr. Hooper reckons the number of hones in the human subject at 248 .

* The bones in the sacrum of the colt consist of five pieces.

f The pelvis of the young animal is made up of the two os innominata, each of which is formed of two pieces; the larger is called os ileum, the smaller, in allusion to the human pelvis, has been subdivided into two portions, named os ischium and os pubis. 


\section{DISTRIBUTION OF THE LYMPHATICS.}

Mr. Percival remarks in his lectures, that " no English veterinarian has, up to the present day, (1820,) been at the pains to demonstrate, practically, the particular distribution of the absorbing vessels of the horse. Professor Girard, whose 'Traité d'Anatomie Vétérinare' does no less credit to the talent and industry of its author than honor to the veterinary school over which he presides, has presented us with an article on the ramification of the lymphatics, which I shall translate.

\section{"THE THORACIC DUCT.}

"The largest, longest, and most remarkable of the lymphatic vessels, in which terminate the majority of the lymphatics of the body, is situated within the thorax, on the right side of the dorsal vertebræ, between the aorta and vena azygos: it receives the lymphatics from the posterior extremities, pelvis, parietes and viscera of the abdomen, head, neck, withers, and left anterior extremity.

"It takes its origin under the loins in a dilation or sinus, situated at the root of the great mesenteric artery, and is named the receptaculum chyli: it directs its course forward, enters the thoracic cavity by the aortic perforation through the diaphragm, extends along the bodies of the dorsal vertebræ, until it arrives opposite the base of the heart, where it curves downward to cross over to the left side in its way to the anterjor opening of the thorax; as it leaves the spine for this purpose, runs over the trachea, and œsophagus; having reached the left side, it stretches forward to the beginning of the anterior vena cava, and terminates in the base of the left axillary vein. Not unfrequently, it ends in the right axillary; in some instances, even in the beginning of the anterior cava. At its termination, it dilates and forms a sinus, whose mouth opens into the vein, is guarded by a broad valve, so disposed as to prevent any reflux of blood into 
the duct.* It has also a ligamentous band around it, at this part, which confines it to the vein recciving its contents.

\section{"THE RECEPTACULUM CHYLA.}

"This reservoir forms the point of general confluence of all the lymphatics of the posterior limbs and abdomen, and that from which originates the thoracic duct. It is maintained by the aorta on one side, the vena cava posterior on the other, and is formed by the union of five or six large lymphatics, of which two or three come from the entrance of the pelvis, two or three others from the mesentery, a single one from the environs of the stomach and liver."

The Professor here makes a classification of the lymphatics of the body.

LYMPHATICS DISCHARGING THEIR CONTENTS INTO THE ABDOMINAL PORTION OF THE THORACIC DUCT.

\section{1. LYMPHATICS OF THE POSTERIOR EXTREMITIES.}

"These are distinguishable into the superficial and deepseated. The first originate from the skin and subcutaneous cellular tissue. They form divers ramifications which accompany the superficial veins; of which the most remarkable attend the vena saphena major, frequently anastomosing with one another, and forming an anastomotic network. All these lymphatics run to the subcutaneous inguinal glands, which are lodged upon the superior and anterior part of the thigh.

"The deep-seated lymphatics take their rise from the foot, ascend along with the plantar veins, continue upward among the muscles, in company with the deep-seated veins, corresponding in their principal divisions to those vessels, and proceed to the inguinal glands.

"All the lymphatics of the posterior limbs assemble at

* Notwithstanding this valve, blood often gains admission into the canal; this is observable in all cases of violent death, or in which struggles and convulsions attend expiration. 
these glands, and here form a plexus, from which several large branches depart and traverse the iliac glands, clinging to the sides of the iliac vessels, and discharge their contents into the pelvic branch, contributing to the receptaculum chyli.

\section{"2. LYMPHATICS OF THE PELVIS.}

"The vessels coming from this cavity run in part to the inguinal glands, and in part to the internal pelvic glands. The superficial lymphatics about the pubes and the outlet of the pelvis, run and join those of the extremities; those of the perineum and anus enter the cavity, and are accompanied by those coming from the croup and tail, both proceeding to the glands within the interior of the pelvis. All the deep-seated lymphatics accompany the veins, make for the pelvic glands, form union with the others, and run and empty themselves into the main pelvic branch, wherein their lymph mixes with that coming from the inguinal glands.

" The lymphatics of the urinary and genital organs, included in the pelvic cavity, also traverse the glands lodged therein and unite with those of the parietes of the pelvis. Those of the scrotum enter the inguinal glands, as also do those belonging to the sheath and penis. The ramifications derived from the testicle and spermatic cord take the course of the veins, and penetrate one or two of the lumbar glands lodged at the entrance of the pelvis. The lymphatics of the mammæ, which are also divisible into superficial and deep-seated, run to the inguinal glands, and anastomose with the superficial set belonging to the inferior parietes of the abdomen; but before they reach these last glands, they pervade those of the mammæ.

63. LYMPHATICS OF THE PARIETES OF THE $\triangle$ BDONEN.

"These vessels, in general but little developed, for the most part run to the inguinal glands. The superficial set of the lower parietes accompany the cutaneous inguinal vein, anastomose with the lymphatics of the scrotum and mammæ, and traverse the glands in the groin: some of them direct 
their course forward, along with the cutaneous external thoracic veins of the thorax, unite with the superficial lymphatics of that part, and proceed to the axillary glands. The deep-seated vessels of the belly run in company with the epigastric vein, and go to the inguinal glands, or else they accompany the pectoral vein, and pervade the glands in front of the thorax.

"The superficial or subcutaneous lymphatics of the loins join either those of the croup or those of the flanks: the deep-seated, which spring from the peritoneum, muscles, or spinal canal, perforate one of the lumbar glands, and pass onward to terminate in the main pelvic branch.

\section{"4. ABSORBENTS OF THE MESENTERY.}

"The mesenteric branches, ordinarily two or three in number, the most considerable of which is constantly united to the great mesenteric artery, receive all the vessels continued from the mesenteric glands, as well as those coming from the mesentery and intestines.

"The mesenteric absorbents, extremely numerous, are sustained between the layers of the mesentery, where they form a vascular network: many of them issue from the exhalent surface of the mesentery and intestinal tube ; others take their rise from the interior of the intestines, from which they imbibe chyle. All these vessels converge towards the lymphatic reservoir, clinging in their passage around the mesentric veins; some, however, taking a solitary course at a greater or less distance from any blood-vessel : having arrived at the root of the mesentery, they pass through one or two, sometimes three, of the mesentric glands, and afterwards join the principal lumbar lymphatics. The absorbents of the cœcum and cœcum caput coli run to the glands set at intervals along the intestinal tube, whence they proceed to the receptaculum chyli.

“5. LyMPhatics OF THE Liver, STOMACH, SPLEEN, AND OMENTUM.

"The hepatic trunk comprises the lymphatics issuing from the above viscera. This branch of the receptaculum chyli not uncommonly consists of two divisions, and receives in 
addition to the above mentioned vessels many ramifications from the cura of the diaphragm.

"The lymphatics of the pancreas, like the above, also run with the divisions of its veins, and join either those of the liver or those of the spleen: some proceed directly to the common hepatic trunk.

“II. RAMIFICATIONS TERMINATING IN THE THORACIC PORTION OF THE MAIN COMMON DUCT.

"1. LYMPHATICS OF THE PARIETES OF THE THORAX.

"The superficial absorbents of the chest take their rise either from the surface of the skin or else from the subcutaneous muscles; they form several large branches which accompany the thoracic cutaneous vein, unite with the superficial lymphatics coming from the anterior parietes of the abdomen, and proceed to the axillary glands.

"The deep-seated set take divers directions, and pass through the different sets of glands. The pectoral, which anastomose with ramifications from the abdomen, follow the pectoral vein, and reach one or two glands at the entrance of the chest. The intercostal spring from the pleura and intercostal muscles, accompany the intercostal veins, pervade the internal dorsal glands, and terminate by several branches in the thoracic duct.

"The lymphatics of the fleshy part of the diaphragm unite, some with the posterior intercostal, others with pectoral; those coming from the crura run to the dorsal glands, where they anastomose with the intercostal : those from the cordiform tendon anastomose with the deep hepatic, run forward between the layers of mediastinum, nearly to the heart, and enter the cardiac glands.

\section{“2. LYMPHATICS OF THE THORACIC VISCERA.}

"The absorbents of the different organs contained within the thorax, traverse one or several of the bronchial or cardiac glands, and afterwards form divers branches, which end 
in the thoracic duct. The pulmonary lymphatics, very numerous, are distinguished into superficial and deep-seated. The first take their rise from the surface of the lungs, creep along under their enveloping membrane, and make for one or more of the bronchial glands. The deep set, which originate from the air-cells, and from the parenchymatous tissue, follow the divisions of the pulmonary veins, run to the roots of the bronchix; there unite with the superficial, and perforate one or two of the bronchial glands.

"The cardiac lymphatics derive their origin either from the surfaces (both exterior and interior) of the heart, or from the muscular substance of the organ; they mount upon the curvature of the posterior aorta, and disappear in the cardiac glands.

"The lymyhatics of the superior part of the mediastinum, and of the cosophagus, join, some the intercostal, and others the bronchial; those coming from the anterior part of this membranous partition, from the thymus, trachea, and œsophagus, unite, either with the pectoral, or close with the cardiac and anterior intercostal.

\section{3. LYMPHATICS OF THE HEAD.}

"The lymphatics of the head form two planes, a superficial and a deep one. The superficial pursue the course of the cutaneous veins, and rum in part to the sublingual and glutteral glands. The deep vessels, which come from the nostrils, fauces, palate, \&c., also run to the glutteral and sublingual, in which they unite with the superficial. From these two groups of glands, through which pass the lymphatics of the head, depart several large branches, two or thrce of which descend upon the anterior face of the trachea; other's follow the course of the deep-seated and cutaneous veins, unite with those of the neck, and descend to the front of the chest. Almost all these vessels terminate in the thoracic duct; some few alone, on the right side, ending in the right axillary trunk. 
"4. LYMPHATICS OF THE LEFT FORE EXTREMITY.

"The iymphatics of this member present the same disposition as those of the posterior limbs, and are divided into superficial and deep-seated. The former, consisting of diverse ramifications, accompany the superficial veins ; the more considerable of them forming a plexus, which accompanies the cutaneous (superficial brachial) vein of the limb. The deep vessels originate from the foot, muscles, and bones, pursue the divisions of the deep veins, and plunge into the axillary glands, wherein they unite with the superficial, and whence they extend to the thoracic duct.

"6 THE RIGHT TERMINATING TRUNK OF THE LYMPHATICS.

"This very short lymphatic canal is obliquely situated at the entrance of the thorax, upon the transverse process of the last vertebræ of the neck, extending in a direction from above downward, and from without inward, and terminating most commonly in the right axillary vein; though, in some instances, it joins the thoracic duct. This trunk is formed by the lymphatics coming from the right axillary glands, and some from the right lung, and right side of the neck and trachea."

\section{ON THE HAIR.}

Professor Percival observes, that "all hair has a common similarity in its structure and mode of growth; whether it assumes the appearance of human hair, that of the coat or mane of the horse, the wool of the sheep, the fur of the rabbit, the bristles of the hog, or the spines of the hedgehog; its particular varieties in every one of these animals are owing to the thickness and disposition of the fibres of its cuticular case. The coat varies in quality, color, and length, in horses of various breeds; the Arabian is characterized by his smooth, silken, and glossy coat; the cart horse, the Shetland pony, 
and others, are contradistinguished by the greater length and consequent roughness, the coarseness, and stubbornness of the hair.

"With regard to color, there is some connection between that of the skin, the hair, and the eyes; black horses have black skins and dark eyes; milk-white and cream-colored horses, light skins and wall eyes. The three primitive colors - those of which all the others appear to be either shades or combinations, are white, red, and black. According to Richerand, the lighter the shade the finer the hair; as a proof of which, he says, there are fewest black hairs in a square inch of skin, more chestnut, and most light-colored. This assertion our observation appears to confirm; for it is comparatively uncommon to meet with a black thorough-bred horse.

"Most animals, at certain seasons of the year, lose one pilous covering, to have it renewed or replaced by another. The pulpy substance at the root of the hair shrinks and dries up, the stem consequently, no longer supplied with nourishment, loses its support and falls off; at the same time, a new pulp appears by the side of the old one, which, during the absorption of the latter, grows and gives root to the new hair; so that the pulp and stem only, and not the bulb, undergo the process of regeneration.

"The hair is speedily reproduced upon any denuded part; so that we are not afraid of the skin remaining bare, when the cutis vera (and consequently the bulbs of the hair) have not been injured; indeed, hair will be regenerated though it be plucked out by the roots. In the case of broken knees, however, it occasionally happens that the contusion of the fall is followed by more or less disorganization of the cutis, and then a scar or bare place remains; or a few light-colored or white hairs only grow upon the place, which appear to be the offspring of defective pulps.

"The time of casting the coat, one that may be compared to the moulting season in birds, is often the epoch from which we may date the origin of disease, and always when more or less debility reigns in the system. 
"On the other hand, the appearance of the hair may be adduced as a sign of internal derangement; such a horse ' has a staring coat,' is an expression in the mouth of the owner, and he generally has recourse to a remedy which restores its smooth and healthy aspect, without knowing at all the connection between the one and the other. The fact is, that this is one of the most remarkable instances we have of the sympathy between the skin and alimentary canal; and that we might, ad infinitum, bestow our labor upon the former without effect, unless we were at the same time to direct our attention to the latter.

"But there are other causes that may give rise to a rough coat. Simply taking a horse into an atmosphere colder than the one he has been habitually exposed to, will make the hair stare; even leaving the stable open to a current of air will do it, which the advocate for a warm stable is no stranger to. Now, this can be no other than the effect of contraction, not of the skin itself, but of the muscular fibres which adhere to it - the paniculus carnosus.

"What I have just particularized are not to be confounded with that variety of rough coat which a horse acquires during the cold season at grass; for this consists in an increased growth of the hair; and hence, it is a fact well known, that a hunter stabled with a long, staring coat in the autumn, cannot be made to look smooth and sleek by any subsequent treatment. Now and then it happens, from some cause or other, the action of the cutaneous vessels being disordered, and the shedding process arrested or but imperfectly performed, the old coat, or some parts of it, remain on until the second time of casting; when this is the case, the hair is said to be set.

"It is a well known fact, that an animal will vary the length and quality of his coat, according to the temperature of the climate into which he is transplanted. Every horseman knows the change that can be wrought in the coat of his horse by warm clothing, to need more than the bare mention of it here, as confirmatory of this point. Heat, then, is 
absolutely necessary to the production of a fine coat;* cleanliness, friction, and attention to the general health contribute to this condition of the hair. Let me not, however, in making this observation, be understood to be an advocate for a hot stable; on the contrary, I have ever, to the extent of my power, inculcated ventilation, which I have always found to be compatible with as much warmth to the skin as was necessary to the production and preservation of a fine coat." Mr. Percival, in a note appended to the foregoing subject, remarks: "There is so little information afloat on this subject, that it behoves us to gather honey wherever it is proffered. A writer in the Sporting Magazine of May last, after asserting that a fine coat is necessary to condition, (where, in my humble opinion, he has put effect for causation, ) and informing us that horses vary much in this particular, for which there is,' says he, 'no ostensible reason,' concludes with the following pertinent communication :

" : The Marquis of Hastings, while governor general of India, being impressed with the idea that geldings would be more efficient in the Indian cavalry, caused two troops to be formed in each regiment, when it was unanimously decided that geldings were very far inferior, and in this particular in cold weather, when their coats were long and rough. In furtherance of this experiment, many horses were castrated, and it was observed that all those that were operated on immediately previous to the commencement of the cold weather

* We have already shown that heat and moisture combined will relax the surface, and favor the exit of morbid accumulations in the tissues. Heat alone would evaporate the natural moisture of the animal, and permit the tissues to contract for want of that moisture. Thus the pores are closed, and the circulation and perspiration are impeded. Let an animal be exposed to a dry atmosphere, and a like contraction and the same effects take place. When an animal is clothed with a blanket, or horse cloth, the insensible per spiration is arrested, and finally condensed on the surface; this furnishes the eiements we require, viz., heat and moisture. If this moisture cannot be produced on the surface, as in common colds, catarrh, \&c., owing to the retrograde course of the fluids, then that moisture may be artificially supplied in the manner we have recommended. (See article LockJaw.) 
were in winter always long-coated; whereas, those that were castrated at the commencement of the hot season kept nearly as fine coats during the cold as the stud horses. When we come to learn what an influence the generative organs of the male have in the system, and how much the production of hair in particular is affected by their functions, we shall not be surprised at the disturbance which castration appears here to have created in the shedding process." " 


\section{GLOSSAR Y}

\section{OF MEDICAL TERMS USED IN THIS WORK.}

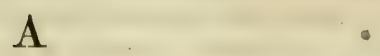

Abdominalis. Pertaining to the belly.

Abductor. A muscle, the office of which is to pull back.

Accelerator Urince. A muscle of the penis.

Acetabulum. A name given to the cavity which receives the head of the thigh bone.

Achillis Tendo. The tendon of the muscle inserted into the hock.

Acromion. A process of the scapula, or shoulder blade.

Alveolus. The socket of a tooth.

Annular Ligament, (from annulus, a ring, because it is ring-like, and surrounds the ligaments at the knee of the horse.)

Antagonist. Such are the flexors and extensors of legs; the former bend, and the latter extend.

Antcrior. A term applied to what may be situated before another of the same kind, as a prominence, lobe, artery, \&c.

Aponeurosis. A tendinous expansion.

Articulation, (from articulus.) A joint.

Allas. The first bone of the neck.

Auditory. Belonging to the organ of hearing.

\section{B}

Biccps, (from bis, twice, and caput, a head.) Two heads, applied to muscles from their having two distinct heads, or origins.

Bifurcate, (bifurcus; from bis, twice, and furca, a fork.) A blood-vessel is said to bifurcate when it divides into two branches.

Brachial. Of or belonging to the arm.

Brevis. Short.

Bronchial. Appertaining to the windpipe.

Buccal, (from bucca, the cheek.) Belonging to the cheek.

Calcaneum. The point of the hock. 
Capsular. Applied to a ligament which surrounds every movable articulation.

Carpus. The knee of the horse, and wrist of the human being.

Cauda. The tail.

Cellular. Having little cells.

Cervical. Belonging to the neck.

Cervix. That part of the animal between the neck and shoulder; applied also to distinguished parts, as the cervix uteri, neck of the uterus, \&c.

Cord. An assemblage of fibres.

Cineritious, (from cinis, ashes.) A name applied to the cortical substance of the brain, from its resemblance to an ash-color.

Commissura. A suture, juncture, or joint.

Condyle. A round eminence of a bone.

Conglomerate. Applied to a gland, which consists of a number of small glands: such are the parotid and salivary glands.

Constrictor. A name given to those muscles which contract an opening of the body.

Corona. A crown. The small pastern is named os corona.

Coronoid. Processes of bones are so called that have any resemblance to a crow's beak.

Corpus. A body.

Costa. A rib.

Cremaster. A muscle of the testicle.

Crico. Names compounded of this word belong to muscles which are attached to the cricoid cartilage.

Cuboides. A bone in the knee of the horse is thus named, from its resemblance to a cube, or die.

Cuneiform, wedge-like. A bone of the knee.

Cuspidatus. The four tushes of the horse are thus named.

Cutaneous, (from cutis, the skin.) Belonging to the skin.

Cystis. Cyst, or bladder.

\section{D}

Dentatus, (from dens, a tooth, from its tooth-like process.) The second vertebra of the neck is known by this process.

Depressor. A muscle is so named, which depresses the part on which it acts.

Diploe. The spongy substance between the two tables of the skull.

E

Elevator, (from elevo, to lift.) A muscle is so called, the office of which is to lift up the part to which it is attached.

Empyema. A collection of pus within the cavity of the thorax. 
Ercctor. The name of a muscle, the office of which is to raise up the part to which it is attached.

Excretory. Applied to small vessels that convey secretion out of the glands.

Exfoliation. The separation of a dead piece of bone from the living.

Exostosis. A morbid enlargement of bone.

Extensor, (from extendo, to stretch out.) A term given to muscles that extend a part.

\section{$\mathrm{F}$}

Facial. Belonging to the face.

Fascia. The tendinous expansion of muscles.

Femoral. Of or belonging to the thigh.

Fibre. A filament, or thread.

Fibula, (from figo, to fasten.) A small bone belind the tibia of the horse, attached to it.

Fimbria. A fringe.

Flexor. The name of several muscles, the office of which is to bend the parts.

Follicle. A small bag, applied to glands.

Foramen. A small opening.

Fossc. A depression.

Frontal. Belonging to the forehead.

Fungus. Proud flesh.

\section{G}

Ganglion. An enlargement in the course of a nerve.

Gastric. Appertaining to the stomach.

Glenoid. The name of articulating cavities in the pelvis.

Glutcal. Belonging to the haunch.

Gracitis, (so named from its smallness.) A muscle on the inner part of the thigh.

\section{$\mathrm{H}$}

Hepatic. Belonging to the liver.

Hyo. Names compounded of this word are connected with the os hyoides.

I

Incisors, (from incido, to cut.) The twelve front teeth of the horse are called incisors. 
Infraspinatus, (from infra, beneath, and spina, the spine.)

Inguinal. Appertaining to the groin.

Inosculation. The running of veins and arteries into one another.

\section{J}

Jugular. Belonging to the throat.

\section{L}

Labrum. The lip.

Lachrymal. Belonging to tears, or parts where they are secreted.

Latissimus. A term applied to a muscle, from its great breadth.

Levator. A muscle, the office of which is to lift up the part to which it is attached.

Longissimus. The longest muscles are so named.

Lumbar. Belonging to the loins.

Mamma. The udder.

Mastoid. Processes of bones are so named, that are shaped like a nipple.

Maxillary. Pertaining to the jaw.

Meatus. An opening that leads to a cavity, or canal.

Medulla. The marrow. The medullary substance within the cranium is called medulla oblongata.

Mesenteric. Belonging to the mesentery.

Molares Dentes. The twenty-four grinders of the horse are so named.

Mylo. Names compounded of this word belong to muscles near the grinders and tongue.

\section{$\mathrm{N}$}

Nasal. Belonging to the nose.

\section{0}

Oblique. A term applied to muscles, from their direction.

Occipital. Belonging to the back part of the head.

Olfactory. Belonging to the nostrils.

Omo. Names compounded of this word belong to muscles that are attached to the scapula. 
Opacity. The faculty of obstructing the passage of light.

Ophthalmic. Belonging to the eye.

Orbit. The two cavities in which the eyes are lodged are thus named.

Os. A bone.

\section{$\mathrm{P}$}

Palato. Names compounded of this word belong to muscles which are attached to the palate.

Papilla. Small eminences, as of the tongue. The teats are so named. Par Vagum. The eighth pair of nerves.

Parenchyma. The tissues.

Pectoral. Of or belonging to the chest.

Periosteum. The membrane that invests the bones:

Pharyngeal. Relating to the pharynx.

Pharynx. A muscular cavity at the back of the mouth.

Phosphate. A salt formed by the union of phosphoric acid and a saline base; hence phosphate of lime.

Phrenic. Belonging to the diaphragm.

Pisiform. Pea-like. A bone of the knee of the horse, and the wrist of man.

Process. An eminence of a bone.

\section{$\mathrm{R}$}

Rectus. Straight. Several muscles are so called.

Rccurrent, (so named from reflection.) Reflected.

Region. A part of the body.

Renal. Belonging to the kidney.

Reticular. Interwoven, like a net.

Retractor. A muscle, the office of which is to retract a part.

Rotator. A muscle, the office of which is to turn a limb.

\section{S}

Sacral. Of or belonging to the sacrum.

Scaphoid. One of the bones of the knee.

Semen. The seed, or prolific liquor of animals, secreted in the testicles.

Semilunar. Half-moon shape.

Scptum. A partition.

Serratus. So called from the saw-like appearance.

Sinus. A cavity, or depression.

Spermatic. Belonging to the testicle.

Spinal. Belonging to the spine, or back. 
Sterno. Names compounded of this word belong to the breast bone.

Styloid. Shaped like a pencil.

Sub. Applied to parts which lie under, as subcartilaginous, (under cartilage) subcutaneous, (under the skin.)

\section{$\mathrm{T}$}

Tarsus. Bones of the hock.

Tensor, (from tendo, to stretch.) A muscle, the office of which is to extend the part to which it is affixed.

Teres. Round, cylindrical.

Transversalis. Transverse.

Trapezium. A bone of the knee.

Tuberosity. Any unequal protuberance.

\section{V}

Velum. A veil.

Vena. A vein.

Vulva. The aperture to the womb. 


\section{DICTIONARY}

oF

\section{THE VETERINARY ART;}

SELECTED FROM WHITE'S COMPENDIOUS DICTIONARY, AND ADAPTED TO THE PRESENT STATE OF REFORNED PRACTICE IN THE UNITED STATES.

CONTAINING

PRACTICAL OBSERVATIONS

ON THE

DISEASES OF DOMESTIC ANIMALS,

AND EXPLANATIONS OF TERMS USED IN THE VETERINARY SCIENCE.

BY GEORGE H: DADD, M. D.

PRACTITIONER OF THE REFORMED VETERINARY SYSTEM OF MEDICINE AND SURGERY.

\section{BOSTON:}

PUBLISHED BY THE AU'THOR.

1850 . 



\section{DICTIONAR Y}

OF

\section{THE VETERINARY ART.}

AbDomen. That part of the animal usually denominated the belly. This cavity contains the intestines, or bowels, liver, spleen, pancreas, kidneys, \&c., and is separated from the thorax, or chest, by the diaphragm.

AвоRтіon. Miscarriage, slipping, or slinking foal or calf, warping. In mares, miscarriage is very generally caused by over exertion during the latter period of gestation. It is not unfrequently brought about by accidents at grass, such as falling in a ditch or hole, and struggling violently to extricate themselves. Kicks on the belly are by no means an uncommon cause of miscarriage ; for which reason, a mare, when near her time, should be kept by herself : after foaling she will require a few weeks' rest, in order to recover from the effects of parturition; and when first brought into work again, the services required of her should be very slight. Exposure to wet and cold will occasion miscarriage; also high feeding and want of proper exercise. Abortion is of more frequent occurrence in sheep than in mares, and is caused by fright, overdriving, and being worried by dogs, and by being kept in cold, damp situations, and on improper food.

Cows are particularly liable to the accident of warping, or slinking the calf. The common cause of abortion is improper feeding. The filthy, stagnant water they are often compelled to drink is likewise a serious cause, not only of abortion, but 
also of general derangement of the animal functions. Dr. White states that " a farm in Gloucestershire had been given up three successive times in consequence of the loss the owners sustained by abortion in their cattle : at length the fourth proprietor, after suffering considerably in his live stock for the first five years, suspected that the water of his ponds, which was extremely filthy, might be the cause of the mischief; he therefore dug three wells upon his farm, and having fenced round the ponds to prevent his cattle from drinking there, caused them to be supplied with the well water in stone troughs erected for the purpose; and from this moment his live stock began to thrive, and the quality of the butter and cheese made on his farm was greatly improved. In order to show," says the same author, "that the accident of warping may arise from a vitiated state of the digestive organs, I will here notice a few circumstances tending to corroborate this opinion. In 1782, all the cows in possession of farmer D'Euruse, in Picardy, miscarried. The period at which they warped was about the fourth or fifth month. The accident was attributed to the excessive heat of the preceding summer; but as the water they were in the habit of drinking was extremely bad, and they had been kept upon oat, wheat, and rye straw, it appears to me more probable, that the great quantity of straw they were obliged to eat, in order to obtain sufficient nourishment, and the injury sustained by the third stomach, in expressing the fluid parts of the masticated or ruminated mass, together with the large quantity of water they drank, while kept on this dry food, was the real cause of their miscarrying."

"A farmer at Chareton, out of a dairy of twenty-eight cows, had sixteen slip their calves at different periods of gestation. The summer had been very dry, and during the whole of this season, they had been pastured in a muddy place, which was flooded by the Seine. Here the cows were generally up to their knees in mud and water. In 1789, all the cows in a village near Mantes miscarried. All the land in this place was so stiff as to hold water for some time; and as a vast quantity of rain fell that year, the pastures were for a 
long time completely inundated, on which account the grass became bad: this shows that keeping cows on food that is deficient in nutrition, and difficult of digestion, is one of the principal causes of miscarriage." It is supposed that the sight of a slipped calf, the smell of putrid animal substance, is apt to produce warping. Some curious cases of abortion which are worthy of notice happened in the dairy of a French farmer. For thirty years his cows had been subject to abortion. His cow-house was large and well ventilated; his cows were in apparent health; they were fed like others in the village; they drank the same water; there was nothing different in the pasture; he had changed his servants many times in the course of thirty years; he pulled down the barn or cow house, and built another, on a different plan; he even, agreeably to superstition, took away the aborted calf through the window, that the curse of future abortion might not be entailed on the cow that passed over the same threshold. To make all sure, he had broken through the wall at the end of the cow-house, and opened a new door. But still the trouble continued. Several of his cows had died in the act of abortion, and he had replaced them by others: many had been sold, and their vacancies filled up. He was advised to make a thorough change. This had never occurred to him; but at once he saw the propriety of the counsel. He sold every beast, and the pest was stayed, and never appeared in his new stock. This was owing, probably, to sympathetic influence; and the result of such influence is as fatal as the direct contagion. (See Youatt.)

The usual symptoms preceding abortion are a sudden filling of the udder, and a loose, flabby, and sometimes swollen appearance of the genitals, which discharge a little red-colored fluid. The lancet and medicine have been resorted to with very little success. Both of them are decidedly injurious: the animal should be put into some dry, sheltered place by herself, and kept on boiled mashes and gruel for a few days.

Absorbents. Medicines that are given for the purpose of neutralizing acid gas, or acidity of the stomach, such as lime- 
water, magnesia, \&c.; yet the relief they afford is only temporary.

Absorbent Vessels. (See Absorption, part first.)

Absinthium. Common wormwood, used for the purpose of reducing swellings that have resulted from violence. Two ounces of wormwood are steeped in one quart of New England rum; if a limb of the animal is involved, the wormwood is then bound on with bandages, and the parts occasionally wetted with the fluid.

Acacia. Gum arabic, used as a demulcent and lubricant. In poisoning it is useful to sheathe the membranes of the stomach and alimentary canal, and will defend them from the action of drastic purges.

Acacia Catechu. Gum catechu. This is a powerful astringent : it is made from a tree that grows in Japan.

Acetabulum. The socket in which the head of the thigh bone is lodged.

AcIDs are distinguished by their sour taste; they readily combine with alkalies, producing effervescence.

Action. The gait of a horse, which depends on his powers and the mode of training:

Actual Cautery. Red-hot iron. (See Firing.)

Acure. A term applied to those diseases which are sudden in their attack and violence, accompanied with great pain.

Age. The age of a horse may be known by marks in the front teeth and tusks of the under jaw, until he is about eight years old, after which period it is a matter of guesswork; yet those who are expert can tell very near the exact age. There are many circumstances which tend to show whether a horse be old or not. The number of a horse's teeth is forty, - twenty-four grinders, and sixteen others, - by some of which his age may be known up to a certain period. Mares have only thirty-six teeth, as in them the tushes are usually wanting. A few days after birth, the colt puts forth two small front teeth in the upper and under jaws, and soon after two more : these are called nippers. The next four shortly afterwards make their appearance. The four corner teeth - as 
they are termed - come a few months after the last named. These twelve teeth, in the front of the mouth, are small and white, and continue without much alteration until the colt is about two years and a half old, when he begins to shed them. 'The two teeth that first make their appearance are the first that are lost, and are replaced by two others, called horse's teeth, considerably stronger and larger than those that have made way for them. Between the third and fourth year, the two teeth next the first fall out, and are in like manner replaced by horse's teeth. Between the fourth and fifth year, the corner teeth are changed; the tushes make their appearance. About the fifth year, the horse is said to have a full mouth. After this period, up to the eighth year, the age of a horse can, with some degree of certainty, be known by the cavities in the teeth, which at first are deep, but are gradually, by the process of mastication, worn down, and about the eighth year disappear. After the fifth year, the above criterion of age may be corroborated by the grooves in the tushes of the male, which are inside: they are two in number. At six, one of these cavities, viz., the one next the grinder, disappears; at seven, the other is considerably diminished, and at eight is, in most, but not always, entirely gone. After this period, the tushes become more blunt and round. The marks in the upper teeth are by some considered indicative of the horse's age; those in the two front teeth disappearing at eight, in the two next at ten, and in the corner teeth at twelve. The marks in the lower teeth will disappear about the eighth year.

As a horse grows old, he generally turns more or less gray; the cavities above the eyes become deeper; the under lip falls; the gums shrink away from the teeth, giving them the appearance of a greater length; the back becomes hollow, or curved.

Age of Neat Cattle is known by their horns. At the age of about two years, they shed their first fore teeth, which are replaced by others, larger and more prominent; about five, the early teeth are all replaced by the permanent ones. As 
the animal advances in years, these teeth wear down, the enamel disappears, and they assume a black or brown appearance. When three years old, a change takes place in the structure of the horns; after which period these appendages, like the permanent teeth, preserve the same character. After the third year, the horns continue to grow as long as the animal lives, and the age is indicated by the rings, or prominences, which are easily distinguished on the horn, and by which the age of the creature may be nearly ascertained, by adding three years to the number of rings.

Arring, in the management of horses, implies exercising them in the open air. (See Exercise, part first.)

Albuman. That part of the white of an egg which coagulates into a solid mass when boiled; it abounds in the bones, muscles, cartilage, hoof, hair, \&c.

Acсоноц. Rectified spirit. This is extensively used in medicine for making tinctures. With an equal quantity of water it is termed New England rum. Alcohol is a powerful irritant and caustic poison, to whatever part of the horse it is applied. If applied externally, it causes swelling, pain, and irritation; if given internally, it absorbs from the living parts the serous or watery portion, and condenses the fibrous structure. Alcohol diluted in any form, acts on the horse as a diuretic, causing the kidneys to secrete a large amount of urine, in consequence of which they became overworked, and finally diseased. It is used as a diffusible stimulant. The best substitute is warm ginger tea.

Alment. That which nourishes the system. (See FeedING, part first.)

Alknlies. There are different sorts: soda, potash, and ammonia, are alkalies.

Aloes. Obtained from the aloe plant. The aloes now in use as a cathartic for horses, cattle, and sheep are the Barbadoes. Pure Barbadoes aloes are of a dark brown color, present a rough appearance when broken, and have a disagreeable smell.

Alteratives. A class of medicines that act gradually and 
permanently upon the horse, by increasing the tone and vigor of the secreting, excreting, and absorbing system, without diminishing or destroying their power. (See Appendix.)

Acthes. Marsh mallows. 'Ihis plant is generally used in the formation of emollient drinks, as it contains a large amount of mucilage.

Alum. A mineral astringent, used to destroy proud flesh.

Amaurosis. A disease of the eye, generally causing total blindness. It may be known by the pupil being large and open; on passing the hand before the eye, the horse will not avoid it.

Anasarca. That form of dropsy that affects the whole, or nearly the whole system, or, in other words, an effusion of serum into the meshes of the cellular tissue.

Anastomosis. The communication of blood-vessels with each other, or their opening one into the other, by which means, when the passage of blood through an artery or vein is prevented by ligature, compression, or any other cause, the circulation is still kept up by means of the anastomosing vessels.

Anatomy. 'The science that teaches the structure of the animal economy.

Analysis. The resolution of compound bodies into their original or constituent principles.

Anchylosis. The loss of motion in a joint. There are two kinds, called complete and incomplete. In the former, the joint has grown together so as to be immovable; in the latter, some motion remains, and the rigidity is owing to the contraction and thickening of the ligaments. Anchylosis in the horse is not unfrequently a consequence of wounds or bruises; the latter, causing an absorption of the fluids that nourish the joint, anchylosis is the result. In bad spavins and ringbones, there is frequently anchylosis of the hock and pastern joints. The author's attention has lately been called to a case of ringbone that had been operated upon by some person totally unacquainted with the nature of the disease. 
The operation was performed in the most cruel and barbarous manner. The operator having never studied the anatomy of the parts, it could not be otherwise expected. On an examination of the animal, ossific or bony deposits were found inside the hind legs, in the form of spavin; deposits also existed on the cannon bones, and on the pasterns, thus proving that the disease was incurable; the general health was impaired, the knees sprung, and the animal was pronounced by the owner to be worthless; yet this specimen of inhumanity, the self-styled "doctor," had the audacity to state that he could perform a cure for the trifling sum of five dollars. The fact of his attempting to cure a constitutional disease by local means, under such unfavorable circumstances, shows that he was an ignoramus; and the barbarous manner in which he performed the operation shows that he was destitute of every particle of humanity. The author has digressed merely for the purpose of warning owners of domestic animals against trusting them, when diseased, in the hands of those who are unacquainted with their mechanism.

Aneurism. A tumor filled with blood, communicating with an artery. It usually occurs from rupture of one of the coats of the artery, and dilatation of the cellular coat : it is then denominated true aneurism. When an artery is wounded, and the blood escapes into the surrounding tissues, it is called false aneurism.

The general mode of curing aneurism is by tying a ligature around the artery; the coats of the artery become united, and part of the artery obliterated; the circulation is carried on by anastomosing vessels. (See Anastomosis.) Some aneurisms have been known to undergo certain natural changes, by which they have been spontaneously cured, thus proving that the vital power is more efficient "than an evil system of medication."

Anise Seed. A mild carminative. It is much used in veterinary practice, and is one of the ingredients in cordial balls.

Anodynes. Medicines that relieve pain, procure sleep, and lessen the irritability of the nervous system. 
Anthelmintics. Medicines that destroy worms, and are supposed to cause their expulsion from the animal. Many of the remedies recommended by veterinary writers would be more likely to kill the horse instead of the former; they are calomel, antimony, \&c. The proper method of preventing the generation of worms in the alimentary canal, is to pay attention to feeding, watering, \&c.

Antmony. A corrosive mineral poison. It has been extensively used in veterinary practice, and has entailed on the brute creation more diseases than it ever cured. There are numerous preparations of antimony, but they are all more or less destructive. Large quantities of this destructive mineral have been used on horses; yet in some cases, where there is vital power enough in the animal to dispossess it from the system, no immediate unfavorable results were observed. Yet it is an agent of such diversified therapeutical powers, that the wisest of the faculty have never ventured to prescribe and fix limits to its action.

Antiseptics. Medicines that correct and prevent putridity; the best and most efficient are charcoal, Peruvian bark, acetic acid, and bayberry bark.

Antrspasnodics. Medicines that are employed in spasmodic and convulsive disorders; the most efficient are assafœtida, pennyroyal, or any of the mints, such as spearmint, catnip. The most powerful in spasm, or lockjaw, are lobelia, warmth and moisture, castor, musk, ginseng, and Indian hemp, or milk weed.

Apoplexy. A disease which is often called staggers. (See part first.)

Arr. A term applied to the upper part of the fore leg.

Aromatics. Medicines that have a warm, pungent taste, and fragrant smell ; of this kind are cardamom seeds, cloves, and nutmegs, sweet flag, \&c.

Arsenic. A destructive mineral poison. It has been used in many diseases of the horse, without the slightest benefit. Dr. White states, "so various are its effects, that he has known a very small quantity to terminate fatally." It was 
formerly used as a local remedy in glanders; but as the disease is general, it could not possibly be cured by local remedies.

Arteries. For a description, see Circulation, part first.

Arteriotomy. The operation of opening an artery.

Ascites. Dropsy of the abdomen. (See Dropsy.)

Asтнма. Supposed to originate in the muscles of respiration. (See Covgh, Roaring, \&c.)

Astringents. Medicines that contract and condense muscular fibre. The principal are kino, catechu, oak bark, nutgalls, and bayberry bark.

Aтmosphere. The name given to an elastic invisible fluid which surrounds the globe; it is composed of oxygen, nitrogen, and a small portion of carbonic acid gas. In stables that are not ventilated, the vapor arising from the dung and urine combine with it, and render it unfit for respiration.

Atras. The first vertebra, or bone of the neck.

Атrophy. A wasting of the body.

Auricles. The two small cavities of the heart. (See HeArt.)

\section{B}

Backgalled. When accidents of this kind occur, the saddle or harness should be padded, or chambered, so as to remove pressure from the part; sometimes they are difficult to heal, owing to the presence of morbific matter in the system. (For treatment, see Appendix.)

Backraking. This is a name given by farriers to the operation of introducing the hand into the fundament, and emptying the rectum of its contents. The use of injections will, ere long, supersede this beastly practice. The most suitable injection to soften the fæces, is warm soapsuds.

Back Sinews. The flexor tendons of the fore and hind legs are so named. They are frequently strained, or otherwise injured, by over exertion, or accidents.

BaLl. Bolus, or large pill. The mode of giving a ball is by drawing out the tongue to the right side, and holding it 
in the left hand, while an assistant stands on the left side and holds the mouth open. The ball is to be held by the finger and thumb of the right hand, drawn into as small a compass as possible, and passed as far as the horse's throat. 'This must be done by a quick motion of the hand, which should be kept towards the roof of the mouth, as there is more room for it in that direction. The most safe and efficient method of giving medicine to either horses, cattle, or sheep, is in a fluid form.

Balsan. A name applied to several resinous substances, such as balsam of tolu, Peruvian balsam, balsam copaiba, \&c., Canada or fir balsam; the medicinal properties are stimulant and diuretic.

Balsam Copaiba, or Capivi, is used for chronic colngh; the dose is about one ounce.

Balsam of Sulpuur. A preparation made by boiling sulphur and olive oil together, until united in the form of a dark-colored tenacious mass. This has been much esteemed by old farriers in obstinate coughs. When mixed with a small proportion of oil of anise seed, it has been thought more efficacious, and is then named anisated balsam of sulphur.

Bandage. Strips of linen, cotton, or flannel, about three or four inches wide. They are serviceable in habitual swellings of the legs, in weakness of the fetlock joint. They are likewise used for the purpose of keeping on dressings, or assisting in uniting parts that are cut or lacerated ; they assist by pressure in expelling matter, or preventing the descent of ruptures, and as compresses for restraining bleeding, or hemorrhage. The mode of applying the bandage to the leg is as follows: the material, after being cut the proper width, must be rolled up, and the bandage fixed by taking two or three turns in the same place; after which the roller may be carried round spirally, taking care that every turn of the bandage overlaps about two thirds of the preceding one. When the inequality of the parts cause the margin to slack, it must be reversed, or folded over; that is, its upper margin must become the lower, \&c. A bandage should be mod- 
erately tight, so as to support the parts without intercepting the circulation, and should be so applied as to press equally on every part. In bandaging a horse's leg, the roller should be applied from the upper part of the hoof to the knee; in every case it is advisable to bandage from joint to joint, thus leaving the joint at liberty. When it is found necessary to bandage a joint, the bandage should be put on in the form of a figure 8 .

BARB. A general name for horses imported from Barbary. The barb, one of the most celebrated of the African races, is to be met with in Barbary, Tripoli, and Morocco; it seldom exceeds more than fourteen hands and a half in height. The barb requires more excitement to call out his powers than the Arabian; but when sufficiently excited, his qualities of speed and endurance render him a powerful antagonist to the Arabian.

Bark. This name is generally applied to several different species of Peruvian bark, the yellow and the red. The active principle of the yellow bark is an alkaloid principle, called quinæ, combined with a peculiar acid, called kinic, or cinchonic, in the state of an acid salt; besides these, it contains an oily and a yellow coloring matter, tannin, kinate of lime, and woody fibre. Their value in treating diseases of the horse, consists in their tonic and astringent properties. It should be given to the horse in the form of infusion; one ounce of powdered bark to a quart of boiling water. It is also useful to restore indolent ulcers to a healthy state. The best tonic for a horse is hydrastis Canadensis, (golden seal.)

Bar Shoе. A particular kind of shoe, which is sometimes used to protect the frog from injury; also in corns. (See Contraction, part first.)

\section{Bars of the Foot. (See Foot, part first.)}

Bars of the Mouth. Transverse ridges on the roof of the mouth; they are most conspicuous, or full, in a young horse. When swollen, or fuller than usual, the horse is said to have the lampas. (See Lampas.)

Basilicon. A digestive ointment, composed of equal parts 
of olive oil, yellow beeswax, and common resin, (or rosin.) These are to be melted over a slow fire, and stirred until the mixture is quite cool.

BAY. A bay color, in horses, is so named from its resemblance to dried bay leaves.

Biceps. The biceps is a double-headed muscle, which serves to bend a limb.

BrLe, or Gall. A bitter greenish fluid, secreted by the liver for the purpose of assisting digestion. In the horse there is no gall bladder, or receptacle for the bile; it passes directly into the duodenum, or first of the small intestines, a few inches from the stomach.

Bilrous. Diseases are called bilious, when they depend on a morbid state of the liver.

Bits. There are various kinds of bits in use; among them are the snaffle and curb. A snaffle may be either plain or twisted, but the latter is apt to make the mouth callous; it consists of two pieces, having a sort of hinge joint in the centre. When used for the purpose of breaking young colts, it should be made large, so as not to hurt the mouth. The form of the curb bit resembles somewhat the letter $H$. The bridle is fastened to the side pieces, which act as levers of different powers, according to the distance from the cross-bar, to which the bridle is attached. The humane man will never inflict unnecessary severity on the horse, and will avoid continual strain on the reins or bridle, which, aside from the torture they inflict, tend to render the horse's mouth callous. The best form of bit, and the most simple, is the stiff, arched bit. The anthor has seen a very fine specimen of this article, manufactured by Messrs. Hannaford \& Ilsley, of this city. 'The centre piece is large and curved; the checks are movable, and their upper ends curved outwards, which prevents their injuring the cheek bones. It is very important that a horse should be properly bitted; many docile horses are rendered stubborn and unmanageable, by having a bit that is too narrow. Many young horses are injured while they are teething, and the mouth is tender, by bearing too 
hard on the rein. The author would suggest a trial of an India rubber centrepiece, in such cases.

Bite of any rabid animal. In most works on veterinary science, the writers recommend excision, or cutting out the bitten part, and afterwards cauterizing with the firing iron; but this method is very unsatisfactory, and only puts the animal to unnecessary torment. The morbid matter from a rabid animal is generally taken up by the absorbents, sometimes in a few seconds, and the operation of cauterizing would then be of no avail. The treatment we recommend, is to dose the animal with a tea of lobelia; half a pound of the herb and seed may be steeped in two quarts of scalding water, and given in doses of half a pint, at intervals of an hour. A large poultice of the same should be bound on the bitten part, and kept in contact with the parts, by bandages, and the poultice renewed every six hours, until all signs of poisoning disappear. The animal should be kept on scalded shorts, in moderate quantities.

Black Water. This is sometimes a termination of red water. (See RED WATER.)

Bladper. The bladder is a musculo-membranous bag, situated, when empty, in the cavity of the pelvis. Its use is to contain the urine, which flows into it through the ureters, from the kidneys. It is divided into three parts, viz., the fundus or bottom, the body, and the neck. When full, the fundus of the bladder protrudes out of the pelvis, into the abdominal cavity; it then receives a covering from the peritoneum. Its other coats are an internal mucous membrane, and an external muscular coat, formed of two distinct sets of fibres; the one longitudinal, and the other circular. The former are thickest about the fundus, the latter about the neck or cervix, which, by this arrangement, is always kept closed, except during the time of voiding the urine. On opening horses that have died from accident, we sometimes find the bladder empty, and its muscular fibres so condensed, that it appears like a solid mass of small dimensions; such is the contractile power of its muscular coat, by which, with 
some assistance from the abdominal muscles and diaphragm, the urine is expelled. The author has opened several horses that have died from lockjaw, and found the bladder distended to its utmost capacity, containing about a gallon and a half of dark-colored fluid resembling coffee-grounds. In one case the muscular fibres about the neck of the bladder were lacerated by the over-distention and spasm of the neck of that organ. When horses are accustomed to drink too much water without being allowed to stale often enough at work, the bladder becomes overworked, and often paralysis, weakness, or local debility sets in, and the neck of the bladder becomes at length so relaxed as to be unable to offer sufficient resistance to the muscles that propel the urine into the urethra, so that it is constantly dribbling off as fast as it is secreted. This is termed incontinence of urine.

Sometimes the irritability of the bladder, in the latter case, depends on the acrimony of the urine; and whenever this is the case, attention to feeding, watering, \&c., will remove it. Diseases of the kidneys and bladder are accompanied with tenderness over the loins, and a remarkable stiffness of the hind legs. Whenever the bladder is distended with urine, recourse should be had to the catheter.

Palsy, or Paralysis, of the bladder is sometimes dependent on functional derangements, as stomach staggers, or injuries to the brain and spinal marrow. (For treatment, see the author's pamphlet.)

Blasting. When cattle or sheep are first turned into luxuriant pasture, after being poorly fed, they frequently gorge themselves with food, which, fermenting in the rumen, or paunch, so distends it with gas, that the animal is often in danger of suffocation. The symptoms are most distressing; and, unless relief be speedily afforded, death very commonly ensues. If the symptoms are very alarming, a flexible tube may be passed down the gullet : this will generally allow the gas to escape and afford temporary relief, until more efficient means are resorted to; these will consist in arousing the stomach and digestive organs to action, by stimulants and car- 
minatives, (see Carminatives, and counteracting the tendency to putrescence by doses of charcoal or lobelia. Some practitioners recommend puncturing the rumen, or paunch; but there is always great danger attending it, and at best it is only palliative, and the process of fermentation will proceed; the gas may escape, but the saterials that furnished it still remain. Youatt states, "A cow had eaten a large quantity of food, and was hoven. A neighbor, who was supposed to know a great deal about cattle, made an incision into the paunch; the gas escaped, a great portion of the food was removed with the hand, and the animal appeared to be considerably relieved, but rumination did not return : on the following day, the animal was dull; she refused her food, but was eager to drink. She became worse and worse, and on the sixth day she died;" thus proving that the remedy was worse than the disease.

When animals are blasted in a moderate degree, the carminative drink, and decoction of lobelia, will prove effectual. In all cases of hove, it will be advisable to give injections of warm water, to which add a handful of salt, and the same quantity of charcoal. As a means of preventing the blast, it may be remarked, that animals should never be turned into any nutritive pasture while the dew is on the ground, or after rain.

Bleeding. (See part first.)

Buemishes. They consist of broken knees, loss of hair, cracked heels, false quarters, splents, windgalls, spavins, \&c.

Burnd, Moon. A disease of the horse's eyes, which is supposed to be the forerunner of cataract, and often ends in total blindness.

Blindness. (See Ere.)

Blister Fuy. Cantharides, or Spanish fly, an acrid animal poison.

Bloodroot. Sanguinaria Canadensis, used to prevent the growth of fungus, or proud flesh, a substitute for caustic.

Blood Spavin. (See Spatin.)

Borax. A crystallized salt : when powdered and moistened 
with honey, it is a useful application for sore mouth and lampas.

Botrs. Short reddish worms which are often found attached to the horse's stomach. Mr. Clark says, "that botts are not, properly speaking, worms, but the larvæ of the gadfly, which deposits its eggs on the horse's coat in such a manner as that they shall be received into his stomach, and then become botts. When the female fly has become impregnated, and the eggs are sufficiently matured, she seeks among the horses a subject for her purpose, and approaching it on the wing, she holds her body nearly upright in the air, and her tail, which is lengthened for the purpose, carried inwards and upwards. In this way she approaches the part where she designs to deposit the eggs, and suspending herself for a few seconds before it, suddenly darts upon it, and leaves the egg adhering to the hair by means of a glutinous liquor secreted with it. She then leaves the horse at a small distance, and prepares the second egg; and poising herself before the part, deposits it in the same way; the liquor dries, and the egg becomes firmly glued to the hair. This is repeated by various flies, till four or five hundred eggs are sometimes deposited on one horse. They are usually deposited on the legs, side, and back of the shoulder - those parts most exposed to be licked by the animal : in licking, the eggs adhere to the tongue, and are carried into the horse's stomach in the act of swallowing. The botts attach themselves to the horse's stomach, and are sometimes, though less frequently, found in the first intestine. The number varies considerably ; sometimes there are not half a dozen, at others they exceed a hundred. They are fixed by the small end to the inner coat of the stomach, to which they attach themselves by means of two hooks. The slowness of their growth, and the purity of their food, which is supposed to be the chyle, must occasion what they receive in a given time to be proportionably small ; from which, perhaps, arises the extreme difficulty of destroying them by any medicine or poison thrown into the stomach." A large amount of opium, tobacco, and corrosive sublimate, sufficient to destroy 
the horse, have from time to time been given; and on opening the stomach, these animals have been found uninjured. "The presence of botts in the horse's stomach is not easily ascertained, as it is certain that great numbers have been found after death in the stomach, without appearing to have produced any kind of inconvenience to the animal while alive. It does not appear that any effectual remedy has yet been discovered for botts." Mr. Blaine says "that he has kept them alive for some days in olive oil, and in oil of turpentine, and that even the nitrous and sulphuric acids do not immediately destroy them. At a certain season of the year, they detach themselves from the stomach, and pass off with the excrement." A run at grass is the most effectual remedy.

Bowels. (See Absorption of the Chyle, part first.)

Bow-LEgGed. Defective conformation of the legs.

Box, Loose. A loose box, as it is generally called, is a place wherein a horse is turned without being fastened to the manger or rack; such a place is useful to turn a horse into when he is sick, or when the mare is about foaling.

Brain. The connection that exists between the brain and stomach by means of the eighth pair of nerves, or par vagum, is the cause of this important organ being often disturbed in its function. 'Thus it is that when the stomach is loaded with food, its function becomes deranged, and the brain is affected sympathetically. A diseased action is then set up, and all the functions become more or less deranged. A horse in this case will become dull and languid, and sometimes labor under symptoms of apoplexy. In consequence of this nervous communication between the stomach and brain, the latter organ is sometimes affected by the irritation of botts in the stomach. The best way to prevent apoplexy, staggers, \&c., is, by attention to diet, exercise, \&c. (See Feeding, ExERCISE, part first.)

Dropsy of the brain does not often occur to horses or cows; but sheep appear to be more liable to the disease than other quadrupeds. The symptoms of the disorder in horses are variable. "In one case there was a considerable degree of 
dulness and heaviness about the head; the pulse was not much affected, but there was loss of appetite. The animal appeared as if suffering much pain in the head, generally keeping it lower than the manger. These symptoms were followed by delirium, convulsions, and death. In another case, when probably the water had accumulated very gradually in the ventricles of the brain, the horse appeared to be free from pain, except when the circulation was hurried by brisk motion, when he would fall down in violent spasms, the fit seldom lasting but a few minutes. This horse, being of scarcely any value, was destroyed, and upon opening the brain, about six ounces of water escaped." Sir George Mackenzie has described two kinds of this disease, which sometimes happen to sheep: "the first consists of an accumulation of water in the ventricles of the brain; the otherwhich is most common - arises from animalculæ, called hydatides. In this case, the water is contained in cysts, or bags, unconnected with the substance of the brain, on which it acts fatally by pressure. Very soon after water has begun to collect, either in the ventricles or cysts, the animal shows evident and decisive symptoms of the disease. He starts, looks giddy and confused, as if at a loss what to do; retires from the flock, and sometimes exhibits a very affecting spectacle of misery."

BrEAKING. The breaking of young horses is a matter of great importance, and should never be intrusted to any one of a cruel or harsh disposition, as, under such a master, the very best tempered horse may be rendered vicious. They are often broken when much too young; they are often found racing at three, and in constant work before they are four years old. This is one of the causes of contracted feet and lameness, that are continually presenting themselves to our notice. Farmers in general put their colts to work too young; and although exercise may improve their growth and constitution, yet this advantage is more than counterbalanced by their being shod at a period when their foot is tender.

Breeding. (See Breeding, part first.) 
Bridue Hand. The left is called the bridle hand, in contradistinction to the right, which is termed the whip hand.

Broken Wind. The origin of broken wind is supposed to be a morbid secretion from the membrane lining the windpipe, bronchial tubes, and ramifications; the air-cells are sometimes ruptured, and the air is entangled in the cellular substance, or common connecting membrane. The bulk of the lungs is greatly increased, while their capacity for containing air is diminished. It is stated in Rees's Cyclopædia, under the head of broken wind, "that after opening more than ten broken-winded horses, their lungs were uniformly found emphysematous. (See Emprysema.) This complaint is generally considered incurable; but it may often be alleviated by constant attention to diet." The animal should be fed on shorts, and green food if it can be procured, and boiled carrots. When used, his exercise should at first be moderate, and he should never be exercised immediately after feeding. If the horse shows any disposition to eat the litter, a muzzle must be provided.

According to Mr. Richard Lawrence, "the most common appearance of the lungs in broken-winded horses is a general thickening of their substance, by which their elasticity is in a great measure destroyed, and their weight specifically increased. At the same time, their capacity for receiving air is diminished." Dr. White writes, "that he has examined the lungs of broken-winded horses without observing this general thickening of their substance: on the contrary, they have appeared superficially lighter and larger than in their natural state. Two horses were purchased for the purpose of making experiments, and so badly broken winded as to be useless. In the first, the lungs were unusually large, and there was a considerable quantity of air in the cellular membrane; but it was not ascertained whether the air had escaped from the air-cells, or had been generated within the common cellular membrane. The other horse was kept about a month in a field where there was no water and very little grass. When taken up, he appeared perfectly free from the disorder. 
He was shot; and upon examining the lungs, they had not the slightest appearance of disease." This proved the superiority of nature's remedies over those of man. The same author relates, that he purchased a broken-winded horse that was incapable of working. By allowing him only a small quantity of hay sprinkled with water, giving mashes, mixed with a small quantity of oats, and only a small quantity of water, taking care at the same time that he had regular and moderate exercise, his wind became gradually better, and afterwards was perfectly free from the complaint.

The author has examined the lungs of two horses which were said to be afflicted, for some time previous to death, with broken wind, without detecting a loss of continuity in their structure; neither was their specific gravity diminished. Dr. C. M. Wood, of this city, suggests that we call broken wind acute or chronic diaphragmitis. The author is inclined to think, that this would give a better idea of the disease.

Bronchia. (See Windpipe.)

Bronchoтомy. The operation of opening the windpipe for the purpose of producing artificial respiration, or to remove any substances that may have lodged in the upper part of the larynx.

Bunss are best treated by a mixture of equal portions of lime-water and linseed oil, the parts being frequently anointed with the mixture.

Burse Mucose. Mucous Bags, or Sacs. These are described as membranous sacs, containing a fluid similar to synovia, or joint oil, and interposed between tendons and the parts on which they move. In violent exertions these vascular membranes, which secrete and confine the synovia, are injured; hence we have windgalls, bog-spavin, \&c.

Butteris. An instrument used by horse-shoers for paring the horse's hoofs.

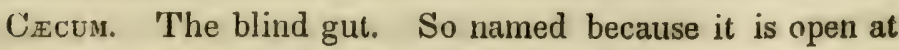


one end only. In the horse this part of the intestines is remarkably large.

Calf, Diseases of. Many of the diseases of the calves originate in a disordered state of the stomach, either from taking too much milk at a time, or from the milk not being sufficiently fresh, or being taken from a cow whose health is impaired. Whenever the stomach is disordered, either by the quantity or quality of the milk, it causes a variety of disorders, such as scouring, want of appetite, costiveness, colic, yellows, convulsions, \&c.

Calkins. A name given to the prominences on horses' shoes, which are turned downward for the purpose of preventing their slipping.

Calving. At the end of nine lunar months the period of the cow's gestation is complete; but the parturition does not exactly take place at that time: it is sometimes earlier, at others later. "One hundred and sixteen cows had their time of calving registered : fourteen of them calved from the two hundred and forty-first day to the two hundred and sixtysixth day, - that is, eight months and one day to eight months and twenty-six days; three on the two hundred and seventieth day; fifty-six from the two hundred and seventieth to the two hundred and eightieth day; eighteen from the two hundred and eightieth to the two hundred and ninetieth day; twenty on the three hundredth day; five on the three hundred and eighth day; consequently there were sixty-seven days between the two extremities. Immediately before calving, the animal appears uneasy; the tail is elevated; she shifts about from place to place, and is frequently lying down and getting up again. The labor pains then come on, and by the expulsive power of the womb, the fœtus, with the membranes enveloping it, is pushed forward. At first the membranes appear beyond the vagina or shape, in the form of a bladder of water: this soon bursts, the water is discharged, the head and fore feet of the calf are protruded (in natural labor) beyond the shape. The body next appears, and the delivery is complete. In a little time afterwards, some trifling 
pains take place, which separate the afterbirth, or cleansings ; and these being expelled, the process is finished.

When the membrane breaks, and the fluid escapes early in calving, and before the mouth of the uterus is sufficiently expanded, the process is often slow, and it is a considerable time before any part of the calf makes its appearance. The practice of hurrying the process by introducing the hand, or driving the animal about when symptoms of calving appear, is very improper. It has been known in many instances to cause the animal's death. It sometimes appears that a wrong presentation takes place, and renders the calving impracticable without assistance. In such cases it is necessary to introduce the hand in order to ascertain the position of the calf, and change it when it is found unfavorable. When, for example, the head presents without the fore legs, which are bent under the breast, it cannot, in this position, be well drawn away without danger. In this case the calf should be gently pushed back in the uterus, placing the cow in the most favorable position, and taking the opportunity for so doing while there are no pains nor straining. When the calf is pushed back, the fore legs are to be carefully drawn downward, in a line with the head, and brought out into the vagina. The author has known several cases, where parturition was seemingly difficult, of a resort to force in extracting the calf; but it should be recollected that nature is never to be interfered with in the process of delivery, or in any of her operations, unless it is clearly ascertained that assistance is necessary. When much force is used in drawing the calf, and especially if the animal be rather fat, a disease of the womb is apt to follow, and puerperal fever sets in, which often proves fatal. Great mischief is also done by endeavoring to extract the calf without regard to its position in the uterus : it is sometimes so placed that delivery is not practicable until the position of the calf is shifted. When much force is used in drawing the calf, it sometimes happens that the womb falls out or is inverted, and great care is required in putting it back, so that it may remain in its situation. In doing so, there is an advantage derived 
from placing the cow in such a position, that the hind parts may be higher than the fore. If any dust or straw remain about the womb, they should be carefully removed before the womb is put back. A linen cloth is then to be put under the womb, which is to be held by two assistants. The cow should be made to rise, that being the most favorable position, and the operator is then to grasp the mouth of the womb with both hands, and gently return it. When so returned, one hand is to be immediately withdrawn, while the other remains to prevent that part from falling down again. The hand at liberty is then to grasp another portion of the womb, which is to be pushed into the body like the former, and retained with one hand. This is to be repeated until the whole of the womb is put back; if the womb does not contract, friction with a brush around the belly and back may excite the muscles to contraction: should this fail, the animal may have an astringent and aromatic drink, made by infusing three ounces of ground poplar bark in about three pints of hot water; when cool, administer with a horn or bottle, taking care, while pouring down the cesophagus, to let it fall gently and gradually; by that means it will pass over the pillars of the æsophagean canal, and on to the third stomach; otherwise it would fall into the rumen, and defeat the object in view.

CалинHоR. A narcotic vegetable poison. This medicine, says Dr. White, "is employed both internally and externally. It is given inwardly as an anti-spasmodic, as in lockjaw, when it is commonly joined with opium; and as a febrifuge, or fever medicine, joined with nitre and antimonial powder." It is no wonder that Youatt and others say, "that the treatment of lockjaw in animals is very unsatisfactory ;" and that Gibson should confess, "that in the administration of these destructive agents there is great danger, and unless the horse is very strong, he may not recover from the experiment." The four articles above named are all more or less destructive, because they war against the living principle; part act as a sedative, and the others as chemical agents. Is it not the duty 
of every man to rescue from such a destructive system of medication one of the noblest and most valuable specimens of God's workmanship in the quadrupedal creation?

Professor J. A. Gallup, in his institutes of medicine, says, "The practice of using opiates and anodynes to mitigate pain in any form of fever and local inflammations, is generally to be deprecated; it is not only unjustifiable, but should be esteemed unpardonable." If these articles are destructive in the human being, they will prove more or less so in all organized beings, in proportion to the power that resists them. Although large doses of poison have occasionally been given to the horse without destroying him, yet they must sow the seeds of future disease.

Capped Hock. A swelling on the point of the hock, generally occasioned by blows : they seldom cause lameness ; but as they are a considerable blemish, an attempt should be made to reduce them by counter-irritants; friction is also useful.

Capsicum. In its pure state it contains tonic and stimulant properties. It increases the physiological or healthy action of the system.

Capsular Ligament. The ligament by which two bones are joined together. It forms a complete sac round them, and serves to confine the synovia, or joint oil.

Caraway Seeds. These are cordial and carminative. The dose is from one to two ounces.

CARBon. Pure charcoal, unmixed with any foreign body. It is antiseptic and absorbent; useful as a poultice in all putrid sores.

CARDitrs. Inflammation of the heart.

Caries. Ulceration, or rottenness of a bone.

Carminatives. Medicines that correct flatulency, or expel wind; the principal of these are the caraway and fennel seeds.

Carotid Artery. A large artery that runs on each side of the neck, near the windpipe. The jugular vein runs immediately over the artery. Yet at the upper part of the neck, 
they are at such a distance that there is no danger of wounding the latter in bleeding.

Cartilage. Gristle. A smooth, elastic substance attached to bones. Cartilages are situated in parts where elasticity is required; they render the parts connected with them capable of slight changes of form, and instant recovery, to accommodate themselves to accidents and circumstances, without serious injury to themselves. There are also inter-articular cartilages; that is, flat, smooth cartilages, between the ends of two bones. These, being covered with synovia, or joint oil, serve to facilitate the motion of the joint.

CAstor. A peculiar matter found in hags, near the rectum of the beaver. It is used as an antispasmodic, in doses of two drachms, (for a horse,) mixed in thin gruel.

Castration. An operation often performed on horses, and other domestic animals. The best method of performing it is by means of the clams and ligature.

Cataplasm, or Poultice. This application, when designed to promote suppuration, or formation of matter, is best made by mixing together equal parts of slippery elm and flax seed, pouring a sufficient quantity of boiling water on the mixture, to make it of the consistence of mush, and binding it on the part; the bandage should not be so tight as to interfere with the return of blood by the veins. A poultice should always be renewed every twelve hours.

Cataract. A disease of the horse's eye. A cataract may be partial or total. The partial cataract is known by specks in the pupil, which interrupt vision in proportion to their size, and according to their situation. In the total, or complete cataract, the whole of the pupil becomes of a white or pearl color. A horse's sight is least injured by partial cataract, when the speck is most remote from the centre of the pupil, and near to the upper margin. When a complete cataract takes place in one eye, the strength of the other becomes established, so that the horse soon accommodates himself to the loss.

Catarrh, or Cold. This is, perhaps, a disorder more com- 
mon in horses than any other. The author attrioutes this (in this city) to the bountiful use of the Cochituate water. When the horse has just arrived from a journey, or is in a state of perspiration, the showering process, so much in fashion just now, is decidedly injurious. If the legs of the animal are sluiced with water, and he is afterwards suffered to stand where a current of air blows on him, he is likely to take cold. Horses accustomed to warm clothing, and warm stables, are, of course, most liable to cold. The symptoms are cough, dulness, want of appetite, discharge from the nostrils, frequently accompanied by sore throat, and difficulty of swallowing.

Catarrh, Epidemic. The epidemic catarrh is so named from its spreading over a country as a general disorder, often for a considerable time. When the disease is so prevalent, it is supposed to depend on a certain state of the atmosphere.

Catheter. A gum elastic tube, for the purpose of drawing off the urine. The one used for the horse is about four feet in length.

Caustrcs. Preparations that destroy the part to which they are applied.

Cellular Membrane. The substance by which various parts of the body are united to each other. The cells of which this structure is composed, communicate with each other; which is proved by making a small opening in the skin of an animal, introducing a blow-pipe, and blowing through it, by which the adjacent skin will puff up; if sufficient power were employed, the air may be thus forced all over the body.

Cerebellum. The small brain. It is situated immediately behind the cerebrum, or large brain, and upon the origin of the spinal marrow.

Chest. (See Thorax.)

Chest Founder. (See Founder.)

Chronic. A term used to denote a disease of long standing, unaccompanied by fever or inflammation.

Chyle. A milky fluid, formed by the action of the gastric, 
pancreatic, and bilious fluids. Chyle is absorbed and carried by the lacteals to the thoracic duct; but, previous to its arrival there, it passes through the mesenteric glands, where probably it undergoes some change.

Cicatrix. The mark that remains after a sore, wound, or ulcer has been healed.

Circulation of the Blood. (See Heart.)

Cuipprang. Cutting the long, rough hair of a horse. It is chiefly done to improve the appearance of the horse. The author doubts its utility. (See article HaIR, part first.)

Clothing. A pernicious custom is often adopted of keeping horses clothed in the stable; making no difference in the warmth of the clothes, whatever the season of the year, or the state of the weather, may be. (This custom is not so prevalent here as in England.) In a good stable, it is probable that even in winter it might be dispensed with; and a horse will then be much less liable to take cold, when he happens to stand in a cold wind and rain. When a horse is moulting, or shedding his coat, light clothing might be useful ; and, at such periods, showering, or standing out in the rain, would be very injurious. In summer, the horse should have a net thrown over him to protect him from the flies.

Clysters, or Glysters. A liquid preparation, forced into the rectum by means. of a syringe. (For preparation of clysters, see APpendix.)

Coffin Bone, or Os Pedis. The bone which is enclosed by the hoof.

Coffin Joint. (See Hoof.)

Culic. A very common disease in horses. It begins with an appearance of uneasiness ; he paws his litter ; sometimes makes ineffectual attempts to stale; stamps with his feet; gathers up his legs, and lies down heavily, groans, and looks round to his flank; lies down heavily again, as before. and rolls on his back. The body sometimes swells. If relief is not promptly afforded, all the above symptoms gradually increase; the pulse becomes quick, the breathing disturbed, and the pain is so great that a violent perspiration breaks out 
and the horse becomes almost delirious, throwing himself about the stall, so that it is dangerous to come near him.

Condrion. The term is used to imply a horse being in perfect health.

Conjunctiva. The external coat or membrane of the eye. (See Ere, part first.)

Consunption. In consumption there is a gradual loss of flesh and strength, while the appetite is seldom impaired in the early stages. It is sometimes accompanied by a discharge from one or both nostrils, and a swelling of the glands under the jaw ; such cases are often mistaken for glanders. Consumption does not often take place suddenly, but is very insidious in its attack; and it often happens, that the complaint is not much noticed till tubercles are formed in the lungs, and the mesenteric glands are diseased. When a horse is observed to lose flesh, his coat staring, his skin feeling as if fast to the ribs, he should be warmly clothed, and fed on scalded shorts, oats, and boiled carrots; by proper attention to stable management, he may gain flesh and strength, his coat will become smoother, and his skin looser. Should it now be the season of the year when good grass can be procured, this will perfect the recovery.

Contagion. The mode in which a disease is communicated from one animal to another. It is derived from the word contact, or touch, and is used in contradistinction to infection, which implies the communication of disease by unwholesome miasmata, sometimes spreading to a very considerable distance.

Contraction. (See Contraction, part first.)

Convalescence. $\Lambda$ state of recovery from illness, or an approach to a state of health.

Convursions. Under this name Gibson has classed lockjaw and staggers. Modern writers treat of these diseases under their respective heads. Calves are subject to convulsive diseases, from indigestion, and the consequent formation of acid in the stomach. It is often occasioned by some bad quality in the milk they drink, when fed by hand. Taking 
too much milk will often bring on the disorder. Carminatives and tonics generally afford relief; after which, it is necessary to be more attentive to the future mode of feeding, giving a little gruel occasionally.

Condials. Medicines are thus termed that possess warm and stimulating properties, such as ginger, caraway seeds, anise seeds, \&c.

Connea. The outer transparent part of the eye.

Corner Teeth. The outermost of the front teeth are thus named.

Conns. (See part first.)

Cononet Bone. Os corona. The second of the consolidated phalanges of the horse's foot.

Cononex. The upper part of the hoof, where the horn terminates.

Corrosive Sublmate. Among the poisons that are given, with a view of curing disease, corrosive sublimate seems to stand foremost in the destruction of vitality, and the production of incurable diseases. Dr. White remarks, "It is necessary to observe carefully its effects; for, whenever it takes off the appetite, or causes uneasiness of the stomach, or bowels, it should be immediately discontinued. A solution of corrosive sublimate in water has been employed as a lotion in mange, but is generally considered dangerous; a fatal disorder of the bowels having, in several instances, followed its use. Five cows, that were bathed with a solution of corrosive sublimate in tobacco water, died soon after."

Cough. A cough is sometimes the first symptom of a cold, or catarrh ; but there is another kind of cough, which accompanies indigestion. Horses that eat too much hay, and drink a large quantity of water, often have chronic cough. This can be removed by proper attention to feeding. (See FEeDING.)

Cows, Disease of. The disorders of cows are not so numerous as those of the horse; they are often brought on by feeding on improper food, or by being kept on low, marshy grounds. Cattle that are brought from a warm to a colder 
climate, and such as are naturally of weak constitutions, are most liable to disease.

Cranr. A spasmodic affection of the muscles, either of a particular part, or of the whole body. In lockjaw, for example, the muscles of the jaw are at first chiefly affected; but, gradually, unless relief is afforded, the spasm, or cramp, generally extends to the neck, limbs, and at length to all parts of the body.

Crassamentum. Red globules, or coloring matter, of the blood, mixed with coagulable lymph.

Cremaster. A muscle which surrounds the spermatic cord, as it passes out of the belly into the scrotum. Its use is to suspend and draw up the testicle.

Crib Biting. A disagreeable and injurious habit, which some horses acquire; it consists of laying hold of the manger with their teeth. It generally proceeds from indigestion.

Cropping the Ears. The ear may be enclosed between the two parts of a carpenter's rule, which can be adjusted and held so as to give the ear any shape that may be required. All that part outside the rule is then cut off with one stroke of a sharp Innife, and then bathed with tincture of myrrh.

Crupper. A strap afixed to the saddle, with a loop at the end, for the purpose of admitting the horse's tail.

Cun. The food contained in the first stomach, or rumen, of a ruminating animal, which is returned to the mouth to be chewed at the animal's leisure.

Cumin Seeds. A carminative, or cordial.

Curs. A swelling of the horse's hock, generally caused by blows.

Cutaneous Diseases. Diseases whose seat is in the skin: as the mange, for example. They are generally dependent on a vitiated state of the secretions, and a disordered state of the bowels.

Cuticle, or Scanf Skin. A thin, insensible membrane, which covers and defends the true skin. It is this which forms the bladder raised by blistering. 
Curss. The skin, or hide, which lies under the cuticle. Besides the cuticle and skin, horses and other large animals have a muscular expansion, which lies immediately under the latter, called the fleshy panicle, by which the skin is moved, so as to shake off dust or flies, or any thing that hangs loose upon the hair.

Cutring. A horse is said to cut, when he strikes the inner and lower part of the fetlock joint, in travelling. The usual mode of correcting this, is to make the outer side of the shoe higher than the inside.

\section{D}

Debility. Debility may be permanent or temporary. In the first, the constitution is naturally weak, or has been rendered so by improper treatment, or sickness; the second generally arises from over-exertion, and, if the exciting cause be frequently repeated, terminates very commonly in a total decay of the constitution. Rest and kind treatment are the best cure for weakness induced by fatigue. The greatest attention should be paid to the degree of work that a horse is capable of enduring, as what may be salutary for him at one period may greatly exceed his strength at another; and this generally depends on the mode of stable management. The common practice of working horses too early frequently results in debility.

Decoction. The process of extracting the virtues of a substance by boiling it in water. The liquid so prepared is termed decoction. Almost all the medicinal properties of plants may be extracted by pouring boiling water over them. In boiling they lose their volatile properties.

Deglutition. The act of swallowing. The power of swallowing is often impeded in the horse by sore throat, distemper, \&c. This impediment is only of a temporary nature ; but there is another, which is of a more serious kind, and interferes with mastication, as well as swallowing. The grinding teeth of horses often wear down in such a manner, 
that the outside edge of the upper grinders irritates or wounds the cheek, and the inside of the lower grinders acts similarly upon the tongue, or the skin connected with it. Whenever a horse is observed to void unbroken oats with his dung, the teeth and cheeks should be examined. It will often be found necessary to rasp the outside edges of the upper grinders, and sometimes the inner edge of the lower ones.

Demulcents. Medicines of a mucilaginous kind, which sheathe the mucous membranes when they are tender and irritable, and defend them from the action of what would otherwise injure them. Of this kind are marsh mallows, linseed tea, solution of gum arabic.

Dentition. The act of changing the teeth, which is going on from the third to the fifth year. During this period, the horse's mouth is apt to become tender, which renders it necessary to keep him for a short time on scalded shorts, or boiled carrots.

Diabetes. An excessive discharge of urine, accompanied by thirst and debility. There are three outlets for the fluids of the body - the surface, the lungs, and the urinary passage. When either is deficient in action, one of, or both the others, must make up that deficiency; so, excess in one produces deficiency in the others; hence, in diabetes we often find a dry skin and staring coat; and in excessive perspiration, the urine is scanty, whatever be the organs affected, or whether the one or the other be excessive or diminished. The indications are, to equalize the action of these opposing or sympathizing surfaces, by restoring the diminished secretions, and cleansing and toning the organ whose action is excessive. All direct efforts to produce specific effects, without regard to a balance of action through the whole animal, do more harm than good.

Diapholnetics. Medicines that promote insensible perspiration, or excite moderate sweating. Of this class are lobelia and thoroughwort, given in infusion.

Dinphragm, Midriff, or Skirt. A muscular and tendi- 
nous expansion, which divides the cavity of the chest from the abdomen, or belly.

Diarriea, or Purging. In Professor Percival's lectures on diarrhœa, he states that "fol" the majority of cases brought to us, we are indebted to the groom, the farrier, and stablekeeper, who used to kill many horses by literally purging them to death. Thirty years ago, an ounce and a half or two ounces of alces, occasionally combined with one or two drachms of calomel, composed the common purge ; and even now, among these people, nine, ten, and eleven drachms are by no means unusual doses. Young horses, on their first arrival in the metropolis, are all physicked; they have given to them, indiscriminately, doses of aloes, every one of which would be sufficient to purge two of them; the result is, that the light-carcassed, irritable subject is carried off at once by superpurgation, while another, or two, may linger in misery and pain from a dysentery that will end in gangrene and death, or be rendered more speedily fatal by the doses of opium, or some other powerful astringent, * which are so perniciously resorted to on these occasions. There is another not uncommon cause of this disease, and that is continuous and excessive exertion. After having been ridden for many hours, a horse will often express irritation in the bowels, by frequently voiding his excrement, which will be found to be

* Suppose the groom, farrier, \&c., do give opium, are they not following in the footsteps of their great prototype, viz., Allopathy? By-the-by, Cullen tells us, "that opium is a narcotic and sedative, and that the natural tendency of such articles is to depress the vital powers, and deprive all parts of sensibility." He supposed, that when a sedative was applied in a moderate dose, the "vis medicatrix" took the alarm in order to throw off the noxious application, and that thus arose those peculiar symptoms of increased action; but when the dose was given as above, "in fatal doses," ne contended that the conservative power of the system was silenced, and unable to offer any salutary resistance. From this we infer, that if you cut off a horse's tail it proves salutary, and excites; but if you knock his brains out, it proves sedative. The true plan is to give antispasmodics, combined with charcoal and slippery elm, remove obstructions, invite action to the surface, \&c. This is the true effect to be produced, and the only justifiable one. 
enveloped in a slimy or mucous matter, that is called by some molten grease."

Dilutents. Those substances that increase the fluidity of the animal economy. Water may be justly considered as the only dilutent.

Director. A grooved instrument, made for the purpose of conducting the knife in open sinuses, and in several other operations of surgery.

Dislocation. A displacement of a bone from its socket. $A$ dislocation of the fetlock joint may be replaced, and kept in its position by bandages; the horse should not take any exercise until it is completely healed. A dislocation of the stifle, or patella, must be reduced by bringing the horse's leg under the belly, and then depressing the outer angle of the patella, or stifle bone, with the hand, which gives the muscles the power to draw the bone into its place. Generally speaking, dislocations are rare.

Distemper. This name is applied to diseases that prevail at particular periods, and spread to a considerable distance. (See Epidemic.)

Docking. Cutting off part of the tail. If this is ever necessary, (and the author doubts it,) then the operation should be performed before the animal is two years old.

Drastic. A term applied to purgatives that operate powerfully.

Drenches, or Drinks. When it is necessary that any medicine should operate speedily, this is the best form in which it can be given. A bottle, with a short neck, is the best drenching instrument. In giving a drench, the tongue should be at liberty, the head moderately elevated; the drench is then poured down moderately. The head is to be kept in an elevated position until the drench is swallowed. If the animal happens to cough while the drench is in his throat, the head should be immediately let down.

Dressing. A term employed to designate medical applications to a wound, or ulcer, and the operation of cleaning a horse. 
Dropsy. This disease consists in a collection of serous or watery fluid, either in cavities, as the chest, belly, or ventricles of the brain, or in the cellular membrane under the skin. Dropsy is more a symptom of disease than a disease itself; but sometimes, on account of the violence and danger of the symptom, it is often treated as a disease. The proximate cause is a check to perspiration; the remote cause is bleeding, or any thing that can debilitate the general system.

Dropsy of the Chest. This is sometimes a consequence of disease of the lungs; and when it happens, those important organs generally are so far disorganized, or injured, that there is very little chance of the animal's recovery.

Dropsy of the Belly, or Ascites. The causes are the same as above; the only difference is, that, from circumstances predisposing the fluid is determined on the peritoneum, (see Peritoneum, ) instead of the pleura.

Duct. A membranous tube, or canal, through which certain fluids are conveyed. Thus the lachrymal duct conveys tears from the eyes to the nose.

Durg. By examining a horse's dung, we are enabled to judge of the state of his health. When the dung is hard, and in small knobs, and covered with slime, laxative medicines are beneficial; and when it is passed in too great quantities, it commonly arises from too liberal allowance of food. If oats are voided whole, it will generally be found to be caused either by a defect of the teeth, or by a too voracious appetite, occasioning the food to be swallowed without mastication; in which case the animal should be fed on shorts, or scalded food.

Duodenum. The first intestine that comes from the stomach. (See Intestines.)

Dura Mater. A strong membrane that invests the brain and divides it into two lobes. It likewise separates the large brain (cerebrum) from the small, or cerebellum. 


\section{$\mathrm{E}$}

EAR. The horse's ear is merely an organ for collecting sound ; consequently he has complete power over the muscles attached to them, and can turn them in different directions.

EFfluvia. Invisible vapors that arise from bodies.

Effusion. The oozing out of serum, or coagulable lymph, from the blood-vessels.

Embrocation. A liquid preparation for rubbing upon the skin, and generally used for strains, bruises, and enlarged glands.

Emetic, Tartar. Tartarized antimony. A corrosive metallic poison. Dr. White relates, "From examining the stomachs of horses that have taken this mineral, I am satisfied that irreparable mischief may be done with it, and certain it is that a vast deal of unnecessary pain has been thus inflicted."

Expнгsema. Swellings which contain air. Such swellings are known by a kind of crackling noise, or sensation, when they are pressed with the finger.

Emulgent Arteries. The arteries which convey blood to the kidneys.

Encanthis. A disease of the inner corner of the eye.

Encysted. A term applied to tumors which consist of a solid or liquid substance, contained in a sac, or cyst.

Enteritis. Inflammation of the bowels. This is only a symptom of disease, and is the result of plethora, or the sudden application of cold to the surface, the overloaded state of the stomach and bowels. Obstinate spasm will produce it.

Epidemic. Diseases which spread over a whole country at certain seasons, or any time. If many suffer in the same manner, it is called epizootic. There are very few diseases which assume, in its latter or earlier stages, such a variety of forms; perhaps depending on the location, and the peculiar state of the constitution. Youat writes, "In 1711, an epidemic commenced, which, although it sometimes suspended its ravages, would visit new districts; it also appeared in a 
certain district, and confined itself to that location. In 1747 , it appeared, and would seem that there was a strange caprice about it. It would select its victims, the best of the herd, around a certain district, and confine itself to that location for a short time; then disappear for several months, return, and pounce upon this privileged spot. In some districts, it would attack the mouth and throat; commencing with a loss of appetite and difficult respiration, terminating with a discharge of blood from the anus. Sometimes the animals will eat and work until they suddenly expire; others will linger in dreadful agony." It appears that this malady is not infectious; for the same author writes, "Cattle were in the same barn as those infected; they ate of the same fodder that the distempered beasts had slavered upon, drank after them, and constantly received their breath and steam, without being the least affected. In 1756, it assumed a different form; some cattle were taken all at once with violent trembling of every limb, and blood ran from the nose, and bloody slime from the mouth, and the animals died in a few hours."

Epiglottis. The cartilage which covers the larynx, or top of the windpipe, at the time food or water is passing into the gullet.

Epilepsy. Falling sickness; fits. Horses, cats, and dogs, are subject to fits, which often depend upon an accumulation of water in the ventricles of the brain, or upon the irritation of worms in the stomach or bowels. During the present year, the author's attention was called to a horse, (the property of Mr. Downs, of this city;) the horse was lying down, and at times appeared insensible; convulsive struggling would take place occasionally. The muscles of the eye were affected by spasm, and distorted; the duration of the fit varied. As the disease progressed, the hind extremities were paralyzed, and the horse would struggle violently at intervals of fifteen minutes. On an examination, after death, nearly a peck measure full of the long round worm was found in the small intestines. The author examined the brain of a horse that was said to die in a fit, and found about five ounces of water 
in the ventricles of the brain. The fits in horses do not exactly resemble the fits of the human body.

Epitaxis. Bleeding at the nose. This sometimes occurs in glanders, and denotes a considerable ulceration within the nostrils. When it happens to a horse in health, it shows an unequal circulation of the blood.

Epsom Salts. Sulphate of magnesia. A neutral salt, often employed as an aperient for cattle; but it is very uncertain in horses, and is apt to gripe sadly.

Eschar. A slough formed by the application of caustic.

Excrescence. Any preternatural formation on any part of the body, as warts, wens, splents, spavins, \&c.

Exercise. (See part first.)

Exostosis. An osseous tumor originating from a bone; such as splent, spavin, ringbone, \&c. Perhaps no animal is more subject to this disease than the horse; and in no department of the veterinary science is there a greater need of reform than in the treatment of the disease now under consideration. Almost every man who knows any thing about a horse can detect a spavin, \&c.; but not one in a hundred can tell any thing about the true nature of the malady, or the indications to be fulfilled in the treatment; and in consequence of a lack of knowledge on this subject many a poor animal has suffered immensely, who, if he was not deprived of the power of speech, would make the ears of his oppressors tingle with a tale of man's barbarity and inconsistency.

The bony structure, being composed of vital solids, although studded with crystallizations of saline carbonates and phosphates, is liable, like other parts of the structure, to take on preternatural or morbid action, and may result from or accompany constitutional idiosyncrasies, resulting from hereditary taints on the side of the dam or stallion. The most frequent causes of splent, spavin, \&c., are undue acts of exertion on hard pavements, and the imposition of weight disproportioned to the strength of the animal: young horses are particularly liable to exostosis when severely worked or overburdened. Any sudden or extraordinary efforts in backing 
or suddenly pulling up at full speed, racing before the horse shall have arrived at maturity, while the joints are yet in a state of imperfection, very frequently lay the foundation of exostosis. The parts being sprained and taxed beyond endurance, disease is excited in the ligamentous substance, and extends itself to the periosteum and bones; the ligaments often become ossified, and are rendered fixtures; the periosteum, being raised by bony accumulations, presents itself in the situation of splents, spavin, or ringbone.

Sir A. Cooper divides exostosis, in reference to its seat, into two kinds - periosteal and medullary; and again, as to its nature, into cartilaginous and fungous. "But," says $\mathrm{Mr}$. Percival, "it is to that kind only which is situated between the shell of the bone and the periosteum covering it, that we have to attend in veterinary practice. On dissection we find the periosteum thicker than usual, with cartilage beneath it, and ossific matter within the cartilage, extending from the shell of the bone nearly to the internal surface of the periosteum, still leaving on the surface of the swelling a thin portion of cartilage unossified."

When the accretion of these swellings ceases, and the disease has been of long standing, they are found to consist on their exterior surface of a shell of osseous matter similar to that of the original bone; consequently, when an exostosis has been formed in the manner here described, the shell of the original bone becomes absorbed, and cancelli are deposited in its place.

"In the mean time, the outer surface of the exostosis acquires a shell resembling that of the bone itself. When the exostosis has been steeped in an acid, and by this means deprived of its phosphate of lime, the cartilaginous structure remains of the same form and magnitude as the diseased deposits ; and as far as I have been able to discover, it is effused precisely in the same manner as healthy bone.

"An exostosis, abstractedly considered, does not appear to occasion much inconvenience to the animal, except in the early stages. A ringbone, confined to the pastern bones, is of little consideration; but should it show itself at or near 
the joint, it seldom fails to produce lameness, which is often of a permanent nature. Lameness, therefore, is not an invariable symptom of exostosis; for most splents, and many ringbones, and even spavins, exist without lameness. When this disease invades ligamentous structure, however, lameness generally accompanies it - an effect we would refer to the excessive tenderness of the part. Should the tumor interfere, either from its bulk or situation, with the motions of joints, muscles, or tendons, lameness is a concomitant, and often irremediable symptom."

It appears that various constitutional and local remedies have been tried for the prevention and dispersion of exostosis, viz., " the actual cautery, ammonia, cartharides, caustic, and setons." The constitutional remedies are of the same destructive nature, and have but too often aggravated that which they were intended to relieve: we do not believe that any specific treatment has ever had the honor of curing these forms of disease; that course of treatment we have ever found the most satisfactory that is calculated to promote the general health by sanative means; we cleanse the system, equalize the circulation, and excite healthy action to the parts by stimulants and counter-irritation, (if the parts are inactive;) poultices, fomentations, \&c., if there is pain, or increased action. If this is done early, exostosis is easily arrested, unless an hereditary taint is manifest.

"The removal of exostosis by an operation, we are told, has been performed with success, and no doubt there are cases in which it may safely be performed; yet it cannot be successful on spavined horses, the natural termination of spavin being anchylosis of the bones of the hock, and interarticular cartilage: a knowledge of this fact has led men to suppose that Nature has turned a somerset; and they endeavor to set her right with the firing iron and the implements of death;. whereas, if her intentions were aided, the result would prove more satisfactory.

Fxtravasation. The escape of blood or other fluids from their proper vessels.

ExE. (See part first.) 


\section{F}

Falling of the Yard or Penis. This disease sometimes happens to horses and bulls, in consequence of swelling, excrescence, and ulceration of the parts, sometimes of an obstinate or malignant nature. It may also be occasioned by too frequent sexual intercourse. It may also depend on weakness of the part; and when this is the case, there is no ulceration nor excrescence about it. If it depend on debility, then tone up the whole animal, and wash the parts, first with Castile soap, then with cold water. If it result from ulceration, wash with weak vinegar and water, afterwards with a mixture of powdered charcoal and water. The latter may be thrown up the sheath with a common syringe or injection pipe. When the ulcers show a disposition to heal, a little powdered bayberry bark will generally complete the cure. When excrescences form on the sheath or inside of it, they should be taken off by applying a ligature tight around their base.

Farcy. A disease of the lymphatics or absorbent vessels, Its most usual form is that of small tumors, or buds, as they are termed, which make their appearance in different parts of the surface, gradually become soft, or suppurate, and burst, and become a foul ulcer. Its cause may be found in any thing that will derange the general system, or produce debility; its proximate cause is immoderate work, inattention to diet, hot unhealthy stables, sudden changes of temperature, standing on filthy litter, \&c.

Fattening. (See part first.)

Fauces. That part of the throat which lies behind the tongue.

Feeding. (See part first.)

Femoral Artery. The principal artery of the thigh.

Femur, or Os Femoris. The thigh bone.

Fetrock. A lock of hair at the lower part of the fore and hind legs.

Fetrock Joint. (See Foot, part first.)

Fever is a powerful effort of the vital principle to remove 
all obstructions to ordinary and proper action. The reason why veterinary practitioners have not ascertained this fact heretofore is, because they have been guided by the false principle that fever is disease. Let them but receive the truth of the definition we have given, then the light will begin to shine, and medical darkness will be rendered more visible.

Fever, we have said, is an effort of the vital power to regain its equilibrium of action through the system, and should never be subdued by the use of agents that deprive the organs of the power to produce it. Fever will be generally manifested in one or more of that combination of signs commonly given as a description of fever, viz., increased velocity of the pulse, heat, redness, pain and swelling, thirst, obstructed surface, \&c., some of which will be present, local or general, in greater or less degree, in all forms of disease. In what is called acute attacks, these signs are very manifest : in chronic cases, they are often faint; but still they exist. When an animal has taken cold, and there is power enough in the system to lieep up a continual warfare against obstructions, the disturbance of vital action being unbroken, the fever is called pure, or unbroken. The powers of the system may become exhausted by efforts at relief, and the fever will be periodically reduced: this form of fever is called remittent. It would be asburd to expect that the most accurate definition of fever would correspond, in all its details, with another case, as to expect all animals to be alike.

There are many agents that obstruct vital action, and many an organ to be obstructed, which some have classed as distinct fevers; for example, milk fever, puerperal fever, symptomatic, typhus, inflammatory, \&c. Our system teaches us that there is but one cause of fever, viz., the natural motive power of the system, and but one fever itself, viz., accumulated vital action; hence the treatment must be physiological.

Veterinary Surgeon Percival, in an article on fever, says, "We have no more reason, not near so much, to give fever a habitation in the abdomen, as we have to enthrone it in the head; but it would appear from the full range of observation, 
that no part of the body can be said to be insusceptible of inflammation [local fever] in human fever, though, at the same time, no organ is invariably or exclusively affected. All I wish to contend for is, that both idiopathic and symptomatic fevers exhibit the same form, character, and species, and the same general means of cure; and that were it not for the local affection, it would be difficult or impossible to distinguish them. When we come to examine the accounts of different authors on fever, and compare them one with another, we can hardly refrain from coming to the conclusion that their descriptions were originally derived from human medicine, and have been but variously modified to suit the prevailing doctrines of the day; they have gone through a system of imaginary fevers, and regularly transferred the observations and language of ancient authors upon diseases of the human species to the constitution of quadrupeds."

In the treatment of disease, and when fever is present, manifested by a determination of blood to the head, the object is to invite the blood downward and outward; or, in other words, equalize the circulation by warmth and moisture externally, as in lockjaw, (which see, part second ;) mix a tablespoonful of alterative powder (see ApPendix) in an antispasmodic drink, (see Artispasmodics;) continue the drinks as occasion may require; rub the legs diligently with a brush; if they are still cold, anoint them with stimulants, (we use horse liniment; tincture of capsicum will answer if the liniment is not at hand.) Bandage the legs with flannel, if the weather is cold ; this diverts the action of the available vital force to the surface and extremities; when this is accomplished, a tea of thoroughwort will arouse the topidity of the bowels. Injections must not be overlooked.

If disease assumes a malignant or putrid type, substitute distemper powder for alterative, and combine with antispasmodic drinks ginger and capsicum, in small quantities. There is no danger in the administration of the latter, either in malignant or epidemic disorders.

In neat cattle. should fever be present, the eyes appear dull 
and watery, the muzzle dry, and rumination has ceased : then the blood, for want of room in the nutritive tissues, is forced upon the lungs, liver, spleen, brain, or other glandular tissues, and men have named the disease congestive fever. The author advises the reader not to feel alarmed about the fever, but set to work and relieve the oppression by the same means as above. Disease of the bowels, garget of the head and udder, will require fomentation and stimulants to the parts.

Filly. A name given to a mare until she is two or three years old.

Film. Opacity of the cornea. (See Ere, part first.)

Filtration. Straining liquids through unsized paper; also through sand or porous stone.

Firing. A severe operation often performed on horses, for spavins, curbs, ringbones, \&c. Such barbarity should never be practised: it is a disgrace to this age of improvement. When discoveries are leaping on discoveries, and medical reform has germinated, shall we not permit the poor dumb brute to share the benefits of our investigations? Every man who loves a horse, or wishes well to the cause of humanity, will say that a more safe and effectual system of veterinary practice is necessary to rescue from the torture of the firing iron one of the noblest and most valuable quadrupeds in the world.

"The rage of firing is very generally, and much too frequently adopted, and no doubt, upon most occasions, hurried on by the pecuniary propensity and dictation of the interested operator, anxious to display his dexterity, or, its Scrub says, 'his newest flourish' in the operation; and when performed, and the horse is turned ont to grass, if taken up sound, I shall ever attribute much more of the cure to that grand specific, rest, than to the effects of his fire." (See Taplin's Farriery, p. 83.) Hence the firing iron, like all other destructive agents, excites the system to rally her powers and resist the encroachments of disease; yet the process is like taking a citadel by storm; the breaches that are made by the weapons of warfare (such are the firing iron, scalpel, lan- 
cet, and poison) can be traced, and leave unmistalrable evidences of their encroachments. Instead of provoling the vital powers to action by such destructive enginery, we should afford Nature all the aid we can, but never interfere with her operations.

Fistula of the Withers. "An obstinate disease of the horse's withers, or points of the shoulder, commonly produced by a bruise of the saddle." No wonder Dr. White calls it "obstinate," when the following treatment is recommended by him. "The scalding mixture - it consists of any fixed oil, (as lamp or train oil,) spirit of turpentine, verdigris, and corrosive sublimate. These are put into an iron ladle, and made nearly boiling hot; and in this state the mixture is to be applied to the diseased parts, by means of a little tow fastened to the end of a stick! It is necessary to prevent the mixture from flowing over the sound parts, as it would not only take off the hair, but cause ulceration of the skin." If this mixture will produce diseased action in the sound parts, we need not ask what will be the result when applied to parts already diseased. The author has cured many cases of fistula, by treating them as common abscesses, with the application of stimulating antiseptic and tonic poultices, (see Poultices,) and by a purifying course of treatment, with proper attention to diet, \&c.

Fleam. An instrument with which horses and cattle are bled.

Flesh. A common name for the muscles of the body.

Flexor Muscles. The flexor muscles are those that bend one bone upon another. The muscles that serve to bend the leg, for example, are named flexors.

Fonling. The bringing forth young in mares is not so often attended with difficulty as in cows, and they have seldom occasion for assistance. They should be placed in a situation where they may have shelter, and where they are free from danger.

Fomentations. Fomentations are generally made by pouring boiling water on camomiles, burdock, poplar bark, \&c. For an emollient fomentation, ground slippery elm is preferred. 
In inflammation of the bowels, for example, it may be fomented with flannels wrung out in a thin mixture of slippery elm.

Fоот. (See part first.)

Foot Rot. This name is applied to a disease in the feet of sheep. This disease often happens to such as are fed in low meadows, or where the grass holds the frost or cold dews for a considerable time. Probably a foul habit of body may be a predisposing cause. In the treatment of foot rot, we should endeavor to find out the cause, or causes, of the disorder, and change the food or location of the sheep. If the disease is spread under the horny covering, all the superfluous horn should be carefully pared away, so that the dressing may be applied to the whole of the affected parts. The dressing is composed of powdered lobelia, formed to the consistence of paste, with honey.

Foul Feeders. Horses are so named that have depraved or vitiated appetites, eating foul litter and earth from the ground.

Founder. A term expressive of the different forms of rheumatism in the horse. Veterinary writers describe three different forms of this disease, viz., founder of the body, chest, and feet. This is one and the same disease, only located in different parts, and may arise from the same general causes; which consist in chilling the animal when exhausted, by which means the perspiration is obstructed, by much fatigue, and by violent and long-continued exertion: exposing the animal to cold wind or rain, or washing his legs and thighs, and sometimes his body, is often the cause of founder. Dr. White calls "founder a term expressive of the ruined state of the horse." And well he might call it "ruined." How many thousand animals have been ruined, not by the disease, but by the treatment! Here is a specimen of it. Dr. White says, "The horse was bled before I saw him: five quarts of blood were taken off. I desired he might be bled again, when half a pailful more was abstracted. In less than an hour I saw him again, and, finding that he was not relieved, took another half pailful, amounting in all to 
four gallons! The horse was sent home, and seemed to be doing well in a straw yard, though very weak and thin. [No wonder, after such a loss sustained by the vital powers.] At the end of three or four months, he began to lose his fore hoofs, and after declining some time longer, he died "- - a victim to science. It is evident from experience and facts, that the above treatment renders the disease incurable, and is the true cause of death; therefore, not suitable to the true ends to be accomplished. What, then, are the true ends to be accomplished? To relax muscular structure, determine action to the surface, improve the secretions, and remove obstructions which disturb or repel vital action. This will equalize the circulation of the blood, when it will be found that there will be no necessity for diminishing its quantity. The inflammation, as it is termed, is always sufficiently controlled when the circulation of the blood is free and universal. Therefore we of the reformed school, instead of withdrawing vital action, promote its equal and universal diffusion.

FroG. The back part of the bottom of the horse's foot.

\section{G}

Galbanum. A gum -resin, sometimes employed as an expectorant and antispasmodic; the dose, three or four drachms. It is used, also, in the composition of warm adhesive plasters, such as gum and diachylon plaster.

GaLL. A common name for bile.

GALL. A sore produced by pressure, or chafing of the saddle or harness.

Gald Bladder. The horse has no gall bladder, or reservoir for bile. A considerable quantity of bile, however, is formed by the horse's liver, and is conveyed by the hepatic duct into the first intestine, or duodenum. In the cow and sheep, the gall bladder is of considerable size.

Ganglion. This term is applied to a natural enlargement, or knot, in the course of some of the nerves. 
Gangrene. An incipient mortification. In this stage of the disease, there is generally a remission of pain; the part is deprived of vital force, by causes inducing a loss of tone.

GaRLIC. It operates upon the horse as a diffusible stimulant and expectorant; possessing, also, diuretic properties. The author considers garlic a valuable remedial agent in the treatment of any disease where the constitution has suffered through hard work, or ill usage. It is a general custom, on the eastern coast of China, to allow cattle to eat as much as they choose. They are never known to suffer any inconvenience from it; on the contrary, they appear to thrive, and are scarcely if ever sick. The only objection to its longcontinued use in cattle is, that it imparts an unpleasant flavor to the meat. It is considered by Gibson to be a valuable remedy in coughs. He advises two or three of the cloves or kernels, cut small, to be given in each feed, and observes that, by continuing this practice, with right and well-timed exercise and careful feeding, he has known many horses to recover, even when there has been a suspicion of their wind.

Gastric JuICE. A juice formed in the stomach for the purpose of digestion.

Gastritis. Inflammation of the stomach.

Gaunt Bellied. A term applied to a horse when he is drawn up in the flank.

Gelatine. A component part of animal matter.

Geldivg. A castrated horse. Such horses are not so vigorous as stallions; the latter are freer from disease than geldings, and will do more work, and keep a better appearance, as to coat and flesh, upon the same quantity of food.

Gentian Root. A good tonic for a horse: the dose is two or three drachms.

Gestation. Being with young. The time of gestation in the mare is eleven months; of the corv, nine months.

Grivger. An aromatic root, possessing stimulant and carminative properties.

Glanders. A contagious disease peculiar to the horse, the ass, and the mule. Many persons suppose that glanders and 
farcy are the effect of a specific poison in the blood; but this theory is exploded. 'The following will show some light on the subject, for which we are indebted to $R$. Vines, V. S. : "All the symptoms of disease which constitute glanders and farcy, invariably depend on the unhealthy state of the system into which it is reduced or brought, and not, as is supposed, from a specific poison contained in the blood; and these symptoms of disease are found to depend on, and arise from, a variety of causes; whether they occur at the latter states or stages of common inflammatory diseases, such as strangles, common cold, distemper, disease of the lungs, dropsy, \&c., or whether they arise independently of such causes; for when the system is brought into an unhealthy state, and is more or less debilitated, from neglect, or by the improper treatment of any of these diseases, [many of thern are improperly treated, - ] farcy, or glanders, is the result. The diseases of every animal will, therefore, assume a character according to the state of the system." Mr. Percival, V. S., says, "The state of the body, or constitution, will always have considerable influence on the character and tendency of disease. In horses whose bodies are, and have long been, in an unthriving and unhealthy condition, a common swollen leg will occasionally run into farcy; and a common cold or strangles, or an attack of influenza, be followed by glanders. In other cases, such unfortunate sequels will supervene without any ostensible or discoverable cause." The great fault of those who have employed their talents in the investigation of the subject (glanders) is, that they take hold of the wrong end of it : they are engaged in attempting to discover the "specific poison," where none exists, when their time would be more profitably engaged in studying the principles of a system of medication that would rid the system of these early exciting causes, viz., common colds, \&c., and thus prevent this great bugbear, glanders. The author can at any time, within a period of a few months, and without the assistance of "specific poison," manufacture a case of genuine glanders out of the following materials: A horse would be 
selected - and many such could be found in the city of Boston - whose general health shall be impaired; let the surface be obstructed by standing in a shower of rain, without any thing to protect the animal from the pelting storm; then put him into a stall near the door, where a current of cold air will pass the hind extremities: he remains in this situation during the night. On the following morning, the animal appears dull, and is off his feed. It is soon ascertained that he has taken cold : now treat him according to the kill-or-cure practice: "If there is difficulty of breathing, and the throat is sore, - or, in other words, the usual symptoms, - the first thing to be done is, to bleed largely, until the horse faints. He should then be put into a cool place. It is often necessary to repeat the bleeding two or three times. If the throat is very sore, blister the part." (See Cantharides.) The secretions now become impaired, there is loss of appetite, the coat stares; there is a dull, sleepy appearance about the animal; the discharge from the nostrils now assumes an acrimonious and putrid character, which, acting chemically on the membrane of the nose, constitutes ulceration: the latter corrode the cartilage and bones, and glanders is the result. Now we will view it in another form. The animal has taken cold; (see Catarrh ;) the lungs - from previous disease, and the subsequent inhalation of impure air in a hot and crowded stable - are incapacitated, and their power to purify and vitalize the blood is destroyed; hence we have deposits of morbific matter on the mucous membrane, which corrode, ulcerate, and finally attack the substance of the lungs, and tubercle is the result, which may terminate in glanders. The expectoration, or passage of acrimonious humors through the nostril of the horse from the lungs, does, in its passage, irritate the schneiderian membrane at a point where it is in immediate contact with ossific or cartilaginous structure, and sufficiently accounts for the ulcers found in the nostrils in the above case. We do not hesitate to say that glanders can be produced without infection, or contagion, and that a common cold or catarrh neglected, or improperly treated, will often terminate in glan- 
ders. Mr. Vines, V.S., states, "that the practice of physicking horses, and exposing them to wet and cold, when they have common catarrh, will produce confirmed glanders."

According to the testimony of Mr. G. Fenwick, V. S., of London, "Glanders is a symptorn of tubercles on the lungs in nine times out of ten;" hence, when a horse has taken cold, and the surface is obstructed, the prudent owner will endeavor to force a crisis; that is, to open the pores of the skin, and promote perspiration. This can be done by the use of warmth and moisture externally, and the administration of warm antispasmodic drinks. This will relieve the stricture of the surface, and permit the egress of morbific matter, which would otherwise be thrown on the lungs, or kidneys. If there is not sufficient power in the system to determine action to the surface, then administer diffusible stimulants. Mr. Youatt remarks, "Improper stable management is a more frequent cause of glanders than contagion. The air which is necessary to respiration is changed and empoisoned in its passage through the lungs; and a fresh supply is necessary for the support of life. That supply may be sufficient barely to support life, but not to prevent the vitiated air from again and again passing to the lungs, and producing irritation and disease. The membrane of the nose, possessed of extreme sensibility, is easily irritated by this poison. Professor Coleman relates a case which proves to demonstration the rapid and fatal agency of this cause: "In the expedition to Quiberon, the horses had not been long on board the transports, before it became necessary to shut down the hatchways: the consequence of this was, that some of them were suffocated, and that all the rest were disembarked either glandered or farcied." In a close stable, the air is not only vitiated by breathing, but there are other and more powerful sources of mischief. The dung and the urine are suffered to remain, fermenting and giving out injurious gases.

Glands. Soft, spongy substances in various parts of the body, which serve to secrete particular humors from the blood.: They are vulgarly called kemels. 
Greet. A discharge of a mucous fluid from the urethra, vagina, or nostrils.

GLotri . The upper part of the larynx, or top of the windpipe. The sensibility of this part is so great, that if any substance happen to fall into the larynx, the most painful and distressing symptoms are produced; and unless the extraneous matter be expelled by coughing, or removed by an operation, (bronchotomy) a fatal termination will be the consequence.

Gonged. A term applied to cattle with an overloaded stomach. When they are in this state, they are said to be blasted, blown, or hoven; probably from the quantity of carbonic acid gas that is generated, and by which the stomach is so distended that cattle often die in consequence of it. When cattle are put into a pasture, which abounds in nutritious food, to which they have been unaccustomed, or have an improper quantity given them, they frequently fill the paunch to such an extent that they are incapable of ruminating: hence, the food remaining in a warm situation, the combined action of heat and moisture generates the gas.

Granulations. A term applied to the little red, grain-like, fleshy bodies, which arise on the surface of ulcers and suppurating sores. Their use is to fill up cavities, and approximate the sides.

Grense. A swelling of the horse's heels, and discharge of stinking matter. (For treatment, see Appendix.)

Gripes. (See Colic.)*

* Scientific Treatuent of Colic, or Gripes. "On the 5th Sept., 1824, a young bay mare was admitted into the infirmary with symptoms of colic, for which she lost eight pounds of blood before she came in. The following drench was prescribed to be given immediately: laudanum and oil of turpentine, of each, three ounces, with the addition of six ounces of decoction of aloes. In the course of half an hour this was repeated! But shortly after she vomited the greater part by the mouth and nostrils. No relief having been obtained, twelve pounds of blood were taken from her, and the same drink was given. In another hour this drench was repeated; and, for the fourth time, during the succeeding hour; both of which, before death, she rejected, as she had done the second drink. Notwithstanding these 
Gristle. A name commonly given to cartilage. (See Cartilage.)

Groganess. A horse is said to be groggy, when he has a tenderness, or stiffness, about the feet, which causes him to go in an uneasy, hobbling manner.

Gullet, or Esophagus. A muscular and membranous tube, by which the food, \&c., is conveyed from the mouth to the stomach. The upper part, or funnel-like cavity, is named pharynx. The gullet passes down the neck behind the windpipe, along the back bones through the diaphragm, and terminating in the stomach.

Guss. The fleshy parts of the sockets of the teeth.

\section{H}

Hавiт. By this term is meant the disposition, or temperament, of the body or constitution, whether natural or acquired. The term habit is also applied to any vice, as starting, kicking, rearing, \&c. All bad habits, whether of the body, constitution, temper, or disposition of animals, may be in some measure corrected, if not entirely put a stop to, by proper attention to breaking, breeding, and stable management.

Halter Cast. Owing to the improper length of the halter, the horse is apt to get his fore leg across it, falls down, and sometimes injures himself considerably.

Halr. This is the name given to the muscular part of the hind leg, terminating in the great tendo Achillis, or hamstring.

active measures were promptly taken, she died about three hours after her admission." (See Clarke's Essay on Gripes.) It appears that the doctors made short work of it. Twelve ounces of laudanum, and the same of turpentine, in three hours! But this is secundum artem. This is called skilful treatment, and justifiable in every case where the symptoms are urgent.

Had the relaxing and stimulating plan, practised by us, been resorted to, and in a proper time and manner, it would probably have saved the poor brute. We have attended a large number of the same sort of cases, and have not yet lost the first. 
HAND. The division in the standard for measuring horses is thus named. A hand is four inches.

Haw. (See Eye, part first.)

Hay. (See Feeding, part first.)

Heart. (See part first.)

HeEL. A term applied to the back part of the termination of the hoof.

Hemlock. A narcotic vegetable poison, deriving its deleterious properties from an alkaline principle, called conia. It has been known to kill many horses, who have partaken of it.

Hemorrhage. A flow of blood from any part of the body, in consequence of the rupture of an artery or vein. Hemorrhage from external injury is most readily stopped by taking up the bleeding vessel, and tying it with saddler's silk; but when this cannot be done, the bleeding may generally be stopped by pressure, or styptics. (See Strptrcs.)

Hepatitis. Inflammation of the liver.

Hide-Bound. When horses are out of condition, and have harsh dry coats, the skin will be contracted and found tight about the ribs. It is a symptom of disease, and shows that the general health is impaired.

Нip-sнот. This is known by one of the hip bones being lower than the other. It generally depends on a fracture of the os innominatum, or small part of the hip bone; the part having formed an irregular kind of union, so that the bone on that side is shorter than the other.

Hock, or Hovgr. The horse's hock is composed of six bones. These bones are all connected together by very strong ligaments, which prevent dislocation, but allow a slight degree of motion among them. The surfaces that are opposed to each other are thickly covered by elastic cartilage, and by a membrane secreting the synovia, or oily fluid, which guards against friction. These bones are so strongly bound together as almost to defy dislocation.

Hoof. (See plate 4, part first.)

Hoor-Bornd. A dry, brittle, and morbid state of the foot. 
A want of vital action, occasioned, says Dr. White, "by inflammation," which he calls disease. Now, it is evident that no vital action, as that of fever and inflammation, can be properly termed disease. The only action that can be properly termed disease, is the chemical action manifested in suppuration and gangrene. This is the great popular error that we are Jaboring to overcome. It is that of attributing disease and death to the action of the powers of life. When a part is become diseased, especially the foot, (for from it the blood has a kind of up-hill work to perform, in returning to the heart by the veins, ) there is a low state of vitality; very little can be accomplished by the vital powers, amounting only to a low form of inflammation. And, of course, the chemical power of decomposition, always present and never tired, gets the advantage and decomposes the part; we then have thrush, which if improperly treated, the hoof falls off by the process of decomposition, or, in other words, mortification. It becomes separated from the living parts, for want of inflammation, or vital supremacy, over chemical agency; and then the loss of the hoof is strangely attributed to inflammation, or the vital power, which did all it conld to prevent such a termination.

Hoof Casting. A partial, or complete separation of the horse's hoof from the sensitive foot. (See plate 5, part first.)

Hoose. A term used by cow doctors. It signifies a cough, either chronic or acute, with which cattle are affected from exposure to cold winds or rain.

Honehound. A bitter vegetable, used in horse practice as a tonic and expectorant.

Hoven. (See Blasted.)

Hydatid. A thin bladder containing a fluid resembling water, and nearly transparent. It is found in different animals. In sheep, it occasions a disease named gid, or giddiness; the hydatid being found in one of the ventricles of the brain, or in its convolutions. On account of the pressure it makes on the brain, it disturbs the functions of that important organ, especially when the sheep are hurried or driven. 


\section{Hydrocele. Dropsy of the testicle and its appendages.}

\section{Hyorophobia. Canine madness.}

Hydrothorax, or Dropsy of the Chest. Mr. Percival informs us, "that the objects to be pursued in the treatment of hydrothorax are twofold: first, we are to diminish any excess of action that may show itself in the sanguineous system,* and thereby lessen the effusion of fluid into the chest; and secondly, by increasing the action of the absorbent system, effect the removal of what is already accumulated." $\dagger$ Most surgeons recommend early tapping in dropsy. The operation may be performed with the common trocar and canula. The best place for the introduction of the instrument, is the space between the eighth and ninth ribs, close to their cartilages; not between the latter, lest the pericardium be punctured. Here, making the skin tense with the fingers of the left hand, the instrument, with its point directed upwards and inwards, may, with a little rotary movement,

* In plain English, abstract blood. This not only diminishes the sanguineous system, but every other function or system. The regulars have tried bloodletting to their hearts' content ; their patients have been rowelled, blistered, calomelized, turpentinized, and hellebored, yet they have never been able to preserve life, "except two solitary cases in Mr. Sewell's practice ;" for Mr. Percival tells us, in his lectures, that "he never saw a case terminate favorably." Is not this a proof that our brethren are on the wrong track? We are told that the proximate causes of dropsy are, "debility, and an obstructed perspiration;" and that it may result from "loss of blood, diarrhœa, diabetes, and other circumstances that rapidly exhaust the system." Hence the processes of cure are just the means calculated to produce the disease. The true indications in the treatment are, to warm and relax the surface, and promote perspiration; for whatever checks it, stops the egress of morbific matter from the system, and, of course, determines it upon the internal surfaces. Diffusible stimulants may be given, to keep up the action on the surface. The general health must be improved.

† The action of the absorbent system never was, nor never can be, excited when the lancet is coöperative. Absorption is a physiological result, and cannot be excited by agents that act pathologically. The balance between exhalation and absorption is lost, in consequence of which, more fluid is poured ont thun is taken up: hence, if we excite the exhalents to throw off the morbid fluids from the surface, there will be less for the absorbent to take up, and the chances of success will be greater. 
gradually be thrust in, until the resistance to its entry suddenly ceases; when the trocar should be withdrawn, and the canula at the same time pushed onwards, lest it slip out. If the flow of water suddenly ceases, a small whalebone probe should be introduced through the pipe.

\section{I}

Ichor. A thin, acrimonious discharge from ulcers, or diseased parts.

Icterus. Jaundice, or yellows.

IDIosyncrasy. A peculiar constitution, or temperament.

Ineum. The last portion of the small intestine. It terminates in the large intestine, or blind gut, named cæcum.

Imposthume. A collection of matter, or pus, in any part.

Incontinence of Urine. A continual dripping of the urine from a horse's sheath. (For treatment, see Appendix.)

Indigestion. (See Remarks on Feeding, part first.)

Inflammation. Inflammation and fever are one and the same thing. When fever is confined to a small part, it is called inflammation. (See Inflammation, part first.) Dr. White, although an advocate of the popular error, viz., bloodletting, makes some very sensible remarks on the subject. If men, generally, would carry out these principles, they would prevent a great loss of property. "It must be obvious, that when an animal is laboring under general infiammation, or fever, in consequence of a suppression of the natural discharges, whether it be perspiration, urine, or dung, he cannot be cured merely by the abstraction of blood; for, however large the quantity abstracted, that which remains will be impure, or acrimonious, and unfit for carrying on a healthy action. It is absolutely necessary to restore the natural discharges by means of suitable medicines, unless that be effected by an effort of nature, which is not an uncommon occurrence, especially when the animal is supplied with some bland fluid, such as bran water or thin bran mashes. The morbid matter sometimes runs off by the nostrils, sometimes 
by the kidneys or bowels, and sometimes by a general relaxation of the skin, and the body is thus restored to health." From the above we are led to the conclusion, that after all, Nature is the most efficient doctor, and that man should be her servant, to procure what she wants, merely to be used in her own way.

Influenza. Epidemic catarrh. Catarrhs, or violent colds, attended with sore throat, and a thin, watery discharge from the eyes and nose. It appears to be infectious, seldom making its appearance withont attacking several horses in the same stable. The horse should subsist on warm gruel, and have a blanket thrown over him, and a drink of hyssop tea. As soon as the surface of the body is relaxed, and becomes moist, the catarrh will disappear.

Infusion. (See Decoction.)

Injection. A term sometimes applied to clysters.

Inosculation. The running of arteries and veins into one another, or the inter-union of the extremities of arteries and veins.

Inspiration. The act of drawing air into the lungs.

Integunent. Any common covering of the body: it generally includes skin, muscle, and membrane.

Intercostal. A term given to parts situated between the ribs: thus we have intercostal muscles, \&c.

Interfering. (See Cutting.)

Interyittent. A name given to disorders that appear to go off at certain periods, and return after some interval.

Intestines. (See Chymification, part first.)

Intus-susception. This is occasioned by one portion of the bowels being forced down within the other.

Iris. That part of the eye by which the light admitted to the retina is regulated.

Irritability. All muscular parts possess the property of contracting, or shrinking, when irritated, and are therefore endowed with irritability.

\section{Issues. (See Rowels.)}

ITCHING. Itching in horses is generally a consequence of foul feeding, and may be occasioned bv mange. 


\section{J}

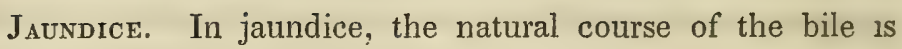
perverted, and reabsorbed into the circulation.

JaW, Locked. (See Lockjaw.)

$\mathrm{J}_{\text {EJUnum. }}$ Part of the small intestine is thus named from its being generally found empty.

Jorsts. A joint is formed, generally speaking, by the heads of two or more bones. These ends are covered by a layer of cartilage or gristle, which is of a yielding nature. There is formed within the joint a slippery fluid, called synovia, or joint oil. The ends of the bones, thus covered with a smonth, yielding surface, so slippery that they move freely on each other without suffering from friction, are then firmly tied together by a strong substance, named ligament, which completely surrounds the head of the bones: this is termed capsular ligament. In some joints we find an additional ligament within the capsular ligament, or cavity : thus, in the hip joint, a strong ligament connects the head of the thigh bone with the socket that receives it.

Joints are subject to disease, either from external injury, or from long-continued exertion of them. In the former, the capsular ligament is penetrated, and a discharge of synovia ensues. Mr. Percival remarks "that, in many cases of open joint, (commonly called so,) there is no division nor injury whatever of the capsular ligament ; but merely the exposure of some bursa mucosa placed between the joint and the external wound: the discharge is of the same kind as in the former case, and we can only determine which it is by carefully probing the wound. Most of all we are likely to make this mistake in the shoulder joint and hock, when heat and swelling are present. From the acute sensibility of ligamentous parts when inflamed, the system quickly, and almost invariariably, sympathizes; so that, in all severe cases of this nature, symptomatic fever supervenes, the pulse becomes accelerated, the horse heaves at the flanks, refuses his food, and shows 
symptoms of the most affecting suffering. It must be borne in mind that, although a joint be not open in the first instance, subsequent sloughing may expose its cavity. Now, the ordinary effects of disease in the synovial membrane are, first, a preternatural secretion of synovia, - hence the profuse discharge observed in these cases; second, an effusion of adhesive matter into the cavity of the joint; third, a thickening of the synovial membrane, a conversion of it into a substance resembling gristle, and an effusion of adhesive matter, and probably serum, into the cellular substance around, by which the external parts and those of the joints are firmly cemented together. In the latter stage the disease commonly extends itself to the cartilaginous surfaces ; they exfoliate, leaving the extremities of the bones denuded, to grate on each other as often as the joint is moved. The bones, in their turn, throw out deposits from their ends around the joint - a process that ultimately ensues, and anchylosis is the result."

The indication to be fulfilled is to promote adhesion by bringing the edges together, and confining them in contact either by taking a few stitches, or shaving the hair off around the parts, and applying strips of adhesive plaster. The parts may have a pledget of lint bound on, moistened with healing balsam; and if the limb will admit of it, a splint may be bound to the back part of it, so as to prevent all possibility of flexion. If union cannot be produced by this means, the parts may be poulticed with astringents. (See Appendix.) The object is to close the joint, and promote granulation. If the parts are inactive, sprinkle the surface of the poultice with charcoal and capsicum. In a case that came under the author's care in this city, and one in which there was no hope of its healing by the first intention, the tincture of capsicum was daily injected: this, together with tonic, stimulating, astringent poultices and fomentations, completed the cure. In cases where the external wound is large, and there is much heat, pain, and loss of motion, poultices of a relaxing and lubricating nature should be used; such are lobelia and slippery elm. A severe injury of this kind may be converted 
into a simple wound by the combined influence of these remedies. The horse should be kept at rest, on a light diet of scalded food, and an occasional dose of alterative powder. (See Appendix.)

When lameness is manifest without heat or swelling, and there is reason to suppose that the animal has been overworked, rest and proper attention to diet will be all that is necessary. When the case is one of long standing, a run at grass may effect a cure, unless there is reason to suppose that the articulatory surfaces of the bones are diseased; we are not supposed to do more for these subjects that alleviate their sufferings, or, what amounts to the same thing, diminish their lameness : restoring them to soundness is out of the question.

Jugular Veins. The large veins of the neck, where a horse is bled.

\section{K}

Kernels. A common name for glands: thus the parotid glands, situated beneath the ear, are termed the kernels under the ear, and the submaxillary glands under the jaws, the kernels under the jaws.

Kidneys. (See Glandular Secretions.)

Kino. An astringent gum resin.

\section{L}

Lacteals. Absorbent vessels which convey the chyle from the bowels into the thoracic duct.

Lameness. The cause of lameness in horses is often very obscure, and can only be discovered by a patient and careful examination. A slight degree of lameness often passes unnoticed; or, if it be observed, the owner too often persuades himself that it will pass off. It is always the most prudent plan to lay up a horse the moment he is observed to be lame, and submit to the inconvenience of doing without his services until he is cured. When lameness is caused by wounds or bruises, the injured part is generally discovered without difficulty, though pricking, in shoeing, is not always so easily 
seen. All lameness from injuries within the hoof is often detected with difficulty. Slight lameness is most readily seen by making the horse trot gently, without giving any support to the head by the bridle or halter, and without urging him with the whip: the lameness is then seen by his dropping harder and dwelling longer on the sound leg than on the lame one, in order to favor the latter; and this, when the lameness is at all considerable, is attended with a corresponding motion of the head, which drops a little whenever he steps on the sound limb. An experienced observer can at any time distinguish lameness merely by seeing a horse walk out of the stable. It often happens, in very severe lameness of one or both fore feet, that the horse, when led out, will appear to be lame in the hind feet also: this is occasioned by the animal endeavoring to favor the fore foot or feet by throwing the bulk of his weight on the hind legs. In all cases of lameness, unless the cause is so evident as to render it unnecessary, it is proper to examine the foot carefully in the first place; and it should never be forgotten that swelling, heat, and tenderness of the fetlock joint, or even the leg, may arise from an injury to the foot. In lameness of the foot, the affected foot will be warmer than the other. Considerable relief may almost always be afforded in foot lameness by keeping the feet moist, or pasturing the animal in soft meadow land, or by stopping the bottoms of the feet with cow-dung and clay; by paring them when necessary. We sometimes find, on examining a lame foot, that there is an enlargement immediately above the coronet, at the heels and quarters, and that this enlargement feels hard and bony. This is termed ossification of the lateral cartilages; it is more distinctly seen by comparing it with a sound foot. In lameness of the foot, there is sometimes a crack in the horn towards the heels, extending from the coronet a little way down the hoof: this happens sometimes after a horse has been travelling. This is named a sand-crack. When the seat of lameness is in the fetlock joint, some degree of heat or swelling will be perceived. As the horse stands, he will be observed to favor the 
joint. Lameness of the back, sinews, or flexor tendons of the leg, is easily perceived by the heat and tenderness of the part. (See Strains.)

Lampas. A swelling and sometimes tenderness of the roof of the mouth, adjoining the front teeth. When the part is tender, and prevents the horse from feeding, he should be fed on scalded shorts for a few days; during that time, the mouth may be washed twice a day with an infusion of powdered bayberry bark. Two ounces of bark may be infused in one quart of boiling water : after macerating for one hour, it will be fit for use.

Larynx. The upper part of the trachea or windpipe.

Lax. (See Scouring.)

Laxative. Medicines that purge gently; the most simple and safe is linseed oil.

Ligaments are strong, elastic membranes, connecting the extremities of the movable bones.

Ligature. Twine, thread, or silk, waxed, for the purpose of tying arteries, veins, or other parts.

Light. (See Stable Management, part first.)

Lights. A common name for lungs.

Lruy. The root of the white lily is frequently used for poulticing.

Linseed, or Flaxseed. An excellent emollient drink is made by pouring two quarts of boiling water on four ounces of linseed, and suffering it to stand in a warm place for a short time. It is useful in cold, catarrh, and in diseases of the kidneys or bladder.

Liquorice. The root, dried and powdered, is used for the same purpose as the last article.

LoBE. A portion of the lungs and liver is thus named.

LockJaw. This disease is too well known to require a particular description. It is evidently a disease of the voluntary nerves, - other parts becoming sympathetically affected, - and often arises from a wound of a tendon, or nerve: it occasionally follows nicking, or docking. Mr. Youatt tells us, "This is one of the most fatal diseases to which the horse is 
subject." For the information of our readers, we will detail the treatment recommended by the above author. We presume that every man of common sense will come to the conclusion that the disease could not be otherwise than fatal under such unwarrantable barbarity. We have no personal disrespect for Mr. Youatt: it is the system of treatment recommended by him that we war against; a system that has killed more than it ever cured. Mr. Youatt observes, "The rational method of cure would seem to be, first to remove the local cause; but this will seldom avail much. 'The irritation has become general, and the spasmodic action constitutional. The habit is formed, and will continue. It will, however, be prudent to endeavor to discover the local cause. If it be a wound in the foot, let it be touched with the hot iron, or caustic, and kept open with digestive ointment. If it follows nicking, let the incision be made deeper, and stimulated by digestive ointment; and if it arise from docking, let the operation be repeated higher.* In treating the constitutional disease, efforts must be made to tranquillize the system; and the most powerful agent is bleeding. [Yes, most powerful to kill.] 'Twenty pounds of blood may be taken away with manifest advantage. There is not a more powerful means of allaying general irritation; the next thing is to

* "First, to remove the local cause; but this will seldom avail much." Then why torture the poor brute? We need not trouble ourselves about the particular nerve affected to enable us to relieve a sympathytic disease, when we have a medicine - lobelia and milkweed, or Indian hemp - that will relax every nerve in the animal. "If it be a wound in the foot, let it be touched with the hot iron." This is a means better calculated to injure than relieve. We should apply, at once, the means that are known to act on the whole nervous structure. "If it follows nicking, let the incision be made deeper; and if it arise from docking, let the operation be repeated higher." What beautiful philosophy this is!-make one disease, to cure another. Is it strange that "this is one of the most fatal diseases?" Is it not a wonder that any live? Must not their escape be attributed to the conservative power of the system, in spite of the violence done? When Mr. Youatt recommends cutting the tail a little higher, to cure a disease that was produced by the same operation, - viz., docking, - he puts the author in mind of the innn who filed the edge of his razor, to sharpen it. 
resort to physic. Here, again, that physic is best which is speediest in its operation; the Croton nut has no rival in this respect ; the first dose should be half a drachm, and the medicine repeated every six hours, in doses of ten grains, until it operates.* The bowels, in all these nervous affections, are very torpid.

"Then, as it is a diseased action of the nerves, proceeding from the spinal marrow, the whole of the spine should be blistered three or four inches wide.

(See Cantharides.) Having bled largely, and physicked, and blistered, we seek for other means to lull the irritation; and we have one at hand, small in bulk and potent in energy, - opium(!) $\dagger$ Give at once a quarter of an ounce, and an additional drachm every six hours."

The best method we know of in the treatment of lockjaw, is, first, to apply a poultice to the foot, (if it has been wounded,) consisting of about six ounces of lobelia, four ounces of skunk cabbage, two ounces of capsicum, powdered; mix them with a suitable quantity of meal sufficient for two poultices, which should be renewed every twelve hours. After the second application, examine the foot, and if suppuration has taken place, and the matter can be felt, or seen, a small puncture may be made, taking care not to let the instrument penetrate beyond the bony part of the hoof. Next stimulate the surface to action, by warmth and moisture, as follows: take

* In the first part of this paragraph, Mr. Youatt observes, "the most porverful agent to tranquillize the system is bleeding." So say the butchers when they bleed the ox, and conduct the process till no blood remains.

$\dagger$ This is a narcotic vegetable poison, and although large quantities have been occasionally given to the horse without apparent injury, experience teaches us that poisons in general - notwithstanding the various modes of their action, and the difference in their symptoms - all agree in the abstraction of vitality from the system. Dr. Eberle says, "Opiates never fail to operate perniciously on the whole organization." Dr. Gallup says, "The practice of using opiates to mitigate pain is greatly to be deprecated. It is probable that opium and its preparations have done seven times the injury that they have rendered benefit on the great scale of the civilized world. Opium is the most destructive of all narcotics." 
about two quarts of vinegar, into which stir a handful of lobelia; have a hot brick ready, (the animal having a large cloth, or blanket, thrown around him,) pour the mixture gradually on the brick, which is held over a bucket to prevent waste; the steam arising will relax the surface. After repeating the operation, apply the following mixture around the jaws, back, and extremities : take, of cayenne, skunk cabbage, and cypripedium, (lady's slipper,) powdered, of each, two ounces, boiling vinegar two quarts; stir the mixture until sufficiently cool, rub the mixture well in with a coarse sponge; this will relax the jaws a trifle, so that the animal can manage to suck up thin gruel, which may be given warm, in any quantity. This process must be persevered in; although it may not succeed in every case, yet it will be more satisfactory than the bloodletting and poisoning system. No medicine is necessary; the gruel will soften the fæces sufficiently; if the rectum is loaded with fæces, give injections of an infusion of lobelia.

Lusbar Muscles. Muscles of the loins within the body, and in the region of the kidneys. These muscles are sometimes injured in violent exertions, and the kidneys often participate in the injury. (See Strains.)

Lungs, or Lights. The organ of respiration. (See ResPIRATION, part first.)

Luxation. A partial displacement of the bones forming a joint.

Lтмрн. (See Blood.)

Lymphatics. (See part first.)

\section{M}

Maceration implies soaking or steeping any substance in water, or other fluids, so as to soften, dissolve, or separate it from some other parts with which it is combined.

Mallenders. A scurfy kind of eruption on the back part or bend of the knee joint.

Mange. A disease which manifests itself in the skin, and 
causes a horse to be perpetually rubbing himself. Cattle, sheep, and dogs are also subject to mange. It is a wellknown fact, that horses are very apt to become mangy, if kept long in the stable without grooming; yet the disease may arise from causes independent of a neglected skin, though it seldom attacks a well-cleansed animal. Mr. Percival observes, "It seems that mange may be generated either from immediate excitement to the skin itself, or through the medium of that sympathetic influence which is known to exist between the skin and the organs of digestion. We have, it appears to me, an excellent illustration of this in the case of mange supervening upon poverty - a fact too notorious to be disputed, though there may be different ways of theorizing upon it."

Mr. Blaine says, "Mange has three origins - filth, debility, and contagion."

Owners of horses must bear in mind, that mange can be communicated by the brush or comb used about a mangy subject; the pustules on the surface contain infectious matter. The author has been very successful in the treatment of this disease, by the daily use of the alterative powder and mange ointment. (See Appendix.)

Marasmus. A decay or wasting of the whole body.

Marshmallows. A plant used for making emollient drinks and fomentations.

Mash. A mash is made by pouring boiling water on bran, or shorts, then covering the buckets until sufficiently cool for use. Mashes are excellent for sick and convalescent horses, and such as have not sufficient exercise to keep them in health.

Masseter. The name of a muscle of the cheek, by which mastication is performed.

Mastication. (See part first.)

Materia Medica. A catalogue and description of the various articles used in medicine.

Maxilla. The jaw.

Maxiluary. Belonging to the jaw ; as the maxillary arte- 
ries and glands. The glands under the jaw are named submaxillary glands.

Mediastinum. A duplicature of the membrane named pleura, by which the cavity of the chest is divided into two parts.

Medicine. Mr. Clark, veterinary surgeon, of Edinburgh, says, "Medicine is often given to the poor brutes unnecessarily, and, of course, mischievously. If a man, or horse, be in a state of health, what more is required, or how can they be rendered better? Health is the more proper state of the animal body, and it is not in the pover of medicine to make it better, or to preserve it in the same state."

Dr. White says, "The custom of giving medicines too frequently is a bad one; the constitution adapts itself to it, which circumstance renders medicine inefficacious when necessary, or, at least, it greatly reduces the effects."

If a horse is in health, the proper way to promote it is to proportion the food to the labor.

Dr. White continues, "Medicines are given to the horse under the title of alteratives. These alteratives are composed of antimony, mercury, sulphur, nitre, aloes, salts," (generally altering bad for worse.)

Mr. Clark says, "that sulphur not only opens the body, but the skin also, and therefore should be used with cantion, as horses are very apt to catch cold on too liberal a use of it."

Salts bring on great sickness, and sometimes violent purging, and, instead of promoting the secretions, occasion great dryness of the skin.

"Aloes given in small quantities, by way of alteratives, and too frequently repeated, weaken the stomach, so as to bring on a lax, or what is called a washy habit of body.

"Antimony should always be rejected, if coarse and black, like gunpowder." (See White's Farriery, p. 559.)

The above author says, "It is amazing what different hinds of trash is forced down horses' throats: the following is a striking instance: A gentleman, in London, was greatly 
prejudiced in favor of vinegar as a cure in many diseases. His favorite horse was taken ill in very warm weather, and as he thought vinegar was a cooling article, he ordered a pint to be given to his horse at once. It was no sooner given than the horse lay down, stretched himself out, and died."

Medulla Oblongata. The commencement of the spinal marrow, within the cranium.

Membrane, Mucous. This membrane is folded into all the orifices of the animal, as the mouth, eyes, nose, ears, lungs, intestines, bladder, \&c. ; in fact, into every cavity that has a direct communication with the external surface. Its structure of arterial capillaries, venous radicles, nervous projections, \&c., is similar to the skin, and is considered a duplicate of the external surface. Its most extensive surfaces are those of the lungs and intestines. This membrane furnishes from the blood a fluid called mucus, to lubricate its own surface, and protect it from the action of materials taken into the system. The skin and mucous membrane are a counterpart of each other. If the action of the skin is suppressed, the mucous membrane performs a part of its office; thus a cold, which closes the pores of the skin, stops perspiration, which is now forced through the membrane, producing discharges at the nose, eyes, \&c.

Serous membrane. Of this kind are the pleura and peritoneum : they are distributed in all parts of the system, lining muscles, tendons, and tendinous sheaths, the ends of movable bones, \&c.; in short, wherever there is need of the protection of parts against friction. They secrete from the blood a fluid called serum, for the purpose of affording this protection. The excessive discharge of fluids into cavities lined by serous membrane, constitutes the different forms of dropsy. There are other membranes, viz., adipose, which secrete the fat of the body; synovial, which secretes synovia, or joint oil ; and cellular membrane, or tissue, is the common connecting substance of most parts of the body.

Mesentery. A thin membrane by which the bowels are held together, and over which the lacteals, or chyle vessels, 
pass. Besides the chyle vessels, there are considerable veins and arteries passing over the mesentery. The arteries are distributed to the bowels, and the veins terminate in the vena porta, or great vein of the liver.

Metacanpis. The metacarpus of the horse consists of one great bone, commonly named the cannon, shank bone, or fore leg, and two small bones, or splent bones, attached by ligaments to the back part of the cannon bone, rather towards the sides. The suspensory ligament passes down on the back part of the cannon bone, and between the two splents. The flexor tendons, or back sinews, pass down over the suspensory ligament. When the bones only of the fore leg are spoken of, they are termed metacarpus. They begin at the knee, and end at the fetlock joint.

Metatarsus. The hind leg, between the hock and fetlock joints.

Metatarsal Bones. The hind cannon, or shank bone, with the two small splent bones attached to it. The large blood-vessels and nerves, in this situation, are also named metatarsal.

Miasmata. Poisonous effluvia.

Midriff. (See Diaphragm.)

Molares. The name of the grinding teeth.

Molten Grease. A name which Mr. Blaine has given to dysentery.

Mortification. A part deprived of vital force, by causes inducing a loss of tone. Bloodletting and poisons of all kinds tend to diminish vitality, and, of course, are calculated to produce gangrene.

Moulting. Casting the coat. In spring the old coat is shed, or thrown off, and the horse gradually improves in spirit, and in appearance; but, during the change, he is more liable to take cold. In the latter part of the year, the coat becomes longer and coarser, and loses its healthy gloss; at the same time, the horse often becomes weak, sweats readily upon moderate exercise, and is often incapable of performing his usual labor. This is more especially the case with horses 
that have been hard worked and badly fed. At both these periods it is necessary to take particular care of horses, and work them moderately. A horse, when moulting, should not be exposed in the stable to a current of air, but kept in a ventilated stable. Warm clothing is improper.

Mucilage. A solution of gum, or any thing that partakes of the nature of gum. Gummy or mucilaginous drinks are useful in internal disease ; the cheapest is an infusion of linseed or marshmallows; but the best, perhaps, is a solution of gum arabic.

Mucous Membranes. (See Membrane.)

Mucous. Many of the secretions of the body are of a mucous nature.

Mucus. A fluid secreted by mucous surfaces.

Muscle. The parts that are usually included under this name, consist of distinct portions of flesh, susceptible of contraction and relaxation.

Musk. A powerful odorous substance, whose medical virtues are chiefly antispasmodic.

Mrrri. A gum resin of a fragrant smell and bitter taste. It is given internally, as a tonic, in doses of one or two drachms. Tincture of myrrh is sometimes applied to wounds, ulcers, and sinuses.

\section{$\mathrm{N}$}

NAG. A name sometimes applied to road horses, and such as have been docked, in contradistinction to those that have long tails, or are used in harness.

Narcotics. Medicines which stupefy, relieve pain, and promote sleep. There are, however, two different ways to effect these objects, and, of course, two different characters of remedies to he used for the purpose. The popular method is to administer opium, whose natural tendency is to depress the vital powers, and deprive them of sensibility. All mixtures, in any form, that contain opium, though soothing for the 
present, are ultimately and surely pernicious. The true plan is to give antispasmodics.

(See Antispasmodics.)

Nares. The nostrils.

Necrosis. The mortification and separation of a portion of dead bone from the other parts of the bone.

Nephritics. Medicines that act on the kidneys.

Nerves. We have already observed that the brain consists of two portions : one large, called cerebrum, and one small, called cerebellum. There are three pairs, or columns, of nervous matter proceeding from the brain, through the back bone, or spinal column: these disperse themselves into branches and twigs, and are distributed over the system.

By a great number and variety of experiments upon living animals, Dr. Bell and others have proved beyond dispute, that the nerves of the anterior (towards the belly) columns are distributed to all the voluntary muscles, and designed to produce voluntary motion; that those of the posterior, or towards the back, are distributed to all the sensative tissues, and designed to convey to the brain all the impressions derived from the presence of external objects. These two arrangements are styled the nervous system of external relation. By similar experiments it was discovered that the two lateral or side columns of nervous matter are distributed to the muscles concerned in the act of respiration.

Lastly, seated principally among the thoracic and abdominal viscera, there are large quantities of nervous matter, having only slight connection with the sensative and motive nerves. This system has many knotty appearances, from the union and distribution of its fibres; these are again distributed to different parts. These are called plexuses, and the whole structure is called the sympathetic nerve. It is sometimes named the nerves of nutrition.

Dr. Curtis observes, "It has long been a subject of inquiry what is the modus operandi of nervous action. Some have supposed that the nerves are solid cords that vibrate, like the strings of musical instruments; others, that they are sheaths containing a subtile fluid, that darts through them as electricity 
does through metallic wires; others suppose that the motion is that of electricity itself. My own opinion is, that it is based on the principle of elasticity. It is well known that, if any number of ivory balls be suspended in contact, and in a direct horizontal line, and a blow be struck on the first in the direction of all the rest, all remain at rest except so many at the other end as exactly equal the momentum of the blow. These fly off from the rest. If the blow be equal to one ball, only one ball flies off. Now it would be the same if the balls were confined in a tube, were the tube ever so crooked, as is proved by the hydrostatic balance of fluids in crooked water-pipes. I believe that the nerves are sheaths filled with extremely elastic globules of matter, and the impressions, or momenta, communicated to one end are transferred to the other, not by the locomotion of the whole globule, but by the elastic spring of its centre. If the impression be made on any of the intermediate globules, the result is the same. It is remarkable that in whatever part of a nerve the impression is made, the effect produced is referred to the extremity." (See Distribution of Nerves, part first.)

Nerving, Nerve Operation. It consists of cutting out a portion of the nerve which supplies the foot, either just above the fetlock joint, which is named the high operation, or in the pastern, which is called the low operation. In the former the sensibility of the foot is supposed to be entirely destroyed, and in the latter only partly so. Dr. White observes, serious mischief, such as the loss of the hoof, has sometimes followed the higher nerve operation.

"After the division of a nerve, the extremities of the divided portion retract, become enlarged and more vascular ; but especially the upper portion; and coagulable lymph is effused, which soon becomes vascular. In a few days the coagulable lymph from each portion becomes united, and anastomosis forms between the blood-vessels; the lymph gradually assumes a firmer texture, and the number of the blood-vessels diminishes, and the newly-formed substance appears to contract, like all other cicatrices, so as to bring the extremities 
of the divided portions nearer and nearer to each other. It is difficult to determine, from an experiment on the limb of an animal, the exact time at which the nerve again performs its functions after being divided. In eight weeks after the division of the sciatic nerve, I have observed a rabbit to be in some degree improved in the use of its legr; but at the end of eighteen weeks it was not perfect. When the nerves of the leg of a horse are divided just above the fnot, they are sufficiently restored to perform their functions, in some degree, in six or eight weeks; but it must be observed that these nerves are only formed for sensation, and it is very different with the nerves of nutrition, voluntary motion, \&c. ; the reunion is sometimes accomplished by granulations. Secondly, I would observe, that punctures and partial divisions of nerves heal in the same way as when there has been a total division; and that, even on the first infliction of the wounds, the function of the nerves is very little impaired." (See Swan's work on morbid local affections.)

Mr. Sewell finds, "that in cases of entire section of a nerve, sensation returns in about two months; but in others, in which a portion of nerve has been excised, that the period of restoring feeling can by no means be foretold: in one of his own horses, he ascertained that there was no sensibility in the foot, even at the expiration of three years; and in some others, after a longer interval, the organ appeared to be wholly destitute of feeling."

Nicking. An operation often performed on horses, to raise the tail, and make them carry it more gracefully, or rather to suit the taste of man.

Nippers. The two front teeth, above and below, have been thus named.

Nitre. An indirect diuretic. It causes a large secretion of urine, but does not provide for the excretion. The author has in his possession the bladder of a horse, the muscular fibres of which are lacerated, in consequence of over distention of that organ from the use of nitre. Dr. White remarks, "I have seen a dose of four ounces given, which occasioned 
alarming symptoms, and appeared to have a poisonous effect."

Nostrils. The nostrils are sometimes diseased, as in glanders.

Nutrition. (See part first.)

Oats. According to Sir H. Davy's analysis, oats contain 742 parts of nutritive matter out of 1000 , which is composed of 641 mucilage, or starch, 15 saccharine matter, and 87 gluten, or albumen. New oats are difficult of digestion.

Oblique Muscles. The muscles of the abdomen, or belly, are thus named. There are four of them: two external and two internal. Some of the muscles of the eye are also named oblique muscles.

Occrput. The back part of the head.

EEmma. A watery or dropsical swelling.

Esophagus. The tube passing from the mouth to the stomach.

Ointments. Unctuous substances of the consistence of butter; when made considerably thinner by the addition of oil, they are termed liniments; but when their solidity is increased by wax, rosin, \&c., they are termed plasters.

Orecranon. The head of the bone named ulnar, (see cut, ) in the horse ; it affords a powerful lever for the triceps extensor cubiti muscle to act upon, in straightening the fore arm upon the humerus. (See Sкeleton.)

Olfactory Nerves are spread over all the interior of the nostril, and constitute the sense of smell.

Onentur. The omentum, or caul, is a double membrane, containing within its folds a considerable quantity of fat, in the human body and many animals. But in the horse this is never seen; nor does the omentum contain much fat; what there is lies in the region of the stomach.

Opacity. A want of transparency in those parts of the eye named pupil, or cornea. 


\section{Opiates. (See Narcotic.)}

Opium. A narcotic vegetable poison. Mr. Coleman "thought, from some experiments made at the veterinary college, that opium has no apparent influence over the nervous system of the horse, and that it does not alleviate pain." Dr. White says, "I think that opium, as to its effect on the horse, does not possess that soothing anodyne, and soporific quality, for which it is justly distinguished in human medicine." Opium always tends to depress the vital organs in proportion to its quantity.

Opodeldoc, or Soap Liniment. A solution of soap and camphor in spirits of rosemary.

Optic Nefve. The nerve on which sight depends.

Orbiт. The socket of the eye is thus named.

Organic. A discase is said to be organic when any particular organ of the body is affected.

Ossification. Ligaments and cartilages sometimes become bony, especially those ligaments which unite the splent to the canmon bones, and the lateral cartilages of the foot.

Ovaries. Two appendages to the womb, or uterus, which are cut out in the operation of spaying.

Overreach. A horse is said to overreach, or overlash, when he wounds the fore heel with the hind foot.

Overwork. Many of the diseases of horses originate in overwork.

\section{P}

PAce. The peculiar manner of motion, or progression. The natural paces of the horse are, the walk, trot, and gallop, to which some add the amble.

Palate. The upper part or roof of the mouth.

Palliative. Medicines and operations by which diseases appear to be relieved, but not cured. However desirable palliatives may be in the diseases of the human body, they are seldom satisfactory in the diseases and lameness of horses.

Palpitation. Beating of the heart against the breast bone, or ribs. 
Palsy, or Paralysis. A loss of muscular power, or an mability to move any part of the body.

Pancreas, or Sweetbread. A glandular substance situated in the abdomen, near the stomach. It secretes the pancreatic juice. (See Nutrition, part first.)

Pannicle, or Fleshy Pannicle. A thin muscular covering attached to the skin of brute animals, by means of which they are enabled to shake it, and get rid of flees, \&c.

Panton Shoe. A contrivance for expanding contracted feet; but like all other mechanical contrivances, they are useless or pernicious.

PAPs. When young horses are cutting their teeth, and sometimes after that period, the excretory ducts of some of the salivary glands under the tongue become enlarged. These are named paps. They should be touched with a solution of alum, and the animal fed on mashes. (See MASH.)

Papiluary. Pap-like; or rather like small or minute paps. A term applied to small elevations on different parts of the body, whether morbid or natural. Those little eminences on the internal surface of the leaves or laminæ of the cow's third stomach, or manyplus, are termed papillary.

PAR V AGUM. The eighth pair of nerves are thus named.

Paracentesis. The operation of tapping, for the purpose of giving vent to water collected in the chest, abdomen, \&c. It has frequently been performed on animals without any benefit.

Parietal. The bones that form the sides of the skull are thus named.

Paring. Cutting the hoof, in order to prepare it for the shoe. (See Shozing.)

Parotid Glands. Two large glands situated under the ears; they secrete saliva, which is conveyed by a duct into the mouth.

PAroxysm. The periodical accession, or the periodical increase, of a disorder.

Parturition. The act of bringing forth young. 
Pastern. The part between the fetlock joint and the hoof. (See cut of the foot, part first.)

Pastern Nerve. The nerve from which a portion is cut out in the operation of nerving.

Pasture. Pastures in elevated situations are the best for horses.

Patella. The knee-pan of the human body, and the stifle of the horse. (See Skeleton.)

Pathology. The doctrine of diseases.

Paunch. The common name for the first stomach of the cow.

Pecronals. Medicines that relieve cough, and other diseases of the lungs.

Pectoral Muscles. The muscles of the breast.

Pelvis. The basin, or that cavity wherein is lodged the bladder, uterus, and the rectum.

Penis. The yard or male genital organs.

Perforans Tendon. The innermost of the back sinews, or that which goes to the back sinews.

Pericardium. The heart bag. (See Heart, part first.)

Pericranium. The membrane that is closely connected with the bones of the head.

Periosteum. The investing membrane of the bones.

Peristaltic Motion. That motion of the muscular coat of the bowels, which causes the food and excrement to pass through them.

Peritoneun. The membrane which forms the external coat of the bowels, and some other of the viscera of the abdomen; it is, therefore, named the peritoneal coat of the bowels. It lines, also, the internal surface of the belly.

Peritonitis. Inflammation of the peritoneum. Diseases of the peritoneum are very rare in horses; and when treated on the depleting, antiphlogistic principles of allopathy, generally terminate fatally. When the physiological equilibrium is interrupted, and inflammation of the peritonenm ensues, the available vital force is concentrated upon a small region of the body. The true indication is, to invite this force 
away from that region, and to distribute it over the general system, that it will not be excessive any where. This mode of relief we call equalizing the circulation: the allopaths term it counter-irritation; they concentrate it in one spot, in the form of rowel and blister, their own works will show with what success.* Our principles teach us to accomplish the object by the stimulating influence of medicated vapor, enemas, nervines, and a mucilaginous diet. Whenever the disease is treated by the abstraction of blood, it generally terminates in dropsy.

Perspiration. The fluid which is secreted by the vessels of the skin. Perspiration is a highly important discharge in horses and other animals. The best medicine to promote sweating in the horse, is a tea composed of lobelia, capsicum, and pennyroyal.

Phanynx. The upper part of the osophagus, or gullet.

Phlegm. A mucous liquid thrown up from the lungs.

Phrenic Nerve. A nerve that passes through the thorax, over the heart, to the diaphragm.

Phrenitis. Inflammation of the brain.

* Mr. Percival details a case of peritonitis, after the usual symptoms in the early stage had subsided. "The horse's bowels became much relaxed : suspecting that there was some disorder in the alimentary canal, and that this was an effort of nature to get rid of it, I promoted the diarrhœa by giving mild doses of cathartic medicine, in combination with calomel!" Nature did not require such assistance: warm drinks, composed of marshmallows, or slippery elm, would have been just the thing:

"On the third day from this, prolapsus ani (falling of the fundament) made its appearance. After the return of the gut, the animal grew daily duller, and more dejected, manifesting evident signs of considerable inward disorder, though he showed none of acute pain ; the diarrhœa continued; swelling of the belly and tumefaction of the legs speedily followed: eight pounds. of blood were drawn, and two ounces of oil of turpentine were given internally, and in spite of another bleeding, and some subordinate measures, carried him off [the treatment we presume] in the course of a few hours.

"Dissection: a shight blush pervaded the peritoneum; at least the parietel portion of it, for the coats of the stomach and intestines preserved their natural whiteness. About eight gallons of water were measured out of the belly. The abdominal viscera, as well as the thoracic, showed no marks of disease" 
Physic. In stable language, the term is applied to purgative medicines.

Physiology. That branch of medical science which describes the functions of every part of the body.

Pia Mater. A delicate membrane, that closely invests the brain.

Prtci, Burgundy. A resin obtained from fir; it is used in the composition of plasters and charges.

Placenta. The afterbirth.

Plate Vein. A large vein that runs from the inside of the fore leg to the chest.

Plethora. A fulness of vessels. Horses are often brought into this state from overfeeding, and want of sufficient exercise. It is known by heaviness, dulness, unwillingness to work. The urine is high colored, and the dung generally hard and slimy. The cure consists in the reduction of the quantity of food, warm mashes, and regular exercise.

Pleura. The membrane which covers the lungs so closely as to appear a part of their substance.

Pleurisy, Puevritis. Inflammation of the pleura.

Plexus. A network of blood-vessels or nerves.

Peeumonia. A general term for inflammation of the lungs.

Porsons. Articles which impede or destroy the vital operations. Some people proclaim that all food is poison; that the difference in the effect produced lies in the quantity given. We deny this: good corn, oats, and hay, whose nature is to nourish and support the animal, can never be a legitimate cause of disease. Its excess in quantity, and its chemical decomposition for want of digestive power, are all of true food that can prove iujurious. On the other hand, experience teaches us that opium, arsenic, corrosive sublimate, tobacco, and calomel are inimical to the animal organization, and will never change their chemical equivalents. A grain of arsenic will always be a grain of that poison, and can be detected after death: the same applies to opium. A very few grains of opium injected into the carotid artery of a dog, killed him in four minutes; when the same quantity was injected into a 
vein, the animal lived twenty-five minutes. When injected into the bladder, it required a larger quantity to destroy life.

Again: one drop of the oil of tobacco applied on the tongue of a rabbit killed him instantly; one drop applied to the same organ of a cat, threw her into convulsions; two drops placed on the tongue of a squirrel killed it instantly. Hence it does not require much penetration in order to decide what is, and what is not, poison. Animals often get, apparently, well, although large quantities of the above poisons have been given. This is no proof that the poisons cured them. In the early stage of disease, the constitution can bear more violence - bloodletting and poisoning - than when it becomes debilitated. This explains the reason why large quantities of opium may be given to a horse at a certain time, without any perceptible effect; at another time, one half the quantity will destroy him.

Poll-Evil. An obstinate disease, which often happens to horses. It generally proceeds from a blow received upon the poll or back part of the head. (See Appendix.)

Ponta. The name of the great vein of the liver.

Poultice, or Cataplasu. The emollient poultice may be composed of equal parts of slippery elm and flaxseed. The intentions to be answered by poultices are relaxation and stimulation. To relax a part, add to the above emollient lobelia; when it is necessary to stimulate, use cayenne. Poultices that are designed for foul ulcers, in addition to the above articles, should contain at least one third powdered charcoal. (See Appendix.)

Prevention of Disease. It is an old, but true, saying, that prevention is better than cure; and we may safely add, less expensive.

Pricks, or Pricking. In shoeing a horse, the nail is sometimes driven in a wrong direction, and the sensible parts are wounded: he is then said to be pricked. When a horse has been slightly pricked, and the nail immediately withdrawn, it may not be followed by lameness; but when the wound is considerable, matter will form : if the matter is not let out by 
paring away the horn, it quickly spreads under the horny sole, and upwards through the laminated substance of the foot, and breaks out at the coronet. (See Cononet.) To prevent this, the parts, as soon as the accident has happened, should be bathed with healing balsam. If the horse goes lame for several days, a poultice must be applied to promote suppuration.

Prime Viæ. The first passages, or stomach, and first intestines.

Probang. An instrument for removing any obstruction in the œsophagus or gullet. It consists of a rather flexible rod, covered with leather, with a round, smooth nob at one end.

Proвe. An instrument for examining wounds.

Prolapsus. The falling down of a part, as of the uterus or fundament.

Psoas Muscles. The muscles that lie under the loins. These muscles are sometimes injured in strains of the loins.

Pulmonary Diseases. Diseases of the lungs.

Pulmonary Vessels. The blood-vessels and air-vessels of the lungs, which consist of the pulmonary artery and vein, and the bronchia, or branches of the windpipe.

Pulse. The beating of the arteries. The horse's pulse is most conveniently felt in that part of the carotid artery which passes under the angle of the lower jaw.

Puncta Lachrymala. Two orifices near the inner corner of the eye, through which the tears pass.

Pupil. The apple of the eye.

Pus. The white matter formed by the process of suppuration.

Pylorus. The inferior portion of the stomach.

Quarter Ill, or Quarter Fivil. There is a variety of names given to this disorder, such as joint murrain, or garget, black quarter, quarter evil, black leg, blaine in the tongue. The causes of this disease are generally too liberal an allowance of food; or a sudden transition from poor keep to luxurious and nutritious diet. In some cases the energy of the 
body is lessened by exposure to cold and wet; hence the quarters and feet swell, and it is this circumstance which has given rise to the name by which the disorder is commonly known. The approach of this complaint is generally indicated by the animal separating himself from his companions; by his appearing dull, listless, and heavy, and by his refusing food. The more immediate symptoms are lameness, and swelling of the hind quarters, and occasionally of the shoulders or back. These swellings, when pressed, make a crackling noise. (See Emphysema.) The mouth and tongue are frequently found blistered in this disease. A spare diet, and keeping the animal in a dry barn, are strictly to be attended to, with an occasional dose of Distemper Powder, (see Appendix) and clysters of thin gruel and common salt. By this means the disease may be subdued. If the disease first appears in the foot, a charcoal poultice must be applied.

\section{$\mathrm{R}$}

RACK Bones. The vertebræ of the back.

Radius. The bone of the forearm.

RaKing. (See BaCK R R AKING.)

Rectum. (See Intestines.)

RED-WATER. This disease often attacks cows, and is named from the red appearance of the urine. The following article, written for the Albany Cultivator, will give the reader our views of the malady. The name is given to it from the appearance of the urine, being only a symptom of general derangement. "The ounce of nitre," recommended in the article alluded to, "would act as an indirect diuretic, and make the powerful animal weak; it might, also, change the appearance of the urine: at best, it would only be treating symptoms, and could not possibly contribute any thing towards the cure. The observing man will recognize a derangement of all the functions, a vitiation of every secretion, and a loss of vital power. We lay it down as a fundamental principle, that those who treat symptoms alone never cure disease, for 
the animal often dies a victim to the treatment instead of the malady.

"This form of disease is considered to be epidemic ; yet all animals are not likely to be attacked, although exposed to the same atmospheric influence; for if there is a perfect physiological equilibrium between the solids and fluids, the nervous system, and the circulation, then the animal is safe. The indications to be fulfilled in the treatment of the disease, are to excite the liver and intestines to action, which are in a torpid state; next, to change morbid action; and lastly, to tone up and invigorate the whole system. There is every reason to believe that this malady will yield just as readily as any other to the proper remedial agents. Your correspondent quotes from a work published in this city, that 'red-water is most common in cows of weak constitution, a general relaxation, poor blood, \&c., that the urine is brown and tinged with yellow.'"

This shows that the system abounds in morbific matter, and Nature is making an effort to rid herself of it, and will do so unless you interfere by using remedies opposed to the vital principle. Many of the drugs used to cure red-water would kill a well animal, whatever they might do the diseased. "In a few days a natural diarrhœa comes on, and the animal is better." This is the manner in which nature attempts to cure : the diarrhœa carries off a large amount of morbific fluid, which could not remain in the system without producing serious consequences. "After the diarrhœa, the animal often gets well." Here Nature speaks in a language too plain to be misunderstood; we must open the sluices of the body. One pint of linseed oil should be given, and its operation assisted in a few hours with injections of warm soap-suds, each injection containing a spoonful of powdered ginger; after the bowels are evacuated, the Distemper Powder - sold by Messrs. Stimpson \& Reed, 26 Merchants Row, Boston - is the only article we use in this form of disease. The animal should be allowed a drink composed of boneset and pennyroyal, one ounce of the former to two of the latter, infused in half a 
bucket of boiling water. The diet should be light and nourishing, as gruel, mashes, \&c.

Respiration. The act of breathing; which includes inspiration, or the taking in of air by the lungs, and expiration, or the act of discharging it.

Ringbone. A bony excrescence on the lower part of the pastern, generally, but not always, causing lameness.

RoARING. A disease which takes its name from the wheezing noise the horse makes in breathing, when put into quick motion. It is supposed by most veterinary writers to be caused by an effusion of lymph in the windpipe. Our own view of the subject is, that it is owing to a contraction of the bronchial tubes.

Rosemary. The essential oil of this shrub is a useful ingredient in stimulating liniments.

Rот. A disease of sheep, resembling pulmonary consumption, complicated with dropsy. Its causes are flooded lands and unsubstantial food.

Rowels. These are considered as artificial abscesses, or drains. They act on the principle of making one disease cure another - a principle that will not stand the test of common sense.

Rumination. Chewing the cud.

Rupture. A swelling caused by the protrusion of some parts of the bowels out of the cavity of the abdomen, into a kind of sac, formed by that portion of the peritoneum (which see) which is pushed before it.

\section{S}

SACRUM. That part of the back bone from which the tail proceeds.

Saliva. Spittle.

Salivation. A profuse and continued flow of saliva.

Sand Crack. A perpendicular crack on the side or quarter of the hoof. 
Sanies. A bloody, or greenish matter, which is sometimes discharged from foul ulcers.

Sarsaparilla. An infusion of equal parts of sarsaparilla and sassafras is useful for animals when the blood is loaded with morbific agents.

Scapula. The shoulder blade.

Scarf Skin. (See Cuticle.)

Scarification. An incision of the skin with a lancet.

Scrrrhus. An indolent, hard tumor.

Sclerotic Coat. (See Eye.)

Scouring. A scouring, or purging, is common among all our domestic animals. It is not a disease, but only a symptom of a loss of equilibrium, which may proceed from improper food, exposure to the cold and rain, which of course includes a loss of caloric, or heat. There is no general remedy, or one more speedy and effectual in the onset, than mucilaginous drinks composed of slippery elm, combined with injections of the same. Warmth and moisture to the surface, and antispasmodics, (which see,) combined with astringents, (barberry bark is the best, in doses of half a tablespoonful every six hours, ) will seldom fail to effect a cure.

Scratches. Troublesome sores about the heels, depending on morbific agents in the system, for the cure of which, see Appendix.

Scrotum. The bag, or covering of the testicles.

Secretion. The word secretion is used to express that function.

Serum. The watery part of the blood.

Sesamoid Bones. Two small bones on the back part of fetlock joint.

Sinew Sprung. A term sometimes applied to strains in the back sinews.

Sitfast. A horny kind of scab, which forms on the skin in consequence of a saddle-gall.

Skin. (See Cutrs.)

Slipping. (See Abortion.)

Sole. (See Foot, part first.) 
SPasm. An involuntary and continued contraction of muscles; thus lockjaw depends on a spasmodic contraction of muscles.

Spavin. A disease of the horse's hock, which generally causes lameness. Spavins are of two kinds: the bone, and the bog, or blood spavin. The former consists of a bony enlargement of the inside of the hock joint, towards the lower part; the latter, of a soft, but elastic tumor towards the bend of the joint. Mr. Percival remarks, "Notwithstanding our confessed inability to cure this disease, we are often called on to treat it, as to the removal of it by means of a chisel, file, or saw. Although the practice is exceedingly commendable in cases of common exostosis, it is not so well adapted to spavin; those who employ such means seldom fail to leave the parts ultimately in a worse state than they found them. Our most successful remedies are such as come under the denomination of counter-irritants."

Spermatic Cord. The vessels, \&c., by which the testicles are suspended, consisting of the spermatic artery and vein, the vas deferens, or seed duct, cremaster muscle, and cellular membrane.

Sphincter. A name given to muscles whose fibres are arranged in a circular direction, and whose office is to shut up the parts to which they are attached; such are the sphincter of the neck of the bladder, and the muscles which close the fundament.

Spine. The spine of the neck and back is composed of many small bones named vertebræ. Seven belong to the neck, eighteen to the back, six to the loins, five to the sacrum, and in the tail there are about thirteen.

Spleen, or Milt. A soft substance, of a long, oval form, and purple color. It seems to be a reservoir for the blood that may be designed for the secretion of bile in the liver.

Splents. These are bony excrescences, which grow on the inside of the shank bone.

STAGgers. This is named from the staggering gait of the animal. It may be brought on by the horse eating too greedily, 
swallowing his food when imperfectly chewed, or eating freely of food that is difficult of digestion. Horses of rather an advanced age and weak digestive organs, when improperly fed, or when a large quantity of meal is allowed, are very liable to apoplexy, or staggers. The disease is generally symptomatic of derangement of the stomach, indigestion, and over-distention of the digestive organs.

Sternum. The breast bone.

Stifle Jorst. This joint is composed of the bones called os femoris, tibia, and patella. (See Frontispiece.)

Stopping. A mixture of clay and cow-dung is employed for the purpose of stopping horses' feet, and keeping them moist.

Strains. For all kinds of strains rest is the best remedy ; sometimes they require poultices, fomentations, \&c. The latter will be indicated by pain and swelling.

Stubs. When a horse is wounded by a splinter of wood, about the foot or leg, he is said to be stubbed.

Styptics. Medicines which stop bleeding. The most effectual method of stopping bleeding, is to tie the wounded vessel.

Sudorifics. Medicines which excite sweating. It is very difficult to sweat a horse, except the process be assisted by warmth and vapor externally. Lobelia, pennyroyal, and capsicum promote the insensible perspiration; they must be given in infusion to the amount of half a bucket or more.

Sulphur. Used in cutaneous diseases as an alterative.

Sweetbread. (See Pancreas.)

Synovia, Joint Orz. A mucilaginous fluid formed within joints, to render motion easy, or diminish friction.

$\mathrm{T}$

Tansy. A medicine used to expel worms.

TAR. Common tar is used as an astringent for horses' feet. 
Tartar, Cream of. Used on horses to promote the secretion of urine.

Tenaculum. A kind of hook, for taking up an artery.

Tendo Achillis. The great tendon, which is fixed or inserted into the calcaneum, or projecting bone of the hock.

Tendon. The white shining extremity of a muscle.

Tenesmus. Continual efforts to void dung, without any discharge.

Tent. A piece of lint, or tow; smeared with ointment, and thrust into a sore, in order to prevent a too hasty and superficial healing.

Thoracic Duct. The trunk of the absorbents. (See Absorbents, part first.)

Thrush. A disease has lately prevailed to a great extent in the New England States, which deserves some consideration. It is called thrush, and is supposed to be a disease of the horse's frog, consisting in a discharge of matter from its cleft, or division; sometimes the other parts of the frog are also affected, - become soft, ragged, and incapable of affording protection to the sensitive frog, which it covers. We cannot agree with many writers, that thrush is a strictly local disease; for after it has passed through the different stages, viz., inflammation, suppuration, \&c., the whole system takes up the diseased action; either by sympathy or irritation. Hence the reader will see the folly of depending on local agents, in the form of ointments, for the cure of the disease, in which all the organs are more or less concerned.

The internal remedies we recommend are alterative powders; remove the cause, if any exist, in the form of bad ventilation, poor diet, hard work, partial grooming, or the sluicing of cold water on the legs. Let the animal have bran mashes, with a few boiled carrots, every night.

The local remedies consist in paring away the ragged or uneven parts of the frog; then wash the surface with castile soap and lukewarm water; afterwards with a solution of common salt, in the following proportions: one tablespoonful Liverpool salt to a pint of rain water; then apply a small 
portion of hoof ointment in the cleft of the frog; let the whole surface be covered with tow, then upon the tow place a flat piece of wood, about the width of the frog, - one of the ends passing under the toe of the shoe, the other extending to the back part of the frog, and bound down by transverse slips of wood, the ends of which are to be placed under the shoe. The moderate pressure thus applied, will contribute materially to the cure and to the production of solid horn. This dressing must be repeated daily. If, after this treatment, matter should discharge, the heel contract, and the horn soften, then apply a poultice of Indian meal, with half a tablespoonful of cayenne pepper on the surface, washing the foot, as above, every night.

Tibia. The bone of the horse's thigh; that is, the bone between the hock and the stifle.

TICкs. Insects that infest sheep and other animals. A strong infusion of lobelia will destroy them.

Tongue. The tongue is a muscular substance, composed of fibres variously arranged, by which it is rendered capable of that diversity of action which we observe; it has also several muscles attached to it. The small bone, to which it has a muscular attachment, is named os hyoides.

Tonrcs. Medicines that augment the strength of the body, such as gentian, wild cherry, poplar bark, \&c.

Trainjng. By the word training is meant, putting a horse in that state in which all the functions of the body are in equilibrium. In order to bring a horse into this desirable state, we refer the reader to articles Feeding, Exercise, \&c., part first.

Tubercles. Small tumors that sometimes suppurate and discharge pus; they are often found in the lungs.

Tumor. A swelling on any part of the body. Tumors are of various kinds; sometimes caused by bruises, or other accidents; at others, arising without any visible cause.

Tunic. A coat, or membrane, investing a part; such as the tunica vaginalis of the testicle.

Turgescence. An over-fulness of the vessels in any part. 
Turmeric. Turmeric root, an aromatic stimulant, sometimes used in jaundice or yellows.

Twiтcr. An instrument made by fixing a noose, or cord, to the end of a stick; this is put on the horse's upper lip and twisted rather tight, which makes him stand quiet during an operation.

Tympanx. A distention of the abdomen by air.

Typhus. Putrid fever.

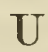

UdDER. The udder is a glandular body, wnose office is to secrete milk. It is divided, in the cow, into four quarters; each of which has an excretory duct, or teat, whose office is to facilitate the extraction of milk. At the extremity of each teat is a contrivance for the purpose of retaining the fluid contained in the udder, until it becomes much distended; when, if not drawn off, it flows spontaneously, and the animal is thereby partly relieved of her burden. Sometimes the udder swells and becomes sore, and is often caused by improper feeding. As there is great sympathy existing between the stomach and udder, whatever deranges the former will also affect the latter, through the medium of sympathetic action. In this case, the cow should be drenched with a tea of pennyroyal and thoroughwort, and fed on gruel. The udder should be fomented with an infusion of mullein leaves. Should the swelling continue and appear painful, the following embrocation may be used: linseed oil and lime water, equal parts, mix. If an abscess forms, and matter can be felt, it should be opened at its most depending part, so that the matter may run freely off.

UlCERS. There are quite a variety of ulcers to be found in animals; the most of them will heal by the application of a mild astringent, or tonic, such as an infusion of barberry bark, or the tincture of capsicum. If it be foul or callous in any part, then powdered bloodroot will be proper. 
URETERS. Two small tubes by which the urine is conveyed from the kidneys to the bladder.

Urethra. A membranous and muscular tube by which the urine is conveyed from the bladder; it is of considerable length in the horse.

Urine, Excessive Discharge of. (See Dubetes.)

Urine, Incontinence of. (See Incontinence.)

Uterus. The womb. The uterus of the mare is very unlike that of the human subject, in whom it consists of one bag, rather of an oval shape, somewhat resembling a pear; but in the mare and other quadrupeds, it has a body and two branches, called its horns. The uterus terminates in the vagina by a narrow portion, called the neck, or mouth of the womb. The extremities of these horns have tubes attached to them, which, from the name of the discoverer, are called Fallopian tubes; one end of each is expanded, and has a fringed kind of edge: this is named the fimbria of the Fallopian tube. The Fallopian tube is very tortuous in its form; and that end which proceeds from the horn of the uterus is extremely small; but the other, which is slightly attached to the ovarium, is considerably larger. The ovarium is an oblong body, about the size of a small hen's egg. The ovaria - for there are two of them - are composed of a number of transparent vesiculæ, called ova, (eggs;) each ovum is surrounded with cellular membrane ; and when the ovum is inpregnated and passes into the uterus, it leaves a mark which is named corpus luteum.

Uvula. In the human subject, the small flesh-like substance hanging in the middle and back part of the throat is thus named. In the horse this is of a very different form. The uvula completely closes the opening to the pharynx, though it readily yields to the passage of food, or any liquid, towards the gullet; it prevents, also, there turn of any thing to the mouth, even the air which is expired from the lungs, unless it be thrown aside by a violent effort, as in coughing. It is on this account that, when the horse is affected with nausea, or has the action of the stomach inverted, - which 
sometimes happens, though very rarely, - the contents of the stomach will be discharged through the nostrils; but if the horse happens to cough during the process, some part will be discharged by the mouth.

\section{V}

VAgINA. The passage from the external pudendum, or shape, to the mouth of the womb.

Valerian. The root of valerian is used as an antispasmodic ; its virtues have been underrated by writers on veterinary medicine.

Veins. The motion of the heart is known to communicate momentum to the blood through the veins. Mr. Percival says, "We are not to reject the power of the heart altogether, merely because the blood flows with a uniform stream in the veins; for the absence of pulsation in them is no proof that the motion of the blood is not influenced by the contractions of the heart; the extreme division which this fluid undergoes in its circulation through the capillaries, and the tortuosity and complication of the numberless small veins, account for the regular and uninterrupted stream which we meet with in the larger branches. To prove that this is the explanation of the fact, if you open a vein that has free and direct communication with the extremity of an artery, (its capillary structure, ) the blood will flow from it with the same pulsatory motion, as if the artery itself had been penetrated; but if the vein be one of large size, remotely situated from any arterial communication, or if it be one that springs from the union of numerous capillaries, that smooth and even stream, with which the blood circulates in the trunks, will be observable here. These facts, then, lead us to conclude that the force of the heart is not sufficient of itself to propel blood through the venous system.

From the collected accounts of writers on this subject, it seems highly probable, that the blood flowing in the veins receives additional momentum from the reaction of the 
capillaries, and that it is further urged on by some contractile force resident in these vessels themselves. That the blood is advanced in its course by the action of those muscles contiguous to veins furnished with valves, is, without doubt, well founded, as far as an occasional auxiliary is concerned, as the common operation of bleeding demonstrates; for it is in consequence of muscular pressure upon the veins about the head, that the motion of a horse's jaw accelerates the flow of blood through the jugular vein: as such, however, it cannot be ranked among the essential causes of the blood's motion in them.

Ventricle. One of the cavities of the heart. (See Heart.)

Vermifuge. Medicines that destroy or expel worms.

Vertebre. The bones of the neck and spine.

Vertigo. A slight degree of apoplexy.

Viscera. The plural of viscus, a term applied to the internal organs, as the lungs, bowels, \&c.

Vives. A swelling of the parotid gland, which is situated between the ear and the angle of the jaw.

Vulva. A name given to the external parts of generation in females.

\section{W}

Wall Eyes. A horse is said to have a wall eye, when the iris is of a light or white color.

Warbles. Small, hard swellings on the horse's back, caused by the pressure, or heat, of the saddle.

Warts. Spongy excrescences which arise in various parts of the body.

Water. (See Watering, part first.)

Wens. Hard tumors, of various sizes, in different parts of the body. The most effectual method of removing them is, to dissect them out, together with the cyst, or bag, in which they are formed. The skin is then to be stitched up, and treated as a common wound. 
Whirl Bone, or Round Bone. The hip joint is thus named.

WIND. The most effectual method of bringing a horse to, is to give him regular exercise. (See Feeding, Exercise, \&c., part first.)

Windgalis. Elastic tumors on each side of the back sinews, immediately above the fetlock joint; they are often caused by hard work, or trotting on hard roads, at too early an age. There are various operations recommended, such as firing, blistering, \&c. ; but the remedy is generally worse than the disease. Rest, bandaging, and the occasional use of liniment, is all that can be done with safety.

Wrthers. The part where the mane ends is thus named in the horse.

Worms. The stomach and bowels of horses are liable to be infested with different kinds of worms; but as the same treatment is proper, of whatever kind they may be, it is needless to enter into a particular description of them. (See Botтs.) Many articles are recommended by veterinary writers, for the purpose of ridding the animal of these pests, viz., antimony calomel, turpentine, either of which would be just as likely to kill the horse as the worms. The true indications to be fulfilled are to tone up the stomach and digestive organs. (See Worm Powder, in the Appendix.*

\section{$\mathbb{Y}$}

\section{Yard, Fallen. (See Falling of the Yard.)}

YARD, Foul. The horse's penis sometimes requires to be washed with soap and water, in order to free it from mucous matter and dirt.

* Dr. J. Hinds says, "Since the worms are not always to be killed, even by strong poisons, (calomel,) nor brought away by brisk purgatives, reason dictates, and nature beckons us to follow her course in affording to the horse a run at grass; if that is impossible, adopt the means nearest thereto that. lie within our reach." If calomel is a poison, - and thousands declare it is, - then it must entail a disease more formidable than the one it is intended to cure, 
Yellows. This disease is indicated by a yellowness of the membranes that line the eyelid, and the inner parts of the lips and mouth. In this disease, the natural course of the bile is perverted; it becomes absorbed into the circulation, and thus tinges the membranes and fluids of a yellow color. The excrement is generally of a lighter color than usual. The disease may be produced by a want of tone in the liver, caused by obstructing the surface. 


\section{APPENDIX.}

\section{DESCRIPTION OF THE ORGANS OF DIGESTION IN THE OX.}

Esophagus, or Gullet. - This tube extends from the mouth to the stomach, and is the medium through which the food is conveyed to the latter organ; this tube is furnished with spiral muscles, which run in different directions. By this arrangement, the food can ascend or descend at the pleasure of the animal. The inner coat of the gullet is a continuation of the same membrane that lines the mouth, \&c. The gullet passes down the neck, on the left of the windpipe, until it reaches the diaphragm, through which it passes, and terminates in the stomach. The food, having undergone a slight mastication by the action of the teeth, is formed into a pellet, and, being moistened by the saliva, passes down the gullet, by the action of the muscles, and falls immediately into the paunch, or rumen : here the food undergoes a process of maceration, or trituration. The food, after remaining in this stomach some time, and the whole mass having been submitted to the action of heat and moisture, passes into another division of the stomach, called the reticulum, the inner surface of which abounds in cells; at the bottom and in all parts of them, there are glands which secrete from the blood, and furnish for the use of this portion of the stomach, a quantity of mucus. This stomach possesses properties similar to those of the bladder and stomach of the horse, viz., that of contracting upon its contents. In the act of contracting, it squeezes out a portion of the semi-masticated food which comes within the reach of the ascending spiral muscles, is embraced by them, and thus ascends the gullet, and passes into the mouth for remastication. The second stomach 
again receives a portion from the paunch, which passes into the stomach in the manner just described.

Rumination and digestion are mechanico-vital operations, and can only be properly performed when the animal is in a physiological or healthy state.

Now, a portion of the food, we just observed, had ascended the gullet by the aid of the spiral muscles, and entered the mouth; it is again submitted to the action of the grinders, and a fresh supply of saliva; it is at length swallowed a second time. It is now of a softer consistence, and better adapted for assimilation. Instead of falling, as at first, directly into the paunch, it continues on to the third division of the stomach, called the manyplus, or manifolds. This division of the organ abounds internally in a quantity of leaves, called laminæ. Some of these are attached to the upper and lower portion of the division, and also some of the laminæ float loose, and penetrate into the osophagian canal. The laminæ have numerous projections on their surface, resembling those papillæ on and around the base of the tongue. The action of this stomach is one of alternate contraction and expansion; this motion is jointly communicated to it by the action of the diaphragm, and its own peculiar arrangement. It will be readily perceived, that by this arrangement the food is submitted to a sort of grinding process. The papillæ, or prominences, present a rough and hard surface, sufficicnt to grind down the food, unless it be of too fibrous a nature, such as fox-grass, corn-stalks, \&c. These articles make sad havoc in this and other organs, owing to their unyielding nature. They overtax the digestive organs; debility ensues; sympathetic action is set up, and a general derangement follows.

The farmer, as Gov. Briggs observes, "is ignorant alike of the disease and the remedy." The neighbors are called in; down go castor oil, aloes, gin and molasses, in rapid succession. He has got inflammation of the insides, says one; give him a half pound of salts : no sooner said than done; the salts are hurried down, and, of course, find their way into the 
paunch. These, together with a host of nostrums too numerous to mention, are tried without effect; all is commotion within; fermentation commences; gas is evolved; the animal gives signs of woe. As a last resort, paunching, bleeding, \&c., follow, and the animal dies under the treatment. A case similar to this came under the author's notice a short time ago. A cow had been indisposed for several days. A man, professing to understand the treatment of disease in domestic animals, was sent for; after giving the usual remedies, without success, he administered a mixture of hog's lard and castor oil. He stated that the object was to wake up the cow's ideas! but, unfortunately, he awoke the wrong ideas, for the cow died a few hours afterwards.

For the information of our readers, we will give two specimens of the recipes used and recommended by the worldlywise for horses.

"To cure a Stifled Horse. - Take one gallon of urine, a small handful of junk tobacco, b.ill down to one quart, then add two ounces of oil of spike, one ounce of oil of amber, two of honey. Rub the stifle hard with the mixture, and dry it thoroughly in with a red-hot fire shovel"(!) (See Green Mountain Freeman, of Nov. 29, 1849.

Our own views of this subject are, that it is the relics of a cruel and barbarous system. The only party that would be likely to derive benefit from the operation, would be the man from whom the shovel was purchased.

Another, from the same Paper. - "For lameness of the shoulder, apply alum salt to the part affected, and rub up and down the shoulder with a brick." (!)

The fourth division of the stomach of the ox is called abomasum. It somewhat resembles the duodenum of the horse, and is the true digestive stomach; it is studded with numerous nerves, blood-vessels, and glands. It is a laboratory admirably fitted up by the Divine Artist, and is capable of carrying on the chemico-vital process as long as the animal lives, provided the healthy functions are not impaired. The glands alluded to secrete from the blood a powerful solvent 
called the gastric juice, which is the agent in reducing the food to a fluid, called chyle: this, however, is accomplished by the united agency of the bile and pancreatic juice; both these fluids are conveyed into the abomasum by means of small tubes or canals. The nutritious portion of the food is taken up by the lacteals and absorbents, (in the same manner as we have already described in the horse;) it then passes on to the thoracic duct, and enters the circulation. 'The feculent matter passes along the intestines, accumulates in the rectum, and is voided at the will of the animal.

The spleen or melt, is an oblong, dark-colored substance, attached to the paunch. It is composed of blood-vessels, lymphatics, and nerves, united by cellular membrane. It appears to serve as a reservoir for the blood that may be designed for the secretion of bile in the liver.

The liver is a dense gland, composed of two lobes, situated below the diaphragm, or skirt, extending to the right side. There is a large vein enters the liver, called vena porta, or gate vein. The blood that passes from the intestines, instead of returning directly to the heart, accumulates in the vena porta; the latter ramifies into innumerable small vessels, through the substance of the liver, from which the bile is secreted; the blood then passes on to the heart.

The bile, having been secreted from the blood, accumulates in the gall bladder, where it is kept for future use. When the healthy action of the fourth stomach is interrupted, the bile is supposed to be reabsorbed, enters the circulation, and invariably produces yellowness of the eyes; the disease is then termed yellows, jaundice, \&c. Sometimes the passage of the bile into the fourth stomach is obstructed by calculi, or gall-stones; they have been found in great numbers in oxen.

The pancreas is composed of a number of lobules, or glands ; a small duct proceeds from each; they unite and form a common canal, which proceeds towards, and terminates in, the fourth stomach, where it assists in the process of digestion, as already stated. 
The intestines assume the same names as those already described in the horse. They are more capacious, and of a greater length, than those of the horse.

Internal and External Relations.-Through the instrumentality of the nervous structure, there is constantly a sympathy kept up between the different parts of the animal; whenever any part is affected, the corresponding part feels the influence. Thus the external surface is opposed to the mucous and serous membranes, as of the lungs, alimentary canal, pleura, and peritoneum; so that if the function of either of these be diminished, or excessive, or suspended, that of the corresponding, or antagonistic, will soon become excessive, or suspended, and the restoration of the lost function is the only true way to effect a cure; hence we repeat what has aiready been stated in part first.

The indications of cure are, to relax, contract, stimulate, and furnish the animal with proper materials for nutrition: this constitutes the whole modus operandi of the medical art.

For example, if the animal is suffered to feed in wet situa tions, the feet and external surface become cold; and hence catarrh, garget, and fluxes, the only sure cure for which is to remove the animal to a dry, warm situation. Restore the lost function by rubbing the surface, and by the application of warmth and moisture; if there is not enough vitality to equalize the circulation, administer warm antispasmodics, (which see.) If the feet are chilled by standing in damp pastures, the circulation of the blood is interrupted, and it will accumulate in the cranium or abdomen.

Again, if the manyplus is distended with food, the animal will appear dull and sleepy, and the proper correction is to dilute the accumulated mass with warm stimulants.

If a mass of hardened food is suffered to remain in any part of the stomach for want of power in the digestive organs to assimilate it, then irritation is the consequence, and inflammation follows. The reader must remember that inflammation is the concentration of the available vital force too much upon a small region of the body, and that it is invited there 
by irritation. Now, the most rational way to proceed is, to remove the cause of irritation, (no matter whether the stomach or bowels are involved, ) and invite the blood to the surface by counter-irritants, (see list of medicines, and distribute it over the general system, so that it will not be excessive any where. This mode of relief is termed counter-irritation. The popular method is to concentrate vital action to a certain spot in the form of a blister, composed of cantharides, which is generally worse than the form of irritation they wish to relieve. We do it by inviting action to all parts of the surface, and of course, throngh all other parts of the body, through the relaxing influence of our medicines. There is generally but little difficulty in producing an equilibrium of action; the great point is to sustain it. When the blood accumulates in a part, as in inflammation of the bowels, the sensibility of the part is so highly exalted that the least irritation calls it back again; hence we recommend bland teas and mucilage of slippery elm to sheathe the surfaces from irritation.

Horn-Ail in Cattle. - On applying the hand to the horn or horns of a sick beast, an unnatural heat or coldness is felt ; this enables us to judge of the degree of sympathetic disturbance; and here, reader, permit us to enter our protest against a cruel practice, that is much in fashion, viz., that of boring the horns with a gimlet, for it does not mend the matter one jot. The gimlet* frequently penetrates into the frontal sinuses which communicate with the nostril, and where mucous secretion, if vitiated or tenacious, will accumulate. Sometimes pus is formed in these sinuses, resulting from common catarrh or hoove; the gimlet often penetrates the sac in which the pus is contained, and matter follows the withdrawal of the instrument, and the operator sagely concludes that he has hit the right spot. Should the animal by any means recover within the space of a week or two, the recovery is strangely attrib-

* When the horns are bored in a transverse direction, and the gimlet passes between the horn and ossific structure, it enters the sinus, and the builglel, niecting with no resistance, concludes that the horn is hollow. 
uted to the boring process. An author whose name has escaped our memory, recommends "cow doctors to carry a gimlet in their pocket." We say to every man, Lead yourselves not into temptation: if you put a gimlet in your pocket, you would be likely to slip it into the cow's horn. Some men have a kind of instinctive impulse to bore the cow's horn; of course we allude to those who are unacquainted with the nature of the malady. It is no more a disease of the horns than it is of interrupted secretion, absorption, \&c., finally, the whole mucous membrane. Horn-ail —as it is improperly termed, for it is only a symptom of derangement - may result or accompany common catarrh, also that of an epidemic form; the horns will also feel unnatural if there is a determination of blood to the head: this might easily be equalized by stimulating the external surface and extremities : a general temperature would be the result. The horns will generally be found hot whenever the vascular structure in the immediate vicinity is distended beyond its physiological state, on account of the ingesta and egesta - what passes in and out - not being duly proportioned : the blood-vessels then become expanded and hot, and febrile symptoms follow; and this loss of equilibrium may result from suffering the animal to wallow in filth, or be exposed in damp situations, thereby constricting the surface, and driving the circulation to the internal organs.

If the insensible perspiration is checked, then it is determined to serous and mucous membranes, and results in hoove, or catarrh, abscesses, dropsy, congestions, hemorrhage, diarrhœa, \&c. Thus, in some cases, the dry and contracted state of the surface determines the fluids that would naturally go there to the internal canal, as the kidneys, producing red water, or to the bowels, producing diarrhœa; but first confines morbific matter in the system, and from it abscesses are formed; sometimes in the udder, called garget; at other times in the frontal sinuses, called horn-ail. In most cases, absccsses will determine towards the external surface, as on the udder, and be discharged; or to the mucous, as in those of the 
head, which are generally discharged by the nostril, if not interrupted by the gimlet and officious meddling.

The mucous membrane is a duplicature of the skin, and is folded into all the external orifices of the animal, as the mouth, ears, nose, lungs, stomach, intestines, and bladder ; but not being exposed to the action of external agents, it is not so strong or thick as the skin. It performs nearly the same office as the skin. If the action of one is suppressed, the other immediately commences the performance of its office : thus a common cold, which closes the skin, immediately stops insensible perspiration, which is now forced through the mucous membrane, producing a discharge from the nose, eyes, bowels, \&c.; so, when great derangements of the mucous membranes exist, debilitating perspiration succeeds. It is evident that a proper attention to pasturing, stall-feeding, and due consideration of the comfort and convenience of the animal, would prevent horn, as well as any other ail that neat cattle are often attacked with. If the horns are cold, it is indicative of disease in the lungs, liver, or intestines; if they are hot, the fluids are determined to the brain.

Mr. Lawson thus discourseth on the diseases of cattle: "It is much to be lamented, that few men of requisite knowledge and experience have written on this subject. The recipes usually recommended are perplexing from their number, useless, or, rather, pernicious, from the heterogenous ingredients they contain, and far too expensive for general use.

"It should be considered that animals living in a state of nature, regulated by the experience and reason of man, would be almost wholly exempt from disease ; that their appetites, unlike our own, may be held under a constant control ; that their diseases result purely from the negligence or erronenus treatment of their owners. They are either exposed too much to the rigors and changes of the weather, or they are gorged with food, denied a sufficient quantity, or supplied with such as generally proves injurious. Hence we learn the chief causes of their maladies.

"Learn to prevent them, instead of undertaking the tedious, 
unsuitable, and hopeless task of learning to cure them. Of all things, let the proprietors of cattle renounce forever the insane folly of offering premiums for curing incurable diseases, and the hope of providing medicines, which, by a sort of miraculous operation, will enable men to continue in the habit of exposing their animals to the constant risk of such diseases."

In addition to these remarks, Dr. White says, "Almost all the diseases of cattle arise either from exposure to wet and cold weather, from their food being of a bad quality, or deficient in quantity, or from being changed too suddenly from poor, unwholesome keep to richer pasture. It is necessary to observe, also, that the animal is more liable to be injured by exposure to wet and cold, when previously enfeebled by bad keep, old age, or any other cause; and particularly when brought from a mild, into a cold, situation, I have scarcely met with a disease that is not attributable to a chill. The foolish, expensive, and dangerous medicines prescribed in works on cattle doctoring must have ruined and destroyed many a valuable animal. These books - referring to Clater, Downing, \&c. - are written in the old style of quackery, and display the grossest ignorance of the subject, which is attempted to be concealed under a multitude of unintelligible words."

The author has been consulted in several cases of disease misnamed horn-ail. In the case referred to, there were slow fecal movements or constipation; the conjunctiva of the eye was injected with yellow fluid, and of course a deficiency of bile in the abomasum, or fourth stomach. The indications were, to promote a healthy action through the whole system, stimulate the digestive organs, remove obstructions, and produce counter-irritation on the external surface. The following certificate - which was received from Deacon Osgood, a highly respectable farmer of Lancaster, Massachusetts, - will show the result of the treatment:- 
"Lancaster, Oct. 9, 1848.

"Messrs. Stinipson \& $\mathbf{R}_{\text {EED }}$ : - In July last, I had a valuable cow attacked with what is commonly called horn-ail, which so reduced her that in a short time she was unable to stand. I administered all the remedies within my knowledge; but she continued to grow worse, and I thought she must dic. The nedicines prepared by Dr. Dadd were then recommended to me by a friend who had used them, and so sanguine was he that they would relieve her, that he procured some, and wished me to use them, which I did with surprising effect. I applied the Liquid Blister a few times, rubbing it in between the horns, and at the same time gave a Physic Ball; and in three hours afterwards the cow was able to get up alone. I then gave the Distemper Powder, and she soon got entirely well. Dr. Dadd's medicines I think are invaluable to farmers and others dealing in cattle, and only require to be known to be extensively used

PETER OSGOOD." 



\title{
DADD'S HORSE AND CATT'LE MEDICINES,
}

\author{
SOLD BY
}

STIMPSON \& REED, No. 26 Merchants Row,

BOSTON.

\begin{abstract}
Also, at Dadd's Horse and Cattle Medicine Depôt,
Nos. 1 \& 2 Haymarket Square, Boston.
\end{abstract}
WITH DIRECTIONS FOR USING THE MEDICINES, AND REMARKS ON VARIOUS DISEASES, THE PROPER
METHOD OF CURE, \&C.

For the convenience of those who have not the time, or means, to make themselves acquainted with our system of practice, we manufacture various kinds of medicine for the prevention and cure of disease; they have been before the public but a short time, and have generally given satisfaction. These compounds are manufactured under the superintendence of the undersigned, who has had ample opportunities of making himself acquainted with veterinary practice, and who has endeavored to obtain a correct knowledge of the modus operandi of therapeutical agents to the cure of disease, and whose chief object has been to combine those agents, that, when given in small quantities, are capable of exciting and increasing the natural functions, without diminishing or destroying their power.

Every description of medicine, used for horses or cattle, can be procured, with suitable directions for their use.

Persons shipping horses can be supplied with every requisite for the voyage.

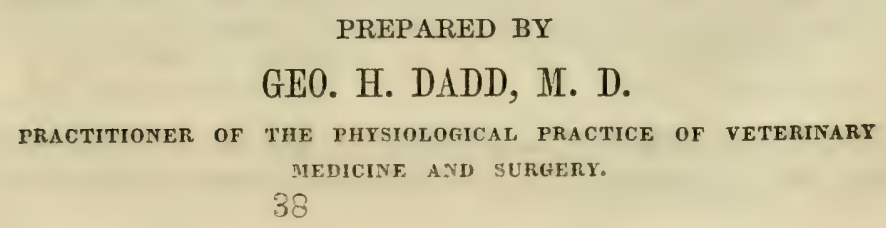




\section{LIST OF MEDICINES AND RECOMNENDATIONS.}

Physic Balls. These are useful in constipation. They are not intended to act as a powerful cathartic, for, as Dr. Gregory observes, "purgatives, besides being uncertain and uncontrollable, often kill from the dangerous debility they produce." These balls are a combination of relaxent, tonic, and stimulant properties, and can generally be used with safety.

Alterative Powder. This is a valuable condition powder, and is the result of many years' practical experience. It may be used with success in vertigo, staggers, and all complaints depending on impaired digestion; also in cutaneous diseases, viz., mange, scabby eruptions, scratches, humors, \&c. It may also be given as a palliative in those incurable diseases, termed glanders and farcy. It is highly recommended for rot, murrain, and diseases of sheep and cattle. Price 50 cents per box.

The following has been received from the Postmaster at South Woburn.

Sept. 22, 1849.

Dr. DADp. Dear Sir:-At the request of a friend, I called at your office to procure a box of Alterative Powders, for which I paid 50 cents. I now take this opportunity to add my testimony in favor of its astonishing and beneficial results. One month ago, my horse, which I value highly, was poor in flesh, with a staring coat and scurfy, but by the use of the above powder is now seventy-five pounds heavier, with a clear skin and glossy coat; this, I am prepared to say, is entirely the result of your powder. If I should be asked which I should prefer to keep my horse healthy, clean, and fat, a box of your powders, or five bushels of the best grrain, I should say the former. My opinion is that the powder acts on the system safer and better than any other treatrient can. Yours, \&c.

\section{N. A. RICHARDSON.}

Boston, Oct. 8, 1849.

Dr. DADD. Sir:-In answer to your inquiry concerning my horse, I would remark that I paid the sum of $\$ 21$ to a horse doctor, without the least appearance of any benefit being derived, and that the box of Alterative Powder, obtained from you, established the health of my horse in a short time. I shall be happy, at any time, to recommend your medicine to my friends.

E. S. CONVERSE.

NEW York, Nov. 29, 1848.

This is to certify that I have used Dr. Dadd's Alterative Powders, and can highly recommend them to the public, as I have tried them, and they have had good success. I have no hesitation in saying they are invaluable, and what are much needed in this large city. I have also tried some of his other compositions, and can highly recommend them also to the public.

INOSES C. BROWN,

No. 93,24 th street, N. Y

Worm Powders. For the removal of worms from the intestinal canal, where, from their presence, they are productive of serious consequences, 
preventing the proper assimilation of the food, destroying the appetite, and causing the animal to lose flesh, and become incapable of continued exertion. These powders are not intended as a direct vermifuge to kill and expel worms directly, yet they do so in some cases. (See certificate from $A$. B. F. Hildreth, Editor of Family Gazette) They act indirectly by toning up the digestive organs and preventing the food from running into fermentation. Price 50 cents per package.

There are no infallible symptoms by which the presence of worms, in the bowels, can be readily distinguished from intestinal irritation, or indigestion, for the latter will be attended with similar symptoms as above.

The author was called in the month of March, 1848, to make a post mortem examination of a horse. The owner stated, that the animal had been treated for a discase of the kidneys, and that the hind extremities were paralyzed some hours before death. There was no emaciation, tucked up belly, or staring coat; the lungs, spleen, kidneys, and pancreas, were in a healthy state. On making an incision into the small intestines, a large number of the teres, or long, round worm, were found; these were traced to the duodenum, and finally, about six wore found in the stomach: in all, about a peck was taken away. Some writers suppose that worms are bred by the mucus in the almentary canal, and others that they always exist, and are necessary to health. I have examined the intestinal canal of many animals, and am fully convinced that no such creatures can be discovered in healthy animals. The proper treatment consists in imparting healthy action to the digestive organs, which the Worm Powders generally accomplish, and sometimes result in the expulsion of the worms. (See following certificate.)

Bradford, Vt., Aug: 1, 1849.

Messrs. Stmupson \& Reed:- I talie much pleasure in expressing my high opinion of Dr. Dadd's horse and cattle medicines. I know several instances in which they have been used with much benefit; but I will mercly relate my own experience with using the Worm Powder. Some time last season your travelling agent left me a pamphlet, giving a list of Dr. Dadd's horse and cattle medicine, together with remarks on the canses, symptoms, and treatinent of diseases in horses and cattle. This pamphlet 1 perused with some care. Last winter, my horse betrayed various symptoms, such as occasional coughing, restlessness in the stall, frequent biting of his sides, \&c., which led me to believe he was troubled with worms. I procured a box of Dadd's Worm Powders, and was four or five days in feeding them to him. I then had occasion to drive him some six or eight miles, and soon noticed, from the frequent evacuations, that he was under the operition of physic ; and by more particular observation I discovered that an infinite number of worms, from three to six inches long, were ejected - not whole, but cut into innumerable shreds. From that time my horse had an increased appetite, began to thrive, and has done well ever since. Yours truly,

A. B. F. HILDRETH,

Editor of Family Gazette.

Diuretic, or Urine Powders, for all obstructions of the kidneys, bladder, or urinary organs. These powders are celebrated for promoting the secretion 
and excretion of urine, and inducing a healthy action of the parts. When the urine is thick and turbid, deficient in quantity, or voided with difficulty, a few doses will generally give relief. These powders tone up and strengthen the secreting organs, equalize the general circulation, promote perspiration, and determine morbific matter to the surface. It is the only medicine that can be used with any chance of success in hydrothorax, or an effusion of serum in the cavity of the chest; in dropsy of the abdomen; or in cases of swelled legs, oftentimes caused by an effusion of water into the cellular tissue. They may be given with safety to all kinds of animals. Price 50 cents per package.

Charlestown, Jan. 12, 1849.

Dr. DADD. Sir:-You desired me to send you word what effect the "Urine Powders" and "Healing Balsam" had on my cows, one of which was troubled with bloody milk, and the other with a large bunch on the ndder. I gave the powder according to your directions, in the first case; the bloody discharge was arrested in a few hours, and no traces of it remain. And in the latter, the swelling commenced decreasing in size shortly after the first dose. The animal, which was wounded so badly in the side, is quite well. The "Healing Balsam" acted like a charm, and from what I have witnessed of the good effects of your medicines, I am safe to say that as soon as they are known they will be extensively used.

Yours, with respect,

E. S. WALDEN.

Hcave Powder, for heaves, pneumonia, thick wind, chronic cough, roaring, bronchitis, catarrh, and all diseases of the respiratory organs, general debility, and loss of condition. There are no diseases that produce sucl disastrous effects as those enumerated; and there is no known remedy that has been able to grapple with the dire foe with such extraordinary success, as Dadd's Heave Powder. Abundant testimonials are in the hands of the proprietors, sufficient to establish the fact beyond a doubt.

These powders promote and maintain an equilibrum between the secreting organs, and are offered to the public with entire confidence, being free from all deleterious articles. A single trial will satisfy every one of their efficacy. Put up in packages, at 5.0 cents and 25 cents each.

Rochester, N. H., Dec. 29, 1848.

Sir:- Having a horse severely affected with the heaves, a few weeks since, I called on you and purchased a box of "Heave Powders," (Dr. Dadd's, ) which I administered according to the directions, with the most satisfactory result. They gave immediate relief, and completely cured the complaint in a few days. The horse is now perfectly well, with no appearance of disease. I consider the Heave Powder a most valuable medicine, and would recommend it to all having occasion for an article of the kind, as eminently worthy of confidence.

To S. J. Bulungs, Druggist, Great Falls, N. H.

Boston, Aug. 8, 1849.

This is to certify, that I have a horse which was afflicted for over one year with heaves, and that I used Dr. Dadd's Heave Powder for a short time, 
which has cured him entirely. I may add, that I have had considerable experience in the practice of horse medicine, and have never found any thing that would act with such surprising benefit, in so short a time.

$$
\begin{aligned}
& \text { JOHN FREEMAN, } \\
& \text { Boston, Mass. }
\end{aligned}
$$

Lancaster, July $25,1848$.

Messrs. Stumpson \& Reen. Gents:- Last winter, a young horse of mine was attacked with a bad cough and shortness of breath; for the cure of which $\mathrm{I}$ followed the directions of a horse doctor, until he pronounced him incurable, and in consumption. I then heard of the medicine sold by you, and prepared by Dr. Dadd, which I procured and used with entire success. The cough and shortness of breath were relieved, and I now think the horse well. The articles I used were Heave Powders and Liquid Blister.

JOHN 'THURSTON.

Horse Liniment, for rheumatism and sciatica, sprain of the muscles or tendons of the back, stifle, lameness, enlarged joints, and lameness of every description. In the absence of acute symptoms it may be safely depended on, as it has never yet failed of giving satisfaction. The basis of this preparation was first used in combination, by the celebrated G. Bott, of Nottingham, since which time the author has made valuable additions, which his experience in the physiological practice has rendered him competent to do. With the valuable additions that have bcen thus made, it is with the greatest confidence that we ask the public to give it at least one trial; we have never in a solitary instance, known the purchaser to be disappointed.

In old chronic cases of the human family, when every other article has failed of affording relief, try Dadd's Horse Liniment.

NEw YoRK, April 14, 1849.

Dr. DADD : - A short time since, a valuable horse of mine was taken lame, and, after using almost all the liniments sold here, I procured and used some of your Liquid Blister and Liniment, which has helped him so much that I feel assured he will soon be entirely well. I have also used your Alterative Powders, and can recommend them as good medicines.

$$
\text { Yours, }
$$

HENRY H. BROWNELL, 34 Canal street, N. Y.

Distemper Powder. This is a truly valuable article to the farmer and stable-keeper; for, if given occasionally, during the spring and summer months, it will prevent distemper in every form; it will, if given in senson, arrest malignant epidenic, catarrh, which often terminates in glanders. In black tongue, horn-ail in cattle, rot in sheep, and red water in cows, it is invaluable. Price $\$ 1$ per bottle.

\section{Extract of a Letter from the Hon. Daniel Webster.}

Marshfield, Aug. 17, 1849.

Dr. Dapb. Dear Sir:-I was sorry to be absent when you called this morning, as I should have been glad to see you.

In relation to the subject of your inquiry, $I$ am happy to say that the 
medicine* which you furnished to $\mathrm{Mr}$. Whiting proved very effectual for the curing of my sheep. The disease was brought into the flock by an imported Leicester buck. It did great injury, and produced considerable loss, but has quite disappeared.

If you shall be equally successful in the treatment of the diseases of which so many fine cattle have died within three or four years, you will do the farming and cattle-growing interests great benefit.

With respect, yours,

D. WEBSTER.

Healing Balsam, for saddle galls, cuts, wounds, bruises, and foul ulcers, for horses or cattle. For description, see directions. Price 50 cents per bottle.

Hoof Ointment, for horses or cattle. This valuable remedy is the only article recommended by the faculty of London and Edinburgh ; for the simple reason, that it does not evaporate so readily as many preparations in use. It is used with great success in brittle hoof, sand crack, lameness from bad crack, fever, and contraction of the foot; it preserves the elasticity of the crust, and allows the sole to descend to its proper position. Those who own oxen, should never be without this article, for their feet are constantly exposed to injury from rough roads and bad shoeing. Price 50 cents per bottle.

Ointment, for mange, scratches, old sores, and all diseases of the skin. It is a well known fact, that horses or cattle are very apt to become mangy, if kept long in the stable without grooming; yet these diseases may arise from causes independent of a neglected skin, but they seldom trouble a wellcleansed animal. This is an important subject to the stable-keeper, for diseases of the skin produce derangement of functions in the stomach and bowels. Price 50 cents per bottle.

Oiniment, for promoting the growth of hair. For horses or cattle, whenever a blemish is produced, either by accident or design, this ointment will promote the perfect growth, and restore it to the original color in a few days. Price 50 cents per bottle.

\section{Directions to those who use Dadd's Horse and Cattle Medicines.}

Endeavor to ascertain, and remove, the direct or exciting causes of disease; they may be found in improper ventilation of the barn, or stable, damaged food, over-feeding, want of cleanliness, over-exertion, and many other causes too numerous to mention, but equally important to the farmer and stable-lieeper.

N. B. Whenever the dry powders are administered in the food, the latter should be wetted, to absorb the fine particles.

Liquid Blister. This is useful in all cases where it is necessary to produce counter-irritation. It will be found very useful in chronic enlargement

* The medicine above referred to by Mr. Webster, was Distemper Powder and Mange Ointment. 
of the joints, inflammation of the lungs or intestines, putrid sore throat, mortification of the extremities, frost-bitten parts, and as a counter-irritant in horn-ail. Price 75 cents per bottle.

Liquid Blister. This is not what its name indicates, (a blister, ) for we would not have the reader suppose that blistering a part will assist us to cure disease; it is, more properly speaking, a counter-irritant.

Dadd's Chart of Veterinary Reformed Practice, being a synopsis of the diseases of horses, cattle, and sheep, with their causes, symptoms, and treatment. Price $37 \frac{1}{2}$ cents bound, 25 cents unbound. No stablekeeper, or farmer, should be without this valuable guide.

\section{IECONMENDATIONS IN FAYOR OF DR. DADD'S MEDICINES.}

[From the New York Ledger.]

We take pleasure in referring our readers to the advertisement of Messis. Stimpson \& Reed, of Boston.

These gentlemen are offering some of the best medicines for the cure of diseases incidental to animals, (and to the lorse especially,) that have ever been introduced in this country. The discoverer of these valuable medicines is the celebrated Dr. Dadd, whose reputation is so weil established as a skilful practitioner, that it needs no encomium at our hands. The doctor has spent many years in the study of veterinary practice, and has also availed himself of the researches of the reformers in medicine; he has commonced a new practice, which will prove of the greatest advantage to those who heretofore have despaired of curing their horses and cattle.

Cuintonville, Feb. 22, 1848.

Dr. DADD. Sir : - We have used your medicines now about four mouths, and they have given us perfect satisfaction in every case, and we can confidently recommend them. WHITCOMB \& HOLMAN, Livery Stable-Keepers.

\section{Newton, (Upper Falls, ) Nov. 10, 1848.}

This is to certify, that one of my horses, a few days ago, was very severely attacked with colic, and was entirely cured in a few hours by the use of Dr. Dadd's medicines. The case was a very severe one; the horse being in great distress, and, in all probability, must have died in a short time, had I followed the directions of the numerous advisers who were present, asserting that nothing short of bleeding conld save him; but having used Dr. Dadd's medicines with entire success, in bad cases of heaves, I had confidence in them, and procured the cordial drink, and gave it; alsu used tho Liquid Blister, which relieved AT oxce, and saved the life of my horse. I carnestly recommend all persons, who have sick horses, to use Dr. Dadd's medicines, believing that they will give entire satisfaction, and sive many valuable horses.

DAVID CORRILL.

[From the Merchant's Ledger, New York.]

Dadd's Cimate of Veterinary Reformed Practice. Br George H. DADD, M. D. We have received from the worthy publisher the above Chart. It contains a "synopsis of the diseases of horses, cattle, and sheep, with their causes, symptoms, and treatment." The author, from education and a thorough lnowledge of the subject, is eminently qualified to produce a Chart invaluable to the owners of horses, cattle, \&c., and from an exam- 
ination of this publication we are free to say, that it contains a vast amount of useful matter, and should be in the hands of all those for whom the work was mainly written. It can be had at Messrs. Stimpson \& Reed's, $26 \mathrm{Mer}-$ chants Row, Boston.

The author would inform the public, that these medicines are not specifics or curealls; yet, if proper attention is paid to diet, exercise, and stable management, they will perform wonders.

The popular notion, that disease is under the control of the lancet, firingiron, and poisonous drugs, and may be cured by them, has caused an immense loss to owners of domestic animals. It probably originated a great portion of disease now existing.

No treatment is scientific, in the opinion of some, unless it includes the lancet, firing-iron, blisters, setons, boring horns, cramming down nauseous medicines, \&c. The fact is, that in nine cases out of ten, they do more harm than good. One object of this work is to correct this erroneous notion. When the nature of our curative agents, more powerful than those of the mineralites, (at least to cure, are understood, and our principles fully carried out, then the practice of veterinary medicine will be a very different thing from what is now taught in the schools of England and France. They will then know the powers that really cure, and devise means of prevention. Animals, when roaming at liberty, are seldom sick, and generally live to a good old age; yet, when they coine under the direction of refined man, they often drag out a miserable existence, and die victims to the popular science of guessing.

\section{Report of the Worcester County Mechanics' Association, in favor of the Author's Medicines.}

617. Dadd's Horse and Cattle Medicines, by G. H. Dadd, M. D., of Boston. It is a matter of congratulation, that scientific men are turning their attention to the wants and recessities of the brute creation. Too long have our noble horses, and our useful cattle, been subjected to the brutal treatment of ignorant empirics, whose highest ambition seems to be the possession of the title of "cow doctor," without a single qualification necessary for the proper exercise of a cow doctor's duties. In the Old World there are schools of study where the veterinary practitioner goes through a thorough course of education, and is prepared to exercise the duties of his profession, understandingly, and with a proper regard to the feelings of his patients; and he takes his station, next in rank, to the regular physician. From a detailed explanation of the course of practice, the design and the operation of the medicine exhibited by Dr. Dadd, the committee see no reason why its use should not be recommended to the public by them, as well as his treatise on the diseases of animals. - Diploma.

Worcester, Dec. 25, 1849.

Dr. DADD. Dear Sir: - The committee, to whom was referred your horse and cattle medicines, felt that the subject was a novel one to them at the time, and, consequently, they did not feel prepared to say as much in favor of the remedies, \&c., as upon more reflection they feel that the subject demands. 
People here have lost confidence in the cattle doctors they have known, and, in the language of one of the committee, "many a noble animal is suffered to sicken and die, for want of proper medical treatment." Several cases in this immediate vicinity were cited, and in view of the great loss of property, as well as for the honor of New England, the hope was earnestly and repeatedly expressed, that success might crown your labors in this important branch of science and skill. May you still go on and prosper; the whole land is before you, and the people prepared, by dear-bought experience, to favor your more rational course of practice.

Yours, \&c., H. F. JOHNSON, M. D.

\section{REMARKS ON CLYSTERS.}

As the more general use of clysters is recommended by the author, especially in acute diseases, he has thought proper to introduce, in this part of the work, a few remarks on them, with examples of their different forms. They serve not only to evacuate the rectum of its contents, but assist to evacuate those of the intestines, and serve also to convey nourishment into the system; as in cases of lockjaw, and great prostration. They soften the hardened excrement in the rectum, and cause it to be expelled; besides, by their warm and relaxing powers, they act as fomentations. A stimulating clyster in congestion of the brain, or lungs, will relieve those parts by counterirritation. A horse that is unable to swallow, may be supported by nourishing clysters; for the lacteals, which open into the inner c $\quad v$ of the intestines, absorb, or take up, the nourishment and convey it intoric shhoracic duct, as already described. Some persons deny the utility of injections. We are satisfied on that point, and are able to convince any one, beyond a reasonable doubt, that fluids are absorbed in the rectum, notwithstanding the opinion of some men to the contrary.

In administering clysters, it ought always to be observed that the fluids be neither too hot nor too cold, and about the temperature of the blood. The common sixteen-ounce metal syringe, with a wooden pipe, about six inches in length, and gradually tapering from base to point, is to be preferred; it is, after being oiled, much easier introduced into the fundament, than one that is considerably smaller; and having a blunt point, there is no danger of hurting the horse, or wounding the rectum.

FORMS OF CLYSTERS.

EMOLLIENT CLYSTER.

Take of powdered slippery elm,...... one ounce.

Boiling water,................. sufficient to form a thin mixture.

The following articles may be substituted for elm: flaxseed, powdered 
licorice, marshmallows, lily roots, gum arabic, olive oil, Iceland moss, either of which will answer the same purpose.

\section{LAXATIVE CLYSTER.}

Warm water......................... three or four quarts.

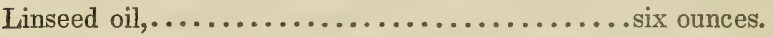

Powdered lobelia,............................. ounce.

If the excrement is hard, common soap-suds will soften it. If the lobelia is not at hand, substitute either of the following articles: assafœetida, ginseng, pleurisy root.

Take of cyprepedium, or lady's slipper,............two ounces.

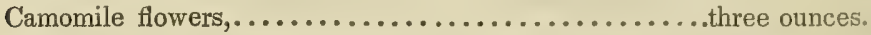

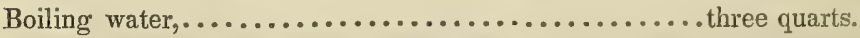

Let the mixture stand a short time, strain through a fine sieve, when it will be fit for use.

\section{STIMULATING CLYSTER.}

Take mucilage of slippery elm, or linseed tea,....... three quarts.

Pure African cayenne, powdered,............... tene teaspoonful.

The pure cayenne gives to the organs an increased physiological action, without astringency or relaxation. A large portion of the capsicum found in the stores is adulterated with logwood, and is decidedly injurious.

\section{DIURETIC CLYSTER.}

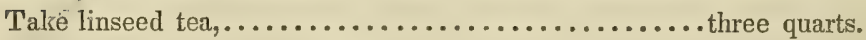

Oil of juniper, ............................ two drachms.

Or substitute for the latter cream of tartar, one ounce.

This clyster may be used with decided advantage in all acute diseases of the urinary organs of cattle and horses. In red water of cattle, the above may be combined with tonics, as wild cherry, prickly ash, golden seal, \&c.; the properties of the latter may be extracted by infusion.

\section{ASTRINGENT CLYSTER.}

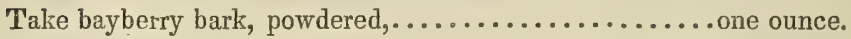

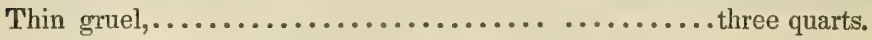

If an alterative effect is required, add lobelia, one ounce.

\section{NOURISHING CLYSTER.}

Gruel made of arrowroot,................... two quarts.

Powdered licorice,...................... four drachms. "6 golden seal,$\ldots \ldots \ldots \ldots \ldots \ldots \ldots \ldots$ four drachms. 
INJECTION FOR PIN WORNS.

Boiling water,............................ three quarts.

Sulphur,............................. four drachms.

Powdered wormseed,$\ldots \ldots \ldots \ldots \ldots \ldots \ldots \ldots$................ ounce.

ANOTHER.

Lobelia and wood ashes, each,................... one ounce.

Boiling water,..........................two quarts.

WASH FOR INFLAMED EYES.

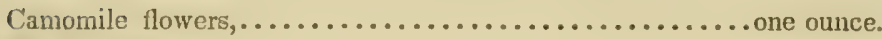

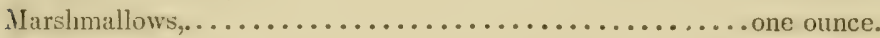

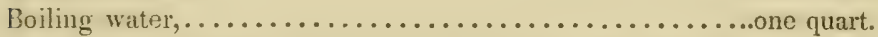

Let the mixture stand one hour; strain it, and bathe the eye occasionally.

\section{IMIPORTANT TO OWNERS OF HORSES AND CATTLE.}

TuE undersigned respectfully inforns his numerons friends and the public, that he continues to practise, successfully, the reforned veterinary art; the principles of which practice consist in the rejection of bloodletting, which has hitherto been the great antiphlogistic of the allopathic school, and which has produced more destruction in the animal kingdom, than the pestilential sword. The medicines used in the physiological practice are safe and efficient, and generally establish the health of the animal, without that tedious convalescence which usually attends the administration of calomel, antimony, corrosive sublimate, arsenic, copper, the mineral acids, \&c.

Every description of medicine used for horses, cattle, and sheep, can be procured, with directions for their use, by applying to the subscriber,

No. 1 \& 2, Holmes Block, Haymarket Square, Boston.

G. H. DADD, M. D.

Dr. Dadd would suggest to his friends the advantages to be derived from his services, in the examination of horses for sale, or purchase, as many purchasers have suffered by dear-bought experience. 





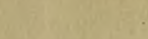


LIBRARY OF CONGRESS

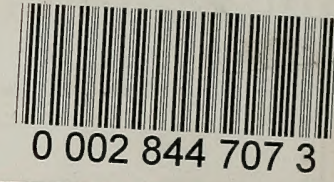

